\title{
On the measurement of multidimensional poverty as a policy tool
}

Citation for published version (APA):

Franco Correa, A. (2017). On the measurement of multidimensional poverty as a policy tool: empirical applications to Chile, Colombia, Equador and Peru. [Doctoral Thesis, Maastricht University]. Datawyse / Universitaire Pers Maastricht. https://doi.org/10.26481/dis.20170112afc

Document status and date:

Published: 01/01/2017

DOI:

10.26481/dis.20170112afc

Document Version:

Publisher's PDF, also known as Version of record

\section{Please check the document version of this publication:}

- A submitted manuscript is the version of the article upon submission and before peer-review. There can be important differences between the submitted version and the official published version of record.

People interested in the research are advised to contact the author for the final version of the publication, or visit the DOI to the publisher's website.

- The final author version and the galley proof are versions of the publication after peer review.

- The final published version features the final layout of the paper including the volume, issue and page numbers.

Link to publication

\footnotetext{
General rights rights.

- You may freely distribute the URL identifying the publication in the public portal. please follow below link for the End User Agreement:

www.umlib.nl/taverne-license

Take down policy

If you believe that this document breaches copyright please contact us at:

repository@maastrichtuniversity.nl

providing details and we will investigate your claim.
}

Copyright and moral rights for the publications made accessible in the public portal are retained by the authors and/or other copyright owners and it is a condition of accessing publications that users recognise and abide by the legal requirements associated with these

- Users may download and print one copy of any publication from the public portal for the purpose of private study or research.

- You may not further distribute the material or use it for any profit-making activity or commercial gain

If the publication is distributed under the terms of Article $25 \mathrm{fa}$ of the Dutch Copyright Act, indicated by the "Taverne" license above, 


\section{On the Measurement of Multidimensional Poverty as a Policy Tool}

Empirical Applications to Chile, Colombia, Ecuador and Peru

Andrea Franco Correa

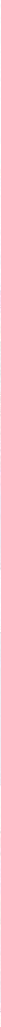




\title{
On the Measurement of Multidimensional Poverty as a Policy Tool
}

\author{
Empirical Applications to Chile, Colombia, Ecuador \\ and Peru.
}

Andrea Franco Correa 
ISBN 9789461596635

Copyright (C) Andrea Franco Correa, 2017

All rights reserved. No part of this publication may be reproduced, stored in a retrieval system, or transmitted in any form, or by any means, electronic, mechanical, photocopying, recording or otherwise, without the prior permission in writing, from the author.

Publisher: Datawyse — Universitaire Pers Maastricht, Maastricht

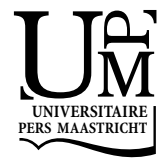




\title{
On the Measurement of Multidimensional Poverty as a Policy Tool: Empirical Applications to Chile, Colombia, Ecuador and Peru.
}

\author{
DISSERTATION \\ to obtain the degree of Doctor at \\ Maastricht University, \\ on the authority of the Rector Magnificus, Prof. Dr. Rianne M. Letschert, \\ in accordance with the decision of the Board of Deans, \\ to be defended in public on Thursday, 12th of January 2017, at 16:00 hours
}

by

Andrea Franco Correa 


\title{
Promoter
}

Prof. Dr. Robin Cowan

\section{Supervisors}

Prof. Dr. Fred Gault

Dr. Gaston Isaias Yalonetzky

\author{
Assessment Committee \\ Prof. Dr. Pierre Mohnen (chair) \\ Dr. Paola Ballon (University of Oxford) \\ Prof. Dr. Enrica Chiappero Martinetti (University of Pavia) \\ Prof. Dr. Franziska Gassmann
}




\section{Acronyms}

AF Alkire-Foster

AHR Adjusted Headcount Ratio

CA Capabilities Approach

CCT Conditional Cash Transfer

CES Constant Elasticity of Substitution

CFA Confirmatory Factor Analysis

DANE Departamento Administrativo Nacional de Estadísticas -Statistical Office Colombia

DNP Departamento Nacional de Planeación -National Department of Planning

DPS Departamento para la Prosperidad Social -Social Prosperity Department

DHS Demographic and Health Surveys

ECLAC Economic Commission for Latin America and the Caribbean

EU European Union

EU2020 European Agenda for 2020

EU-SILC European Union Statistics on Income, Social Inclusion and Living Conditions

EUROSTAT Statistical Office of the European Union

FA Factor Analysis

FOD First Order Dominance

FGT Foster-Greer-Thorbecke

GDP Gross Domestic Product

HDI Human Development Index

HDR Human Development Report

IADB Inter-American Development Bank 
INEC Instituto Nacional de Estadística y Censos -Statistical Office Ecuador

INEI Instituto Nacional de Estadística e Informática -Statistical Office Peru

LSMS Living Standard Measurement Survey

MECOVI Programa para el Mejoramiento de Encuestas y la Medición de las Condiciones de Vida en América Latina y el Caribe

MESEP Misión para el Empalme de las Series de Empleo, Pobreza y Desigualdad

MDG Millennium Development Goals

MICS Multiple Indicator Cluster Survey

MIMIC Multiple Indicators and Multiple Causes

MPI Multidimensional Poverty Indicator

NBI Necesidades Básicas Insatisfechas

NGO Non-Governmental Organization

NL The Netherlands

NLPCA Non Linear Principal Components Analysis

OECD Organization for Economic Co-operation and Development

OPHI Oxford Poverty and Human Initiative

PND Plan Nacional de Desarrollo -National Development Plan

POLS Probit Ordinary Least Squares

PPP Purchasing Power Parity

ROC Receiver Operating Characteristic

SEM Structural Equation Modelling

SISBEN Official Targeting Index of Colombia

SOD Second Order Dominance

SWB Subjective Well-Being 
UK United Kingdom

UN United Nations

UNDP United Nations Development Programme

UNIDOS Red para la Superación de la Pobreza Extrema -National Strategy to Overcome Extreme Poverty, formerly Red JUNTOS

US United States of America

WHS World Health Survey 


\section{CONTENTS}

1 Introduction $\quad 21$

2 Literature Review $\quad 25$

2.1 Conceptual Framework of Multidimensional Poverty Measurement . . . . 26

2.1.1 Poverty as a Multidimensional Concept . . . . . . . . . . . 26

2.1.2 Multidimensional Poverty Measurement . . . . . . . . . . . . . 34

2.1.3 Other Multidimensional Welfare Assessments . . . . . . . . . . 39

2.2 Poverty Dynamics . . . . . . . . . . . . . . . . . . . . 41

2.2.1 Dynamic Monetary Poverty . . . . . . . . . . . . . . . . 42

2.2.2 Dynamic Multidimensional Poverty . . . . . . . . . . . . . . . 42

2.2.3 Panel Data vs. Cross Sectional Data . . . . . . . . . . . . . . 43

2.3 Choosing indicators and dimensions under the Capability Approach . . . 45

2.4 The Governance of Poverty . . . . . . . . . . . . . . . . 46

2.4.1 Examples from supranational level . . . . . . . . . . . . . 47

2.4.2 Poverty, Planning and Evaluation . . . . . . . . . . . . 48

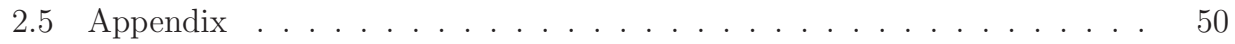

2.5.1 Aggregative indices . . . . . . . . . . . . . . 50

2.5.2 Inventory of studies using AF Method . . . . . . . . . . . . 54

2.5.3 Inventory of studies on income and other dimensions . . . . . . 58

2.5.4 Most Important Panel Datasets -Active . . . . . . . . . . . . . . . 62 
3 An individual-centered approach to multidimensional poverty $\quad 63$

3.1 Introduction . . . . . . . . . . . . . . . . . . . . 64

3.2 Selection of the unit of analysis: Individual vs. Household . . . . . . . 65

3.3 Dataset Characteristics . . . . . . . . . . . . . . . . . . . . . 67

3.3.1 The selected countries . . . . . . . . . . . 67

3.3.2 The selected datasets . . . . . . . . . . . . . . . . . . . . . 67

3.4 Selecting Functionings ． . . . . . . . . . . . . . . . . . . . . . . . 69

3.4.1 Proposed Indicators . . . . . . . . . . . . . . . 71

3.4 .2 Analysis of trends in main indicators . . . . . . . . . . . . 72

3.4.3 Deprivation and Poverty Cut-offs . . . . . . . . . . . . . . 79

3.5 Multidimensional Poverty Index -Results . . . . . . . . . . . . . . . . . 83

3.5.1 Individual Multidimensional Poverty . . . . . . . . . . . . . 83

3.5.2 Household Level Multidimensional Poverty Index . . . . . . . . . 88

3.6 Conclusion . . . . . . . . . . . . . . . . . . . . . . . . . . . . . 89

3.7 Appendix . . . . . . . . . . . . . . . . . . . . . . . 92

3.7.1 Descriptive Statistics . . . . . . . . . . . . . . . . 92

3.7.2 Cross-checking the contents in the datasets . . . . . . . . . . . . 92

3.7.3 Translated Questionnaires . . . . . . . . . . . . . . 93

3.7.4 Indicators Cut-off and particularities of each dataset . . . . . . . 109

3.7.5 Confidence Intervals for First Wave . . . . . . . . . . . . . . . . . 111

3.7.6 Elimination of an indicator . . . . . . . . . . . . . . . . . 112

4 Folding and Un-Folding Multidimensional Poverty 115

4.1 Introduction . . . . . . . . . . . . . . . . . . 116

4.2 Subgroup decomposition in Multidimensional Poverty Indicators . . . . . 117

4.3 Stochastic Dominance by region . . . . . . . . . . . . . . . . 120

4.3.1 First Order Dominance Comparisons . . . . . . . . . . . . . . 120

4.3.2 Second Order Dominance Conditions . . . . . . . . . . . . . . . 124

4.3.3 Contributions of regions and indicators . . . . . . . . . . 125

4.4 Hasse diagram and ranking orderings . . . . . . . . . . . . . . 125

4.5 Conclusions . . . . . . . . . . . . . . . . . . . . . . . . . . . . . . . . . . . 129

4.6 Appendix . . . . . . . . . . . . . . . . . . . . . . 132

4.6 .1 List of regions . . . . . . . . . . . . . . . . . . . . . . . . . . . . . . . . . . . . . . . . . . . . . . . . .

4.6 .2 Pair-Wise comparison -FODC . . . . . . . . . . . . . . 133

4.6.3 Contributions per Region to the National Average . . . . . . . . . 139

4.6.4 Pair-Wise comparison -SODC . . . . . . . . . . . . . . . . 140

4.6 .5 Hasse Diagrams . . . . . . . . . . . . . . . . . . . . 146 
5.1 Introduction . . . . . . . . . . . . . . . . . . . . . . . . 152

5.2 Demographic and Political Changes in the Region . . . . . . . . . . . . 153

5.2 .1 Demographic Profile . . . . . . . . . . . . . . . . 153

5.2 .2 Political and electoral changes . . . . . . . . . . . . . . 156

5.2 .3 Social Protection Profiles . . . . . . . . . . . . . . . 158

5.3 Decomposition Techniques in Multidimensional Poverty Indicators . . . . 159

5.3.1 Shapley decomposition . . . . . . . . . . . . . . . . . 159

5.3 .2 Percentage changes . . . . . . . . . . . . . . . . . 161

5.3.3 Reversed Generalized Lorenz Curves . . . . . . . . . . . . . . . . 161

5.4 Results . . . . . . . . . . . . . . . . . . . . . . . . . 162

5.4.1 Shapley Decomposition Results . . . . . . . . . . . . . . . . 164

5.4.2 Percentage Changes . . . . . . . . . . . . . . . . . . . . . . 167

5.4.3 Reversed Generalized Lorenz Curves . . . . . . . . . . . . . . . 171

5.5 Conclusion . . . . . . . . . . . . . . . . . . . . . . . . . . . . . . 172

5.6 Appendix . . . . . . . . . . . . . . . . . . . . . . 175

5.6 .1 Confidence Intervals ． . . . . . . . . . . . . . . . . . . 175

5.6 .2 Grouping Shapley Decompositions . . . . . . . . . . . 176

6 Multidimensional Poverty as a Policy Tool $\quad 177$

6.1 Introduction . . . . . . . . . . . . . . . . . . . . . . . . . 178

6.2 Measurement of poverty and public policy applications in Colombia . . . 179

6.3 Methodology . . . . . . . . . . . . . . . . . . . . . . 181

6.3 .1 In-depth interviews . . . . . . . . . . . . . . . . . . . . . . . 181

6.3.2 Analysis of Official Documents . . . . . . . . . . . . . . . 183

6.3.3 News . . . . . . . . . . . . . . . . . . . . . . . . . . . . . . . . . . . 184

6.4 Hypothesis tested . . . . . . . . . . . . . . . . . . . . . . . 185

6.5 Main Results . . . . . . . . . . . . . . . . . . . . . . . . . . 186

6.6 The exit conditions of the Strategy to Overcome Extreme Poverty . . . . 196

6.6.1 UNIDOS in a nutshell . . . . . . . . . . . . . . . . 196

6.6.2 Multidimensional Poverty Index used as exit condition . . . . . . 199

6.7 Conclusions . . . . . . . . . . . . . . . . . . . . . . . 200

6.8 Appendix . . . . . . . . . . . . . . . . . . . . . . . . . . . . . 202

6.8.1 Consent Form -English . . . . . . . . . . . . . . . . . 202

6.8.2 List of Official Documents Included in the Analysis . . . . . . . 203

6.8.3 Institutional Arrangement in Colombia . . . . . . . . . . . . . . . 204

6.8.4 Coding Categories-Interviews . . . . . . . . . . . . 205

6.8.5 Coding Categories-News . . . . . . . . . . . . . 207

7 Concluding Remarks $\quad 208$ 
Key Terms

Valorization

About the author 


\section{LIST OF FIGURES}

2.1 Two Attributes Cases . . . . . . . . . . . . . . . . . . . . 36

2.2 Dynamic Monetary Poverty Schema . . . . . . . . . . . . . . . 43

3.1 Raw and Censored Data for Children . . . . . . . . . . . . . . . 80

3.2 Raw and Censored Data for Adults . . . . . . . . . . . . . . 81

3.3 Raw and Censored Data for Elderly . . . . . . . . . . . . . . . . . 82

3.4 AHR for Children . . . . . . . . . . . . . . . . . . . . . . . . . 84

3.5 AHR for Adults . . . . . . . . . . . . . . . . . . . . 85

3.6 AHR for Elderly . . . . . . . . . . . . . . 86

3.7 Aggregated AHR . . . . . . . . . . . . . . . . . . . . . 87

3.8 AHR for Households . . . . . . . . . . . . . . . . . . . . . . . . . . . 88

3.9 Comparison of AHR with and without years of schooling in elderly . . . 112

4.1 Hasse Diagrams- Example . . . . . . . . . . . . . . . . . . . . . . 127

5.1 Population Pyramids . . . . . . . . . . . . . . . . . . . 154

5.2 AHR over time: Children . . . . . . . . . . . . . . . . . . . . . 163

5.3 AHR over time: Adults . . . . . . . . . . . . . . . . . . . . . 164

5.4 AHR over time: Elderly . . . . . . . . . . . . . . . . . . 165

5.5 Shapley Decomposition Within Effect . . . . . . . . . . . . 166

5.6 Shapley Decomposition Incidence Effect . . . . . . . . . . . . . . . . 168

5.7 Percentual Changes Chile . . . . . . . . . . . . . . . . . . . . . . . 169

5.8 Percentual Changes Colombia . . . . . . . . . . . . . . . . 169

5.9 Percentual Changes Ecuador . . . . . . . . . . . . . . . . . . . 170 
5.10 Percentual Changes Peru . . . . . . . . . . . . . . . . . . . . 170

5.11 Reversed Generalized Lorenz Curves . . . . . . . . . . . . . . . . . . . 171

6.1 Targeting Mechanisms Milestones in Colombia -SISBEN . . . . . . . . 179

6.2 Cluster of words in official documents . . . . . . . . . . . . . . . . 193

6.3 Current Institutional Framework . . . . . . . . . . . . . . . . 198 


\section{LIST OF TABLES}

2.1 Inventory of MPI applications using AF . . . . . . . . . . . 54

2.2 Inventory of applications of Income and other measures . . . . . . . . 58

2.3 Available Panel Datasets . . . . . . . . . . . . . . . . . . . . . . 62

3.1 Measures of Poverty, Human Development and Inequality . . . . . . . . . 68

3.2 Description of Datasets . . . . . . . . . . . . . . . . 69

3.3 List of indicators proposed . . . . . . . . . . . . . . . 71

3.4 AHR score for $\mathrm{k}=30 \%$ by subpopulation . . . . . . . . . . . . . 86

3.5 Rankings for different $k \ldots \ldots \ldots$. . . . . . . . . . . . . . 87

3.8 Variance Ratio: Excluded over Included . . . . . . . . . . . . . . . . . 113

4.1 Sample size by region and age group . . . . . . . . . . . . . . . . . 132

4.2 FOD Pair-Wise Comparisons - Unrestricted Children . . . . . . . . . . . 133

4.3 FOD Pair-Wise Comparisons- Unrestricted Adults . . . . . . . . . . . . . 134

4.4 FOD Pair-Wise Comparisons - Unrestricted Elderly . . . . . . . . . . . 135

4.5 FOD Pair-Wise Comparisons-Children Restricted . . . . . . . . . . . 136

4.6 FOD Pair-Wise Comparisons -Adults Restricted . . . . . . . . . . . . . 137

4.7 FOD Pair-Wise Comparisons -Elderly Restricted . . . . . . . . . . . . . 138

4.8 Contributions (\%) per Region to the National Average when k=30\% . . . 139

4.9 SOD Pair-Wise Comparisons - Unrestricted Children . . . . . . . . . . . 140

4.10 SOD Pair-Wise Comparisons -Adults Unrestricted . . . . . . . . . . . . . 141

4.11 SOD Pair-Wise Comparisons -Elderly Unrestricted . . . . . . . . . . . . 142

4.12 SOD Pair-Wise Comparisons - Restricted Children . . . . . . . . . . . 143 
4.13 SOD Pair-Wise Comparisons -Adults Restricted . . . . . . . . . . . . . 144

4.14 SOD Pair-Wise Comparisons -Elderly Restricted . . . . . . . . . . . . 145

5.1 Dependency Ratios and Population Shares through Time . . . . . . . . 155

5.2 Social Expenditure as a \% of the GDP . . . . . . . . . . . . . 156

5.3 Presidential Changes in the four countries . . . . . . . . . . . 157

5.4 Confidence Intervals for comparisons over time . . . . . . . . . . . . 175

5.5 Shapley Classification . . . . . . . . . . . . . . . . . 176 



\section{ACKNOWLEDGEMENTS}

It took 6 years to finally write this chapter. One year ago, after sending my draft, I left my beloved Maastricht, came back home an started a new life. All over again. The distance for the fairy tale town and life, is probably a plus when the time for writing the acknowledgement comes. I will probably forget some names in here, as it always happens, but they would never be erased from my hearth and the memories of those days, that looking back are the most amazing 5 years of my life.

Writing a thesis is in many cases an isolated process. I have the luck to have three amazing people to whom I would always have to report and who to bother whenever I felt frustrated. Despite being in different places of the world there was not a time when one of my e-mails was not replied in between half an hour and three days. That is a luck not every $\mathrm{PhD}$ student can count in. It was a pleasure to share and cherish the job of being Gaston's student. He is not only one of the most intelligent persons I have ever known but also an amazing human being. Both qualities that made my life easier and that I tried to replicate every single day. I will ever be in debt not only for the knowledge shared but also for the great opportunity you gave me. You were the person that could see through the dark the light at the end of the tunnel, always. Fred, was the person I could always count in with his patience, support, knowledge and at the end, the commitment to make me finish this thesis despite myself. Your trust is embedded in my heart. Robin despite being the director of the $\mathrm{PhD}$ programme was always the person I will look in the crowd to find the eyes of approval, the honest truth that would make me harder and stronger. Thanks for your support from the very beginning and for joining this team. 
I am thankful by the disposition of my assessment committee: Pierre Mohnen, Franziska Gassman, Enrica Chiappero and Paola Ballon. I am honoured by counting you in this process, for the time you took and for each and every single one of your comments. They made this thesis better. I would like to thank Franziska for all the moments we shared through the years, mostly but not only limited to the outside chair, for the time you took to convince my stubborn mind to do better, and for being there at every step.

This $\mathrm{PhD}$ was funded by the Colombian Government, through the National Department of Planning loan-scholarship. I am grateful to those who shared their knowledge about qualitative analysis at UNU-MERIT/MGSoG, to those who allowed me to approach subordinates and finally to those who accepted to be interviewed. I not only enjoyed to recall the process of public policy making with them, but also the hours of transcripts and coding as well. I am thankful for the patience, willingness and openness, the job that they do and the satisfaction they showed made my qualitative work easier. I would also like to thank Melanie Waidler for her ability to put together a cover for this thesis.

Growing up into the $\mathrm{PhD}$ life requires much more than academic feedback. It requires a space and a time. Getting to know people and chat around the coffee corner in Keizer Karelplein. Living in Maastricht is not possible without all your warm and help. First, I would like to thank the deans of the UNU-MERIT, Luc and Bart, for your support during this time. To the directors of the PhD Programme, Mindel and Tatiana, and particularly to the administrative staff, Susan, Janneke, Herman, Mourik, Sueli, Mieke, Anouk, Monique, Diego, Ad, Mitie, Vivianne, Marc and Wilma. Thanks for your support, your willingness to help and the smiles whenever we crossed paths. I left out from this list to whom I designated my adoptive family in Maastricht. Eveline, there is no way to put into words what you represent to me. For all your love, and kindness, teaching us the dutch life and how to cook a zuurvlees, I am in debt for a life time.

I failed in becoming a paranoid android because I had the pleasure to share my ride with the usual suspects at the restaurant at the end of the galaxy. Each one of them made this ride joyful, made it hard to come back. First, to my original batch: Richard, Serdar, Corinne, Marta, Hampton, Valery, Michaela, Mahmut, Florence, Yulia, Omar, and Patricia, for all the experiences of our first year. To all the people who made my life happier during all the years: Cheng, Iman, Nasser, Hendrik, Sepideh, Dorcas, Guney, Oxana, Saba, Shuan, Francesca R, Kutay, Francoise, Ibrahima, Shuan, Ozge, Michiko, Nyasha, Sonila, Ayo, Mueid, Elvis, Mira, Ayla, Corinne B, Ana Cristina, Camilo, Silvia, Juan Carlos, Cho, George, Hugo, Hasse, Mario, Stefania, Bart, Nga, Clotilde, Katrin, Julieta, Tigist, Ortrun, Biljana, Tatevik, Lorena, Eli, Nevena and Sheng. To colombian friends in Europe and back at home Vicky, Cristophe, Nancy, Robinson, Oscar, Carolina, German, Adriana and Violeta. A la colonia colombiana en Maastricht: Jose, Angelo, Elizabeth, Daniel, and Gabito. To all my office mates for the craziness of small spaces: Bianca, Gintare, Irina, Mary, Giacomo and Kristine. To those deep in my hearth for all the things we lived: Josy, Ilire, Charlotte, Daniel, Samy, Giorgio, Karen, Arturo, Andy, Fernando, Santana, Luciana, Howard, Alejandro and Francesca G. To my housemates for all the dinners, drinks and all the late night 
chats: Carlos, Andrés, Sebastián and Thuy. To the usual suspects in each and every conference: Corinne B, Natasha, Elias, Javier and Nicolai. To the WLC, because "time is an illusion, lunchtime doubtly so": Simone, Tobias, Jennifer W and Iulia, you not only feed me, but also made me laugh and where there whenever cry was the answer. I still wake up to read the menu for the day, and I still miss that moment. Marta and Corinne what a wonderful team built in one year and still alive. It was worthy!

Going up and down, in the roller-coaster and doing it alone is not an option during a $\mathrm{PhD}$. With the following people I left a piece of myself spread all over the world. From each one of them I learnt about myself, I learnt to trust, I learnt to give away. I consider you part of my family. You made me feel free to be as honest as I can be, as cute as I never imagined. I still think of each one of you almost in a daily basis. I still miss you. For all your love, interventions and all that we lived and we will live in the future... Thanks! Richard, for organizing my life in a perfectly functional schedule; Jennifer for teaching me that life is to enjoy and "el que es lindo es lindo"; Auntie Elisa, for making me feel comfortable in every single moment, made me happy and listen to ten thousand times the same old stories, and the unforgettable pilates ball; Auntie Alison, for keeping me grounded and trusting me, trying to follow my spanish, sharing the recreational break, and all the nights up and down the Sint Servaasbrug and the Capucijnenstraat; Paula, for the laughs and the commitment, for sharing those long years, for being honest and without filter; Mary, for the hard honest friendship, sharing and office was not easy but ardilla you made each day easier, specially with all the cookies; Marco, for as many cappuccinos as it takes to solve it; and Zina, for trusting me blindfolded, for the paper unfinished and for the advice in life and all that jazz. You made difficult to choose who among you will seat behind me. In any case I will feel protected and surrounded by love.

Coming back to Colombia was very difficult. Finding a place like home again after all those years was not an easy task. I am thankful to those I have the pleasure to meet and work with at the ICBF in Colombia. You made possible the last months of this ride. To all my team a big thanks. You opened the door and trust me despite not knowing anything about me. To all my long lasting friends, for all your support, e-mails, calls, chats and keeping up to me during my years outside: Connie, Aura, Vicky, Lyna, Palo, JuanPa, AdriC, AdriB, Lucho, Cristina, Nico, Anna, Juanita, Catherine, Jose, Vicky, Nery, Bibi, Sandra S, Andrés, Sandra P, Mauricio and JuanG. Gracias Totales!

A mi familia, quienes incansablemente me apoyaron en todos y cada uno de los momentos durante estos largos años. A Marcela, por cuidar de mis papas todos estos años, por atravesarse el Atlántico dos veces para darme ánimo y recorrer el mundo juntas, gracias hermosa hermana además por tu amistad de todos los días. A mi mami, por todo su amor, por todos y cada uno de los días que esperaste para que te contara como transcurría mi día, y a pesar del tono triste de la voz darme ánimos en esa travesía. A mi papi, por insistir hasta el cansancio en que hiciera el $\mathrm{PhD}$, terminara de una vez todos los capítulos y dejara de inventarme más, y al final, por convencerme de ajustar cada comentario. Papis, por todo lo que sacrificaron, por todo lo que esperaron, por todo su amor día a día durante toda mi vida, mi eterna deuda de amor. Al amor de mi vida, que un buen día 
me dijo, yo me voy a Europa, y tu Doctorado qué? Y finalmente me convenció de que aplicara, que me dio la libertad para hacer ese sueño realidad y quien me ha apoyado a cada paso que doy en la vida. Todo mi amor y eterno agradecimiento por los días que no pudimos estar juntos, y todos los que están por venir. Luna, espero verte de nuevo en algún lugar maravilloso donde podamos volver a juntar garra-cara-caricia. Gracias por ese último año de tu vida, y por enviar a Kira a la puerta de la casa. 


\section{CHAPTER}

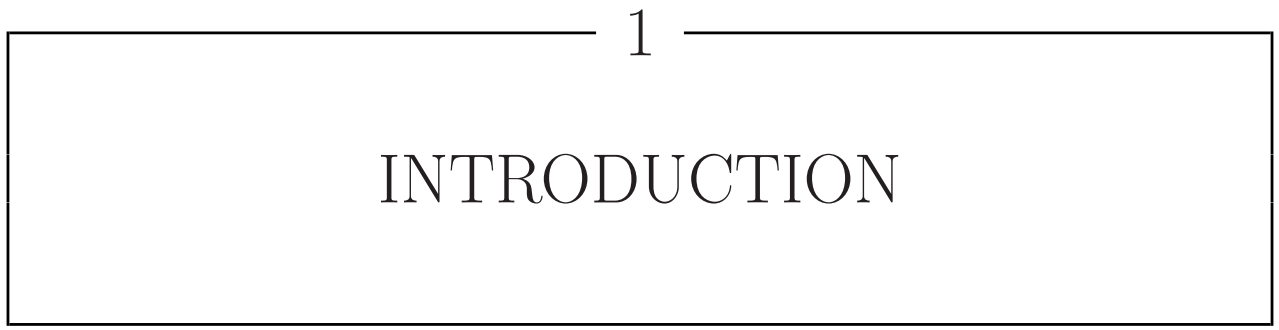

"Development professionals have more power to change the world for the better than is normally realized. To grasp and use that power requires questioning conventional concepts and realities, exploring and embracing a new paradigm, adopting a new professionalism, empowering the poor to analyze and express their reality, and then putting that reality first".

Chambers (1995, p. 178-179)

The measurement of poverty has been under constant scrutiny from academics and policy-makers. For many years, income (or consumption/expenditures) has been used as a proxy to understand and measure poverty. Nonetheless, over the last decades, increasingly theoretical and methodological discussions have shifted the attention to what is now called Multidimensional Poverty. Starting with the seminal works of Peter Townsend (1979), Amartya Sen (1976) and John Rawls (1971), social scientists have devised different approaches to understanding poverty without relying on income. Some of these are the basic needs approach, material deprivation, subjective well-being, and the capability approach.

Since 2010, the Human Development Report (HDR), the publication containing the Human Development Index, has included a ranking of more than 100 developing countries, in the form of an index, referred to as the Multidimensional Poverty (MPI). The publication of the HDR not only sparked a debate about the interpretation of such rankings and comparisons of poverty between countries but also about the measurement of poverty in general (See Decanq and Lugo (2010), Ferreira and Lugo (2013), Ravallion (2011) and Alkire (2011)). The ranking published in the HDR is constructed on the basis of the most widely used counting index of multidimensional poverty, the Adjusted Headcount Ratio ( in this thesis AHR) of the Alkire-Foster (AF) family of indices. 
Several points have been mentioned as drawbacks of any multidimensional measure, but especially the AHR. There are several arbitrary decisions involved in computing multidimensional indices which affect the final scores as there is no certainty about their impact on the overall result. Despite these criticisms, the AHR has become widely applied, not only in the academic world but also as a tool for advocacy, targeting, monitoring and evaluating social policies and programs; particularly noteworthy are the cases of Mexico (CONEVAL), Colombia (DNP) and Brazil (Minas Gerais Multidimensional Intervention). ${ }^{1}$

In a world where composite indices are being increasingly used as policy tools, rankings are used as tools for governance and synthetic indices are perceived as data simplification of complex phenomena. They are the most popular statistics used by the media, public officials and academics. Although easy to communicate, the simplicity attributed to them is misleading. The process that converts raw data into the index itself is not easy to communicate (e.g. methods of aggregation, interpretation of the final value of the ranking, mong others), and certainly not easily understood by the general public and, in some instances, not even by those in charge of constructing them. The best way to measure different phenomena is a matter of disagreement, but if composite indexes on the measuring of well-being are here to stay, the best solution is to understand and transparently perform the tests that will certify that at least all the possible scenarios are being considered, and that choices are made with a full understanding of the consequences of normative decisions. Regardless of the method, the measurement of poverty will be full of normative decisions about what constitutes poverty, by whom and under which circumstances it is considered poverty. The topic of this dissertation consists in understanding the effect of those normative decisions, with empirical applications to the particular contexts of Chile, Colombia, Ecuador and Peru. The following paragraphs present an outline of the dissertation with a description of each chapter.

Chapter 2 summarizes the different conceptual frameworks used over the years to understand and grasp the definition of poverty and the different solutions provided for its measurement. Concept and measurement are linked to each other and reflect many decisions about what is understood by poverty. This chapter sets the tone of what will be described in the following chapter. It constitutes the core theoretical framework of the dissertation, introduces the concepts and the general method used throughout this dissertation. There is no agreement regarding the 'ultimate' definition and method to measure poverty. Nonetheless, the wide application of counting methods has attracted attention and it is according to this approach that new developments on measurement have rapidly occurred ${ }^{2}$. This approach takes into consideration that the raw data for many usually analysed indicators come in the form of ordinal as opposed to cardinal data. Particularly, the AHR of AF, has gained popularity due to its identification

\footnotetext{
${ }^{1}$ Recently the Oxford Poverty and Human Initiative created the Multidimensional Poverty Peer Network with the objective to increase the use of the method as a public policy tool.

${ }^{2} \mathrm{~A}$ recent trend, the non-counting identification approach is starting to develop. An example of it is the hierarchically structured composite index of Permanyer and Riffe (2015).
} 
function, integrating union, intersection and intermediate approaches. With it not only comparative rankings of countries are constructed but also public policies and monitoring mechanisms are developed and implemented, especially in developing countries.

Chapter 3 introduces the AHR index and shows that in order to follow the Capability Approach (CA) theoretical framework, it makes sense to follow individual achievements instead of generalizing them by household. Three age groups are defined for this task: children (less than 18 years old), adults (18 to 59 years old), and elderly (older than 59 years old). Thresholds for each variable included and their definitions are shown in this chapter as well. It is also the introduction to the model used in the empirical analysis, as the same core index will be used throughout the rest of the dissertation. The main argument of the chapter is that households should not be considered as unitary decision makers, as it is usually done in monetary measures. While many resources are shared among the household members, each individual still experiences different trajectories and needs, depending on age group or sex, among other characteristics. For instance, achievements of the household will not be different if one takes into consideration the employment of at least one family member when the unit of analysis is the household as opposed to the employment status of each member individually. A comparison between the individual and the household as unit of analysis is performed including all the possible indicators and maintaining the same thresholds, to make both measures comparable.

Poverty is unevenly distributed between and within countries, and in order to find out where the poor are, decompositions are needed; this is the topic of Chapter 4 . In the process of aggregation of the AHR, some important information about the distribution of multidimensional poverty is lost. To recover it, it is needed to perform a process of unpacking the index. Similarly to the case of monetary poverty measurement, the identification of poor individuals relies in the setting of a normative poverty line, or a poverty cut-off in terms of multidimensional poverty measurement, denoted as $k$. This $k$ value represents not only the multidimensionality of the measure but it is a central decision that needs to be taken under uncertainty by decision-makers or policy-makers. The main objective of this chapter is to find out if it is possible to observe a preorder of the ranking between the regions, with the help of Stochastic Dominance and Hasse Diagram Techniques (HDT). First order conditions are rarely used in the literature to prove stability of rankings and support normative decisions. Recently, second order dominance conditions have been found for the case of counting methods as in Lasso de la Vega (2010) and Chakravarty and Zoli (2012), and they are still not widely used. Hasse Diagram Technique is applied for other composite indexes but, to the knowledge of the author, it has not been applied to the AHR.

The measurement of multidimensional poverty has been evolving rapidly. New techniques to evaluate the performance over time along different dimensions are increasingly available but scarcely used and understood. Chapter 5 condenses the known techniques to assess the reasons behind changes over time in multidimensional poverty, through counting methods, and tries to find out the usefulness of each technique. 
Increasingly, countries, especially in Latin America, are using multidimensional measures of poverty to assess the impact of poverty-reducing policies. Chapter 6 shows a case study of the adoption of an AHR in Colombia as a policy tool, in both a national development goal and an application as a mechanism to 'exit' social assistance. In other words, when do the people considered as poor cross the imaginary poverty line and become non-poor. Using qualitative techniques the chapter finds factors that played a definitive role on the political decision to include a multidimensional poverty measure as a public policy tool and offers lessons for future applications.

Multidimensional poverty measurement is a recent niche for research and exploration. Built on techniques and concepts inherited from the monetary approach, the field has taken advantage of its learnt lessons and has put into practice variations of them. Despite the lack of consensus and the incipient advance on available techniques for the analysis, public policy-making could benefit greatly from the applications performed in different contexts. Poverty and well-being are a sensitive topic in countries with high levels of inequality. Access to social assistance and social security has been the focus of strong reforms in middle income countries in recent years. Social protection systems, especially in Latin America, have advanced in coverage and innovated in mechanisms to transfer the benefits of growth to the poorest. Nonetheless, they are still at an early stage of development. Efforts seem ineffective both in monetary and non-monetary indexes. Services are segmented by the particularities of the labor market in the region.

In this sense, the research presented in this dissertation is a first examination of the usefulness of multidimensional poverty indexes in terms of policy-making, with particular focus on Latin America and specific results for Chile, Colombia, Peru and Ecuador. It offers a road map to complement the measures that, although used widely, lack the analysis of the implications of normative decisions in the overall result. A deeper knowledge of the tools available and their effect does not substitute, but complement, the moral, political and technical judgements that need to be taken into account to construct a measure of poverty. The techniques used to assess multidimensional poverty presented in this dissertation will show divergent or overlapping results. They will provide additional information that will not be gathered unless they are applied. This information will strengthen the power of the measurement and the objective underlining it, as well as provide sufficient transparency and clarity for those who are working to eradicate poverty, and for those who are considered poor. If there is one lesson to be learnt from this dissertation, it should be that policy-makers need to distance themselves from the need to obtain a simple plain number and instead, start questioning the assumptions behind their choices and to see how much these choices affect the goals, policies and results obtained. By accepting that there is no singular way to measure poverty, by subjecting their proposals to open debate, by including the views of the poor, and filling their measures with creativity and transparency, the fight against poverty is less a scientific topic and more a matter of policy-making. 


\section{CHAPTER}

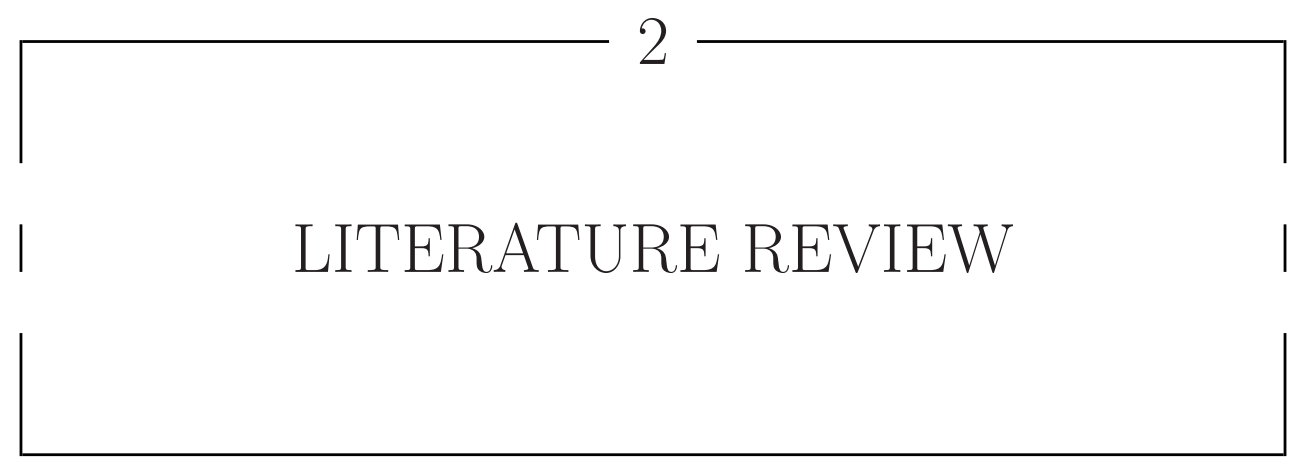

This chapter presents the literature review of multidimensional poverty measurement. It starts introducing the main conceptual frameworks developed through the years in the field such as income approach, capabilities approach, basic needs, social exclusion, among others; and argues that despite their differences poverty is a multidimensional concept. For each one of the main trends shows the different works related to both theoretical and measurement debates, with an special focus on the capabilities approach and the counting approach to its measurement.

This chapter provides the introduction behind the logic of each one of the subsequent chapters. It shows how multidimensional poverty dynamics has been inherited from the income approach, and it is a niche that had been recently applied and developed for the counting approach. It also shows that multidimensionality means selecting dimensions to materialize the measurement. Finally, the chapter argues that poverty is part of the political process, and hence, the definition and its measurement are attached to particular policy objectives. It means that at the end, the measurement of poverty is a public policy tool both for the supranational level as for the country/local level. 


\subsection{Conceptual Framework of Multidimensional Poverty Measurement}

At the dawn of the 20th century Rowntree wrote a book about the well-being of the inhabitants at York. The book is a masterpiece on the measurement of poverty at a time where access to data was remarkably limited. General household surveys were not even considered as a source of information. Rowntree evaluated the living conditions of Yorkers in terms of income, food, housing and health and concluded: "That in this land of abounding wealth, during a time of perhaps unexampled prosperity, probably more than one-fourth of the population are living in poverty, is a fact which may well cause great searchings of heart. There is surely need for a greater concentration of thought by the nation upon well-being of its own people, for no civilisation can be sound or stable which has at its base this mass of stunted human life" (Rowntree, 1908, p. 304).

The search for the concept and measurement of poverty is not a new issue. Despite the efforts and the amount of research and resources invested in it, there is still no consensus on the ultimate definition and operationalization for its measurement. Concept and measurement are attached to each other. A particular definition and the space in which it is evaluated affect the dimensions included in its measurement (Ruggeri et al., 2003). There will probably never be consensus about which is the best way to measure poverty, because it is a vague and broad concept that evolves over time and for which different approaches need to be taken into account according to the context in which the method is applied. Nonetheless there is a search for it and more often than anyone can imagine, the choices that are made are used as a policy tool, and hence they have consequences on the lives of real people.

The only agreement in this field of study is that poverty is a multidimensional concept. Even traditional monetary measures of poverty are considered as being multidimensional. According to Ravallion (2011, p. 236) besides the measures of rice consumption in countries such as Vietnam before the 1990s there have been no other attempts for uni-dimensional measures. Despite this confusion, monetary measures are often perceived as uni-dimensional when in reality, several different goods and services are used in their construction.

\subsubsection{Poverty as a Multidimensional Concept}

The 'income paradigm of poverty', as defined by Bourguignon (2006) has been traditionally dominant in the literature. Poverty is conceptualized following the maximizing utility behavior subject to a budgetary restriction. The individual choices over a set of goods and services are conceived as an expression of the revealed preferences of the 
individuals, rational and autonomous with access to a full set of information. Under this tradition, poverty is defined as a standard of living below a poverty line fixed using monetary resources (income, consumption, expenditure).

However, since the late 1970s different authors have identified the limitations not only in the concept of poverty but also of the indicators used. Townsend (1979) was a pioneer arguing that poverty was not a lack of income to purchase goods in the market but the lack of resources to participate in society. He also introduced different indicators, mainly focusing on the access to goods and services, to account for his concept of poverty.

In 1971, Rawls presented his 'justice as fairness' conceptual framework under the social contract tradition: "It conveys the idea that the principles of justice are agreed to in an initial situation that is fair" (Rawls, 1971, p. 11). He describes his approach as based on principles of justice, using the concept of the original position of equity. For Rawls, the space of equality is the set of 'primary goods' in which he positions: rights and liberties, powers and opportunities, income and wealth, and health and vigor.

The 'basic needs' approach is another example of conceptual framework in the study of poverty. Its emphasis is on the services and commodities that individuals can obtain. According to Streeten (1998, p. 26) the measurement of poverty is a process of disclosing six veils, where each veil shows a different aspect of it. In the fourth veil he refers to what is now known as the basic needs approach: "Beyond the fourth veil are direct measures of physical inputs to meet basic needs, such as, calories consumed, yards of cloth bought, cubic feet at house room occupied, hospital beds available, school enrollment, letters posted, etc". He thinks that despite the fact that this veil is full of means, as in the monetary approach, those are means that move beyond the income paradigm and refer to goods and services favoring the human needs.

Also at the end of the 1970s Sen proposes the 'capability approach' as a framework to understand development and specifies that poverty is a 'capability deprivation'. He argues that income is not a satisfactory space to evaluate the well-being of individuals. For him, the monetary tradition is a very limited framework to understand development. Income is just one particular means among many others but not an end in itself: "Aristotle had pointed out, at the very beginning of his Nicomachean Ethics, that income and wealth are only instrumentally ${ }^{1}$ valued, and we have to go deeper to understand what makes human life rich and human freedoms effective" (Sen, 2006, p. 35).

\footnotetext{
${ }^{1}$ The argument of Sen (1999, p. 90) is that poverty can be perceived as a capability deprivation when the focus is shifted from means (e.g. income) to ends (objectives that people want to pursue) as for instance health and education with their instrumental (indirect effects on productivity) and intrinsic (direct effect, like living a healthy life or being educated) value.
} 
The proliferation of conceptual frameworks since the late 1970s has shifted the focus of understanding and measuring poverty from income to other dimensions of development. At the same time research on its measurement is booming. It is a complex subject to navigate and although several innovations have been proposed, the 'income paradigm' is still the main framework used to understand and measure poverty. "Life is richer and more complex than buying and selling goods and services, but unfortunately, this creates the need for alternative measures which are not so readily available and are likely to generate more controversy and more difficulties in measurement" (Fleurbaey, 2015, p. 201). Poverty has different shapes and magnitudes. Poverty can be defined in terms of income, capabilities, basic needs, social exclusion, vulnerability to risk shocks. It can be considered permanent or transitory. It can be defined in relative or absolute terms. It can be understood in objective or subjective terms. The discourse in the field of poverty studies has agreed, at least, that poverty is multidimensional, as noted by Jenkins and Mickelwright (2007, p. 7), "these developments reflect the view that poverty is not only about having enough money, and that inequality is not just about differences in money income".

The rest of this section presents a summary of the most important conceptual frameworks that dominated the field in the last 40 years, as well as their strengths and limitations.

\section{Income Poverty}

Under the welfarist approach, well-being is measured on the basis of a proxy of utility based on resources like income, consumption or expenditure. Resources are compared with a minimum requirement of goods and services valued in monetary terms or poverty line. This is a simple optimization problem under a constraint in the budget. On the other hand, poverty lines can be defined in absolute, relative and even subjective terms. Absolute poverty lines are based on the construction of a basket of basic goods, and services following nutritional and cultural patterns, mainly in developing countries, while relative poverty lines take into account the distribution of resources. Examples of absolute lines are for instance the national poverty lines or the 1.90 USD used by the World Bank, while examples of relative poverty lines are the Laeken Indicators of the European Union (ECLAC, 2006).

In 1995, the National Research Council of the US prepared a report suggesting variations to the measurement of income. The main conclusion of the report was: "The current measure [income poverty] needs to be revised: it no longer provides an accurate picture of the differences in the extent of economic poverty among population groups or geographic areas of the country, nor an accurate picture of trends over time. The current measure has remained virtually unchanged over the past 30 years..." (National Research Council, 1995). The final recommendation of the report was that consumption is best suitable for the task. Examples of the duality between income/consumption approaches to measure monetary poverty are abundant and several arguments both in favor and against have 
been noted. Consumption is desirable whenever effects of social policies and programs need to be assessed. As mentioned by Bavier (2008), despite the method, trends of monetary poverty are similar with either one, income or consumption. At the end, the decision will be based on the quality of the data collected.

According to Meyer and Sullivan (2012), consumption has been largely used as an alternative method to assess income poverty because: i) it captures better the permanent income and isolates the fluctuations of the original variable; ii) it includes the assessment of anti-poverty policies (e.g. reductions in taxes and social transfers); iii) it avoids the bias on the sub-reporting of income sources (although there is bias on the reporting of consumption data collected from household surveys). Despite its advantages, the main drawback of consumption-based measures is the quality of the information collected. Both approaches are affected by the bias in the Consumer Price Index.

Despite the improvement of consumption in the monetary measurement, advocates of non-monetary approaches claim that monetary poverty is a very limited tool to assess the complexity of the subject. Income measures are based on cash flows. Often the advantages/disadvantages of non-cash income are neglected in the measurement of income poverty. A recent example of the effects of including non-cash income can be found in Maestri (2015) where home-owners rent is imputed and housing expenses are deducted from disposable income, using EU-SILC data for 2010. Also, monetary poverty is not robust for international comparisons as it depends on the value and methods to construct poverty lines (Blackburn, 1998). Lastly, regardless of the common conception, monetary measures are as well a multidimensional. For instance, consumption of valuable goods is combined in a single index expressed in monetary terms. As a consequence, monetary poverty measurement is not devoid of value judgements (e.g. which goods are considered part of the basic basket) but it is still perceived as the most 'scientific' one (Ruggeri et al., 2003, p. 29).

\section{Capabilities Approach}

The 'capabilities approach' (CA) is the theoretical framework introduced by Sen at the end of the 1970s. Sen argues that measuring material prosperity by using the monetary approach has several drawbacks. He recognizes that income is important, as an instrument, but that it is not the ultimate dimension to evaluate the well-being of individuals. His theory was the base point for the creation of the Human Development Index of the UNDP in 1990, and for setting a new approach on development that was made explicit by the UNDP from that moment onwards (Fukuda-Parr, 2003). 
According to Sen, the 'concept of development' is related to the achievement of a 'better life' by individuals: "People value their ability to do certain things and to achieve certain types of beings (such as being well nourished, being free from avoidable morbidity, being able to move about as desired, and so on). These 'doings' and 'beings' may be generically called the 'functionings' of a person (Sen, 1988, p. 15).

Achievements are not only a matter of possession of some goods and in this sense, Sen separates himself from the 'income paradigm' of poverty. He considers that also availability and effective access to public goods and services have to be taken into account to assess the well-being of individuals. Living a healthy life will be a function of the structure of health services (in terms of access and quality of the services) as well as particular genetic considerations intrinsic to each human being and cultural traditions.

Different feasible sets of 'functionings' constitute the capabilities that a person can reach. Having the freedom to chose among different sets is determinant for the capabilities framework: "Being able to freely choose to lead a particular life may be a point of a richer description of the life we lead, including the choices we are able to make" (Sen, 1988, p. 17). For Sen it is not enough to account for the achievements of a person, but it is also important to consider the process of selection (or not) in choosing a particular life between different alternatives. By choosing, individuals are exercising their agency, another central concept for Sen. To clarify, he introduces the example of a fasting person vs. a starving person. Both persons achieve the same outcome (not eating), just one of them had the freedom to choose between eating and not-eating, while the other was forced to starve, and therefore his/her alternatives were reduced to only one.

The CA is defended as a pluralist and objective conceptual framework: "It is the people themselves who decide the type of development they want" (Deneulin, 2006, p. 2). Sen also puts a lot of effort in stressing the role of agency and empowerment. The chosen functionings to evaluate the well-being of individuals had to be selected on the basis of the 'greater goods'(independent of personal preferences). He argues that poor people have the tendency to adapt to the situation they live in and therefore their expectations are going to be limited. ${ }^{2}$

In the end, Sen's CA proposes a new paradigm to interpret poverty: "poverty as a basic 'capability failure', that is, as the inability of individuals and communities to choose some valuable 'doings and beings' which are basic to human life" (Alkire, 2002, p. 156) independent from the bundle of 'basic goods' ${ }^{3}$. The selection of the capabilities to be included is decided upon their relationship with the 'life people wants to live'. In other words, the capabilities will be defined by each individual on the basis of their intrinsic value.

\footnotetext{
${ }^{2}$ Sen uses his argument of 'adaptive preferences' to defend why subjective approaches to the conceptualization and evaluation of poverty are limited in assessing deprivation by functionings.

${ }^{3}$ Inability is understood differently from disability. Disability is also a concept for which there is not a consensual definition. Inability refers to a practical opportunity to reach a particular objective, as being nourished. For a discussion about disability and the CA see (Mitra, 2006)
} 


\section{Material Deprivation and Social Exclusion}

Material deprivation is a concept developed by Townsend (1979). In a broad sense, it is defined as the inability to live a decent life. It is a concept that has evolved over time and that has been adopted by the Organization for Economic Co-operation and Development (OECD) and the European Union (EU). The OECD defines material deprivation as: "the inability for individuals or households to afford those consumption goods and activities that are typical in a society at a given point in time, irrespective of people's preferences with respect to these items" (OECD, 2007).

Mainly motivated by the European agenda, the language of social exclusion has opened its way through the literature on poverty and it is interlinked with the concept of 'material deprivation': "Social exclusion is a complex and multidimensional process. It involves the lack or denial of resources, rights, goods and services, and the inability to participate in the normal relationships and activities, available to the majority of people in a society, whether in economic, social, cultural or political arenas. It affects both the quality of life of individuals and the equity and cohesion of society as a whole" (Levitas et al., 2007, p. 25).

The concept in itself is a widely debated topic. Many definitions are available, focusing on different levels of exclusion, from strong ones as isolation or denial of access; to soft ones, as lack of participation, deprived choices; and combinations in-between. It refers to deprivations that are caused by structural factors inherent to the society or to individual characteristics, as summarized in Levitas et al. (2007).

In the EU, social exclusion (at risk of poverty or social exclusion) is defined as: "the situation of people either at risk of poverty, or severely materially deprived or living in a household with a very low work intensity" (EUROSTAT, 2015). In other geographical areas, social exclusion is a more complex topic. It also borders with the discourse on discrimination (e. g. immigrants, race, ethnicity, gender, religion, sexual orientation, among others) but undoubtedly it is also linked to human development and capabilities.

\section{Justice as fairness and Primary Goods}

Sen used Rawls as a source of inspiration for his CA framework. Despite this, both frameworks are different in the flexibility of what constitutes a 'primary good'. Rawls in the early 1970s developed the theory of justice as fairness. He identified two basic principles to which any society and its institutions should adhere: i) political liberty and freedom of speech and assembly; and ii) distribution of income and wealth, equal opportunity. He claimed that "injustice is tolerable only when it is necessary to avoid an even greater injustice"(Rawls, 1971, p. 4). He argues that if we could go back to an 'original position', where neutral unbiased human beings agree upon rules that a society should follow, everyone in principle would be willing to accept them. He believed that in the 'original position' equality is the maximum principle, the 'state of nature'. Using 
the contract theory, Rawls argues that although primary goods "are things which it is supposed a rational man wants whatever else he wants" (Rawls, 1971, p. 79), an index of primary goods will unavoidable be incomplete because the emphasis should be on the fulfilment of plans executed using those goods instead of on the goods themselves. His conceptual framework does not consider the satisfaction of individuals, but instead the liberty to pursue whatever plans of life each individual has. It is easy to see the common arguments in the CA and in the justice as fairness frameworks. Both frameworks are based on the individual fulfilment of plans and the choices taken in the exercise of freedom of action.

\section{Basic Needs}

Following the increasing disappointment in the monetary measurement of poverty, the 'basic needs' approach is another framework that emerged at the end of the 1970s. It advocates for the inclusion of basic social indicators to account for those neglected dimensions of poverty, considering that at that particular moment the quest for 'social indicators' was still in its infancy and several choices were criticized because of its narrowness. "The main basis of the basic needs approach, in fact stems both from the view that raising incomes alone is insufficient in view of the inefficiencies in the consumption patterns of the poor and the lack of availability of essential goods and services" (Hicks and Streeten, 1979, p. 570). The approach focuses on the basic resources that should be available for every individual in society. The tradition was led by the World Bank and found a consistent application in Latin America and the Caribbean. Misunderstood as an approach only focused on commodities its main focus is on 'opportunities for a full life': "These all-purpose means for a good life are commonly labelled as 'resources'. In a narrow economic interpretation, resources are typically limited to financial means, either income or imputed value of public goods. But far broader interpretations are encountered in disciplines other than economics. Political philosophers, in particular, have investigated the large range of resources that are arguably needed for well-being or quality of life" (Robeyns and Van der Veer, 2007, p. 30).

\section{Social Risk Management}

In the early 1990s, the Social Risk Management Approach (SRM) dominated the language in the field of poverty reduction. The framework focuses on the links between the extent of social protection systems and the risk and uncertainties that poor and vulnerable people face. People considered as poor are the most exposed to different types of risks (e.g. diseases, infant mortality, among others), and at the same time that are the most vulnerable in terms of tools to face the hardship (e.g. lack of resources, education and land, among others). The main objectives of SRM are: "i) to enhance individual and social welfare in a static setting; ii) to contribute to economic development and growth from a dynamic perspective; and iii) to serve as crucial ingredients for effective and lasting poverty reduction" (Holzmann and Jorgensen, 2001). With a particular 
practical focus and less of a philosophical background the framework established itself in the field of poverty reduction interventions led by the World Bank. The idea behind SRM is to design policies and programs focused on the different types of risks (for instance, earthquakes, illness of the main breadwinner, unemployment, among others) in order to mitigate, prevent and cope with their consequences in people's lives.

In conceptual terms SRM is closely related to the livelihoods approach, as mentioned by Chambers (1995), especially in terms of the tangible and intangible assets that poor people use to cope with struggle (sources of income, food and support that are unconventional and informal). This resources are usually excluded from the conventional data gathering.

\section{Participatory Assessments}

Up to now, all the conceptual frameworks summarized in this chapter focus on an ideal state of understanding poverty from the point of view of researchers and academics or as Chambers (2007, p. 142) names it 'ivory tower' concept of poverty. However, in the 1990s participatory poverty assessments (PPA) started to be used, mainly in African countries, to include the views of the poor not only in the definition of poverty but more importantly in the design and implementation of policies and programs to overcome it. In a way, the concept developed through participatory approaches has helped the understanding of poverty and its 'hidden dimensions'. Since the years 2000 the World Bank has led an extensive application of the participatory research in the field of poverty, and PPAs were transformed in a comparative study. Mainly based on qualitative approaches, the PPAs go beyond the information obtained by quantitative measures. Common trends were easily found in the comparative study: i) poverty is multidimensional, ii) poverty is usually linked to a lack of resources, iii) poverty includes a psychological dimension (invisibility, stigmatization, lack of participation, among others), iv) access to basic services as water, sanitation, electricity and roads is claimed as a source of poverty, v) health is highly valued by poor people, vi) poor people's vulnerability is understood in terms of destitution caused by lacking assets more than income (Narayan and Patel, 2000, p. 31). The approach has not been free from criticism. The main dissenters claim that real PPAs will require an extensive sample of interviews in order to include a broad range of views, which will cause PPAs to be extremely expensive. Another claim is that trusting only what the poor people think will fall into the same information trap as the utilitarian-monetary approach. As explained by Sen (1999, p. 62): "The deprived people tend to come to terms with their deprivation because of the sheer necessity of survival, and they may as a result, lack the courage to demand any radical change, and may even adjust their desires and expectations on what they unambitiously see as feasible". However, insights of the extended use of this approach complement the findings of exclusively quantitative approaches by making researchers aware of previously neglected topics, by reinforcing the understanding of the multidimensionality of poverty and by changing the instruments used in the measurement of poverty. 


\subsubsection{Multidimensional Poverty Measurement}

Without explicit measures, conceptual frameworks are just abstract definitions of problems, and measures that do not rely on a conceptual framework are pieces of information that do not relate to particular goals and objectives. Conceptualization of poverty is therefore attached to its measurement. To perform effective measures, choices need to be made, based on value judgements or in statistical analysis. For instance, measures require the selection of a particular conceptual framework, a method, dimensions to be included and excluded, valuation of weights, scales of measurement in each dimension, setting up thresholds, and finally, the translation of the results in simple and readable numbers (OECD, 2008). Measures can not be calculated without regard to the particular context in which they are applied and the sources of information available.

Measurement of multidimensional poverty is a complex subject. Not only because there is no consensus about a conceptual framework but also because of its multidimensionality. The whole is not simply the sum of its parts: "To describe multifaceted, multidimensional concepts consisting of many interrelated elements and patterns for which, generally speaking, the whole cannot be fully understood by separately analyzing its components" (Chiappero, 2008). It is precisely this argument of complexity and vagueness of poverty that ends up being extremely appealing for jointly studying the performance of different dimensions.

On the topic of the operationalization of the capabilities approach there is still no consensus. It is possible to argue, as was explained in Section 2.1.1, that to fully account for capabilities deprivations a whole new dataset needs to be created, while for now the only possible option will be the measurement of achievements (or the lack of them). Others argue that different types of indices or methods used are in fact the most accurate operationalization of Sen's conceptual framework. Atkinson (1999, p. 185-186) said, referring to the capabilities approach of Amartya Sen, that "it is important to bear in mind that there is more than one way in which an idea of this kind can be operationally effective. In particular, the application of an idea may be powerful in theoretical terms, without necessarily leading to a quantitative measure". While theoretical frameworks have evolved since the late 1970s, operationalization of the measurement has attracted attention since the early 2000s. This struggle is the topic of the rest of this section. It shows a typology of the different initiatives in the measurement of multidimensional poverty. Following Coromaldi and Zoli (2012), the methods can be divided into 'aggregative' and 'non-aggregative'. On the 'aggregative' side composite indices are the final result, while in the 'non-aggregative' approach a dashboard of several indicators is the outcome. Whenever multidimensional is mentioned as an approach to the measurement of poverty, or for that matter, of any other subject, does not mean that automatically the only choice is to aggregate different dimensions in a composite index (Ravallion, 2011). 


\section{Counting Approaches-Aggregative}

Following Sen (1976), one can quantify the number of poor people by basically relying on two steps: identification of the poor and aggregation. In multidimensional poverty, individuals are characterized by attributes, that will depend on the selection of the conceptual framework to apply and in the availability of data. These attributes are known as functionings, achievements or capabilities in the CA framework, while in the Basic Needs Approach they are known as needs. The different dimensions are considered as attributes that are compared with a standard expressing a 'minimally acceptable level' as defined by Bourguignon and Chakravarty (2003). The individuals under this level are identified as deprived in a particular attribute, and hence as "experiencing a functioning failure" (Bossert et al., 2013) under the CA framework or as lacking access to goods and services, rights, and so on.

In a simple case of only two attributes ( $x$ and $y$ ) with minimally acceptable levels (the dashed lines $z_{x}$ and $z_{y}$, respectively), there are four possible cases, as shown in Figure 2.1. I. is the case in which the individual is not deprived in any of the two attributes; II. and IV., are the cases in which the individual is deprived in one of the attributes; and III. is the case in which the individual is deprived in both attributes. Once the situation for each dimension for every individual is identified one can aggregate and find the level of multidimensional poverty. To identify those cases the concept of 'union' and 'intersection' approach is introduced. In the union approach the criterium to be considered as multidimensionally poor will be to belong to the regions II through IV. In the intersection approach only individuals in region III are considered as multidimensionally poor. When more than two attributes are considered the intermediate approach needs to be included by fixing a threshold for the minimal number of dimensions. In the AHR (Section 2.1.2 and Appendix 2.5.1) for more than two dimensions, the union identification approach is a particular case when $k=1$, and in a similar way the intersection is the particular case when $k=d$, when $d$ is the total number of indicators included in the multidimensional analysis.

However, this black and white approach was adapted by Duclos et al. (2006), where an intersection is considered in the shape of a 'poverty frontier' (the curve in Figure 2.1). In this case a person is considered non-poor even for cases below the threshold in one of the attributes (e.g. $y<z_{y}$, or vice-versa, considered poor even if $y>z_{y}$ ). In the case with three dimensions, the frontier becomes a boundary surface.

Most of the variables that could be used to include other dimensions of well-being besides income are discrete variables, hence indices that only deal with continuous variables are inapplicable in practice. ${ }^{4}$ The best approach would be what has been denominated as 'Counting' approaches, which focus on "counting the number of dimensions in which people suffer deprivation"(Atkinson, 2003, p. 51). Other applications

\footnotetext{
${ }^{4}$ Variables besides income and years of schooling are difficult to quantify. Most of the variables to assess well-being or poverty are either: dichotomous and measure the access to a service, as for instance sanitation (yes/no) or they are categorical variables, as for instance the type of cooking fuel: gas, electricity, kerosene, wood, charcoal, among others.
} 
Figure 2.1: Two Attributes Cases

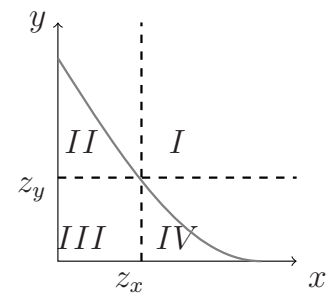

Source: Author's elaboration based on Bourguignon and Chakravarty (2003) and Duclos et al. (2006)

of the counting methods to the measurement of poverty can be found in Bossert et al. (2013), Chakravarty and D'Ambrosio (2006) and Rippin (2010). The application of Alkire and Foster (2011a) will be explained in the following section.

Counting methods can be used to measure the behavior of individuals in terms of poverty (individual poverty function), as well as to summarize the performance of a region, or a country (social poverty function). After counting the dimensions in which an individual is considered deprived (a matrix of 1 and 0 for each individual among the different dimensions) a measurement of breadth, in terms of the sum of the weighted number the dimensions the person is deprived (1's) is included to complete the individual poverty function. The average of individual deprivations in a particular population is combined to obtain the social poverty function. A generalization of counting methods as well as a detailed explanation of the elements introduce in this section are shown in Appendix 2.5.1.

Recently, the work of Permanyer and Riffe (2015) has shown that different hierarchical models could be built and the 'counting' can be replaced by a decision tree. The options are compared with the results from the different indicators showing paths and using Hasse-diagram techniques to order them.

\section{Alkire-Foster Family of Multidimensional Indicators}

The Alkire and Foster (2011a) (AF) method derives from the Foster-Greer-Thorbecke (FGT) family of indices of income poverty (Foster et al., 1984), but it is applied to a multidimensional setting. It is the most extended and applied counting method based on the CA theoretical framework, but as mentioned before not the only one. It creates a composite index with the assessment of achievements using micro-data. The identification step is divided in two parts: First, thresholds are defined for each indicator (deprivation cut-offs), then each indicator/dimension is weighted and a second cut-off (poverty cut-off or $k$ ) is defined, as explained in Appendix 2.5.1. As a consequence it is known as a dual-cut-off approach. This poverty cut-off allows the selection of any of 
the three possible identification approaches: union, intersection and intermediate. ${ }^{5}$ The method has the advantage of dealing with more than two dimensions, as well as with either continuous ${ }^{6}$ or discrete data, and it fulfils the axiomatic requirements described in Appendix 2.5.1. It requires micro-data at individual level to assess deprivation in each indicator for each person making it more demanding in terms of data requirements.

The AF method uses, similarly to the FGT $\left(P_{0}, P_{1}, P_{2}\right.$ or $\left.P_{\alpha}\right)$, three subindices: the Adjusted Headcount Ratio $\left(M_{0}\right.$ or AHR), the Adjusted Poverty Gap $\left(M_{1}\right)$ and the measure of severity of deprivation $\left(M_{2}\right)$. The family of indices is described as $M_{\alpha}$ where $\alpha$ is an indicator of the level. However, for $\alpha \geq 1$ the data should be cardinal. Dichotomized or ordinal data will not suit the properties of the indices, and therefore the measures of breadth and severity cannot be obtained. Nonetheless, the AF and other 'counting' methods provide a measurement of breadth that depends on the number of dimensions in which an individual is considered deprived, and that can be used for different types of functions and not only the AF, as proved by Chakravarty and D'Ambrosio (2006).

\section{The MPI}

The Multidimensional Poverty Index (MPI) was first published in the Human Development Report of 2010 (UNDP, 2010). It is known as the global MPI because it includes more than 100 countries in its sample. It follows the Alkire and Foster (2011a) method, especially the Adjusted Headcount Ratio (AHR). In order to create a ranking of countries from the poorest to the richest, the MPI uses different data sources such as: Demographic and Health Surveys (DHS), Multiple Indicators Cluster Surveys (MICS), and World Health Surveys (WHS). It uses the household as the unit of analysis. It distinguishes three different dimensions and uses 10 indicators: nutrition and child mortality in health; years of schooling and attendance in education; electricity, sanitation, water, floor material, cooking fuel, and assets in living standards. The final result is a composite index that represents the level of 'joint disadvantages'. As a method of aggregation it considers equal weights for dimensions and for indicators inside a dimension (nested weights) and a weighted average. Finally, to identify those multidimensionally poor it fixes the second cut-off in $\frac{1}{3}$ of the indicators (Alkire and Santos, 2014).

This particular way of operationalization has attracted a lot of attention from different sources: international organizations, academia and researchers, policy-makers and governments. Despite the fact that different approaches have been implemented in the last 15 years, this has been the most widely discussed, used and applied. A list of published papers with specific applications of the MPI is shown in Appendix 2.5.2.

\footnotetext{
${ }^{5}$ However, as mentioned by Silber and Yalonetzky (2014) there are other identification functions from a range of discrete as in Alkire and Foster (2011b) to fuzzy as in Rippin (2010).

${ }^{6}$ Besides the AHR, the other indices part of the family AF (gap and severity of poverty) do not provide additional information when variables are discrete.
} 


\section{The Debate}

The popularity of the MPI feeds an ongoing academic debate. Clearly there are two different sides: on the one hand the advocates of multidimensional composite indices and on the other hand, the skeptics. They disagree on the best way to measure multidimensionality. The leading skeptic has been Ravallion (2016), who questions the need to aggregate different indicators in a single number when a dashboard is preferable and easy to understand. For him, the aggregation process inserts a great deal of arbitrariness to it, especially the selection of weights and the subsequent collapsing mechanism. Besides him, others have elaborated on the weakness of the method, in terms of the substitutability/complementarity between dimensions implicitly assumed by the aggregation mechanism as mentioned in Alkire (2011).

On the advocates' side, there are obviously the proponents of the index, mainly the UNDP, Alkire and Foster (2011a) and the Oxford and Human Initiative (OPHI). For them multidimensionality can only be achieved when the different dimensions are collapsed and therefore the 'joint distribution' is captured by a single number. In a similar side, the Atkinson's Commisssion (2016), recommends the World Bank a Complementary Indicator of Multidimensional Poverty based on the counting approach, despite recognizing that it is possible that the academic debate will never be settled. Another interesting point of view is that taken by Roodman (2011), who mentions that in order to find a number, comparisons of incomparable categories need to be performed. Roodman thinks that there is not a problem in doing so as long as the decision is explicitly and clearly communicated. However, he recognizes that there is some risk at the moment of creating a synthetic index that should be avoided: "While being artificial and crass, indexes are also mathematical abstractions, beautiful when done right, pregnant with philosophical questions" (Roodman, 2011, p. 484).

A neutral cluster of researchers has emerged, claiming that normative decisions are an obvious source of disturbances. Multivariate stochastic dominance establishes itself as the middle ground. Basically the objective is to find the conditions under which a distribution dominates another, and to define ranges in which dominance can be found and cases where it cannot. Another approach is the construction of Venn diagrams to show the overlap between different dimensions. A last approach is to include multivariate association analysis (Ferreira and Lugo, 2013). All of the middle ground approaches still rely on a 'joint distribution' under the assumption that the result is more than the aggregation of its parts.

Caveats of the MPI application are also shared by every other application that relies on secondary data and international comparisons of countries. Surveys are performed at different moments of time and not all the indicators are available for every country, forcing the adjustment of weights inside each dimension. Besides, there are issues of representativeness of the sample that affect the analysis of sub-national groups (Alkire et al., 2015b). 


\subsubsection{Other Multidimensional Welfare Assessments}

Despite the fact that this thesis focuses on the measurement of multidimensional poverty using the AF counting method, and bases it on the CA theoretical framework, this section provides a summary of other types of measurement of welfare, available in the literature, which although not applied in this work, are important to summarize in order to understand the evolution of the measurement of poverty.

\section{Income and other dimensions}

Exhaustive research has focused on the interlinks between income and other dimensions. From a descriptive point of view towards a more analytical view, the field is full of examples of studies that mix income with other dimension(s). An extensive inventory of these efforts is listed in Table 2.2 in Appendix 2.5.3. The table presents other dimensions, the methodological approach, the country of study and the main findings.

\section{Capabilities}

Following the conceptual framework of Sen (1988), operationalization of the CA using methods different from the counting methodologies has also been increasingly found. The Fuzzy set technique was applied both to the measurement of income (Cerioli and Zani, 1990) and multidimensional poverty. It is a technique that avoids imposing an arbitrary cut-off. Instead it relies on a membership function that is based on the distribution of the population (Lemmi and Betti, 2006). However, the choice of the membership function is discretionary (e.g. linear, trapezoideal and non-linear) (Chiappero, 2006). Examples of applications are, for instance, those performed by Kim (2015) for the UK, Wagle (2009) for the particular case of the US, Betti et al. (2008) for Italy, Deutsch and Silber (2005) in Israel, among others.

Another branch on the operationalization of Sen's framework is based on the latent variables models, as for instance confirmatory factor analysis (CFA), multiple indicators and multiple causes (MIMIC) and structural equation modelling (SEM). All the methods collapse a long number of indicators into a small number of factors (Tomlinson et al., 2008). Examples of applications can be found in the works of Alkire et al. (2015a); Anand et al. (2011); Krishnakumar and Nagar (2008); Krishnakumar (2008); Krishnakumar and Ballon (2008); Tomlinson et al. (2008); Kuklys (2005); among others. 


\section{Material Deprivation and Asset Indices}

Material deprivation is often compared or considered complementary to income. There are two main trends in its measurement in the literature. The first led by Townsend (1979) focuses on 'living a decent life' operationalized in the lack of necessities expressed in a list of items, as in the works of Townsend (1979) for Britain, and Chow (1983) and Saunders et al. (2014) for Hong Kong. The second focuses on the concept of 'enforced lack' as in the work of Nolan et al. (1993). Other applications also use different techniques as latent class analysis models and regression based methods to find the association between 'basic deprivation' and income, economic vulnerability, intergenerational mobility, social exclusion and effects of economic recessions (as in Whelan and Maitre (2014); Whelan et al. (2013); Whelan and Maitre (2008, 2007a,b, 2005); Saunders and Naidoo (2009); Ayala et al. (2011); Devicienti and Poggi (2011); Barcena-Martin and Lacomba (2014); Gerovska-Mitev (2015))

Another approach is to build asset indices, formed by a collection of the goods used in the construction of material deprivation indicators. These indices have been used for a variety of purposes as, for instance, an approximation to the definition of economic status, as complementary information to income poverty, whenever the collected information of income/expenditure/consumption is not accurate or incomplete, to explain inequalities in health and education, among others (as in the works of Filmer and Scott (2008); Fusco and Dickes (2008); Brandolini et al. (2010); Harttgen et al. (2013). Nonetheless, as mentioned by Harttgen et al. (2013), assets indices suffer from several drawbacks: i) in comparisons over time, the list of relevant assets may change or become obsolete; ii) prices of assets can alter their demand; iii) surveys only ask for the ownership (or not) of durable goods, neglecting important complementary information such as, purchasing date, in order to include depreciation rates; and iv) some of the assets included in the list depend on the effectiveness and priorities of public policy.

\section{Subjective Well-being or Happiness}

The main hypothesis behind this framework is that despite the importance of income, for the subjective well-being of individuals, there are other dimensions that are neglected and that play an important role (as in the work by Shams (2014) for Pakistan, Guardiola and Garcia-Quero (2014) for Ecuador, Main and Bradshaw (2012) for children in the US, Blazquez and Budria (2014) and Van Praag and Ferrer-i Carbonell (2008) for Germany and Rojas (2008) for Mexico) ${ }^{7}$.

The main drawbacks found in the happiness literature are the fact that people have a tendency to adapt their expectations over time, and hence their aspirations in life also have a tendency to change with greater income or access to material well-being. Additionally, levels of individual satisfaction also depend, in relative terms, on the group

\footnotetext{
${ }^{7}$ The questions more often use are those related to life satisfaction, level of happiness, having (or not) a good life (Rojas, 2008), or used an economic ladder question Lokshin and Ravallion (2000)
} 
to which the interviewee is being compared, and the stability of the level of satisfaction will depend on the particular moment in which the survey is performed. However, the idea of empowering people to define by themselves what constitutes a happy and fulfilling life remains appealing, as mentioned by Kingdon and Knight (2006). Subjective wellbeing is measured by the perception of individuals of their own lives. The income related version is the creation of a subjective poverty line as in Hagenaars and de Vos (1988) based on the minimum income that is 'sufficient'.

\section{Others}

It is not surprising to find that on the methodological quest for a multidimensional index of poverty, a conceptual framework is often neglected. Many applications available in the literature do not attach themselves to any particular concept measured. They solely focus on the methods used, but despite their weakness they are innovative applications in the measurement itself. Statistical methods are widely used and empirical applications are drawn from developed as well as underdeveloped countries. Examples of these are: i) in the aggregative side: a combination of techniques, as factor analysis, to find out the relevant domains, and clustering of deprivations to create a typology of multidimensional poverty, as in Luzzi et al. (2008) or Multiple Correspondence Analysis as in Asselin and Anh (2008); ii) In-Between side: the use of clustering and mapping different combinations of paths as in Lucchini and Assi (2013), or non-linear component analysis (NLPCA), as in Coromaldi and Zoli (2012); and iii) Non-Aggregative side: where dashboards are the result, as in Delamonica and Minujin (2007).

\subsection{Poverty Dynamics}

A static assessment of poverty neglects the inclusion of processes that are fundamental for the persistence and therefore for the elimination of poverty (Addison et al., 2009). Therefore the field of poverty conceptualization and measurement has evolved to include an assessment of its dynamic behavior over time: 'Poverty dynamics'. It refers to the measurement of poverty over time, and it has been traditionally dominated by the income poverty paradigm. Recently there is an increased interest in calculating dynamic poverty using different conceptual frameworks. For instance, Devicienti et al. (2014) measured the overlap between current and persistence of income poverty over time and material deprivation; or in the case of multidimensional measurement of poverty Bossert et al. (2012); Nicholas et al. (2013); Alkire et al. (2014) among others.

This section summarizes the development in both the monetary and the non-monetary measurement of poverty over time. 


\subsubsection{Dynamic Monetary Poverty}

In the monetary approach, there are two ways of analyzing persistence of poverty over time as shown in Figure 2.2. First the measurement of transitions in/out of poverty, mainly focusing on developed countries, as for instance the works of Damioli (2010), Polin and Raitano (2014) and Jenkins and Van Kerm (2014) in EU; Valetta (2006) in Canada, Germany, Great Britain and the US; Jenkins and Rigg (2001) and Jenkins and Van Kerm (2011) in the case of Britain; Kyzyma (2014) in the case of Germany; Riegg et al. (2008) for the US; Headey et al. (2005) for Australia; and Oxley et al. (2000) in OECD countries. And second the study of chronic poverty, also divided in two branches: the components and the spells approaches, as summarized by Foster (2009). In the components approach an average income poverty is calculated and compared to a poverty line. This approach is not sensitive to the time spent in poverty. By contrast, the analysis of the 'spells' focuses on the duration, frequency, position and vicinity of poverty episodes and quantifies their implications. In this case, an additional cut-off needs to be defined: the minimum duration of the spell; and an additional property is included: 'time monotonicity'. Nonetheless, within and between the two approaches there is no consensus about the best way to undertake the measurement of dynamic monetary poverty.

When income is used in the measurement of poverty, the permanence or not of a household in poverty could follow different trajectories: always poor, usually poor, churning poor, occasionally poor and never poor, following Hulme and Shepherd (2003, p. 405). Income as a measure of poverty is highly variable, and depending on data availability, it is preferable to make poverty assessments based on consumption or expenditure data. Expenditure data shares some, but not all, of the limitations of income data, as for instance the impossibility to value the informal exchange of goods (Moser and Felton, 2009).

Nonetheless, the persistence of a household in poverty over time is an indication of some level of deprivation. To define the trajectories that households or individuals follow, researchers have adopted a normative standard of persistence over 3 or 5 years, in order to classify the unit as 'chronically poor' (Hulme and Shepherd, 2003). This threshold depends on the frequency of collection of the data and on the hypothesis that the longer the persistence in poverty the higher the probability to remain poor for an extended period.

\subsubsection{Dynamic Multidimensional Poverty}

Researchers performing analysis on dynamic poverty agree on the relative variability of income over time. Income could be a more straightforward tool to analyze transient poverty. In this sense, multidimensional deprivation could be used to assess poverty in the long run, the type of poverty that is considered chronic: "Extreme poverty results when the lack of basic security simultaneously affects several aspects of people's lives, when it 
Figure 2.2: Dynamic Monetary Poverty Schema

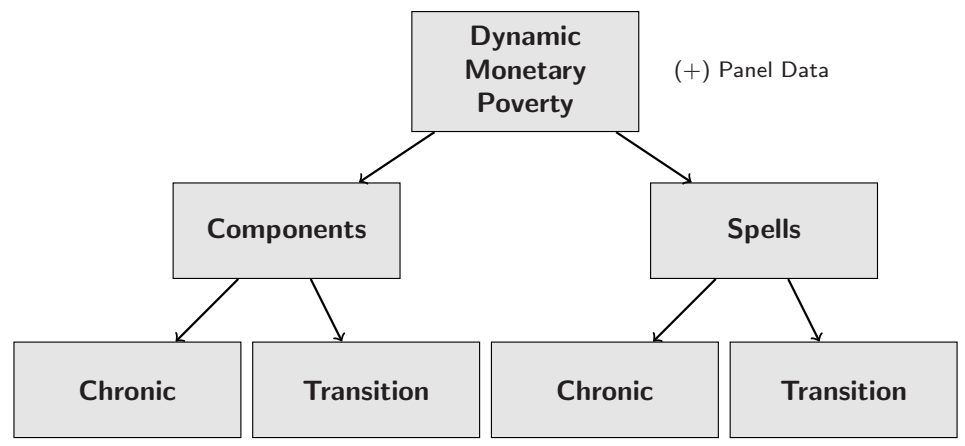

Source: Author's elaboration based on literature review

is prolonged, and when it severely comprises people's chances of regaining their rights and re-assuming their responsibilities in the foreseeable future" (Hulme and Shepherd, 2003, original in Wresinki, 1987 quoted in p. 407). The complementarity between income and multidimensional approaches to the measurement of poverty seems closer when time is included in the analysis. Nonetheless, analysis performed of overlapping between monetary and multidimensional measures of poverty has shown that this result is also context dependent (De Neubourg et al., 2012).

A main drawback of multidimensional measurement, besides the lack of consensus in the field of measurement of poverty, is that it mixes both stock and flow variables. Depending on the particular application, some variables included do not change over time which makes them somehow complementary to income, but others are highly variable. Inertia over stock variables suggests destitution over critical aspects of well-being of individuals (e.g. poor material of the walls), but at the same time it is compared with variables that could be used as a mechanisms of risk management (e.g. selling livestock under a crisis).

The inertia/variability of some indicators also depends on the particular age group of the individuals (e.g. years of schooling for adults and elderly is perceived as a static indicator, while for children it is considered very dynamic). Finally, it has been argued that it is already complicated to interpret the aggregation and weighting of multiple indicators when a composite is constructed on static measures of poverty; and therefore, when dynamic analysis is included, not only the different behavior of indicators but also the comparability over time add noise to the final result (Günther and Klasen, 2009).

\subsubsection{Panel Data vs. Cross Sectional Data}

It is possible to measure dynamic multidimensional and income poverty depending on the availability of data. Under ideal circumstances, with the availability of Panel Data, particular individuals can be followed over time. However, the main limitation of panel data is that it is costly and complex, as for the purpose of some research 
topics (e.g. intergenerational transmission of poverty or well-being) several waves need to be available in which well-being indicators are included and preserved unchanged. Furthermore, panel data collection is in its infancy in Latin America. ${ }^{8}$

Another way to collect data over time is the cross-sectional analysis. The countries in the sample used in this thesis (Chile, Colombia, Ecuador and Peru) had a long standing tradition of performing recurring Living Standard Measurement Surveys (LSMS) for which most of the indicators are collected in the same way, and therefore comparability over time is not affected. Since 1996 cooperation has been established between the statistical offices of some Latin American countries, the World Bank, the Inter-American Development Bank (IADB) and the Economic Commission for Latin America and the Caribbean (ECLAC) with the objective of improving access to information about the quality of life of individuals living in the region. The MECOVI program, a Spanish acronym for Program for the Improvement of Surveys and the Measurement of Living Conditions in Latin America and the Caribbean, implicitly helped to standardize the application of the Living Standard Measurement Survey (LSMS) in the region.

Besides the advantage of availability, the surveys are comparable between countries. Nowadays, the structure of the LSMS in the region is policy driven. In the last years countries have improved and distanced each other from the original versions in an effort to gather quality information to measure phenomena of particular interest for each one of them. Nonetheless, the commonalities are still a reason strong enough to argue for the practical use of the surveys in this dissertation. However because these surveys are not panel datasets their main drawback is that transitions in and out of poverty of particular individuals or households are impossible to obtain. As the same individual (or household) is not followed over time only performance on the average trends of a country (or region) can be deducted (anonymous case). As a consequence, the time analysis presented in this book is not based on the analysis of transitions nor on the differentiation of chronic and transitory poverty, for which the works of Nicholas et al. (2013), Bossert et al. (2013), Apablaza and Yalonetzky (2013), Alkire et al. (2014), and Gallegos et al. (2015) show interesting results.

\footnotetext{
${ }^{8}$ An inventory of the longest and most known panel datasets is presented in Appendix 2.5.4. The IADB organized a technical cooperation to finance and support the development of Panel Datasets in the region. So far, Colombia, Costa Rica, Ecuador, El Salvador, Honduras, Mexico, Paraguay and Uruguay have signed. Chile has a long history on design and implementation of Panel Datasets.
} 


\subsection{Choosing indicators and dimensions under the Capability Approach}

The central key for multidimensionality is to select the dimensions in which well-being or poverty are going to be evaluated. The inclusion of particular dimensions and their respective indicators is a normative judgement based on the importance of a particular aspect in the life of individuals. As mentioned by Fukuda-Parr (2003), "the range of human capabilities is infinite and the value that individuals assign to each one can vary from person to person".

For Sen, the CA has to remain pluralistic. In this sense, he does not set a particular list of capabilities. He argues that capabilities need to remain flexible to be easily adapted to different contexts and spaces: "poverty is a major evaluative concern in most societies, and how we identify poverty as a matter of some practical moment in the context in which questions of this kind are posed" (Sen, 1992, p. 107). This liberty to define what is considered as a valuable 'functioning' is what has been described as the 'vagueness' of the concept.

Other scholars have taken a chance to define a list of goods, services and principles that any society could agree on. Even through the use of participatory assessments the definition of this basic list is set by the means of what the poor really value according to their particular context (Chambers, 2007). The main advocate for a defined list has been Nussbaum (2003, p. 46) who has detached herself from Sen's point of view in this particular topic: "They give us a general sense of what societies ought to be striving to achieve, but because of Sen's reluctance to make commitments about substance (which capabilities a society ought most centrally to pursue), even that guidance remains but an outline". This particular point has been a central topic of debate about the extent of the operationalization of the CA. Many authors have settle for a list of capabilities, or basic needs, or values. ${ }^{9}$ Arguments for and against a definition of a list are abundant in the literature. For Nussbaum, there is a universal 'consensus' around essential features as: life, health, bodily integrity, senses, emotions, practical reasons, affiliation, other species, play and control over the environment, politics and property. Others have criticized this approach by exposing how such lists are just expressions of a westernized reality (Ruggeri et al., 2003, p. 32).

In order to solve this puzzle some strategies are used. Depending on the context, it is easy to find agreement on a 'basic set of capabilities' and to set a baseline: "Understanding poverty as a basic 'capability failure', that is, as the inability of individuals and communities to choose some valuable 'doings and beings' which are basic to human life" (Alkire, 2002, p. 156). Basic capabilities are compared in terms of basic needs. Of course, Sen disagrees about this compromise with a set of basic needs. He thinks that needs are a narrower concept when compared to the capabilities one. He conceives needs as

\footnotetext{
${ }^{9} \mathrm{~A}$ summary of the different available list was performed by Alkire (2002).
} 
commodities and lacking philosophical concept. It is on this particular point that we can encounter the biggest differences between Sen and Rawls. Rawls establishes a list of what he calls the 'primary goods' under two general principles: i) political liberty and freedom of speech and assembly; and ii) distribution of income and wealth, equality of opportunity. Rawls also mentions that there is a need to distinguish primary goods from the distribution of natural goods as health, vigor, intelligence and imagination (Rawls, 1971).

Capabilities are difficult to measure as there are no reliable sources of information that could account for the different sets of functionings and for the choices made by each individual. In other words, data limitations only allow to account for some achievements. Researchers can only observe the outcome of the individual's decision, and it is only possible to assume that some choices are not valued by the societies. A value judgement needs to be enforced, and therefore some dimensions will be missing. In the end, the selection of domains is also a practical decision that depends on available data and a compromise has to be made.

\subsection{The Governance of Poverty}

"Poverty is inherently political since it carries the imperative to respond to eradicate it" (Tomlinson et al., 2008, p. 599). It is not easy to distinguish between poverty, its measurement and the objectives of policy-making, because neither the concept of poverty nor its measurement are isolated from the political process (Atkinson and Marlier, 2011). Consensus of the experts in the measurement of poverty has moved from the hegemony of the 'income paradigm' to the inclusion of several different dimensions, applying different conceptual frameworks. In most countries the measurement of poverty is not considered in isolation from planning and policy-making. Identification of who are the poor, and where they live, is used as a powerful policy tool. On top of that, more and more, governments and international organizations are asking who is considered poor, and what do the poor need to become self-sufficient. Eligibility of beneficiaries of social programs and transfers of cash and in-kind depends on the particular indicator that is being used. The selection of a particular goal is not only a topic of advocacy but also a topic of public policy. The 'governance of poverty' takes place at three different levels: Macro (Supra-national and International Organizations), Meso (National) and Micro (Local and Individual level).

Indicators, as shown by Atkinson and Marlier (2011, p. 297-298), used to monitor performance in poverty should fulfil certain properties. i) "An indicator should identify the essence of the problem and have an agreed normative interpretation"; ii) "an indicator should be robust and statistically validated"; iii) "an indicator should be interpretable in an international context"; iv) "an indicator should reflect the direction of change and be susceptible to revision as improved methods become available"; and v) "the measurement of an indicator should not impose too large a burden on countries, on 
enterprises, nor on citizens". Setting particular indicators and goals translates specific problems into finding particular solutions through policies. Sometimes indicators are used to advocate for a particular issue, but in other instances, indicators are part of an intricate set of policy-planning and policy-making decisions. In the former case, indicators need to be comparable and adaptable not only to different contexts but also over time. In the latter case, indicators constitute a baseline for interventions, and therefore require of policy-planners, statistical offices and experts, agreement towards the normative decisions that are taken. These decisions need to take into consideration probable deviations of the trend, not only based on measurement errors coming from the sources of information, but also from normative decisions, as these can change due to political influence.

\subsubsection{Examples from supranational level}

At supranational level, indicators are used as the primary means to advocate for a particular goal. In order to achieve this objective lobbying is needed. Depending on the extent of the supranational organization, heads of State, high level bureaucrats, as well as international organizations, NGOs, experts, civil society and groups of interest need to reach consensus. Two examples of supranational level governance of poverty are the Millenium Development Goals (MDGs) of the United Nations (UN), and the Agenda of the EU for 2020 (EU2020).

The MDGs have attracted the attention of governments and international organizations over the last 15 years. Their construction heavily relied on the participation of different actors (international organizations, governments, and civil society, among others). They were set as the 'global agenda': "The designers used MDGs as normative objective, to build consensus among world leaders at the Millenium Summit, and to provide benchmarks for monitoring implementation" (Fukuda-Parr, 2010). Since the official signature of the agreement, the MDGs have constituted part of the global governance of poverty through indicators, especially since MDG1 is focused on halving extreme poverty from an income perspective. The objective has been exemplary in achieving political commitment from different actors but ownership has not been proven. Despite the effort, the MDGs as a policy tool did not overcome the advocacy objective. Influx of donors' resources was not targeted to countries in need, as mentioned by Baulch (2006). Instead of being perceived as a 'global goal' the MDGs were sometimes received as an imposition from developed to developing countries preserving the traditional division between North-South, and West-East (Lang and Lingdau, 2015). The re-negotiation of the post-2015 agenda has already ended and MDG1 has not been immune to criticisms coming from the non-income approaches. Poverty is still at the top of the development agenda with the definition of five targets under the motto: "End poverty in all its forms everywhere" (UNDP, 2015). The calls for a change in the measurement have been heard (Lang and Lingdau (2015), Melamed (2015), Greenstein et al. (2014), among others): "Only if the way of measuring progress reflects a comprehensive understanding of development, policies will mutually reinforce each other and create synergies. Multidimensional 
and comprehensive goals and policies need multidimensional and comprehensive measures as a basis for decision-making" (Lang and Lingdau, 2015, p. 408). Explicitly goal 1.2. has adopted the Multidimensional Poverty Index (MPI) as a method to measure the reduction, by 2030, of the number of people living in poverty in all its dimensions.

Another example of supranational governance of poverty is the EU2020 Agenda. Europe has led the efforts to harmonize and operationalize a set of indicators, share a common conception of social exclusion, as introduced at the beginning of the chapter. This agenda was partly motivated by the Open Method of Coordination of a supranational level and the goals signed and agreed by the parties in the Lisbon Strategy. Monitoring the evolution of indicators was considered in the first round of agreements but specific goals were not defined until 2010 when the EU2020 Agenda was formalized and goals related to employment, education and social inclusion were set, as shown in Atkinson and Marlier (2011). These goals were set, according to Stewart (2012), as a result of the effects of the global financial crisis, an increasing call for shorter term indicators and a higher access to better and more often collected data.

\subsubsection{Poverty, Planning and Evaluation}

There is a wide evidence demonstrating the relationship between growth and efficient and transparent bureaucracies. The hypothesis that governments should be kept at a minimal size as opposed to market forces has been debunked and replaced by a hypothesis that emphasizes the efficiency of bureaucratic entities that pursue the reduction of poverty. This assumption is concentrated mainly on the macro-analysis between economic growth and corruption, transparency and rule of law. Nonetheless, more and more governments are moving towards a more multidimensional approach to development.

Governments are also active agents in the design and planning of strategies to overcome poverty in its multiple shapes. Evans and Rauch (1999), citing Weber, mentioned that bureaucracies are relevant entities that monopolize policy decision-making, and that whenever these bureaucracies work on a meritocratic basis, public servants, expecting long-term rewards, will facilitate growth.

More and more often different operationalizations of the measurement of functionings under the CA have been used to evaluate policies and programs (Alkire, 2008). This core information usually refers to the analysis of expansion or contraction of certain capabilities, sometimes focusing more on the description of affairs than on giving recommendations to improve or speed up the process. Its application relies on the value judgement of public servants who use this tool in an evaluative form. However, different applications have focused on practical issues such as targeting, exiting and evaluation of impact of particular interventions. In targeting, alternative mechanisms have been proposed based on the Alkire and Foster method, as for instance the case of 
India Alkire and Seth (2013), targeting of CCT in Mexico (Azevedo and Robles, 2013) and in Colombia (See Chapter 6). In exiting conditions, the formal example is the exiting mechanism of the multidimensional strategy to eradicate poverty in Colombia (See Chapter 6). Finally, to assess the effectiveness of social programs an example is the combination of a multidimensional index with difference-in-difference techniquesas in Islam (2014) for the case of Bangladesh.

The power that bureaucrats and technocrats have to reduce or eradicate poverty and injustice is sometimes undervalued. It requires that they themselves believe and act in creative ways in the descriptive and prospective aspects of well-being, and define the principles to which a particular society ascribes. An exercise that is most of the time done in solitude. Participation of the poor people is highly valued and needed: "Development professionals have more power to change the world for the better than is normally realized. To grasp and use that power requires questioning conventional concepts and realities, exploring and embracing a new paradigm, adopting a new professionalism, empowering the poor to analyze and express their reality, and then putting that reality first" (Chambers, 1995, p. 178-179). 


\subsection{Appendix}

\subsubsection{Aggregative indices}

\section{Functional Form}

This appendix explains the counting framework for measuring multidimensional poverty that will be used throughout the thesis. These measures simply count the dimensions in which individuals are considered poor (see Atkinson, 2003, p. 51). Sen (1976) points out that identification and aggregation procedures are needed to perform this process. Another important characteristic is that this approach can deal with ordinal and dichotomous data. This section briefly summarizes the dichotomous case. ${ }^{10}$

All counting measures involve three steps: a) identification of the dimensionally poor, b) identification of the multidimensionally poor, and c) aggregation to find the social poverty function.

In order to identify the dimensionally poor, a matrix of achievements $\left(X_{i j}\right)$ is constructed holding the raw information for each indicator $[j=1,2, \ldots, d]$ and each individual $[i=1,2, \ldots, n]$. Then a threshold or indicator specific deprivation cut-off is set $\left(Z:=z_{1}, z_{2}, \ldots, z_{d}\right)$ for each of the indicators. An example with $d=3$ and $n=4$ is shown below, when $x_{1}$ and $x_{2}$ are dichotomous variables and $x_{3}$ is cardinal.

$$
X_{i j}=\left(\begin{array}{ccc}
1 & 0 & 13 \\
1 & 1 & 8 \\
0 & 0 & 7 \\
1 & 0 & 5
\end{array}\right) ; \quad Z_{j}=\left(\begin{array}{lll}
1 & 1 & 8
\end{array}\right)
$$

The value of $x_{i j}$ is then compared to the cut-off $z_{j}$. All dimensionally poor individuals are identified as Indicator Deprived or $I\left(x_{i j} ; z_{j}\right)$, as shown in equation 2.1.

$$
I\left(x_{i j} ; z_{j}\right)=\left\{\begin{array}{l}
1 \text { for } x_{i j}<z_{j} \\
0 \text { for } x_{i j} \geq z_{j}
\end{array}\right.
$$

Aggregating this function for all $i$ 's and $j$ 's, gives the matrix of deprivations constructed, holding dimensions $n \times d$.

\footnotetext{
${ }^{10}$ This Appendix is a summary of the explanations found in Alkire and Foster (2011b) and the detailed exposition of counting methods of Silber and Yalonetzky (2014).
} 


$$
I_{\left(x_{i j} ; z_{j}\right)}=\left(\begin{array}{ccc}
0 & 1 & 0 \\
0 & 0 & 0 \\
1 & 1 & 1 \\
0 & 1 & 0
\end{array}\right)
$$

You can transform this matrix into a vector of deprivations by summarizing the number of dimensions the person $\mathrm{i}$ is considered deprived, multiplying by the vector of weights or $W:=\left(w_{1}, w_{2}, \ldots, w_{d}\right)$ satisfying two conditions shown in Equation 4.4: a) The weights sum to unity, and b) the weights are non-zero.

$$
\sum_{j=1}^{d} w_{j}=1 \quad \text { s.t. } \quad w_{j}>0, \quad \forall j \in[1, d]
$$

Adding up the number of deprivations by individuals gives the vector of deprivation counts or $c_{i}$. As shown by Silber and Yalonetzky (2014) the counting function is defined as the weighted sum of deprivations of each individual.

$$
C_{i} \equiv \sum_{j=1}^{d} I\left(x_{i j}<z_{j}\right) w_{j}
$$

The vector of weights $\left(W_{j}\right)$ alters the counting vector $\left(C_{i}\right)$, using an example with equal weights $(0.33)$, the original vector becomes a weighted sum when they are applied:

$$
C_{i j} \equiv \sum_{j=1}^{d} I_{x_{i j} ; z_{j}} w_{j}=w_{j}\left(\begin{array}{l}
1 \\
0 \\
3 \\
2
\end{array}\right) ; \quad\left(\begin{array}{c}
0.33 \\
0 \\
1 \\
0.66
\end{array}\right)
$$

An illustration of how weights affect the counting vector is shown below for a case of unequal weights, where $w_{1}=0.25, w_{2}=0.30$ and $w_{3}=0.45$ then $C_{i}$ is:

$$
C_{i j} \equiv \sum_{j=1}^{d} I_{x_{i j} ; z_{j}}=\left(\begin{array}{c}
0.30 \\
0 \\
1 \\
0.75
\end{array}\right)
$$

Then a second cut-off sets a minimum number of deprivations $(k)$ that an individual should have in order to be considered as multidimensionally poor. Or, any individual with $C_{i} \geq k$ is multidimensionally poor. With the second condition fixed the identification of multidimensionally poor individuals is completed. The matrix of deprivations is 
transformed into the Poverty Identification Matrix, or $\Psi\left(X_{i} ; Z, W, k\right)$-a censoring matrix which identifies all individuals who are multidimensionally poor.

$$
\Psi\left(X_{i} ; Z, W, k\right)=\left\{\begin{array}{lll}
1 & \text { for } & C_{i} \geq k \\
0 & \text { for } & C_{i}<k
\end{array}\right.
$$

Three approaches exist to identify the multidimensionally poor: i) union, or at least one dimension or $c_{i j} \geq \min \left\{w_{1}, w_{2}, \ldots, w_{d}\right\}$; ii) intersection, or all the dimensions or $C_{i j}=1$; or iii) intermediate, by selecting a value in-between a range or $C_{i j} \geq k$ where $k \in(1, d)$. From the example, it is clear that $\frac{1}{4}$ of the population will be considered definitively non-poor, regardless of the selection of $k$, which is the case of individual 3 as $C_{3}=0$.

Once the individuals have been identified, a measure of breadth of poverty is included in the index $(g)$. With ordinal variables, the breadth of poverty is based on the number of deprivations in which the individual is considered deprived. Equation 2.5 is the individual poverty function based on the identification and breadth measures.

$$
p_{i}\left(X_{i} ; Z, W, k\right)=\Psi\left(X_{i} ; Z, W, k\right) \times g\left(X_{i} ; Z, W\right)
$$

Finally, the last step is to construct the social poverty function $(P)$ which is simply the average of the individual poverty functions $\left(p_{i}\right)$.

$$
P(X ; Z, W, k)=\frac{1}{N} \sum_{i=1}^{N} p_{i}\left(X_{i} ; Z, W, k\right)
$$

\section{Properties}

Most of the properties listed are inherited from the monetary approach and transformed to the requirements of a multidimensional poverty measurement. Basic and generic properties applicable to every multidimensional indicator following Silber and Yalonetzky (2014), Chakravarty and Silber (2008) and Bourguignon and Chakravarty (2003) are summarized:

1 Strong Focus: Poverty results are independent of the levels of achievement in the attributes above the poverty line. Weak Focus: Poverty results are independent of the achievements of the non-poor individuals.

2 Symmetry/Anonimity: Individual characteristics different from those related to the achievements are irrelevant for the assessment of poverty.

3 Monotonicity: If there is an improvement of a poor person in an achievement then poverty should not increase.

4 Continuity: Poverty varies continuously with $x_{i j}$ 
5 Principle of Population: Replication of population in a positive number of times does not alter poverty.

6 Scale Invariance: Scales transformation of achievement should not alter the poverty result.

7 Sub-group Decomposability: The social poverty function is the result of a weighted average of sub-group population poverty levels.

However some properties are only applicable to the multidimensional poverty approach, as the following:

- Weak Transfer: Under progressive (regressive) transfer of achievements poverty should not increase (decrease). 


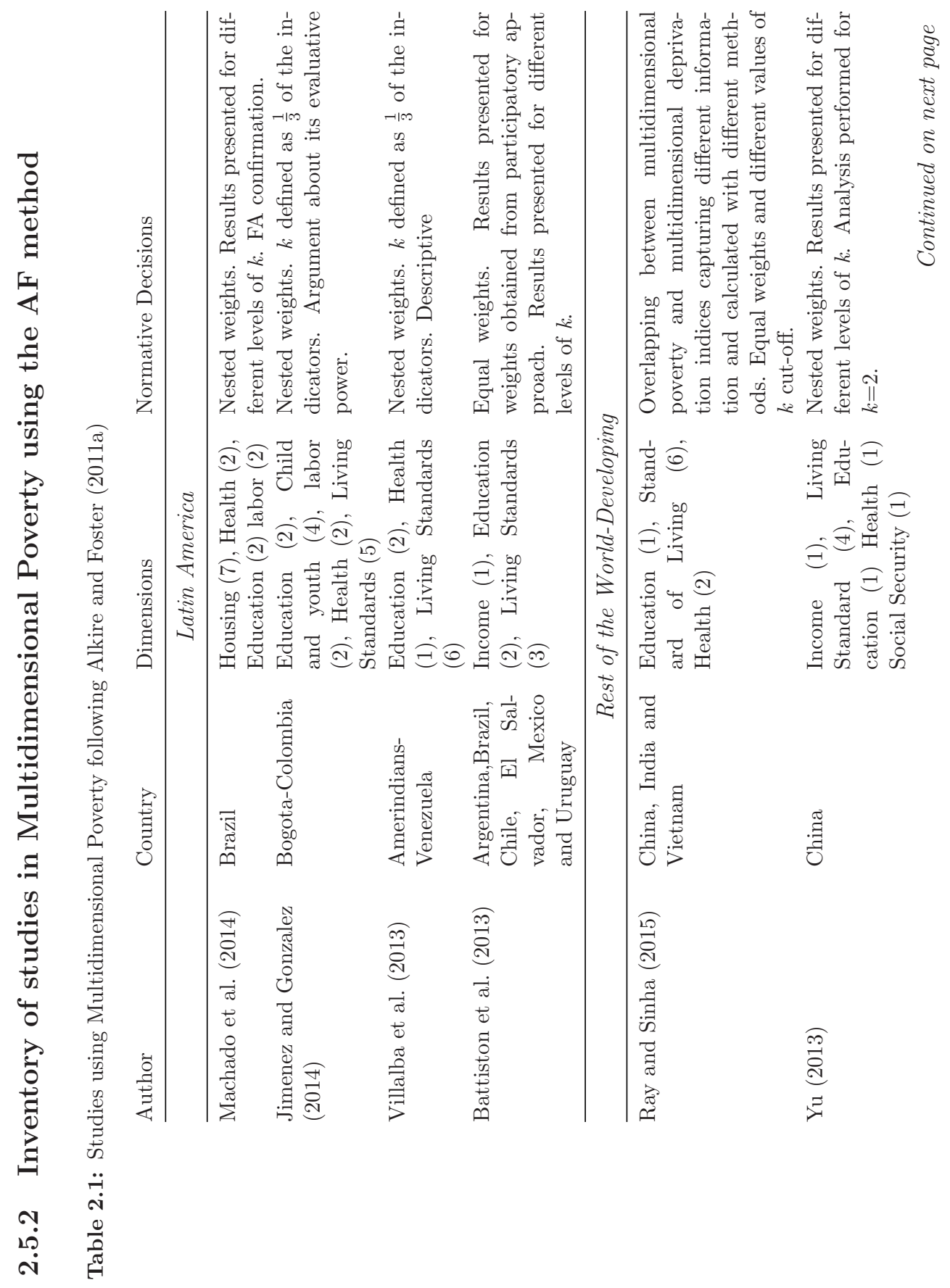




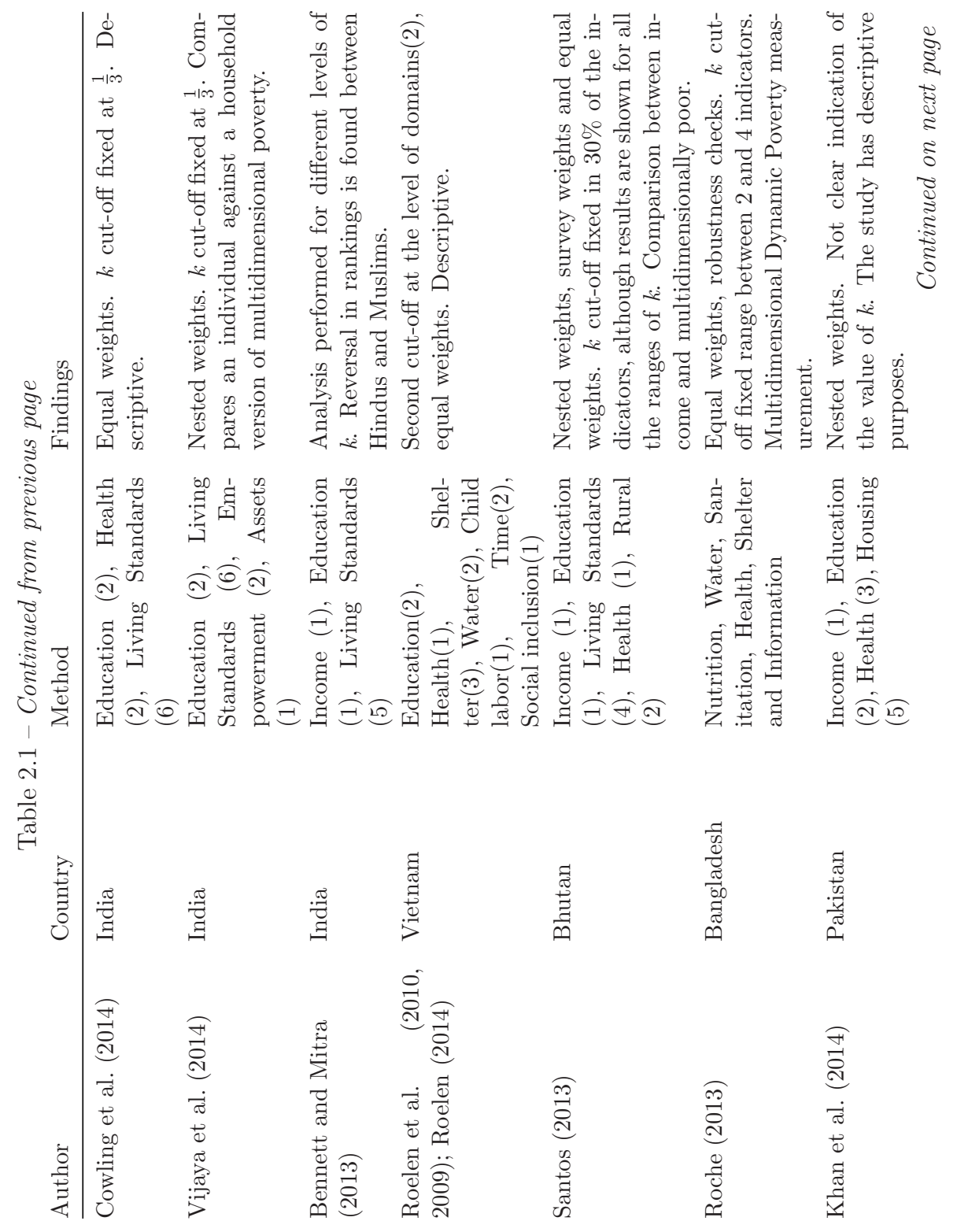




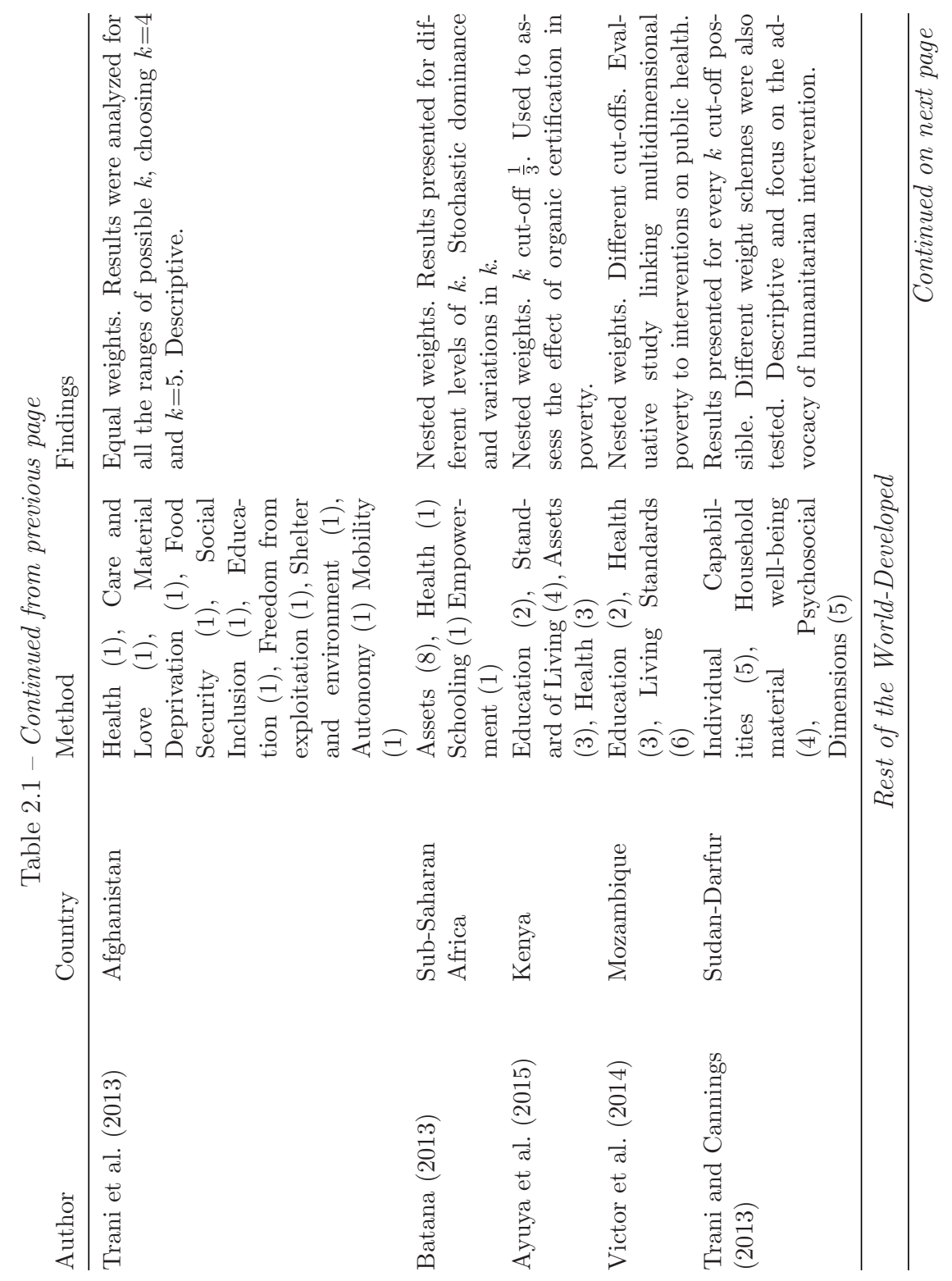




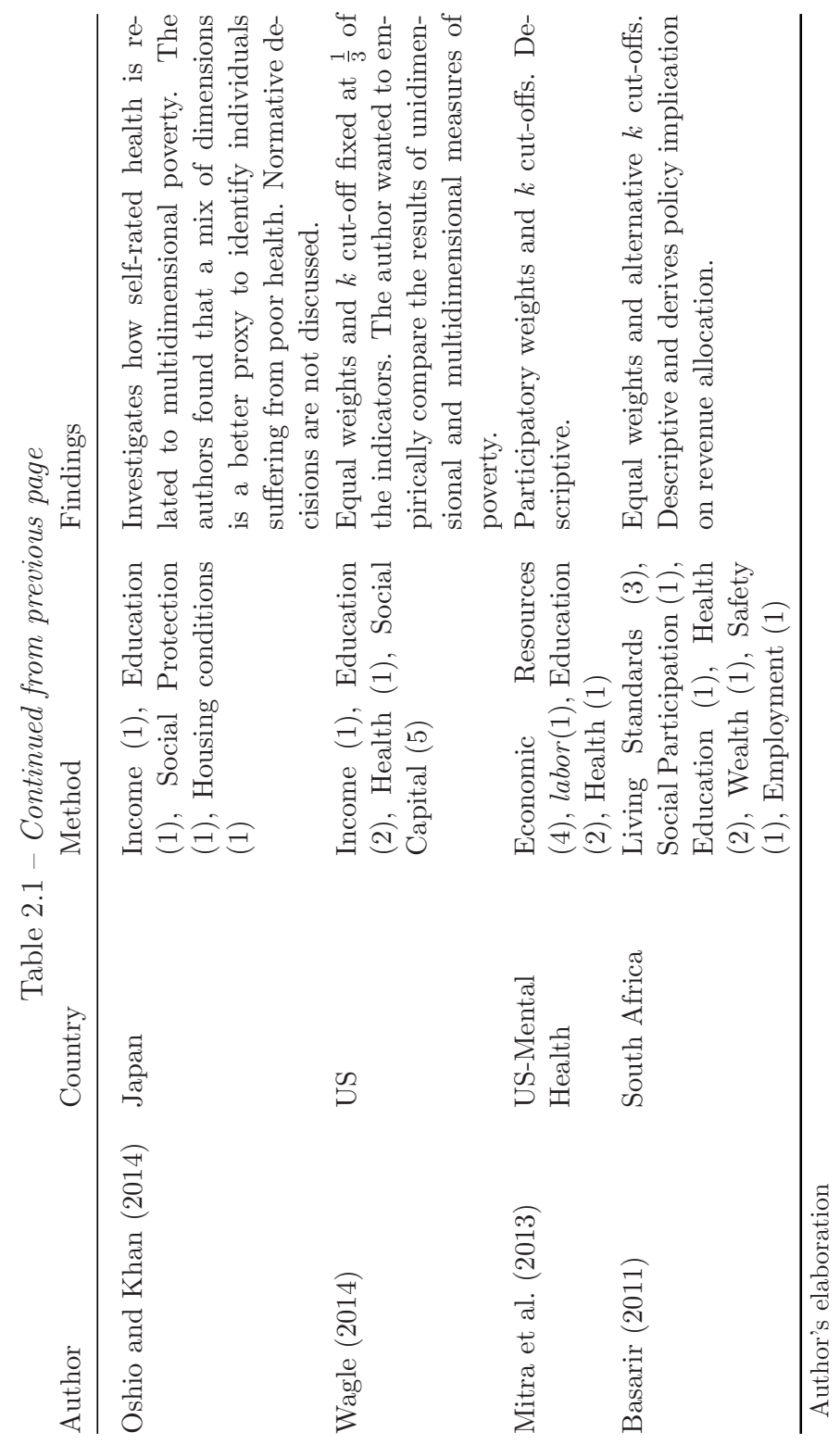




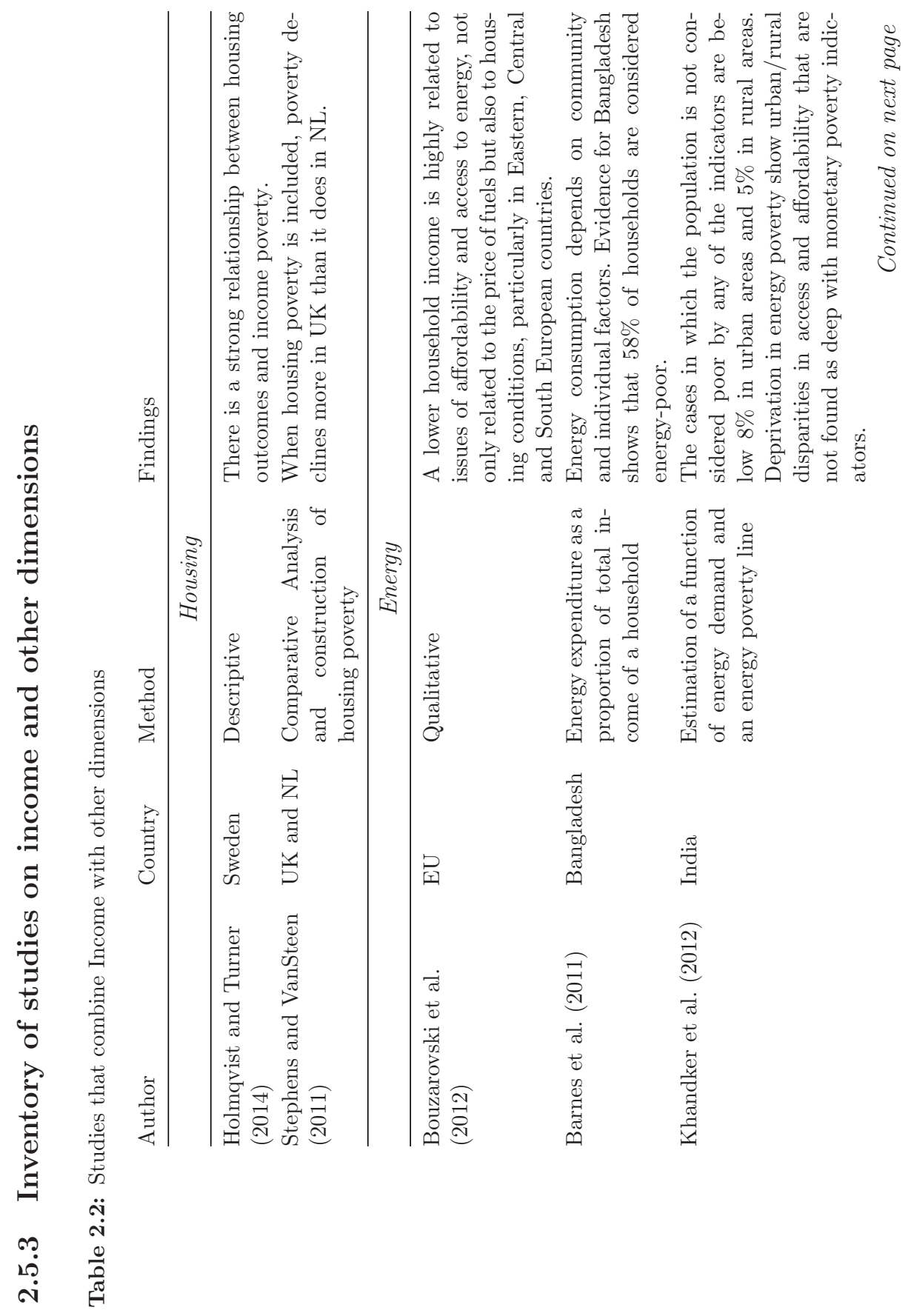




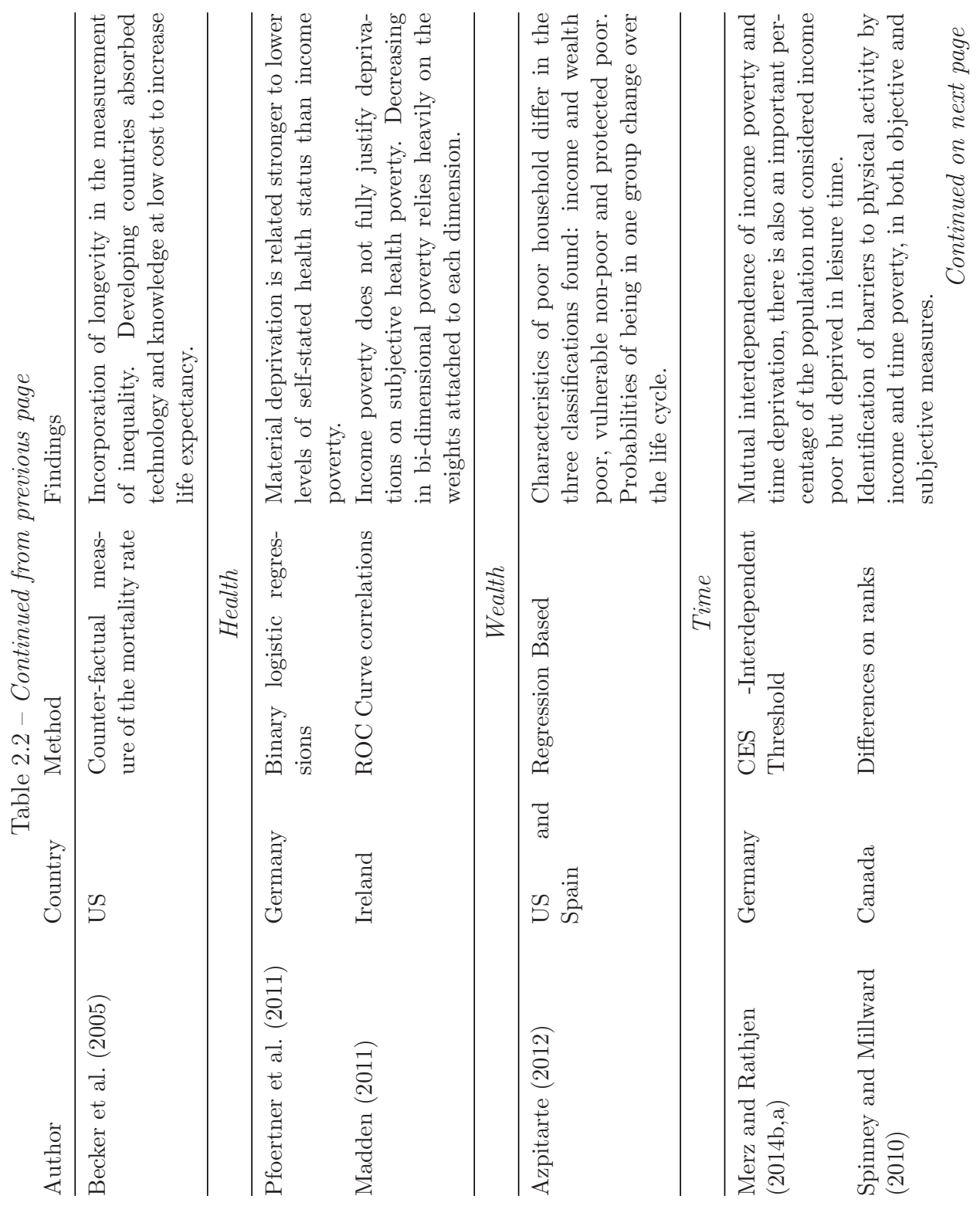




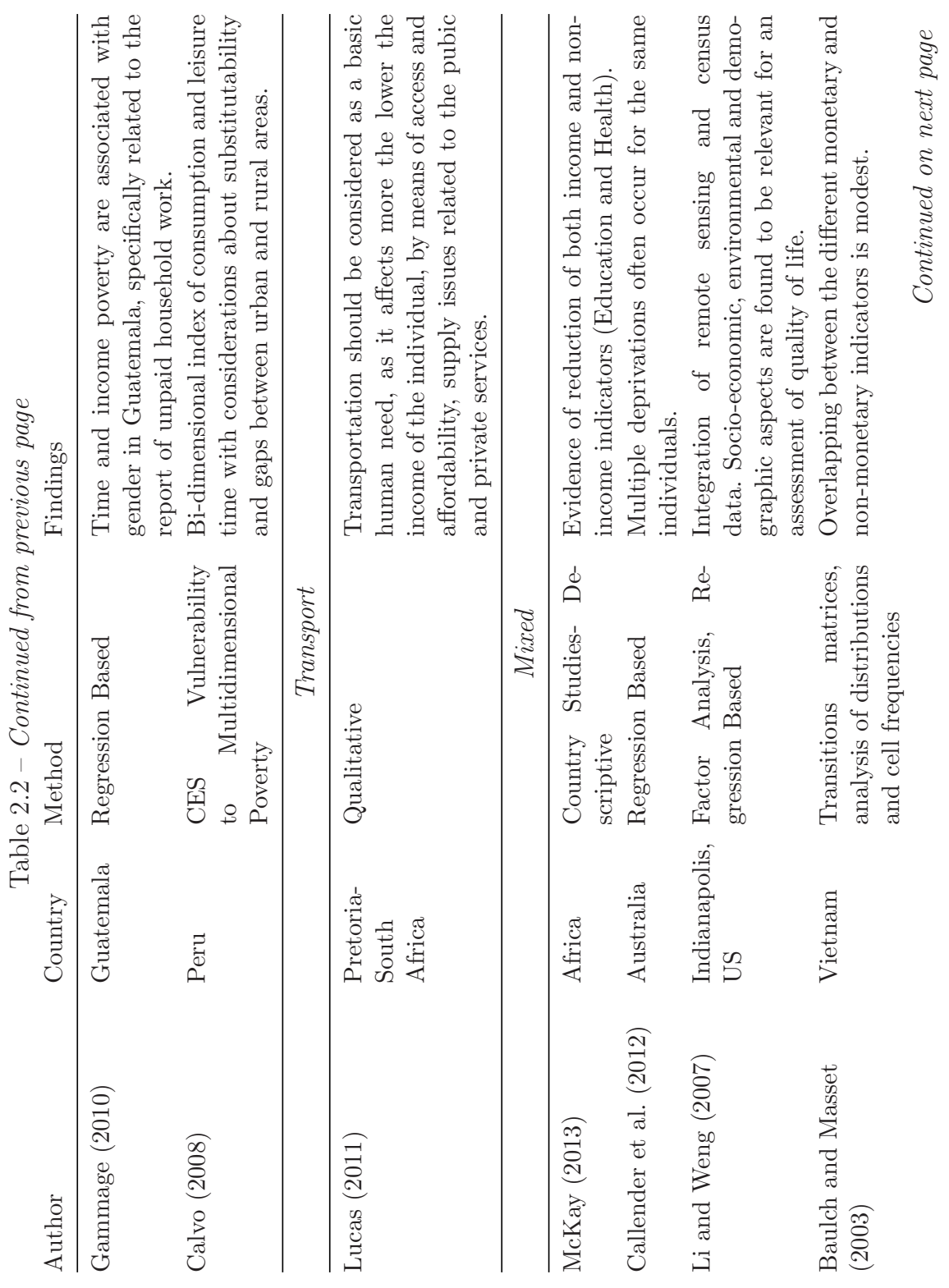




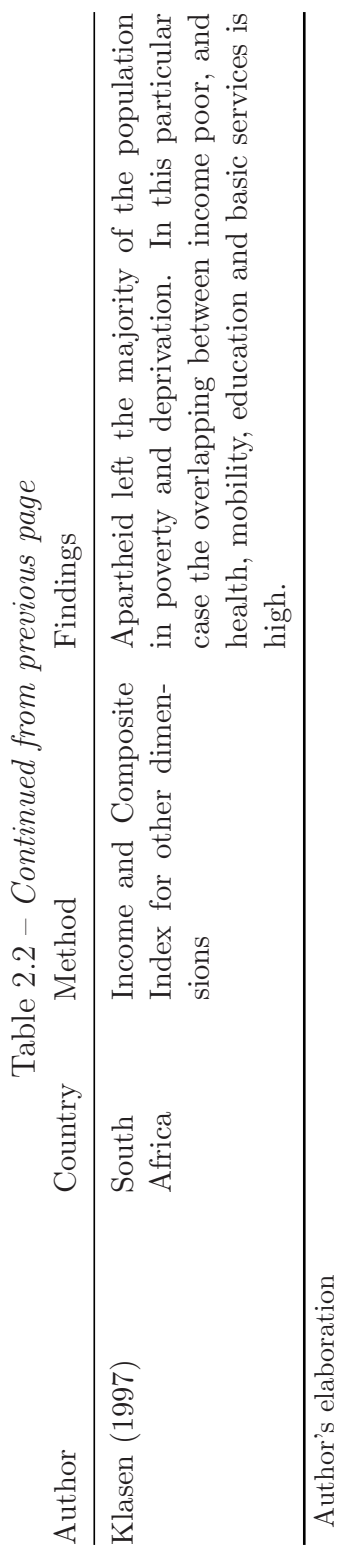




\subsubsection{Most Important Panel Datasets -Active}

Table 2.3: Available Panel Datasets

\begin{tabular}{|c|c|c|c|c|}
\hline \multicolumn{5}{|c|}{ World } \\
\hline Country & Name & Since & Waves & Frequency \\
\hline U.S. & $\begin{array}{l}\text { Panel Study of Income Dy- } \\
\text { namics }\end{array}$ & 1968 & 37 & $\begin{array}{lr}\text { Annual } & \text { until } \\
\text { 1997, } & \text { Biennial } \\
\text { since }\end{array}$ \\
\hline Germany & $\begin{array}{l}\text { German Socio-Economic } \\
\text { Panel Data }\end{array}$ & 1984 & 30 & Annual \\
\hline $\begin{array}{l}\text { United } \\
\text { Kingdom }\end{array}$ & $\begin{array}{l}\text { British Household Panel } \\
\text { Survey }\end{array}$ & 1991 & 18 & Annual \\
\hline Australia & $\begin{array}{l}\text { Household, Income and } \\
\text { labor Dynamics }\end{array}$ & 2001 & 13 & Annual \\
\hline Switzerland & Swiss Household Panel & 2002 & 15 & Annual \\
\hline $\begin{array}{l}\text { New Zeal- } \\
\text { and }\end{array}$ & $\begin{array}{l}\text { Survey of Family, Income } \\
\text { and Employment }\end{array}$ & 2004 & 8 & Annual \\
\hline Canada & $\begin{array}{l}\text { Canadian Household Panel } \\
\text { Survey }\end{array}$ & 2007 & 2 & Occasional \\
\hline Netherlands & $\begin{array}{l}\text { Longitudinal Internet Stud- } \\
\text { ies for the Social Sciences }\end{array}$ & 2007 & 7 & Annual \\
\hline China & $\begin{array}{l}\text { Chinese Family Panel Stud- } \\
\text { ies }\end{array}$ & 2010 & 3 & Annual \\
\hline \multicolumn{5}{|c|}{ Latin America } \\
\hline Chile & $\begin{array}{l}\text { Encuesta de Protección So- } \\
\text { cial }\end{array}$ & 2002 & 4 & Biennial \\
\hline Uruguay & $\begin{array}{l}\text { Encuesta Longitudinal de } \\
\text { Proteccion Social }\end{array}$ & 2013 & 1 & Occassional \\
\hline Colombia & $\begin{array}{ll}\text { Encuesta } & \text { Longitudinal } \\
\text { Colombiana } & \end{array}$ & 2010 & 2 & Biennial \\
\hline
\end{tabular}

Source: Statistical Offices of the Countries. Author's elaboration. 


\section{CHAPTER}

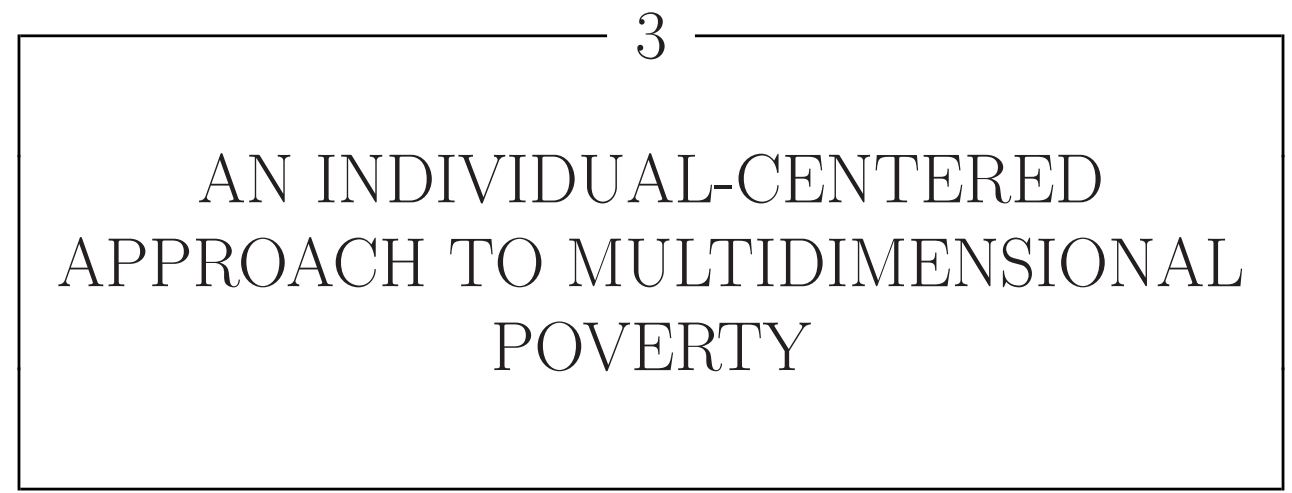

This chapter deals with the selection of the unit of analysis in multidimensional poverty assessments, which is a central decision to take, both from the academic and normative points of view. It compares the results of an individual-level Multidimensional Poverty Index for Chile, Colombia, Ecuador and Peru with a household-based measure. In the construction of the index, four dimensions were initially identified: living conditions, health, education and labor. The motivating theoretical framework is based on Sen's Capability Approach (See Chapter 2) and the index used is the Adjusted Headcount Ratio (AHR) of the Alkire-Foster (2011a) family of indices (See Appendix 2.5.1).

Individuals have varying preferences and needs depending on their age (Osberg, 2012), which do not necessarily align with the collective preferences of the household. Following Sen's approach, capabilities are understood as an individual concept. The individual index is constructed using three age groups: children (less than 18 years old), adults (between 18 and 59 years) and elderly (60 years or older). Multidimensional poverty is considerably different from income poverty in all countries. A simple ranking constructed with the Multidimensional Index and using the four countries for each sample, shows that the ordering prevails for smaller levels of the deprivation cut-off. In every scenario, Chile has the lowest scores of multidimensional poverty, followed by Colombia. Differences between Ecuador and Peru show that the rank-ordering does not prevail when the unit of analysis or cut-offs change. 


\subsection{Introduction}

The main contribution of this chapter is the introduction of an individual-level measure of multidimensional poverty. Most calculations of multidimensional poverty take the household as the primary unit of analysis, and thus forgo the opportunity to understand poverty from an individual perspective. Moreover, as Osberg and Sharpe (2014) argue, in the particular context of the economic insecurity literature, many dimensions of well-being are only relevant at the individual level, and these dimensions may vary over a person's lifetime. In addition, the internal decisions of a household are not, generally, democratic. They reflect the will of a benevolent dictator, who is the main decision-maker for a particular household (Bolt and Bird, 2003).

This chapter introduces the core of the multidimensional index that will be discussed through the rest of the book. This thesis will show applications of the Adjusted Headcount Ratio (AHR) of the Alkire-Foster family of poverty measures (Alkire and Foster, 2011a) in four countries in South America: Chile, Colombia, Ecuador and Peru. This measure sets indicator deprivations cut-offs $\left(z_{j}\right)$, weights $\left(w_{j}\right)$, and a poverty identification cut-off $(k)$. The AHR is composed of two sub-indices: the headcount ratio $(H)$ that measures the ratio of multidimensionally deprived individuals and the Average Deprivation $(A)$, the measure of breadth. A detailed explanation of the method and a generalization of counting approaches is shown in Appendix 2.5.1 in Chapter 2.

The chapter also compares the individual-based approach with the household-level approach, in order to assess the impact of the decision about the unit of analysis. First, a multidimensional poverty index is calculated for three age groups in each country: children and adults (12 indicators), and the elderly (13 indicators). The results show that the elderly are by far the most deprived sub-population. Then, a simple ranking comparison for different poverty cut-offs is conducted. Chile is the least multidimensionally deprived country, followed by Colombia, Peru and Ecuador. Second, an aggregated index is calculated. The results are similar to those obtained by creating a sub-population ranking based on the three age groups mentioned above. The chapter also calculates results for different levels of the poverty cut-off $(k)$, or the minimum percentage of indicators for a person to be considered deprived. The ranking only remains when low levels of $k$ are considered (less than or equal to 50\%).

Third, a household-level analysis is conducted, taking into consideration the 16 indicators used in the individual index ${ }^{1}$. In order to make both measures comparable, a household was considered deprived in a particular indicator if at least one member in the household was considered deprived. The last two places of the ranking were reversed. Chile is still the least deprived country, followed by Colombia, Ecuador and Peru. Multidimensional

\footnotetext{
${ }^{1}$ When counting the different indicators per age group, the total amount of indicators that can be applied to a household is 16 , considering the different indicators applied for each age group
} 
poverty is consistently higher on this index than on the individual one. Hence, the selection of the unit of analysis is a major decision. It not only affects the way poverty is understood but also the identification of who is poor and thus how many poor there are.

The remainder of this chapter is organized as follows. The next section discusses the unit of analysis. Sections three and four briefly introduce the countries in the sample, describe the data, and detail the decisions taken to fix deprivation cut-offs. Section five presents the main results and section six concludes.

\subsection{Selection of the unit of analysis: Individual vs. Household}

The unit of analysis in most of the multidimensional poverty assessments is the household. This decision implicitly assumes that every individual inside a household has the same level of poverty as the household itself.

Defining a household is problematic and complex, as mentioned by Bolt and Bird (2003, p. 2) "the household means different things to different people, in different times and places, and by using the household as a unit, researchers and policymakers make a set of implicit assumptions about what takes place within it". The most widely accepted definition of a household is the one used by the United Nations: "a household is a group of people who live and eat together" (Bolt and Bird, 2003, p. 10), but although it is pragmatic this definition remains problematic.

Individuals within a particular household may have different living arrangements, which makes it difficult to differentiate the traditional household from other ones (e.g. a household member who lives temporarily in two different households). Assuming an equal distribution of poverty among the members of a household also implies that the household acts like a 'unitary decision-maker'. Usually, it is assumed that the decision making process of a household is the result of an agreement among its members (assuming the household pools all resources to the benefit of every member in the group). Nonetheless, this assumption lies far from reality. There are often one or two members of the household who are the decision-makers and act as benevolent dictators. Few households act as democratic units in which every decision and resource is submitted to a voting mechanism. These models of the household are known as 'unitary models' (Chiappori et al., 1993, e.g. see). Furthermore, this concept of the household and its measurement unavoidably excludes some populations from the sample (e.g. military, the homeless, the imprisoned, nursing home and foreign populations; all of whom are not sampled in the household surveys). The European Union (EU) also recommends the measurement of social indicators using the individual as a unit of analysis. The 
argument behind that decision is to focus on citizens, more broadly defined: "all those living in the EU" (Atkinson et al., 2002), which underlines the deficiencies in gathering information about excluded populations.

Sen (1992) also emphasizes the importance of defining the space within which the capabilities of individuals are assessed and relates these spaces to equality considerations. Individuals not only begin life with different initial endowments but also get affected by the environment they grow up and live in. "Had all people been exactly similar, equality in one space (e.g. income) would tend to be congruent with equalities in others (e.g. health, well-being, happiness). One of the consequences of 'human diversity' is that equality in one space tends to go, in fact, with inequality in another" (p. 20). Choosing a space implies choosing a unit of analysis. It is part of the type of information the researcher is acquiring and analyzing (e.g. which indicators, dimensions, and for which unit).

Considering a household as a unitary group also has implications for poverty and inequality measurement (e.g. see Chiappori et al., 1993, p. 20). An equal distribution of resources among members of a household implies that poverty measures, irrespective of the unit of analysis used, will produce the same results. However, there are cases in which the household could be useful as a unit of analysis, for instance when policies and programs target it (e.g. conditional cash transfers). In any case, as there are indicators that differentiate between individuals in the same household, there are also indicators that cannot be divided among each member (e.g. shared resources as: the material of the walls and floor, access to clean water and sanitation, among others). In those cases, it is assumed that all the members of the household share the same deprivations (or benefits).

The analysis performed in this thesis adopts an individual approach to the measurement of poverty based on the assumption that the household is a complex unit of analysis in which both cooperative and non-cooperative outcomes could occur. This approach allows measuring the differential poverty levels of individuals according to their age. Different indicators are constructed taking into account specific needs and situations, so that individuals are compared not with other members of the household but with other members of their society based on their age. Other examples of this approach are measurements of economic insecurity, where indicators by age group are often used (Osberg and Sharpe, 2014) or the analysis performed by UNICEF with the Multiple Overlapping Deprivation Analysis (MODA) but limited to children exclusively (De Neubourg et al., 2012). Moreover, the decision taken eases the exercise of policy-making by taking the individual and his/her particular deprivations into account instead of an average performance of members in a household. 


\subsection{Dataset Characteristics}

\subsubsection{The selected countries}

The sample consists of four Latin American countries: Chile, Colombia, Ecuador and Peru, which account for almost $28 \%$ of the population of South America. ${ }^{2}$ The countries are located in the west of South America, from north to south and bordering with the Pacific Ocean. They share common borders. Peru shares northern borders with Ecuador and southern borders with Chile. Colombia borders Ecuador and Peru. Moreover, the Andean Mountain Range extends over the territories of all the countries in this sample. The common language is Spanish, although native dialects are widely used among the indigenous communities and are also recognized as official languages.

Table 3.1 shows different measures of poverty and inequality for these countries. Levels of income poverty are measured by: the National Poverty Line (two different sources), and the USD $\$ 1.90$ per day $^{3}$. Other measures are the Gini Coefficient for income distribution, the Human Development Index (HDI) and the Multidimensional Poverty Index (MPI). Chile is by far the country which is least poor, while Ecuador and Peru have comparable levels of poverty. Colombia is the poorest country in the sample on every indicator except the MPI.

\subsubsection{The selected datasets}

Data for each country comes from the Living Standard Measurement Surveys (LSMS) ${ }^{4}$. Table 3.2 summarizes the sampling frame. All the surveys are representative of the national and regional level at least, with the exception of Chile that is representative at the local level ${ }^{5}$. The main objective of every dataset is to define and classify households and individuals, especially those who are poor, and to identify subgroups of population for whom the social policies are designed. ${ }^{6}$ The sample excludes individuals in the military, jails or hospitals.

The different sample sizes of each dataset do not affect the level of comparison for each country, as explained in Grosh and Muñoz (1996, p.54) "the sample size needed for a given level of precision is almost independent of the total population". The sample size is related to the level of disaggregation desired by governments and statistical offices to

\footnotetext{
${ }^{2}$ According to data from the World Bank WDI for 2011.

${ }^{3}$ The new poverty line by the World Bank since 2015. It uses 2011 as the period of reference for international prices.

${ }^{4}$ For the analysis performed in this chapter the first survey mentioned in table 3.2 , for the analysis performed in chapter 5 it will be the second survey.

${ }^{5}$ Sample weights are used to calculate the different indicators and the composite index.

${ }^{6}$ Basic statistics of subgroup populations are presented in Annex 3.7.1.
} 
Table 3.1: Measures of Poverty, Human Development and Inequality

\begin{tabular}{|c|c|c|c|c|}
\hline & \multicolumn{4}{|c|}{ Poverty $\%$ of Population by Country } \\
\hline & Chile & Colombia & Ecuador & Peru \\
\hline & \multicolumn{4}{|c|}{ Income Poverty } \\
\hline \multirow[t]{2}{*}{ National Poverty Line ${ }^{\mathrm{a}}$} & $14.4 \%$ & $32.7 \%$ & $25.6 \%$ & $23.9 \%$ \\
\hline & $(2011)$ & $(2012)$ & $(2013)$ & $(2013)$ \\
\hline \multirow[t]{2}{*}{ Persons Living in Poverty ${ }^{\mathrm{b}}$} & $11.0 \%$ & $32.9 \%$ & $32.2 \%$ & $25.8 \%$ \\
\hline & $(2011)$ & $(2012)$ & $(2012)$ & $(2012)$ \\
\hline \multirow[t]{2}{*}{ PPP $\$ 1.90$ per day ${ }^{c}$} & $0.9 \%$ & $6.1 \%$ & $4.4 \%$ & $3.7 \%$ \\
\hline & \multicolumn{4}{|c|}{ Well-being by country } \\
\hline GDP p.c. $\operatorname{PPP}(2015)^{a}$ & 22.316 & 13.800 & 11.388 & 12.402 \\
\hline Income Gini coefficient (2010) ${ }^{c}$ & $52.06^{\mathrm{c}}$ & 55.91 & 49.26 & 48.14 \\
\hline HDI score ${ }^{d}$ & 0.819 & 0.719 & 0.724 & 0.741 \\
\hline HDI place ${ }^{e}$ & 40 & 91 & 89 & 77 \\
\hline HDI level & Very High & High & High & High \\
\hline Inequality Adjusted HDI score & 0.664 & 0.519 & 0.537 & 0.561 \\
\hline \multirow{2}{*}{ MPI score ${ }^{f}$} & $\ldots$ & 0.022 & 0.009 & 0.066 \\
\hline & & $(2010)$ & $(2003)$ & $(2012)$ \\
\hline MPI Headcount $(\%)^{\mathrm{f}}$ & $\ldots$ & 5.4 & 2.2 & 15.7 \\
\hline
\end{tabular}

${ }^{\text {a }}$ Source: World Bank. World Development Indicators.

b Source: Economic Commission for Latin America and the Caribbean (2013) Social Panorama of Latin America and the Caribbean. Calculations on the basis of household survey tabulations. For Colombia, figures are based on calculations of the National Statistical Office.

c Source: Poverty and Equity Databank, World Bank, Povcal Net. Data refers to the most recent available information during the period 2000-2014. For the GINI coefficient with the exception of Chile (2009), the source is 2010. The closer to zero the more equal a country is.

d 2013, UNDP. The figures show the value of the indicator, the position in the world ranking and the level of development. The closer to one, the higher the level of human development.

e The place is based on a sample of 186 countries in the world.

${ }^{\mathrm{f}}$ UNDP (2013) Human Development Report 2013. The rise of the south: Human progress in a diverse world.

g Oxford Poverty and Human Development Initiative (2014). Peru Country Briefing, Multidimensional Poverty Index Data Bank. OPHI, University of Oxford.

explain different phenomena. In the particular case of Chile (see table 3.2), the sample is designed to validate results for different levels of representativeness such as national, regional, urban and rural, and communities. ${ }^{7}$

The surveys were conducted at different times. Of particular interest is the difference between Chile, Colombia and Peru compared to Ecuador for the baseline assessment performed in this chapter. However, the first available LSMS wave for Ecuador is from 2005 (see table 3.2) which asks for some caution in interpreting the findings.

\footnotetext{
${ }^{7}$ Communities are a Chilean political-administrative division.
} 
Table 3.2: Description of Datasets

Basics

\begin{tabular}{ccccll} 
& Year & HH & Individuals & Sampling & Type \\
\hline Chile & 2009 & 71.460 & 246.924 & Stratified, Two stage & LSMS \\
& 2011 & 70.890 & 200.032 & Stratified, Two Stage & LSMS \\
Colombia & 2010 & 14.801 & 53.456 & Stratified Multi-stage & LSMS \\
& 2013 & 20.878 & 73.155 & Stratified Multi-stage & LSMS \\
Ecuador & 2005 & 13.581 & 55.666 & Three-Stage & LSMS \\
& 2014 & 28.970 & 109.694 & Three-Stage & LSMS \\
Peru & 2010 & 27.176 & 87.047 & Stratified Multi-stage & LSMS \\
& 2013 & 29.935 & 124.038 & Stratified Multi-stage & LSMS \\
\hline
\end{tabular}

Source: Statistical Offices Official Manuals: Chile; Ministerio de Desarrollo

Social, Colombia: DANE, Ecuador: INEC, Peru: INEI. Sampling frame for

two moments in time. The second wave will be used in Chapter 5 .

Appendix 3.7.2 matches the contents across the different datasets of the first wave. In order to carry out comparisons between countries, all modules that are missing in at least one survey have been excluded (expenditures, disabilities, children care, information, communication and technology, ethnicity, governance and corruption, participation, migration, remittances, social capital and rural income).

The countries were chosen primarily due to the fact that different rankings can be constructed with different measures of poverty and well-being, due to data availability, and due to the homogeneity of the LSMS data. The latter is particularly important in Latin America ${ }^{8}$.

\subsection{Selecting Functionings}

Following Sen's CA, the measure of multidimensional poverty requires a list of functionings. A decision about a particular set of those functionings, as explained in Section 2.3 is not a minor decision. Functionings are understood "not in terms of the commodities that people can consume but in terms of what people are or do like being healthy, reading or writing, taking part in the life of the community" (Deneulin, 2006, p. 4). Accordingly, in this chapter, any measure of material well-being (e.g. material goods or assets) is disregarded and instead seemingly disparate aspects are included (e.g. level of education of the elderly). The variables selected must be perceived as having intrinsic value, instead of being reached as means to an end (Sen, 1999).

\footnotetext{
${ }^{8}$ See Section 2.2.3.
} 
Capabilities are combinations of functionings for which an individual makes a free choice. As mentioned by Alkire (2002, p. 8-9): "The definition of capability does not delimit a certain subset of capabilities as of peculiar importance; rather the selection of capabilities on which to focus is a value judgement (that also depends partly on the purpose of the evaluation), as is the weighting of capabilities relative to each other". Sen did not define a particular set of functionings, arguing the following reasons: 1) to avoid over-specification of the human nature, 2) to adapt it to different theoretical and practical needs, 3) to apply it to different contexts and to different moments of time, and 4) to value its incompleteness, both theoretically and practically. He also explained that the capability approach is not an "all or nothing exercise" (Sen, 1992, p. 48). He argued that the lack of clarity and agreement about the concepts of well-being, poverty and inequality should be made explicit, as well as the value judgements adopted. Finally, he also stated that the availability of information limits the selection of the capabilities set. ${ }^{9}$

This chapter defines four categories or dimensions of functionings, based on the concept of achievements. ${ }^{10}$ "Living may be seen as consisting of a set of interrelated 'functionings', consisting of beings and doings. A person's achievement in this respect can be seen as the vector of his/her functionings" (see Sen, 1992, p. 39). Indicators included in this comparative analysis measure if an individual has fulfilled (or not) a normative threshold.

Additionally, two practical considerations are made. First, the individuals were classified in three different groups, adapted to the Latin American context: children ${ }^{11}$ (individuals less than 18 years old), adults (between 18 and 59 years old) and the elderly (60 or more years old). An age threshold to separate children from adults is set considering the legal definition of majority of age in the countries of the sample. ${ }^{12}$ The other age threshold fixed is 60 years old to differentiate between adults and the elderly. This arbitrary definition coincides with the legal age for retirement and the epidemiological profile of the population in the region. ${ }^{13}$ (Del Popolo, 2001)

\footnotetext{
${ }^{9} \mathrm{~A}$ complete assessment about the argument against a predetermined list of capabilities see (Sen, 1992) Chapter 3.

${ }^{10} \mathrm{It}$ is not possible to measure capabilities with the available information. The second-best option is to measure funtionings. An exploratory analysis to test the domains is performed in section ??

${ }^{11} \mathrm{~A}$ more specific division of this sub-group, for instance children younger than 5, children from 5-14, and teenagers, would have been desirable. The datasets do not contain the necessary information to perform it as shown in Appendix 3.7.2. The implications of this choice are not possible to be included because of lack of information but it is true to mention that this is not an homogeneous group so the result here will lack the specificity applied to each one of the subgroups.

${ }^{12}$ The majority of age is defined as the age in which an individual is legally no longer considered a child or in other words, when the person becomes 18 years old. See Chile: Ley 19221 18th of May of 1993, Colombia: Ley 27 de 1977, Ecuador: Art.21 Código Civil Ecuatoriano, and Peru: Ley 26.579, Art. 1.

${ }^{13}$ According to the laws in each country the mandatory ages of retirement are: Chile 65 years old, Colombia 55 for women and 60 for men, Ecuador 60 years old, and Peru 65 years old
} 
Second, a process of pairing every question across the four datasets is performed. Indicators are excluded if their objective is to measure material well-being (e.g. assets: telephone, mobile, internet, personal computer, cable tv, fridge, car and washing machine, and so on) or monetary poverty (e.g. income or consumption/expenditures), for reasons explained above. Indicators that represent a subjective account of well-being are disregarded as only objective measures are considered. ${ }^{14}$

\subsubsection{Proposed Indicators}

Table 3.3 presents the final list of indicators with their definition, unit and subgroup identification. As mentioned in Section 2.1.2, the operationalization of the CA is still a matter of discussion. With the available information in each country dataset, only achievements can be measured. A new dataset needs to be created in order to measure capabilities. Besides, even though some of the indicators could be perceived as means, they are also considered as ends in themselves (e.g. education for elderly, as shown in Appendix 3.7.6 and clarified in Chapter 2 with the concept of instrumental and intrinsic values.). ${ }^{15}$ Common or public household characteristics (e.g. electricity) were attributed indistinctly to all individuals living in the same household. ${ }^{16}$

Table 3.3: List of indicators proposed

Name $($ code $) \quad$ Definition

Group

Household Level

\begin{tabular}{|c|c|}
\hline $\begin{array}{l}\text { Type } \\
\text { Dwelling } \\
\text { (dwell) }\end{array}$ & Assesses the fitness of the housing unit for human habitation \\
\hline $\begin{array}{l}\text { Wall Material } \\
(\text { walls })\end{array}$ & $\begin{array}{l}\text { Measure of quality of the structure of the housing unit. De- } \\
\text { termines if the materials of the dwelling are permanent }\end{array}$ \\
\hline $\begin{array}{l}\text { Floor Mater- } \\
\text { ial (floor) }\end{array}$ & $\begin{array}{l}\text { Measure of quality of the structure of the housing unit. As- } \\
\text { sesses the quality of the material of the floor }\end{array}$ \\
\hline $\begin{array}{l}\text { Electricity } \\
\text { (elect) }\end{array}$ & Measure of the lack of basic services inside the housing unit \\
\hline $\begin{array}{l}\text { Overcrowding } \\
(\text { crowd })\end{array}$ & $\begin{array}{l}\text { Determines the shortage of space based on the number of } \\
\text { rooms and persons in the household }\end{array}$ \\
\hline $\begin{array}{l}\text { Sanitation } \\
(\text { sani })\end{array}$ & $\begin{array}{l}\text { Measures the presence of basic sanitary facilities in the hous- } \\
\text { ing unit }\end{array}$ \\
\hline
\end{tabular}

Continued on next page

\footnotetext{
${ }^{14}$ Two additional indicators available in the data-sets were not included: preventive use of healthcare and protection for retirement. Particularly for the case of Ecuador, strong assumptions needed to be used, to include them. Moreover the correlation between these indicators and others (i.e. effective use of health and long run unemployment) was either perfect positive or perfect negative.

${ }^{15}$ The translation of the questions used to create these indicators is presented in Appendix 3.7.3, showing the category and the questions used. Variations are more commonly found in the options than in the phrasing of the question.

${ }^{16}$ Questions related to the living conditions are shared among all the household members.
} 
Table 3.3 - Continued from previous page

Name Definition

Population

Water (wa- Assesses the access of the housing unit to a clean water source All

ter)

Tenure (ten- Qualifies the legality of possession of the land and building in All ure) which the housing unit is set

Individual Level

Literacy Measures the ability of an individual to read and write

(liter)

Measures the ability of an individual to read and write

Adults and

Early Educa- Defines the access of children to a program of early education

Elderly

tion (educa)

Children

(Less than

5)

Education Quantifies the enrollment of individual in the educational sys-

(educa) tem

Children

(5 to 17

years)

Years of Measures the human capital stock of the individual according

Schooling

to minimum international standards

Adults and

(yrssch)

Access to Ascertains the coverage of health insurance by individuals

Elderly

health insur-

ance (hins)

Effective ac-

cess to health

Measures the extent of use of the health system in case of

All

services when

needed (heff)

Long run un- Measure of social exclusion of the labor market

Adults

employment

(unempl)

Income secur-

ity in old age

(security)

Child labor Measures unacceptable form of labor for children

Children

Evaluates the access to an income source for old-age individu- Elderly

als, either job related income or pension transfers

$(\mathrm{clab})$

Source: Author's elaboration. The code will be used from now on to identify each one of the indicators.

\subsubsection{Analysis of trends in main indicators}

In this section a descriptive analysis of key indicators in the last ten years is presented. It is also explained which are the differences in the operation of the social protection system and particular social policies for each country. 
Age and Income Poverty: Generalities from the region.

According to income measures performed by (ECLAC, 2012, p 61) children are the most deprived population. Half of the children (population less than 18 years old) are considered to live in poverty or extreme poverty. In the case of elderly, only $12 \%$ of the people over 60 years old are considered poor. Regarding education, half of the individuals classified as indigent between 25 and 65 years old did not complete primary education. Less than $1 \%$ of this population which is considered poor completed tertiary education. In children, less than 15 years old dropping out from school and being considered as indigent accounts for $8 \%$. Unemployment is not a big factor but economic activity is. For the population 15 years or older, only $8 \%$ of the population considered extremely poor are unemployed. Non economically active individuals classified as indigent are $46 \%$ of the population. The performance of living conditions indicators, related to the dwelling, ownership, access to electricity and drinking water, are not an issue. The most prevalent aspect for those classified as extremely poor is the lack of adequate infrastructure to sanitation facilities, just $47 \%$ of those classified as extremely poor have access to it.

\section{Education}

Although the countries differ in the policies applied in the educational sector, every country had advanced in coverage. Probably, the most important achievement is to recognize the importance of pre-school education. In Chile, Ecuador and Peru, early education is, in principle, compulsory. The rates of coverage for pre-school education range between $37,4 \%$ in Chile and $66,2 \%$ in Peru. Colombia does not present official statistics of coverage, mainly because the data from private institutions is not available. Although in Colombia early education is not mandatory it is free in public institutions, as in Chile and Peru.

The levels of primary education attendance are higher than $90 \%$ in every country. In general, the system is highly segmented, with a mix of public and private institutions. In every country the basic education is compulsory and free in public institutions. The richest attend the private schools meanwhile the poorest have access to the public institutions.

A coverage problem is evident when more years of schooling are being added. The secondary education is still well behind in coverage compared with the primary education. Ecuador is the country with less coverage for secondary education $(54,8 \%$ in 2009), followed by Peru (78,3\% in 2009), Colombia (79,4\%2009) and Chile ( $81 \%$ in 2008).

Colombia, Ecuador and Peru had considered in their institutional arrangement education focused on special needs of populations as indigenous, bilingual, afro-descents and Roma. 


\section{Employment}

Employment outcomes are highly correlated to the educational attainments of the individuals. Results of the region and of the countries used in this paper, for this particular dimension are summarized in this section (World Bank, 2012). Also figures from the Socio-Economic Database for Latin America and the Caribbean are used to enrich the particular context of study. During the period 2000 and 2010 a general trend in the region was the reduction in labour income inequality ${ }^{17}$. From the countries in this sample, Ecuador was the most successful one in closing the labour gap with a reduction of 11 Gini points for employees and 8 Gini points when employers and self-employed where included. Chile reduced it in 4 Gini points (both measures), meanwhile Peru decreased it in less than a Gini point for employees and increased it in less than a Gini point when others are included. Colombia was the only country in this sample in which the trend was completely opposed to the regional trend. Inequality grew less than a half Gini point for employees, and near 2 Gini points including self-employed and employers. This phenomenon is caused by an intertwined of supply and demand forces of the labour market.

From the supply side, the increase in the level of education of the population, in general, was evident since early 1990s. Chile experienced and steadily reduction of the labour force with only primary education or less and an increase in both labour force workers with secondary and tertiary education. Ecuador showed a fast expansion during the 90s but not during 2000s. In Colombia this achievement was present during the 2000s. Peru, did not reduced the education of their labour force in primary but the effort was evident in an increase in tertiary education. In terms of Gini Education Trends (90s to 2000s), Colombia, Chile, and Ecuador showed a performance under the average of the region as a whole (the reduction in the Gini for education was less than 1 Gini Points) ${ }^{18}$. Peru's performance was over the average of the region with a reduction of more than 2 Gini points.

Regarding the quality of education, the Program of International Student Assessment (PISA) measures the standardized cognitive results for a sample of countries around the world. Although, from the sample used in this paper, results for Ecuador are not shown, it is clear that for the LAC region, the socio-economic background of children has an impact on the results.

\footnotetext{
${ }^{17}$ Labour income inequality measured with a focus on individual salaries for population between 16 and 65 years old.

${ }^{18}$ Colombia's performance was the poorest of the 15 countries in LAC considered in the study
} 
Also in the supply side factors taken into consideration, there is a tendency to reduce the gap in gender inequality in the labour force participation for the region. Chile, Colombia and Peru, follow this general trend, although the figures for Chile are the most successful ones in the region. Ecuador increased the gender inequality in labour force during the period 1990 to 2000, and reduced it since then, but the country has not achieved the levels prior to 1990 .

In the demand side, countries with an increase sector of exportations of commodities had focus more and more in less intensive skill labour.

Other important indicators that give a glimpse of the evolution of the labour market in the countries in particular, are those related to unemployment and informality. Regarding unemployment, Peru has been the most consistent country in the reduction of unemployment figures since the 90 s. In 2011 , the unemployment rate was $3.8 \%$, the lowest from the sample of countries used in this paper. Chile has presented a downward trend with increasing figures during economical crisis. In 2011, the unemployment rate was $7.7 \%$. Colombia and Ecuador also experience a downward trend since the 2000s with the levels of unemployment for 2011 in $9.9 \%$ and $4.5 \%$ respectively. The main population affected by unemployment is the youth (15-24 years old). In Chile (19.9\%), Colombia (20.6\%) and Ecuador (11.5\%) the trend has been steady. Peru's (9.5\%) youth unemployment rate has been growing in the last three years ${ }^{19}$.

In the region, unemployment tends to be not a long term issue. In 2011, the figures range from 0.8 months in Peru to 5.5 months in Colombia. This phenomenon is due to the high levels of informality. According to the productivity definition of informality 20 in 2011, Chile has the lowest rate (33.1\%) compared with Colombia (60.9\%), Ecuador $(60.1 \%)$ and Peru (61\%). In all the countries of this sample, the population with a higher rate of informality are the elderly, ranging from $61 \%$ in Chile to $85 \%$ in Ecuador. Furthermore, when considering the social security definition of informality ${ }^{21}$ the same trend is shown. In 2011, the rates are really small for Chile (17.7\%) when compared with Colombia (43.3\%), Ecuador (46.9\%) and Peru (49.9\%). In a longer trend perspective, every country has managed to reduce the proportion of population considered informal by this definition partially due to the social security reforms which took place since the mid 90s. In terms of age groups, over the period, elderly are the population with more percentage of workers considered informal in Chile (36.7\%), Colombia $(86.6 \%)$ and Ecuador $(63 \%)^{22}$. By contrast in Peru the group that shows higher percentage of informal population is the youth $(77.4 \%)$ and that trend is shown since there is data available for the country.

\footnotetext{
${ }^{19}$ Figures are for 2011

${ }^{20}$ Informal workers are considered those who work in a small firm (less than 5 workers), non professional self-employed or zero income worker

${ }^{21}$ If the person does not have access to pension when retired

${ }^{22}$ Only figures for 2011 are presented
} 
Finally, regarding child labour there is not a common trend to follow for the region and the countries in this sample. Chile has experienced a decreasing trend since $1990(1.2 \%)$ to $2011(0.5 \%)$. Colombia showed an increase in the figures in the early 2000s but decreased it to $7.9 \%$ in 2011 . The phenomenon in the country is specially focus on low income quantiles and in rural areas. Ecuador (4.2\% in 2011) and Peru (28.4\%) present a wide variation in the indicator. In Peru the phenomenon is particularly attached to income poor, meanwhile in Ecuador is not that clear, as higher rates of child labour are also presented in the 4 th quantile.

\section{Health}

Conditions on health and institutional arrangements in the countries of this sample differ. In 2011, the Journal of Public Health from Mexico elaborated an in depth analysis of health outcomes and health systems in the region. The main results of the publication are shown here using as references the papers from Becerril et al. (2011); Guerrero et al. (2011); Lucio et al. (2011); Alcalde et al. (2011). Infant mortality ranges from 21 (over 1.000 alive new born) in Peru (2008) to 7.9 in Chile (2005). The epidemiological profile of every country has moved from a high prevalence of deaths in communicable diseases to non-communicable diseases. In Peru, infectious respiratory diseases is still the most common cause of death for both men and women. In the case of Chile, Colombia and Ecuador, the most common causes are related to non-communicable diseases as cardiovascular, cerebrovascular, diabetes and hypertension conditions. It is particularly important to highlight that in the particular cases of Colombia, Ecuador and Perú, violence related deaths and car accidents are still important.

Coverage of the health insurance ranges from 95\% in Colombia (2010) to $28.5 \%$ in Ecuador (2010). The institutional design of the health system in the countries of the sample shows a mix of public and private arrangements. It is also common to find special regimes for military and police members as well as their families. The private sector covers mainly the wage earners and their families, meanwhile the public sector is specialized in the coverage of the population without the ability to pay. Chile, and Peru have a minimum coverage plan defined by the government The plan covers the whole population and a list of specific interventions. Particularly, in Chile and Colombia, the coverage plan is different according to the regime the individual is enrolled in. That means that for the private (Chile) or contributory (Colombia) regimes there is a much more extended coverage plan than for the poor population ${ }^{23}$. For those interventions not covered in the mandatory plans the population has to attend the private providers. There are also certain critics about the lack of supply and long waiting lists for those patients in need, particularly for the cases of Chile and Peru. In the case of Colombia the Law has established a mechanism called "Tutela" for the individuals to claim their right to a full coverage of interventions. Ecuador has the less developed health insurance system from the countries of the sample. The coverage relies mostly in the public provision of services to the uninsured. Nonetheless, the Ecuadorian government is the only country

\footnotetext{
${ }^{23}$ Colombia is at the moment undergoing a Health System Reform in which the equalization of covered interventions is mandatory for Constitutional Law
} 
in this sample with an special coverage for the peasants population, called "Seguro de Salud Campesino" in spanish (Peasants Health Insurance). It is also key to highlight that the coverage of family members is more limited that the coverage for the main contributor, specially in the cases of Colombia and Ecuador. The increase on the levels of coverage in the last 20 years had relied mainly in the existence of subsidized insurance schemes with a focus on poor population. The contributory regimes coverage (either public or private) highly depend on the association of individuals with the labour market.

\section{Living Conditions}

Following (Rojas and Medellin, 2011) there are three categories to analyse non adequate housing in terms of quality ${ }^{24}$ lack of access to essential services to the household members (energy, water and sanitation), poor shelter conditions, understood as overcrowding and poor quality of building structure and insecure tenure of the house or land. Although there is not a consensus among the field in the variables, indicators and categories of analysis, the framework of measurement adopted by the Interamerican Development Bank has the advantage of its generality and the fact that most of the countries include in their surveys the standard measurement of this variables ${ }^{25}$.

Regarding the access to basic services, countries in this sample shown a high rate of coverage in water, sanitation and electricity. Access to water increased in Chile from $84.8 \%$ (1987) to $96.9 \%$ (2011). Peru shows the same performance as Chile of increasing coverage from $63.6 \%$ (2003) to $75.5 \%$ (2011). Peru is the country with the lowest rate of coverage from this sample. In Colombia and Ecuador after an initial improvement in the 90s a little step back in coverage shows a decrease path, from 92.1\% (2001) to $91.1 \%$ (2011) in the case of Colombia and from $87.5 \%$ (2003) to $89.9 \%$ (2011) with some coverage rates of near $92 \%$ in 2008 . The lack of access to pipe water is mainly a poor phenomenon as the first and second income quantiles are still the less covered. Sanitation or access to a hygiene facility show the same patterns as the access to piped water.

Access to electricity is the indicator with the best performance. In Chile for 2011, coverage is almost $100 \%$. And the differences between quantiles are minimum. In Colombia for 2011, electricity coverage was of near $97 \%$. With a nearly $100 \%$ coverage for the fifth quantile. Ecuador coverage is almost 97\% also in 2011, with less dispersion between income quantiles. And Peru coverage of electricity is the lowest from this sample achieving in 2011 almost $90 \%$. In this particular case, the poorest income quantile only has a coverage of almost $68 \%$.

\footnotetext{
${ }^{24} \mathrm{~A}$ different category is the measurement of quantitative shortage of housing, which is understood in terms of not enough housing units to overcome the demand for housing. This category, as explained by the authors, analyses multi-households arrangements and non-upgradable shelters (Rojas and Medellin, 2011, 3-4)

${ }^{25}$ Data update was extracted from the SEDLAC
} 
In terms of low quality materials for housing, country specific definitions were taken into account. In the cases of Chile, Colombia and Peru, material of the walls was considered and in Ecuador floor material was accounted. In general, low quality dwellings reduced over time in the four countries. Chile is the best performer in this sample moving from $27.2 \%$ (1987) of the population living in a low quality material dwelling to $5.7 \%$ (2011). Ecuador reduce the share in almost 10 percentage points from $35.8 \%$ (2003) to $23.5 \%$ (2011) in eight years and although Peru also reduce it, the share only improved in 2 percentage points in the same time span as Ecuador, moving from 16.6\% (2003) to $14.3 \%$ (2011). Colombia is the country with the highest share of people living in low quality of materials dwellings, with a modest improvement reducing the share from $55.2 \%$ (2001) to $47.3 \%$ (2011) in ten years. In the four countries, the poorest quantile showed the highest share of households living in poor infrastructure dwellings.

Overcrowding is measure by international standards as arrangements in which more than 3 people sleep in one room. On average, the countries in this sample had been below the threshold. Chile diminish it from 0.9 (1987) to 0.6 (2011), Colombia passed from 1.6 (2000) persons per room to 1.2 (2011), Ecuador has improved from 1.8 (2003) to 0.7 (2011) persons per room, and Peru from 1.9 (2003) to 1.6 (2011). With the exception of Chile and Ecuador, the figures shown are mainly driven by the poorest quantile which doubles the richest one performance.

In terms of insecure tenure of house or land, the percentage of house owners has not variate in Chile since 1987. Up to date, $63.1 \%$ of the population owns their house. When analysing the indicator by income distribution, as expected, the first quantile is the one in which less ownership is present. In Colombia, ownership status has decreased over the period $2000(58.8 \%)$ to 2011 (45.5\%), mainly in the first three quantiles. Ecuador has decreased in a disperse way. Some years the share of house owners decreases above the ranges of previous years and in some others it increases but never to the levels of $2003(76.4 \%)$ which is the highest point in the distribution. The share of the secure tenure in 2011 was near $68 \%$. The phenomenon of lack of tenure in Ecuador is proper of middle quantiles (2nd to 4 th). In Peru, there is also a pattern of decreasing the share of ownership moving from $75.2 \%$ in 2003 to $68.5 \%$ in 2011 . The quantile which reports the highest level of ownership is au contraire the poorest one.

ne performance.

In terms of insecure tenure of house or land, the percentage of house owners has not variate in Chile since 1987. Up to date, $63.1 \%$ of the population owns their house. When analysing the indicator by income distribution, as expected, the first quantile is the one in which less ownership is present. In Colombia, ownership status has decreased over the period $2000(58.8 \%)$ to 2011 (45.5\%), mainly in the first three quantiles. Ecuador has decreased in a disperse way. Some years the share of house owners decreases above the ranges of previous years and in some others it increases but never to the levels of $2003(76.4 \%)$ which is the highest point in the distribution. The share of the secure tenure in 2011 was near $68 \%$. The phenomenon of lack of tenure in Ecuador is proper of 
middle quantiles (2nd to 4 th). In Peru, there is also a pattern of decreasing the share of ownership moving from $75.2 \%$ in 2003 to $68.5 \%$ in 2011 . The quantile which reports the highest level of ownership is au contraire the poorest one.

\subsubsection{Deprivation and Poverty Cut-offs}

The next step to calculate the AHR of AF, is to define the deprivation cut-offs. Setting a threshold is also a normative decision. In Annex 3.7.4 the cut-offs are described in terms of deprivation (lack of fulfillment). Then a particular poverty cut-off $(k=30 \%)$ is selected. The decision is taken based on the threshold defined by UNDP. Nonetheless, this chapter shows the calculation and analysis of the results for the multidimensional index when different levels of $k$ are used.

An analysis of both 'raw' (uncensored results by indicator) and 'censored' (when the second cut-off is imposed) is shown in the remaining of this subsection (see Figures: 3.1, 3.2, and 3.3). The union approach (deprived in at least one dimension) is compared to the intermediate approach $(k=30 \%)$. This analysis shows that whenever the censoring is chosen above the minimal threshold (union approach) the deprivation among the set of people variates. ${ }^{26}$ The analysis below gives further information with regards to the particular context and the situation for each population subgroup.

From the figures it is easy to conclude that the subgroups performed differently per country, although some patterns can be identified. Orders of magnitude in the depicted graphs are different, especially when comparing the data for Ecuador and Peru with those for Chile and Colombia. The former two countries exhibit higher percentages of deprived population.

For children, in every country sanitation is a serious concern (consistently in the top 3). It is counter-intuitive to find, for instance, that in the case of Chile (3.1a), education is among the indicators with the highest level of deprivation (4\% raw) although it is compulsory. After $k=30 \%$ restriction is applied, only less than $1 \%$ of children are deprived in education. In Colombia, see Figure 3.1b, the levels of deprivation in various indicators (raw) are above $10 \%$ in the subgroup (e.g. tenure $(20.5 \%$ ), access to clean water $(18.2 \%)$ and sanitation facilities $(13 \%))$. The results reflect increasing levels of insecurity about land ownership and the reduction in basic services coverage, which is particularly important for the poorest population. The levels of deprivation in every indicator fall into the range of $0 \%$ and $6 \%$, once $k$ is set. Water $(5.7 \%)$ and sanitation $(5.5 \%)$ are the indicators with the highest percentage of deprived children.

\footnotetext{
${ }^{26}$ In a way the censoring biases the results against the population with lower amount of deprivations (low $k$ ) by converting their deprivations as non-deprived.
} 
Figure 3.1: Raw and Censored Data for Children

a. Chile

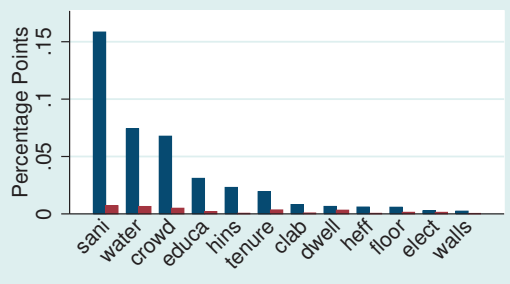

c. Ecuador

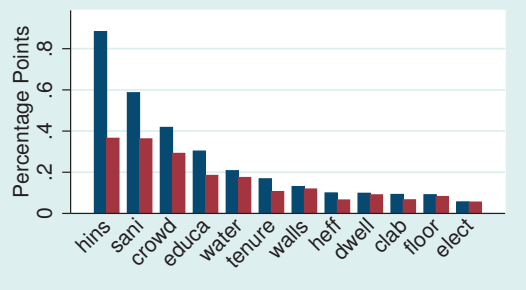

b. Colombia

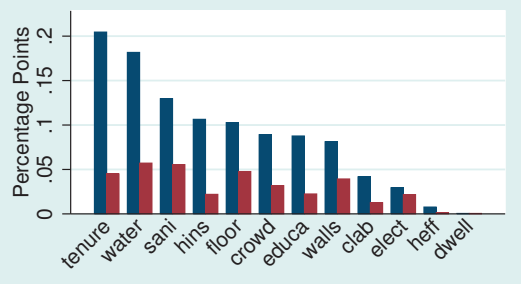

d. Perú

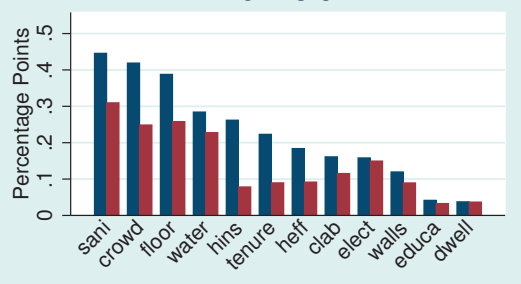

Censored

Source: Chilean, Colombian, Ecuadorian and Peruvian LSMS. Author's calculations. Vertical Axes express different magnitudes.

In Ecuador (see Figure 3.1c), children are more deprived in access to health insurance (88\%), a phenomenon that occurs also in the other subgroups but to a lesser extent. When $k$ is imposed, deprivation percentages fall in the range between $37 \%$ and near $0.5 \%$. Health insurance $(36.5 \%)$ and sanitation $(36.25 \%)$ remain as the indicators with the lowest performance. Peru (see Figure 3.1d) shows a better performance when compared to Ecuador. The indicator with the highest deprivation is access to sanitation $(44.6 \%)$. Crowdedness (42\%) and poor floor material (38.8\%) are also lagging. There is no big change when the $k$ threshold is imposed.

The most important issues for adults are education, measured by years of schooling, and health insurance. Chilean adults (3.2a) are more deprived in education (13.6\%) and sanitation $(14.7 \%)$, than in other dimensions. When the data is censored, the levels of deprivation decrease to the range between $1 \%$ and $0 \%$. Raw indicators for Colombia show a similar trend when compared to Chile; but this picture changes when the censoring is applied. Colombia shows a high level of deprivation in terms of educational attainment (67.42\% uncensored and $8 \%$ censored). Tenure of the dwelling still shows important deprivation levels (17\% -uncensored- of adults are deprived).

Ecuador is the most deprived country of the sample, as shown in Figure 3.2c. The same pattern of deprivation found for children is replicated for adults: health insurance $(72.4 \%)$, sanitation facilities $(50.4 \%)$, education (41.4\%) and crowdedness $(26.2 \%)$. The fifth indicator, only measured for adults, is long term unemployment $(19.22 \%)$. When the restriction over $k$ is applied, sanitation shows the highest level of deprivation 
Figure 3.2: Raw and Censored Data for Adults

a. Chile

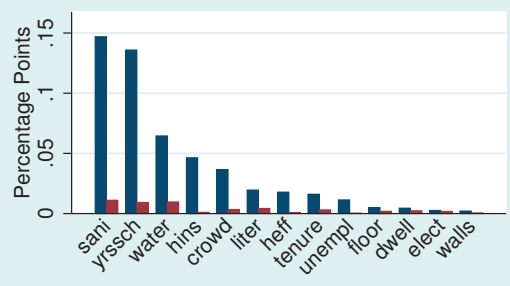

c. Ecuador
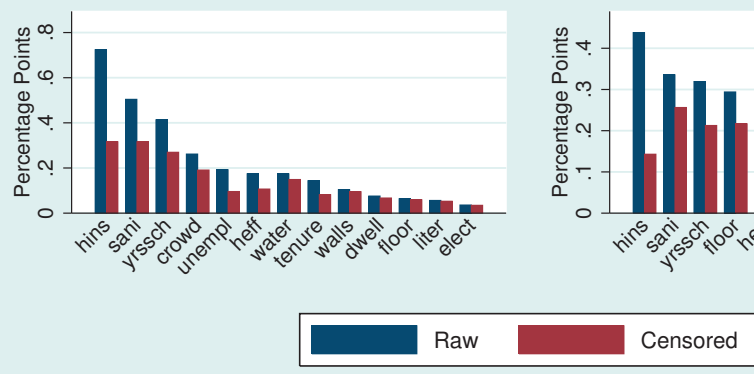

b. Colombia

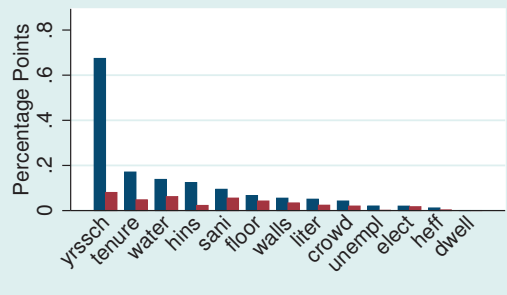

d. Perú

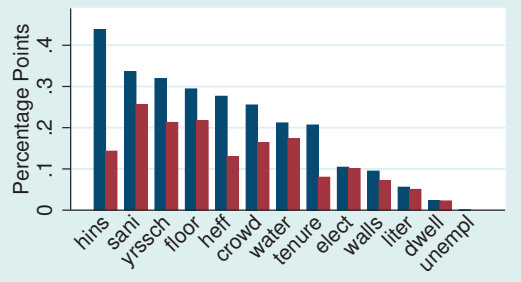

Source: Chilean, Colombian, Ecuadorian and Peruvian LSMS. Author's calculations. Vertical Axes express different magnitudes.

(31.64\%) followed closely by health insurance (31.61\%). Censored deprivations for adults variate between $3 \%$ and $32 \%$. Peru, see Figure 3.2 d, reflects the smaller levels of health insurance coverage (43.8\%). The indicators for sanitation (33.5\%) and educational attainment $(31 \%)$ are also important. A particularity found is the highest level of deprivation in effective use of healthcare in case of need (27.6\%). When the censored condition is applied, sanitation (25.6\%), poor floor material (21.6\%) and educational attainment $(21.2 \%)$ show the most deprived percentage of individuals in this subgroup.

Elderly are more deprived in education measured by years of schooling and income security in old age. ${ }^{27}$ Compared with children and adults, the levels of deprivations of elderly in Chile are comparatively higher, see Figure 3.3a. Income insecurity $(60.4 \%)$ and educational attainment $(56.8 \%)$ are the indicators with the highest percentage of deprived individuals in Chile. The levels of deprivation in the third indicator, sanitation $(17.2 \%)$ are considerably lower. After censoring, the same indicators remain the ones with the worst performance, but at different levels (between $0 \%$ and $8 \%$ ). In Colombia, see Figure 3.3b, educational level measured by years of schooling (90.21\%) is the indicator with the highest percentage of deprivation. This result reflects the lack of enforcement of policies to ensure primary education several decades ago. Income security

\footnotetext{
${ }^{27}$ In the cases of Peru and Ecuador variables related to the health dimension: health insurance and effective use of healthcare services show higher levels of deprivations.
} 
$(49.03 \%)$ is the second worst indicator reflecting the poor coverage of the social security system. When $k=30 \%$ is imposed, the levels of deprivation decrease to a range between $14 \%$ (years of schooling) to $0.1 \%$ (type of housing).

Figure 3.3: Raw and Censored Data for Elderly

a. Chile

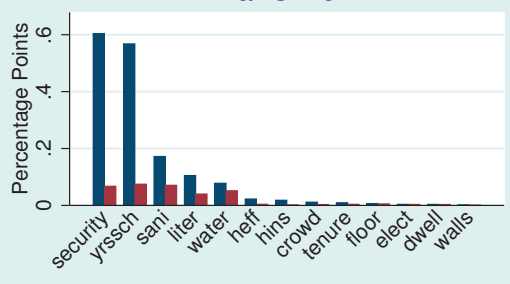

c. Ecuador

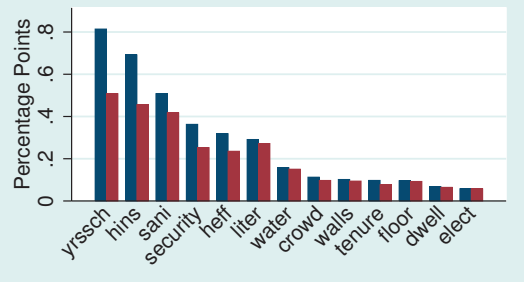

Raw b. Colombia

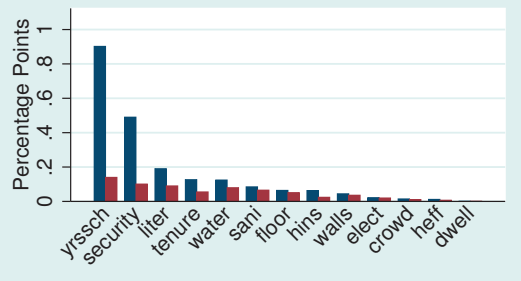

d. Perú

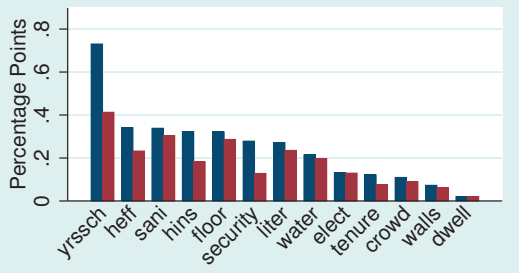

Censored

Source: Chilean, Colombian, Ecuadorian and Peruvian LSMS. Author's calculations. Vertical Axes express different magnitudes.

Figure 3.3c, shows the analysis for Ecuador. Ecuador remains the country with the highest deprivations. Consistently with the cases of Chile and Colombia, educational attainment $(81.4 \%)$ is the indicator with the highest deprivations within this subgroup. Access to health insurance is also an important indicator to account for deprivations $(69.2 \%)$. When the censoring is applied the results follow the same trend. Ecuador and Peru show a poorer performance in the indicator for literacy, both raw and censored ( $27 \%$ and $23 \%$ censored results respectively), when compared to Chile and Colombia. After the $k$ restriction is imposed, the results vary. In the case of Peru, most of the indicators found to show higher deprivations in raw terms remain those with the worst performances (years of schooling (41\%), sanitation (30.2\%), poor floor material $(28.6 \%)$, literacy $(23.5 \%)$ and effective use of healthcare $(23.2 \%)$ ). An exemption is the indicator for health insurance that it is replaced, in importance, by the use of healthcare services, when the restriction is imposed. In Peru, a long waiting list is an important obstacle to effectively use healthcare services. 
The analysis contrasting raw and censored headcount shows the importance of digging deeper into the results before and after censoring, if the objective is to use the measure as a policy tool.

\subsection{Multidimensional Poverty Index -Results}

In this section, the results of the headcount ratio, the average intensity and the adjusted headcount ratio are presented for different values of the poverty cut-off $(k)$. Also, differences among the values of the final AHR are presented in this section. Differences are calculated using the definition of Saltelli et al. (2005, p. 309) as presented in Equation 3.1. A and $\mathrm{B}$ are two different countries, $P A$ and $P B$ are their respective Adjusted Headcount Ratio, or the social poverty function shown in Equation 2.6. ${ }^{28}$

$$
D_{A B}=P_{A}-P_{B}
$$

In subsection 3.5.1 subgroup population comparisons between countries and their subsequent aggregation are introduced. In order to compare the effects on the variation of the unit of analysis, household multidimensional poverty is shown in subsection 3.5.2.

\subsubsection{Individual Multidimensional Poverty}

Chile is by far the least multidimensionally poor country, followed by Colombia, Peru and Ecuador. Colombia's second place in this ranking comes as a surprise, not only because of its behavior in terms of income poverty but also in multidimensional poverty. The last two countries in the ranking (Ecuador and Peru) indicate a similar performance, although Ecuador is the country with the lowest performance. The crossing of curves, for adults and elderly, in the case of the last two countries, occurs when considering higher values of $k^{29}$

The average intensity of poverty (A) is a measure of breadth of poverty (Equation 2.5 or $g$, basically defined as the average weighted dimensions in which the poor are deprived.). It is expected to increase with higher values of $k$. Chile also performs consistently better than the rest of the countries in terms of breadth.

\footnotetext{
${ }^{28}$ Differences between indicators and weights or $W$ can be also calculated but they are not used in the application of this chapter.

${ }^{29}$ For the following cases: $\mathrm{k}=50-60 \%$ and $\mathrm{k}=80 \%$ for adults and $\mathrm{k}=50-60 \%$ and $\mathrm{k}=90 \%$ for elderly.
} 
The differences between countries confirm the crossing of the curves depicting the final index in the cases of Ecuador and Peru, for the elderly and adults. The results show that the elderly subgroup is the most deprived, particularly important is their performance in the Chilean case. Nonetheless, when the national level is calculated, the level of poverty of the elderly does not affect the position of Chile in the ranking. ${ }^{30}$

Figure 3.4: AHR for Children
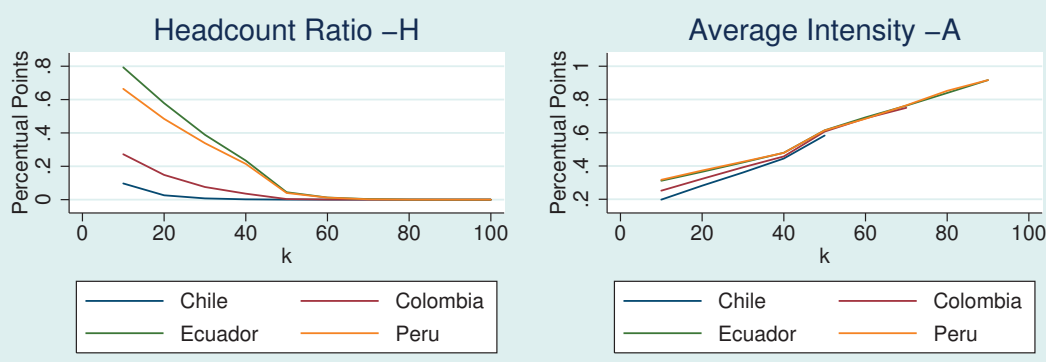

AHR
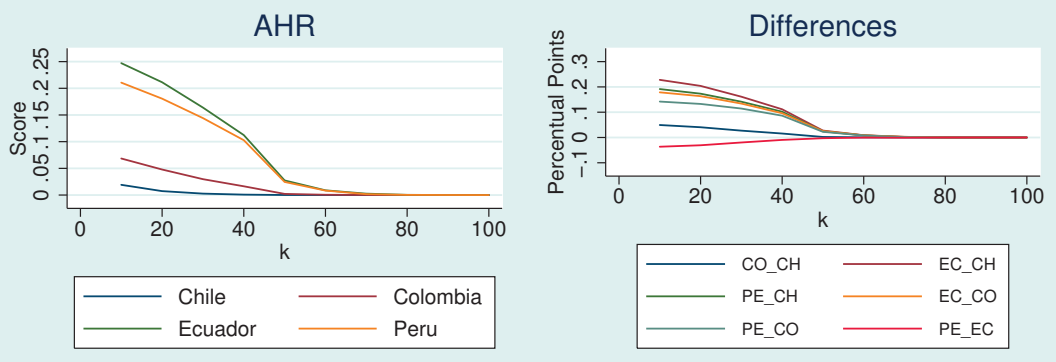

Source: Chilean, Colombian, Ecuadorian and Peruvian LSMS. Author's calculations.

Figure 3.4 presents the case of children. The AHR score ranges from 0.019 (Chile) to 0.2471 (Ecuador) when the lowest level of $k$ is considered. ${ }^{31}$ Peru is the worst off country of this sample. When the standard poverty cut-off is considered, $k=30 \%$, the results for the AHR score are: Chile (0.0027), Colombia (0.0297), Peru (0.1441) and Ecuador (0.1639). Differences between countries tend to be insignificant to values of $k$ higher than $50 \%$. The highest difference between countries is found between Chile and Ecuador (More than 20 points) $^{32}$.

The less multidimensionally poor subgroup in overall is adults (Figure 3.5). When $k=30 \%$ is considered, Chile is the least poor country with a score of 0.0038 , followed by Colombia (0.0316), Peru (0.1247) and Ecuador (0.1412). The differences between country are smaller when comparisons between adults and children are performed. Ecuador and

\footnotetext{
${ }^{30}$ In Chapter 5, the effects of changes of the population shares will be assessed.

${ }^{31}$ As explained in Atkinson (2003) the union approach is defined as the percentage of individuals deprived in at least one indicator or in our case $k=10 \%$ of the indicators

${ }^{32}$ Confidence Intervals for the AHR are presented in Appendix 3.7.5, for all the populations considered and every country.
} 
Figure 3.5: AHR for Adults
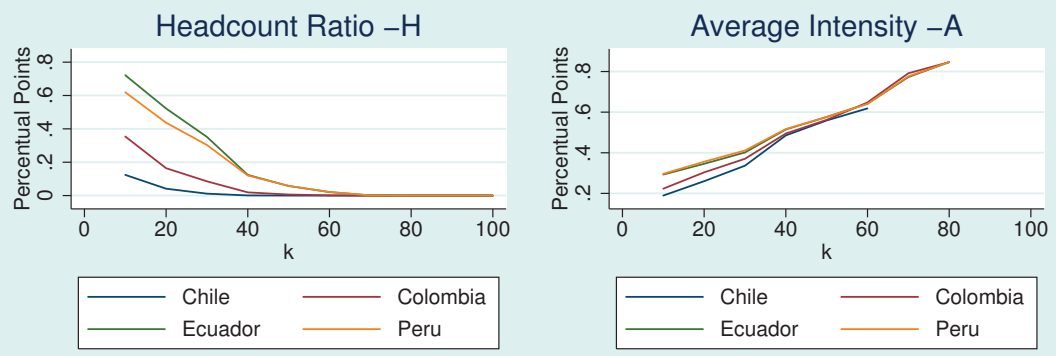

AHR
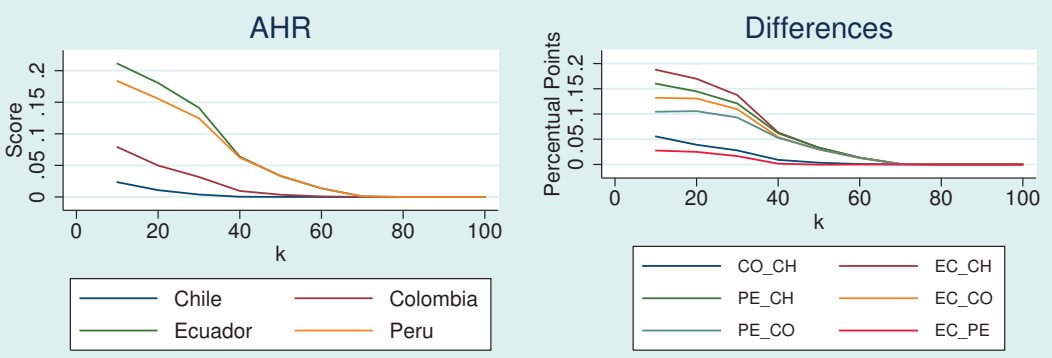

Source: Chilean, Colombian, Ecuadorian and Peruvian LSMS. Author's calculations.

Peru are the most similar countries and the gap between Chile and Colombia is bigger for this subgroup. The differences become insignificant to levels of $k$ equal or higher than $70 \%$ of the indicators. The highest difference is found between Chile and Ecuador.

The results of the index for subgroup elderly (Figure 3.6) are consistent with the results of the two previous subgroups. The headcount ratio for the union approach ranges from $48 \%$ in Chile to $82.45 \%$ in Ecuador. The final index result ranges from a score of 0.10 (Chile) to a score of 0.27 (Ecuador). The differences in the AHR show that for values of $k=50 \%$, Peru and Ecuador reversed their ordering. The level of multidimensional poverty is higher for this subgroup. After analyzing the raw censored results and the AHR for this particular sub-group, in Appendix 3.7.6 a sensitivity analysis excluding years of schooling is performed. However, despite its statistical influence, the rest of the analysis will include this indicator because it is perceived as having not only an instrumental but also an intrinsic value on the lives people choose. That means that education is not only used as a mean to achieve better outcomes in labor or income through the life time but also as a goal, as in the case in which education is valued by itself and people consider themselves as part of the society by being better educated. A sensitivity analysis is used to find if there are substantial changes in the overall ranking and is it is not the case it will be used as part of the index.

Using the cut-off of $k=30 \%$, as shown in Table 3.4, children are the less deprived population sub-group in Chile and Colombia. In Peru and Ecuador, the least deprived population are adults. 
Figure 3.6: AHR for Elderly
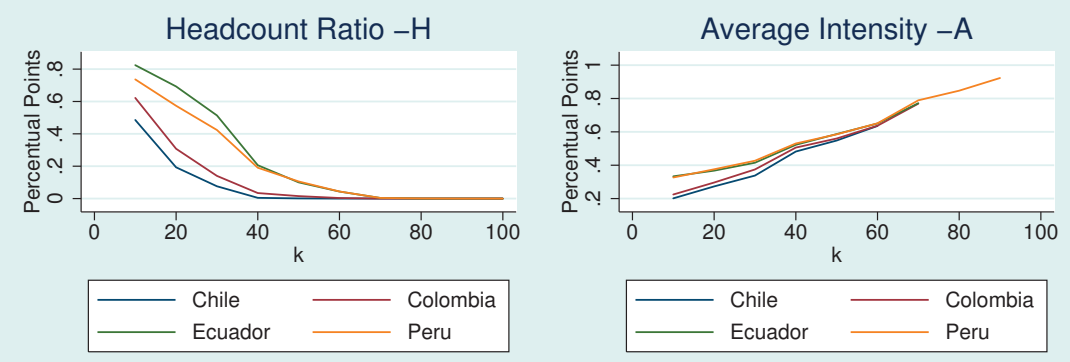

AHR
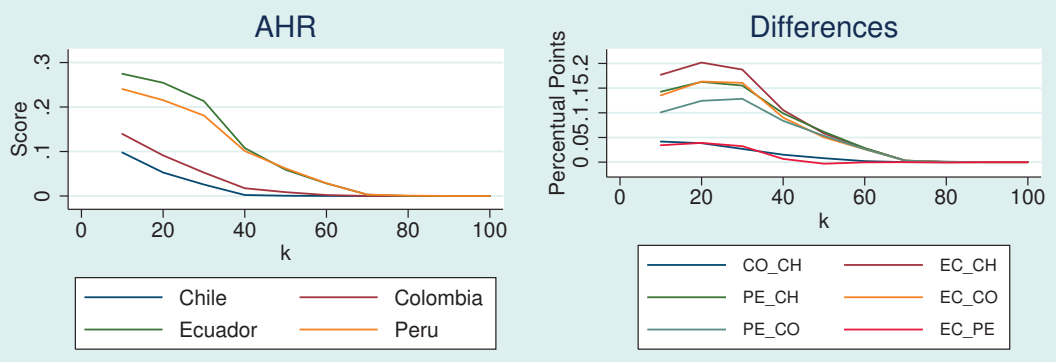

Source: Chilean, Colombian, Ecuadorian and Peruvian LSMS. Author's calculations.

Table 3.4: AHR score for $\mathrm{k}=30 \%$ by subpopulation

\begin{tabular}{lllll} 
AHR & Chile & Colombia & Ecuador & Peru \\
\hline Children & 0.0026 & 0.0297 & 0.1639 & 0.1441 \\
Adults & 0.0038 & 0.0316 & 0.1412 & 0.1247 \\
Elderly & 0.0257 & 0.0525 & 0.2132 & 0.1809 \\
\hline
\end{tabular}

Source: Author's calculations

Aggregation to get the national AHR for each country is performed (see Figure 3.7). The share of each sub-group, understood as the percentage of population in the sample that falls into each age category, was used to find the final index. The results show the influence of the size of the population (see Annex 3.7.1).

In every country, the smallest share is for elderly, ranging between $9.2 \%$ in Ecuador to $16.8 \%$ in Chile. The smaller amount of population in this age group benefits Ecuador in the overall general ranking. When considering the size of the population Ecuador is consistently well off compared with Peru.

In summary, the ordering is similar once the values of the AHR by sub-groups are added, using the population share for each country. Chile remains the least multidimensional deprived country (0.007), followed by Colombia (0.031), Peru (0.1363) and Ecuador (0.1572), for the particular case of $k=30 \%$. At higher values of $k$, the ordering does 
Figure 3.7: Aggregated AHR
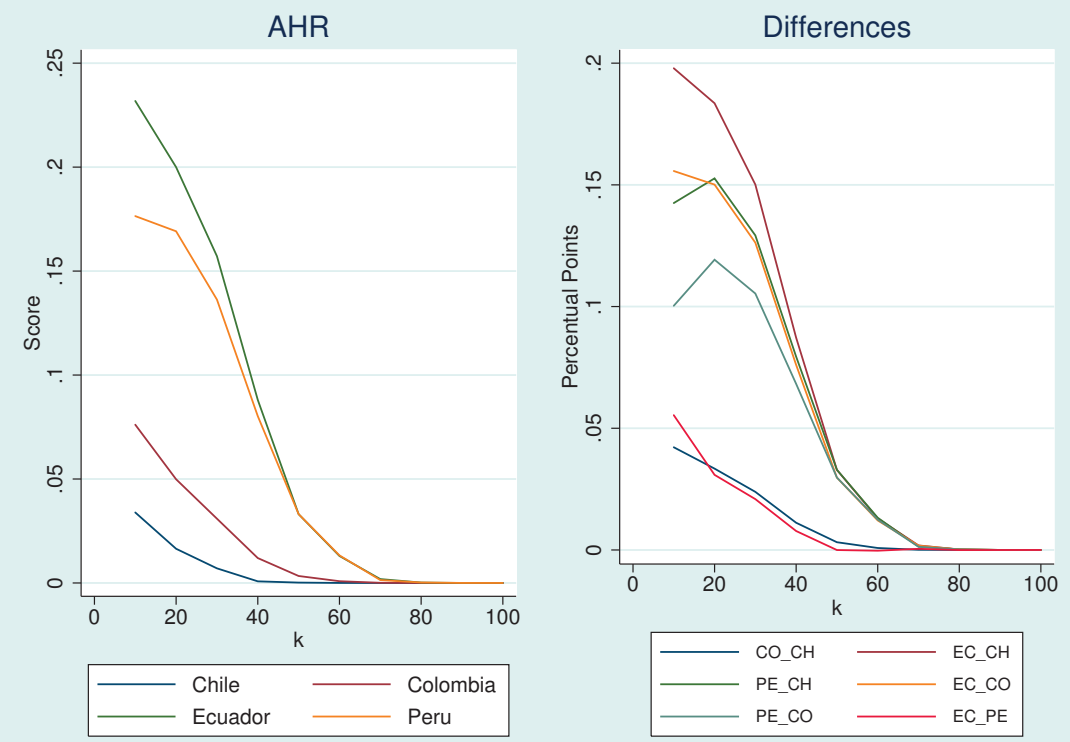

Source: Chilean, Colombian, Ecuadorian and Peruvian LSMS. Author's calculations.

not prevail. The order in the ranking is reversed for the last two countries (Ecuador and Peru), as shown in Figure 3.7. A ranking reversal is evident when the lines of two different countries cross.

Table 3.5 presents the rankings for different levels of $k$. Peru and Ecuador switch places due to the differences in multidimensional poverty of the elderly. The graph of differences among countries confirms this finding.

Table 3.5: Rankings for different $k$

\begin{tabular}{|c|c|c|c|c|}
\hline$k$ & Chile & Colombia & Ecuador & Peru \\
\hline 10 & 1 & 2 & 4 & 3 \\
\hline 20 & 1 & 2 & 4 & 3 \\
\hline 30 & 1 & 2 & 4 & 3 \\
\hline 40 & 1 & 2 & 4 & 3 \\
\hline 50 & 1 & 2 & 3 & 4 \\
\hline 60 & 1 & 2 & 3 & 4 \\
\hline 70 & 1 & 2 & 4 & 3 \\
\hline 80 & 1 & 2 & 3 & 4 \\
\hline 90 & 1 & 1 & 3 & 4 \\
\hline 100 & 1 & 1 & 1 & $1^{*}$ \\
\hline
\end{tabular}

Author's calculations. * Whenever the result is zero for more than one country, the ranking will be the same. 


\subsubsection{Household Level Multidimensional Poverty Index}

By means of comparison the same index is calculated but using households as a unit of analysis. The same indicators and cut-offs explained in section 3.4.3 are considered. Equal weights are applied to the 16 indicators. A household is considered deprived in one particular indicator when at least one member is deprived..$^{33}$

Figure 3.8: AHR for Households
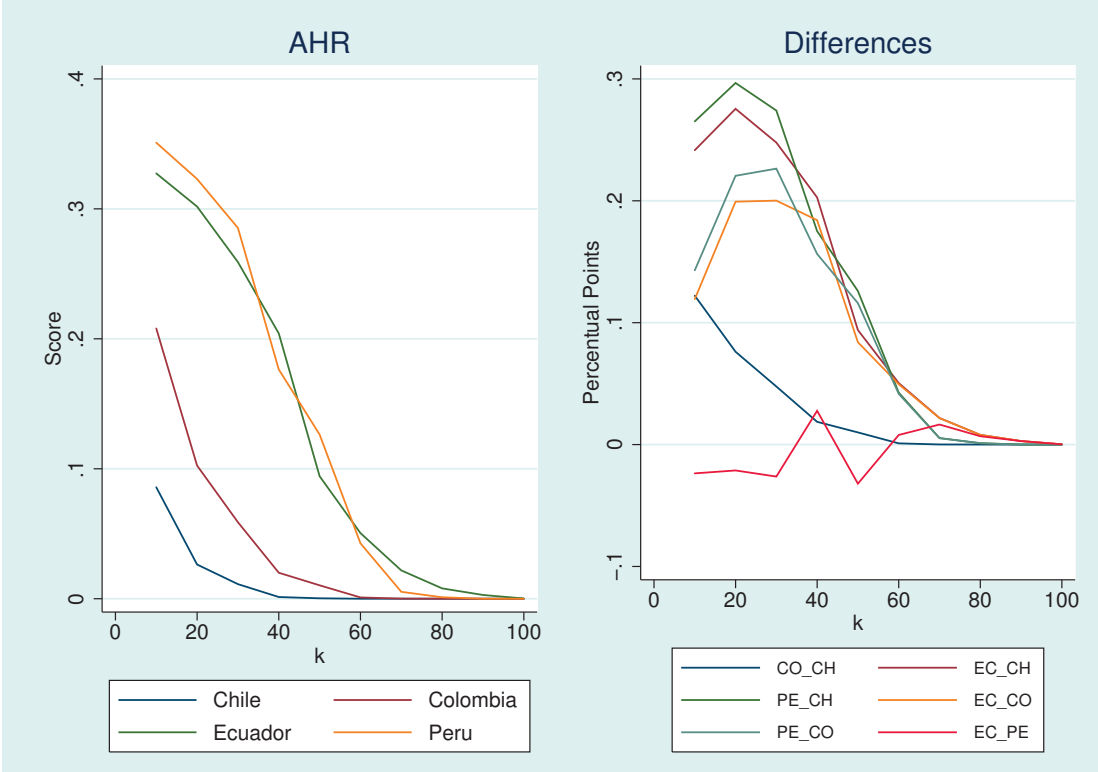

Source: Chilean, Colombian, Ecuadorian and Peruvian LSMS. Author's calculations.

Results are presented in Figure 3.8. By changing the unit of analysis a different scenario is portrayed. Ecuador and Peru remain as the most multidimensionally poor countries, but just this time the constant crossing of the curves is evident. Analyzing only the $\mathrm{H}$, Colombia and Peru are the countries with the higher percentage of individuals deprived in at least one indicator. This is due to the levels of deprivation in the education indicator. In Colombia more than 9.7 households out of every 10 have at least one member who has not completed at least eight years of education and deprivation in income security at old age is present in above $80 \%$ of the households. In the case of Peru education and years

\footnotetext{
${ }^{33}$ The decision is adopted to make both measures, individual and household-based, comparable. The most popular application of household-level MPI, performed by UNDP and OPHI, considers for instance in the dimension of education the complete opposite condition stated here. The cut-off defined is having at least one household member who has completed five years of schooling and having at least one schoolage child (up to grade 8) who is not attending school. (UNDP, 2013, Technical Notes p. 7).
} 
of schooling are the highest deprived indicators (99\% and 80\%). The graph showing the differences among countries confirms the switch in the ordering between Ecuador and Peru when the AHR is calculated using the household as unit of analysis. Defining a ranking is more complicated in this case.

\subsection{Conclusion}

Composite indices are increasingly used as tools for governance. Indices are perceived as data simplification of a highly complex process (see Davis et al., 2012, p. 18). Results from rankings are one of the most popular statistics used by the media, public officials and academics. Although easy to communicate, the simplicity usually attributed to composite indices is misleading. The process that converts raw data into the index itself is not easy to communicate, and certainly not easily understood by the general public. Transparency of decisions is asked for, as well as a clear assessment of the impact of these decisions.

This chapter addresses precisely one of the normative decisions taken, the unit of analysis. It examines to what extent the use of the individual as a unit of analysis changes the results of a multidimensional index as opposed to a household unit of analysis. This chapter also introduces the core index to be used in the remainder of this thesis. The individual unit of analysis is based on the construction of three age groups: children (less than 18 years old), adults (18 to 59 years old), and elderly (older than 59 years old). An AHR index is calculated for each group and country (Chile, Colombia, Ecuador and Peru). It also introduces the indicators included following the capability approach theoretical framework. Indicators are included when the following conditions are fulfilled: 1. The indicators express an achievement for individuals in the sense of creating or improving human capabilities, 2. The indicators do not express subjective well-being, 3. The indicators are not a measure of material or income poverty, and 4 . The indicators are comparable among the four datasets.

The result of the individual approach showed that the elderly, as opposed to children, is the most multidimensional deprived population subgroup. The driving factors are the minimum years of education and the access to sources of income after retiring age (either pension or labor). In the particular case of Ecuador and Peru, the poor coverage of health insurance and the limited access to effective healthcare in case of need were also driving factors. ${ }^{34}$ For children and adults, living conditions are the main source of deprivations. Lack of piped water and adequate facilities for sanitation is known for increasing probabilities of contagious diseases. Although numbers of

\footnotetext{
${ }^{34}$ In the case of Ecuador, health insurance was a determinant factor for every subgroup, in both raw and censored headcounts
} 
diseases by this cause had fallen in the region these diseases are still a major cause of preventable deaths. Conflicts related to the ownership of the land are of particular interest in the Colombian case. Crowdedness is a conflicting aspect in the case of Peru.

When comparing the raw and censored headcount between countries the levels for Chile are comparatively lower than those for the other countries. The AHR shows that Chile is the country with the best performance in this ranking.

In order to compare the extent of the change in the unit of analysis a household-level index is constructed.Taking all the possible indicators into account, a household was considered deprived if at least one individual was considered deprived. The last choice was made in order to make both thresholds, individual and household, comparable. For example, if a particular individual is deprived in one indicator then all the other members of the household will be considered deprived when a household level index is calculated. A common pattern was found. Chile was still the least multidimensionally poor country followed by Colombia, Ecuador and Peru. The ranking of the two last countries was reverted from the individual case. Also the differences between Colombia (2nd) and Ecuador (3rd) are not as wide as before. The multidimensional poverty scores of individuals (after aggregation according to the percentage of subgroup population in the sample) are close to $1 / 3$ in the cases of Chile and Colombia, 1/2 for Peru and almost the same for Ecuador. Household multidimensional poverty is consistently higher.

As mentioned in section 3.5.1 and section 3.5.2 a constant crossing of the headcount ratio and multidimensional poverty curves for Ecuador and Peru was found for the elderly and adults subgroups, for the aggregation of the individual indices and for the household index, when higher levels of the 'Poverty Threshold' or $k$ were considered. The decision about the poverty cut-off induces arbitrariness in the calculation of the overall result and could cause contrary conclusions (Lasso de la Vega, 2010). Interestingly, in the empirical case presented in this chapter, it was not possible to establish a consistent ranking between Ecuador and Peru when a $k$ higher than 50\% was considered. This result is consistent with previous findings in the literature, as for instance in Lasso de la Vega (2010) and Ravallion (2011).

The main limitations found in this chapter are: First, the indicators included in the multidimensional index are, in strict sense, not considered capabilities but functionings, an issue which has been noted as a weakness of the theoretical framework. Second, the decision about which unit of analysis and where to set the thresholds affects the overall result. In order to create transparency, and depending on the use of the index (e.g. whether it is used as a policy or advocacy tool) the choice about the unit of analysis needs to be supported and explained. And third, the results in this section suggest that even with a limited amount of countries with a similar context, the choice of the second cut-off affects the ordering of the ranking, regardless of the selected unit of analysis. 
Finally, the lesson of this chapter is the importance of using different robustness tests and comparisons of normative choices. To make their effects explicit in the result of a composite index is to armour and support the decisions not only in a theoretical framework but also in an empirical and context-specific scenario. 


\subsection{Appendix}

\subsubsection{Descriptive Statistics}

\begin{tabular}{|c|c|c|c|c|}
\hline & Chile & Colombia & Ecuador & Peru \\
\hline & \multicolumn{4}{|c|}{ Population Shares } \\
\hline Children & $26.97 \%$ & $35.5 \%$ & $41.7 \%$ & $36.9 \%$ \\
\hline Adults & $56.22 \%$ & $53.8 \%$ & $49.1 \%$ & $51.84 \%$ \\
\hline \multirow[t]{2}{*}{ Elderly } & $16.8 \%$ & $10.7 \%$ & $9.2 \%$ & $11.22 \%$ \\
\hline & \multicolumn{4}{|c|}{ Basic Descriptive Statistics } \\
\hline Household Size & 4.35 & 3.47 & 5.13 & 5.11 \\
\hline $\begin{array}{l}\text { Male Head of } \\
\text { Household }\end{array}$ & $66.93 \%$ & $67.31 \%$ & $79.04 \%$ & $75.74 \%$ \\
\hline Mean age & 34.35 & 29.88 & 43.29 & 30.77 \\
\hline
\end{tabular}

Source: Author's calculations based on country LSMS exclusively for the first wave

\subsubsection{Cross-checking the contents in the datasets}

\begin{tabular}{|c|c|c|c|c|}
\hline & \multicolumn{4}{|c|}{ Modules } \\
\hline & Chile & Colombia & Ecuador & Peru \\
\hline Demographics & $\mathrm{Y}$ & $\mathrm{Y}$ & $\mathrm{Y}$ & $\mathrm{Y}$ \\
\hline Education & $\mathrm{Y}$ & $\mathrm{Y}$ & $\mathrm{Y}$ & $\mathrm{Y}$ \\
\hline Health & $\mathrm{Y}$ & $\mathrm{Y}$ & $\mathrm{Y}$ & $\mathrm{Y}$ \\
\hline Labor & $\mathrm{Y}$ & $\mathrm{Y}$ & $\mathrm{Y}$ & $\mathrm{Y}$ \\
\hline Income & $\mathrm{Y}$ & $\mathrm{Y}$ & $\mathrm{Y}$ & $\mathrm{Y}$ \\
\hline Expenditures & & $\mathrm{Y}$ & $\mathrm{Y}$ & $\mathrm{Y}$ \\
\hline Living Conditions & $\mathrm{Y}$ & $\mathrm{Y}$ & $\mathrm{Y}$ & $\mathrm{Y}$ \\
\hline Disabilities & $\mathrm{Y}$ & $\mathrm{Y}$ & $\mathrm{Y}$ & \\
\hline Children & & $\mathrm{Y}$ & $\mathrm{Y}$ & \\
\hline $\mathrm{ICT}$ & $\mathrm{Y}$ & & $\mathrm{Y}$ & $\mathrm{Y}$ \\
\hline Ethnicity & $\mathrm{Y}$ & $\mathrm{Y}$ & $\mathrm{Y}$ & \\
\hline Governance & $\mathrm{Y}$ & & & $\mathrm{Y}$ \\
\hline Participation & $\mathrm{Y}$ & & & $\mathrm{Y}$ \\
\hline Migration & Y & $\mathrm{Y}$ & $\mathrm{Y}$ & \\
\hline Social Mobility & $\mathrm{Y}$ & $\mathrm{Y}$ & $\mathrm{Y}$ & $\mathrm{Y}$ \\
\hline Remittances & & & $\mathrm{Y}$ & $\mathrm{Y}$ \\
\hline Social Capital & & $\mathrm{Y}$ & $\mathrm{Y}$ & $\mathrm{Y}$ \\
\hline Rural & & $\mathrm{Y}$ & $\mathrm{Y}$ & $\mathrm{Y}$ \\
\hline
\end{tabular}

Source: Statistical Offices Official Manuals: Chile; Ministerio de Desarrollo Social, Colombia: DANE, Ecuador: INEC, Peru: INEI. $\mathrm{Y}=$ Information is available 


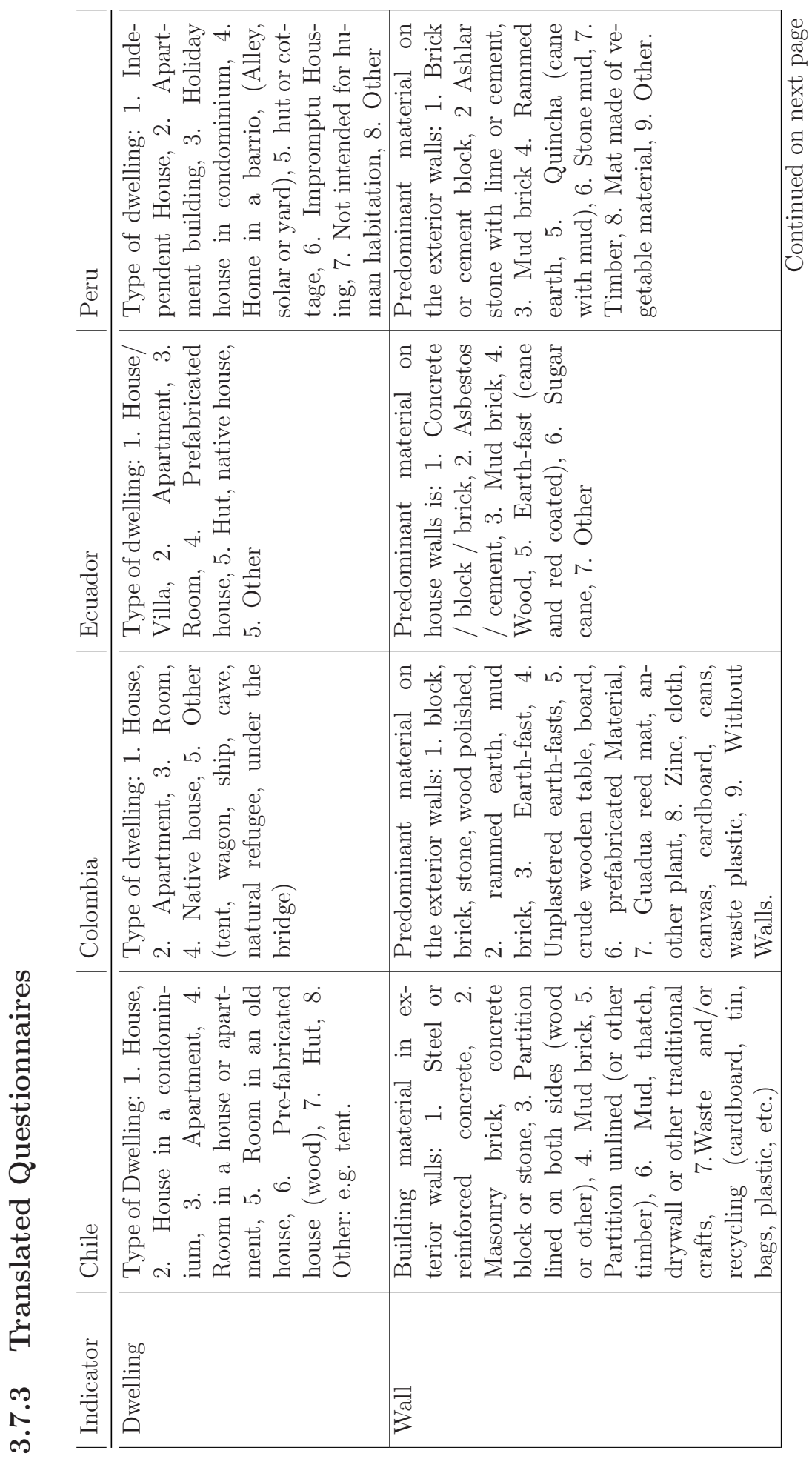




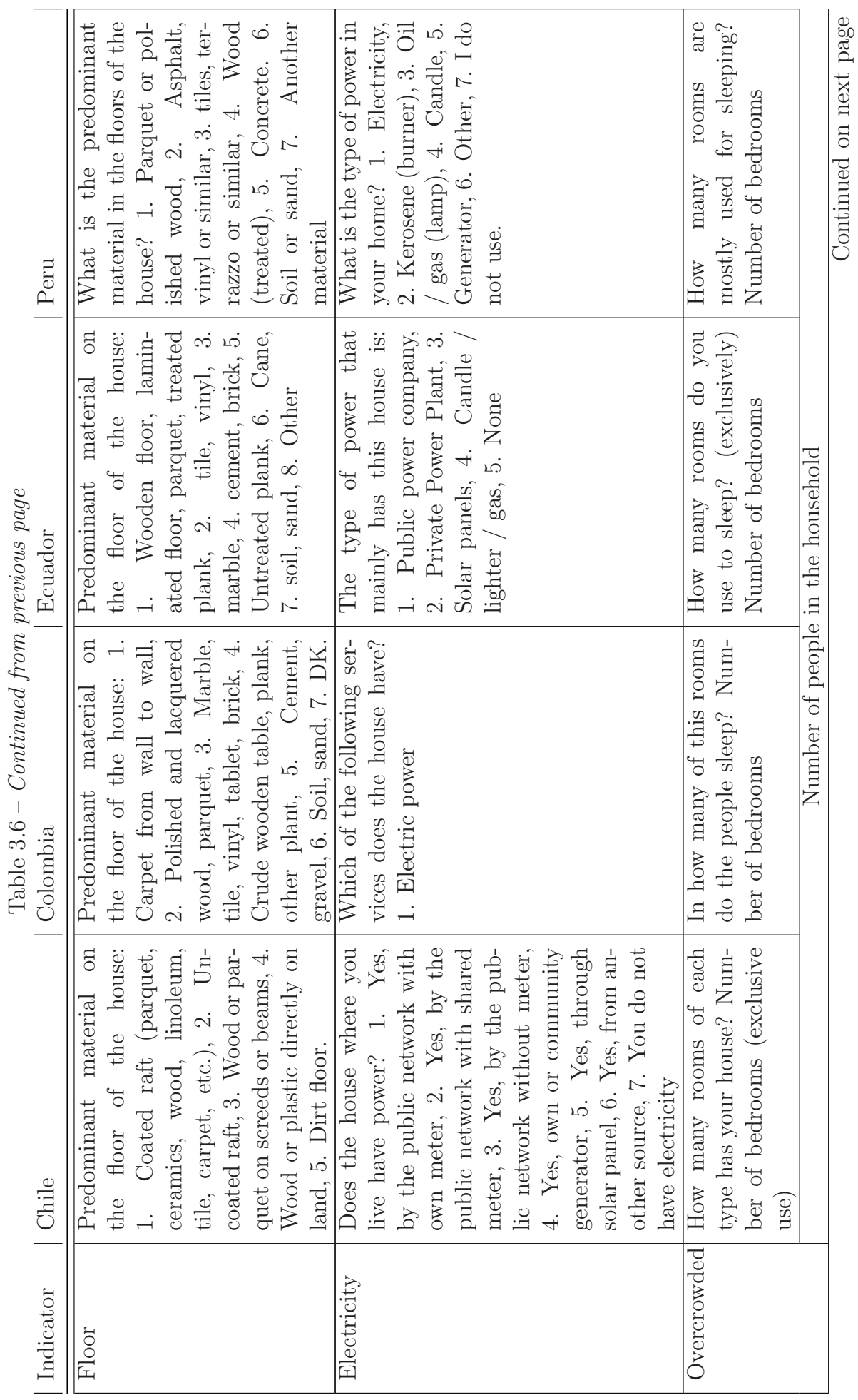




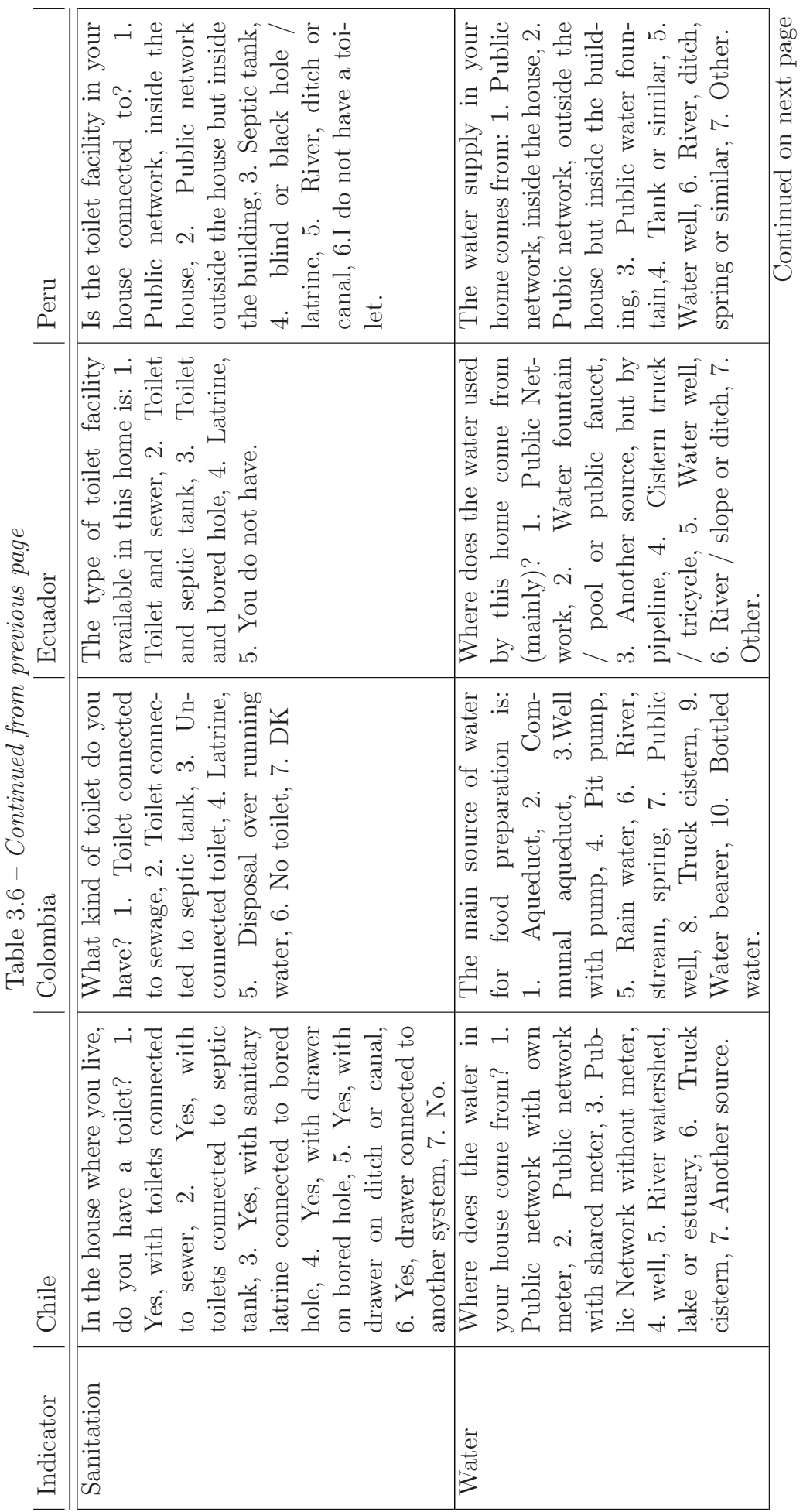




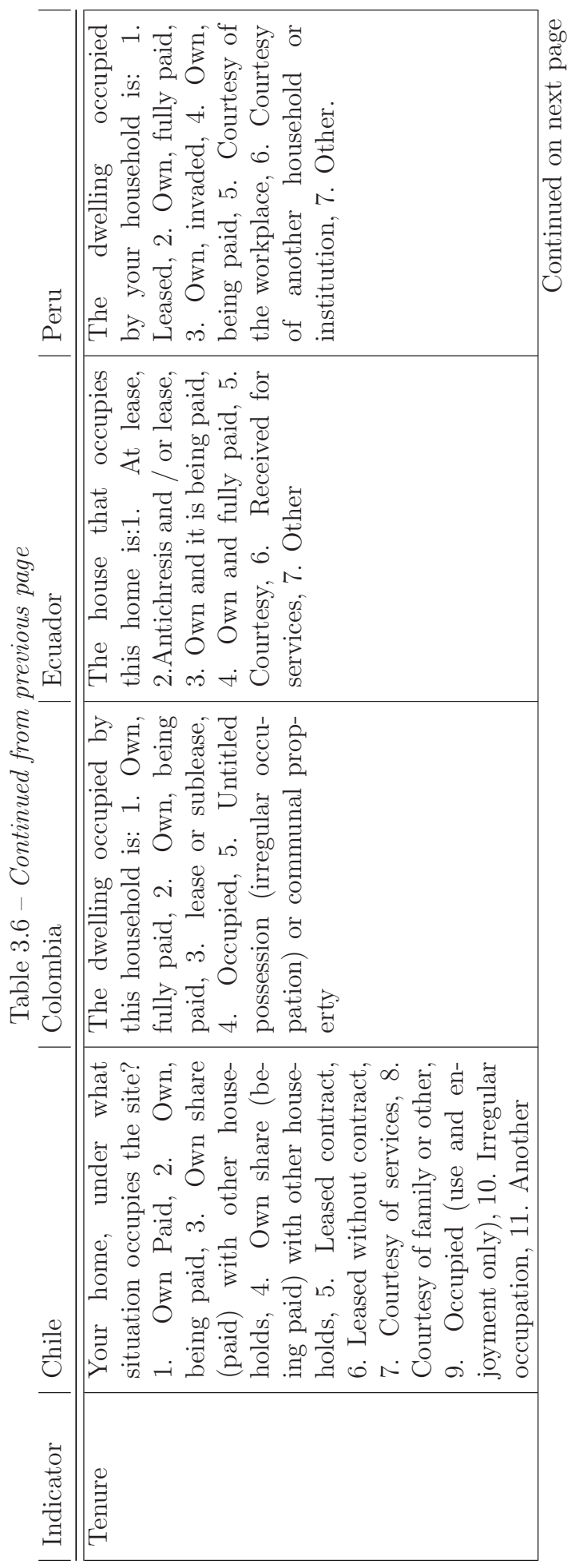




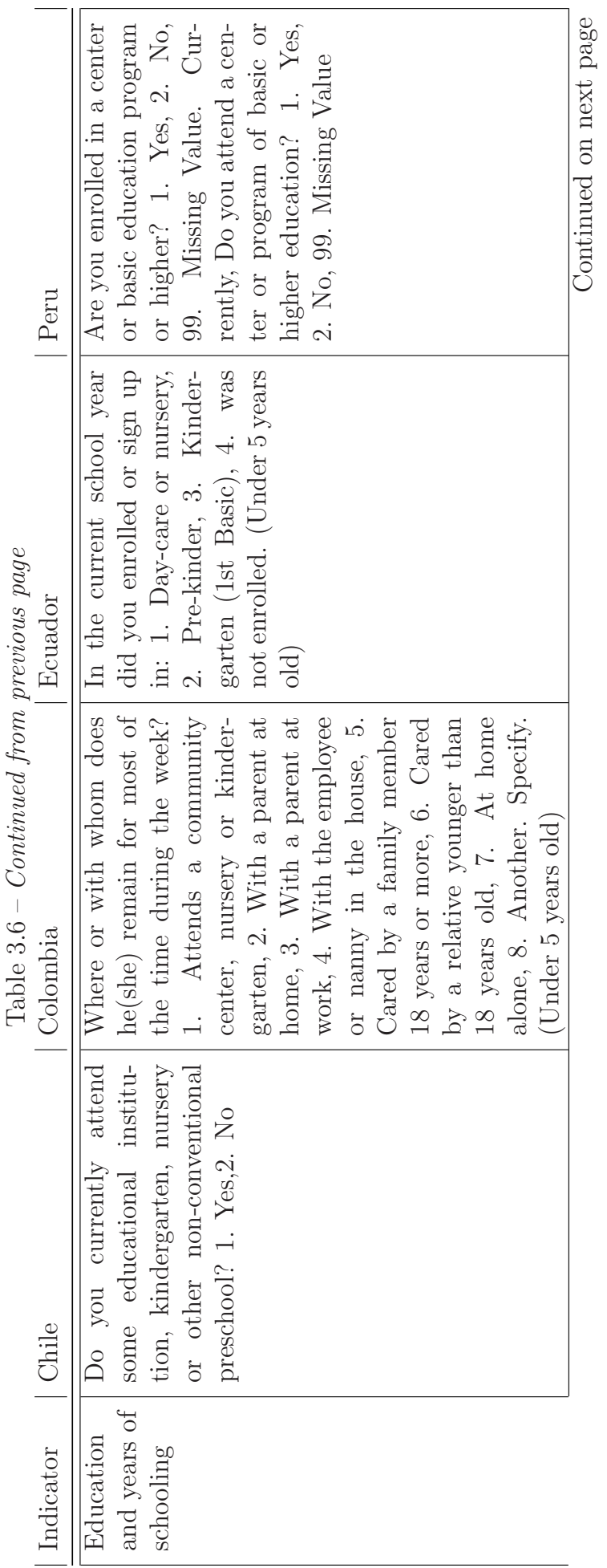




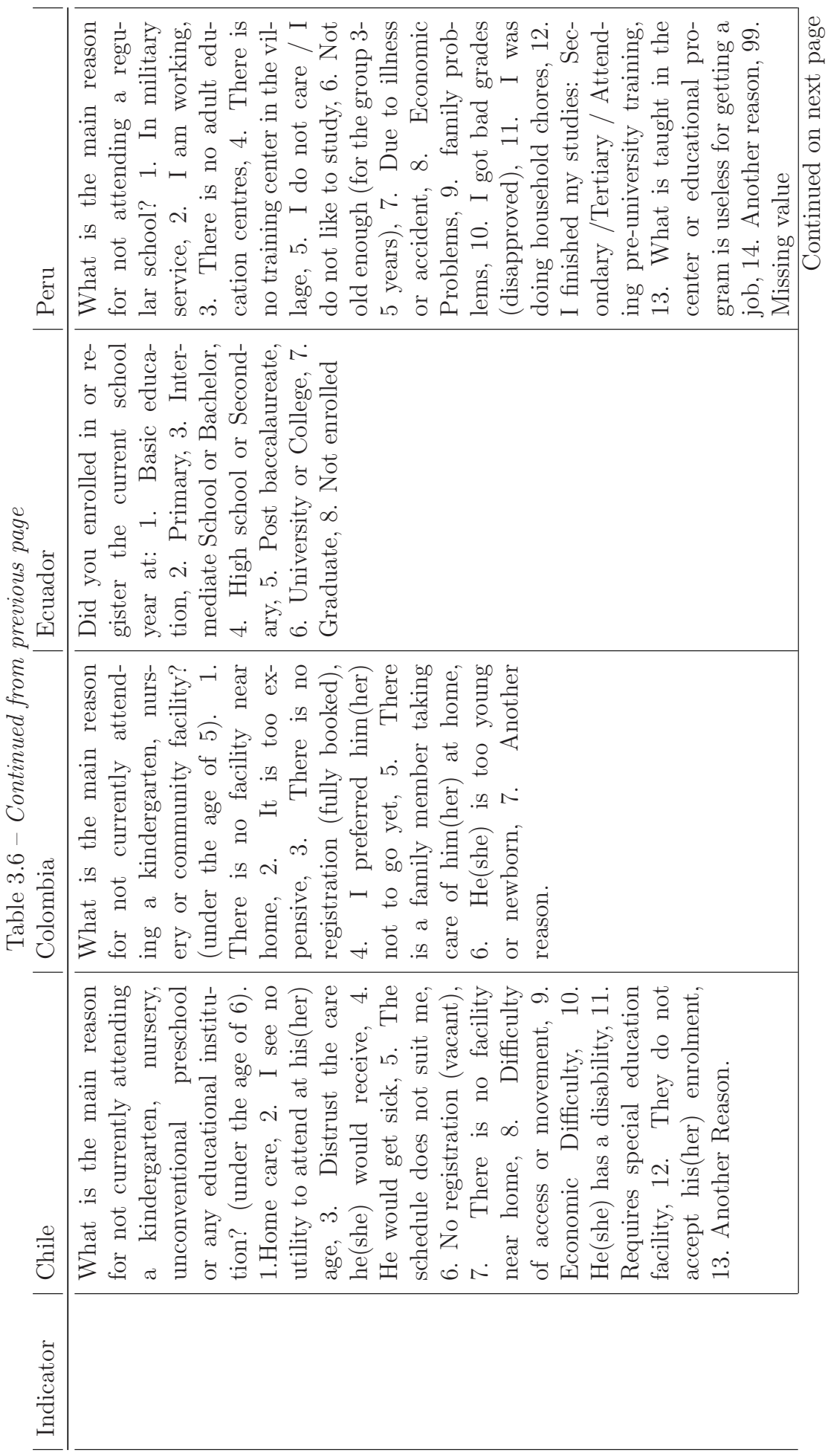




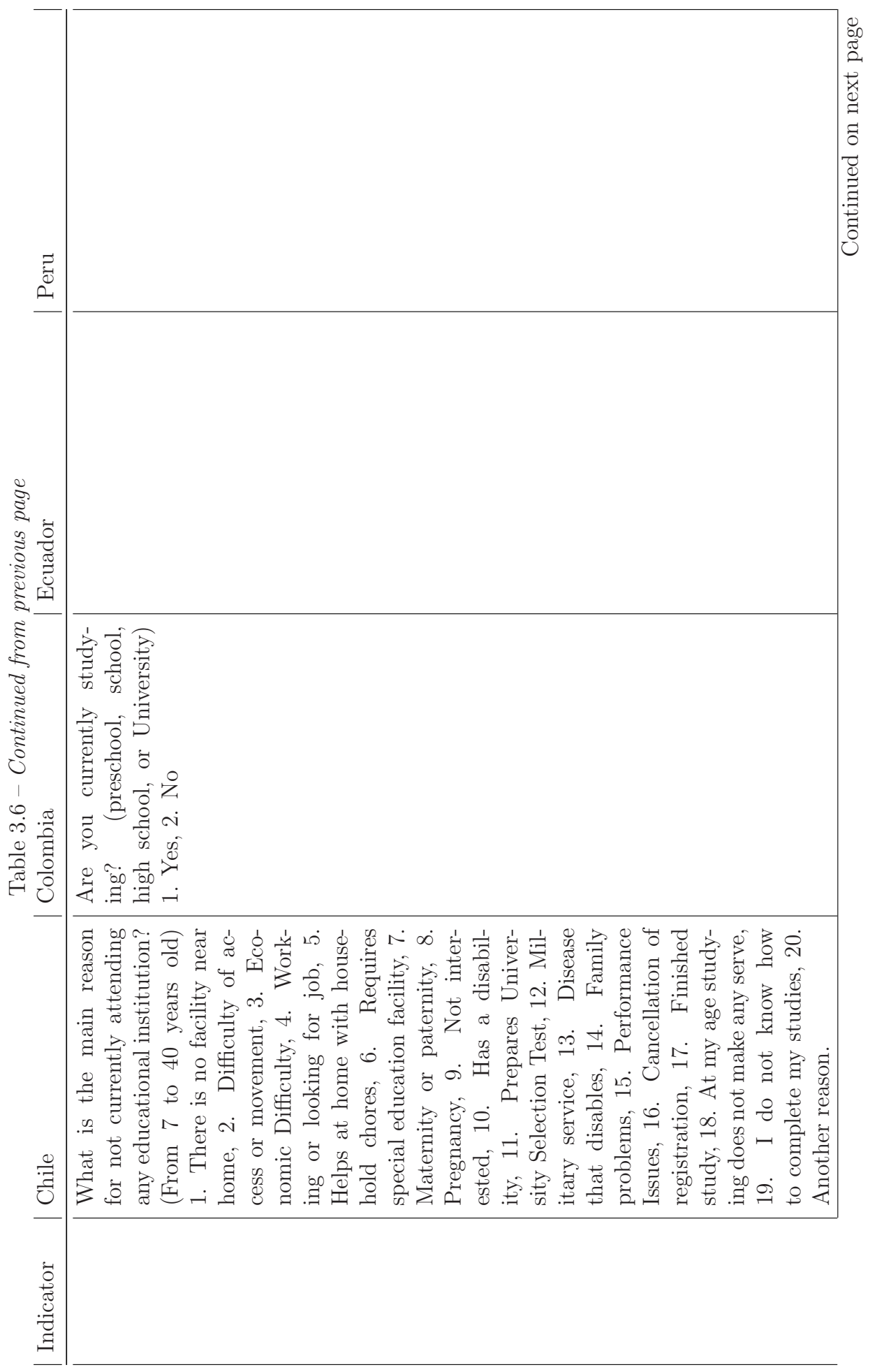




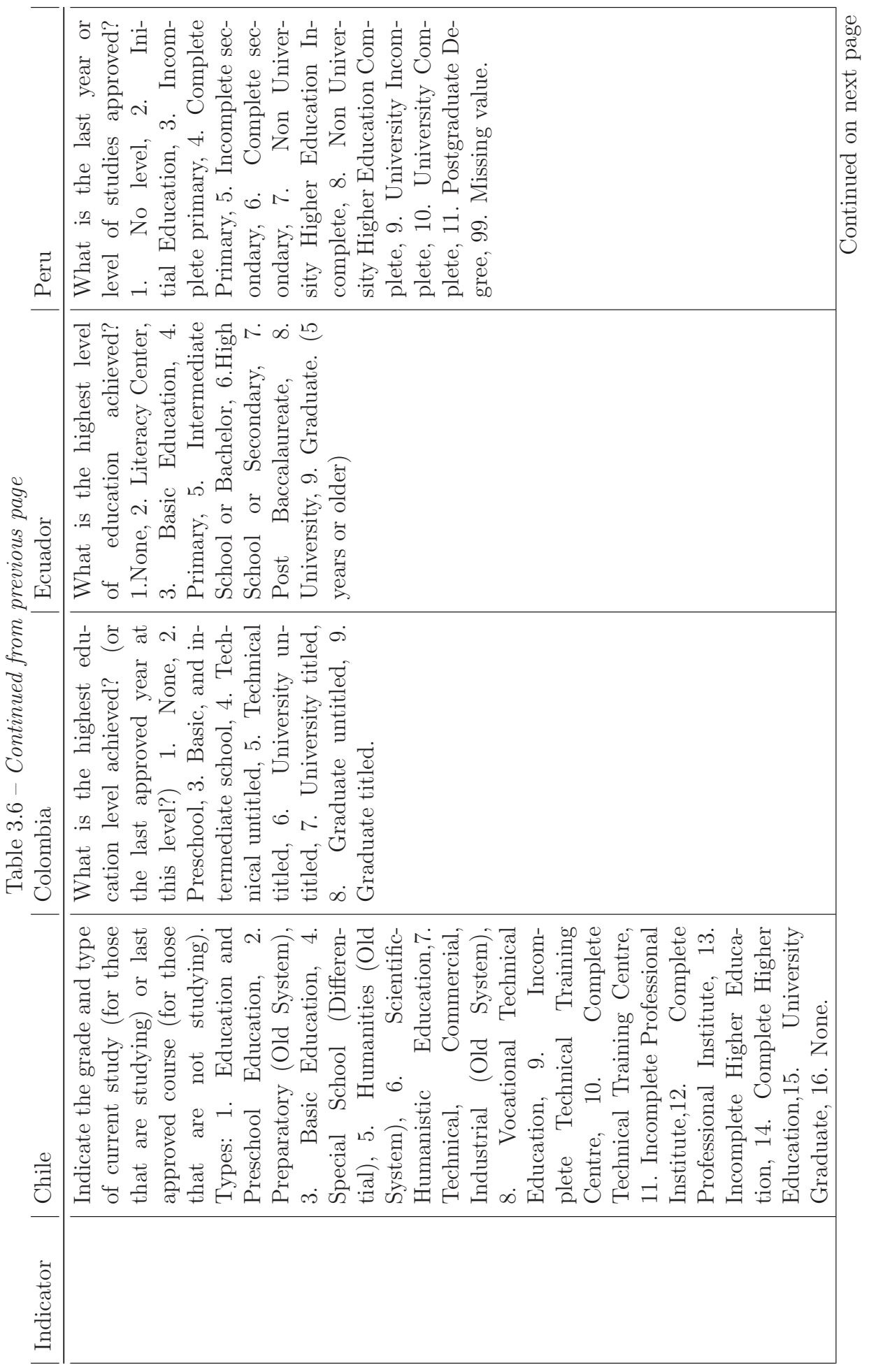




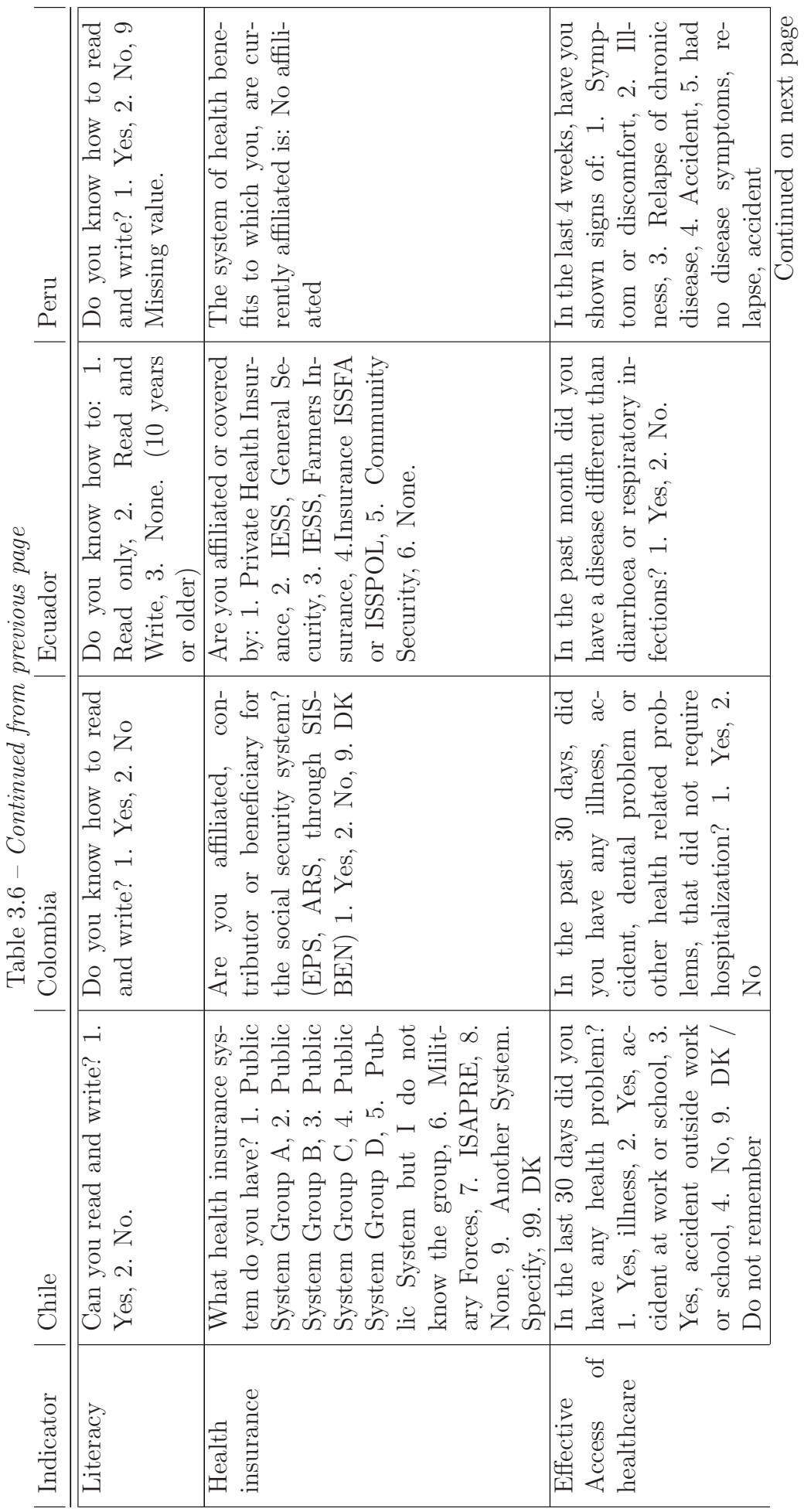




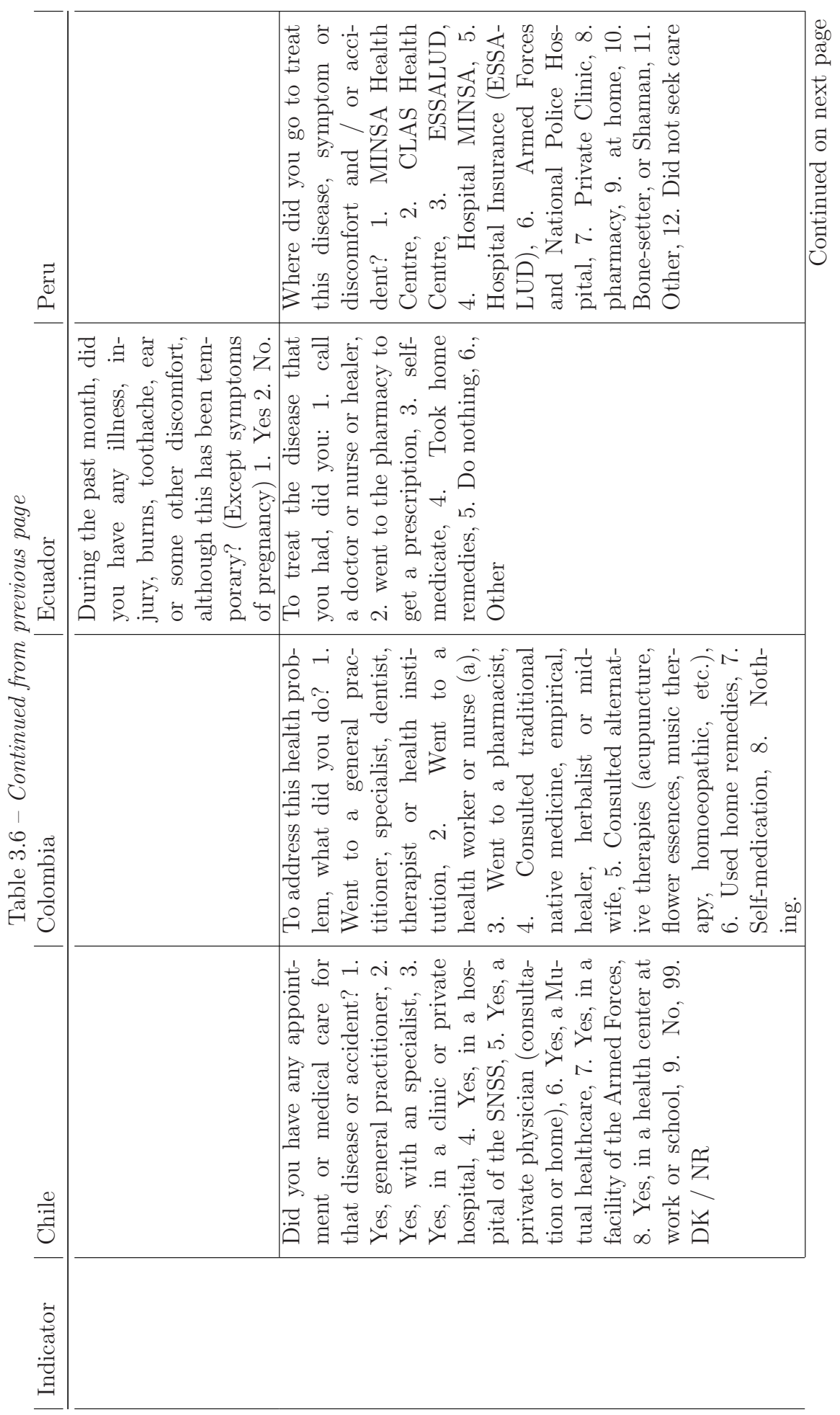




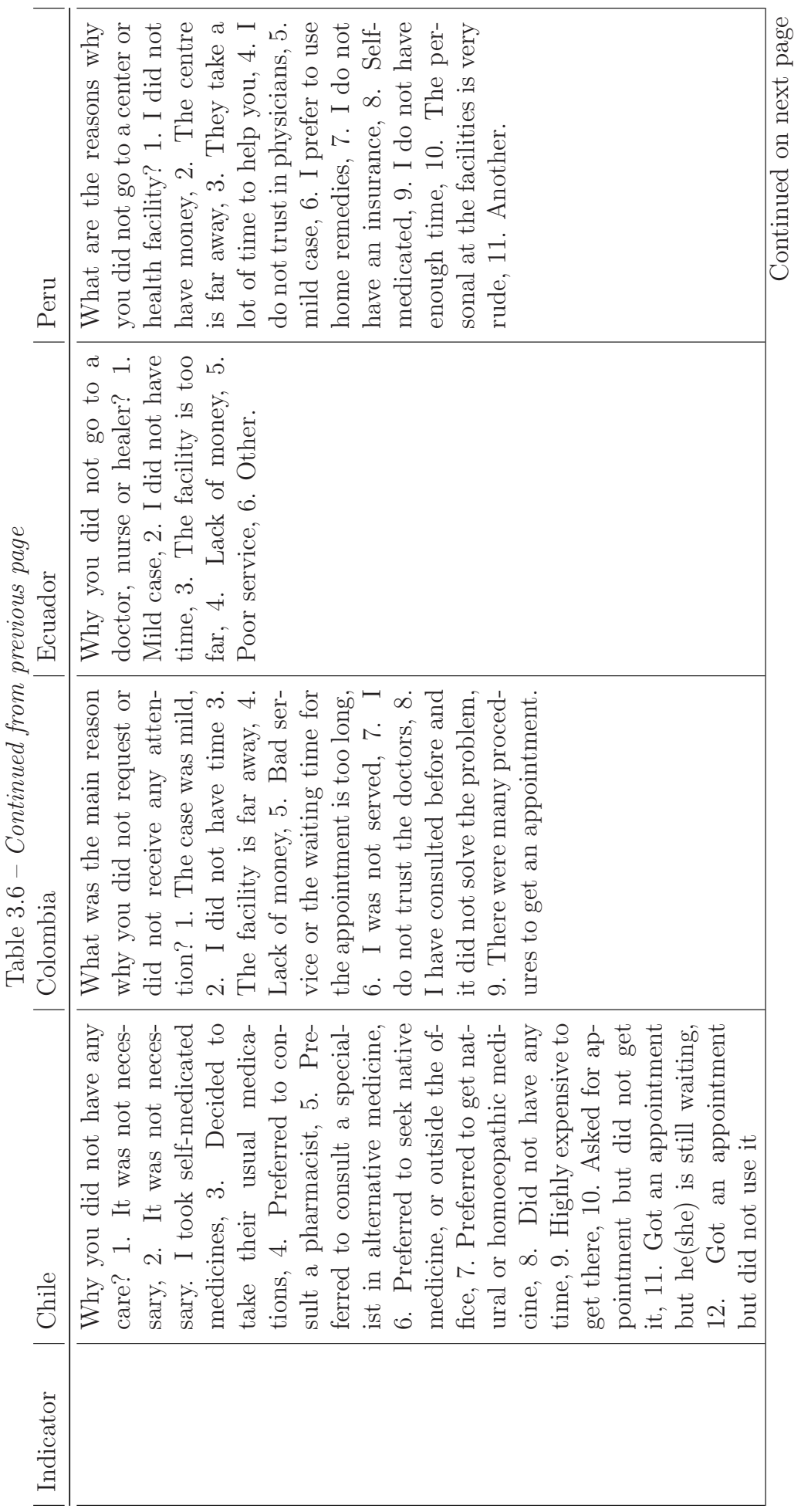




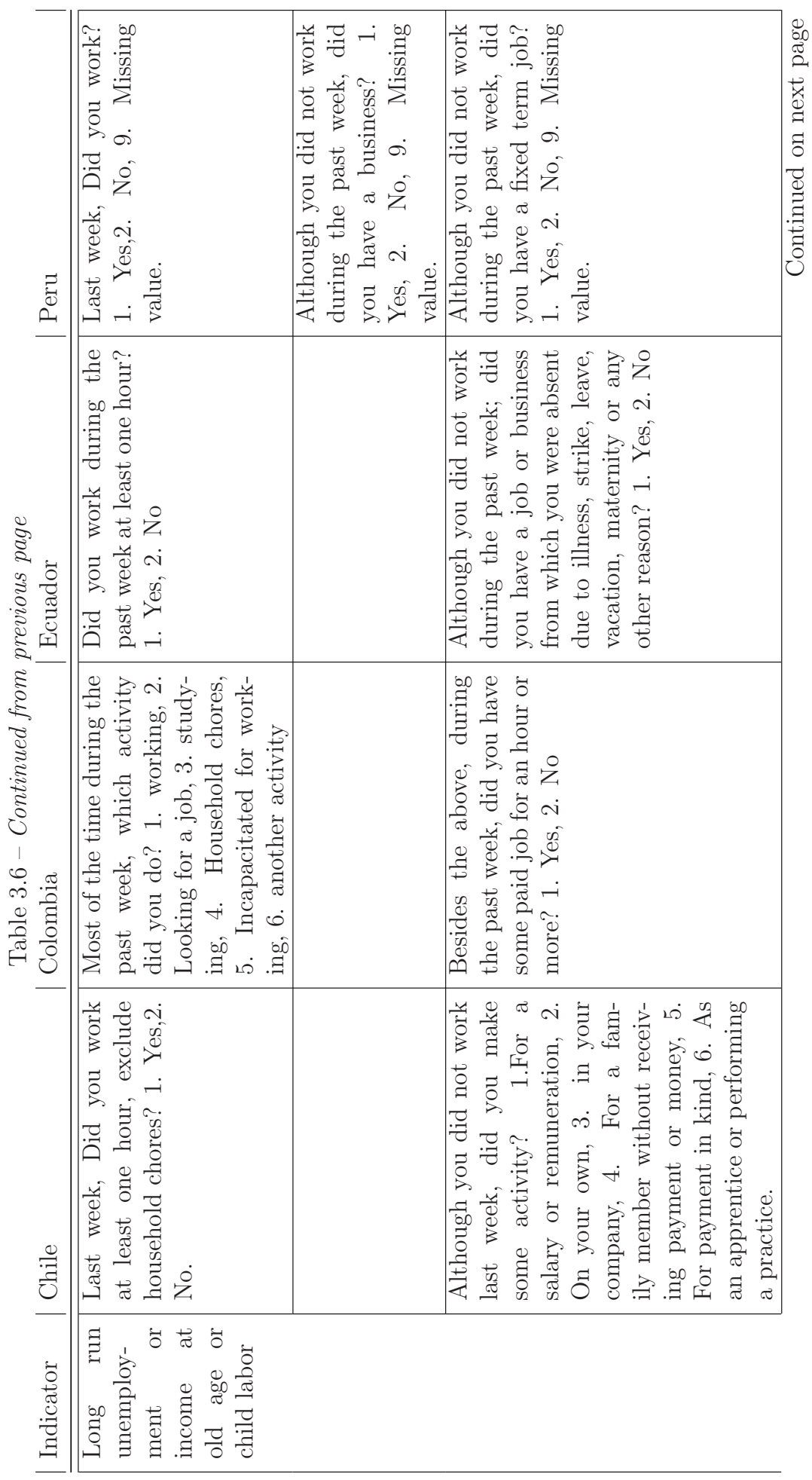




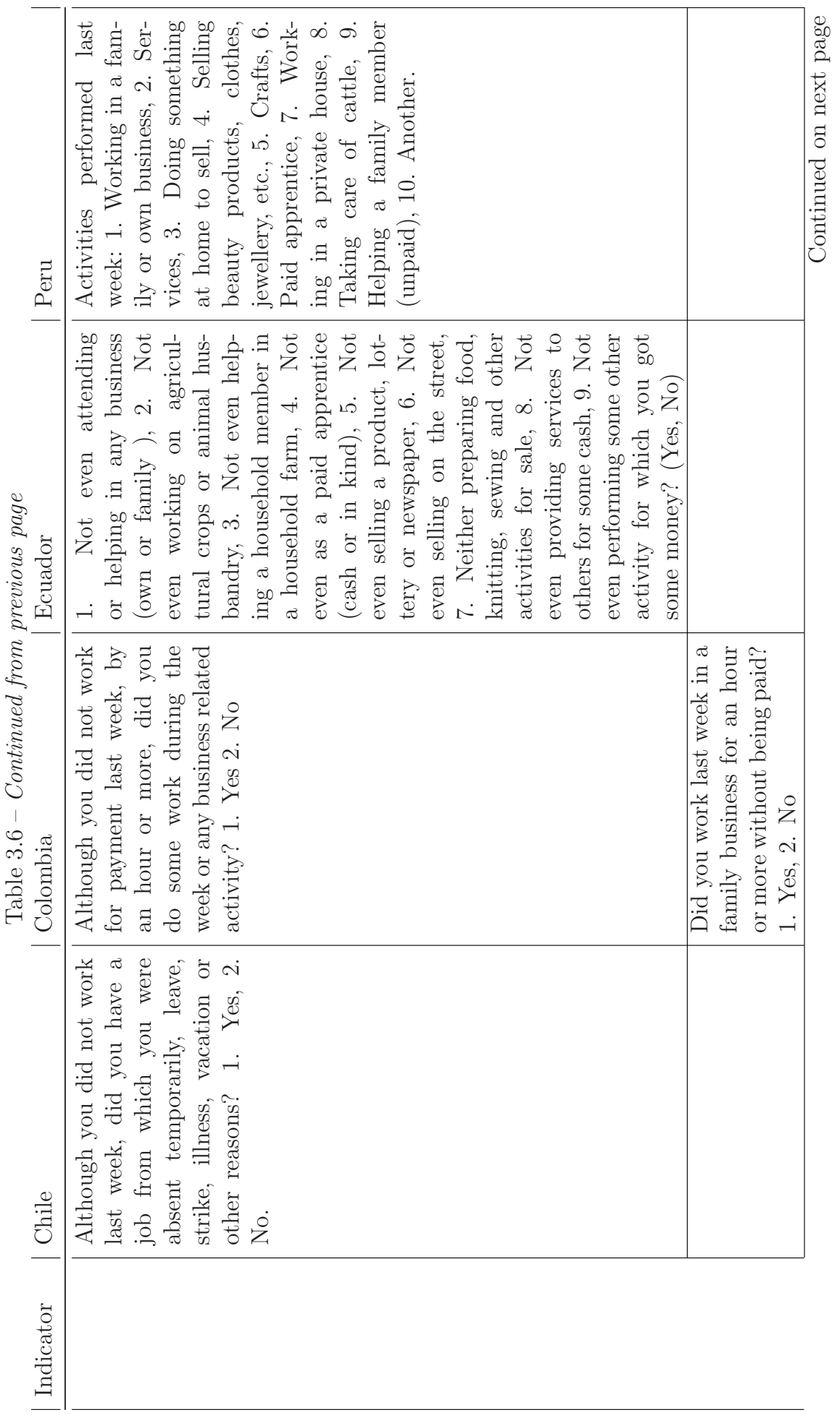




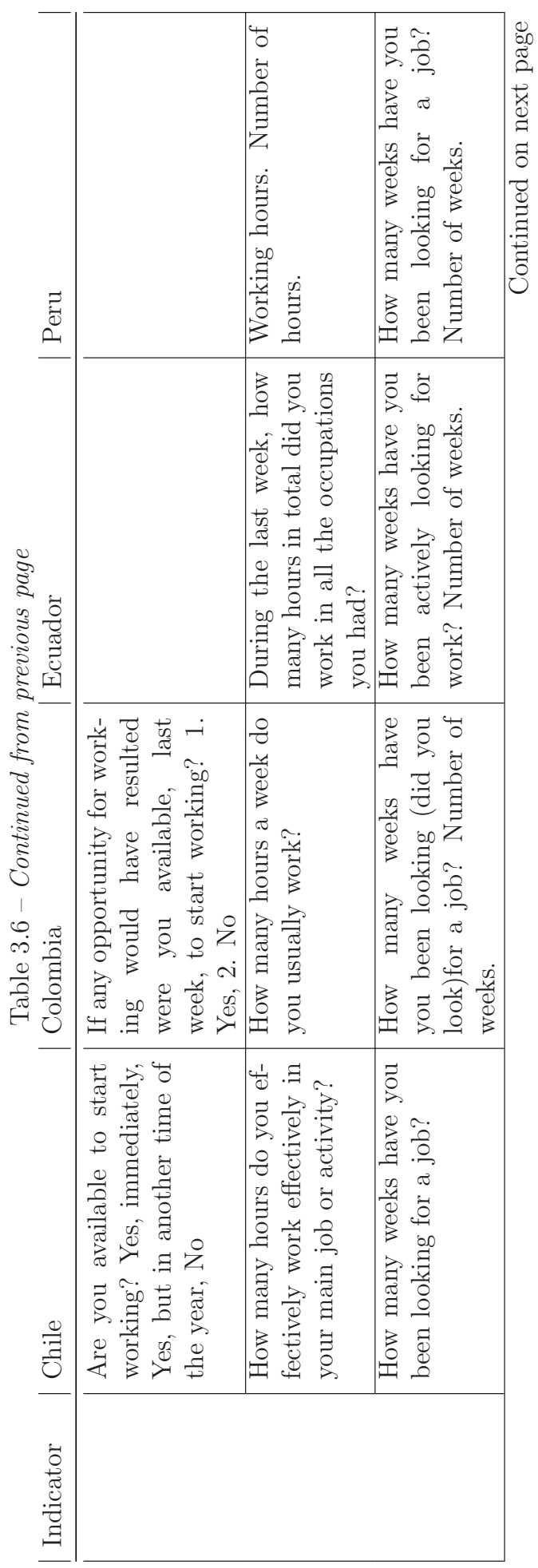




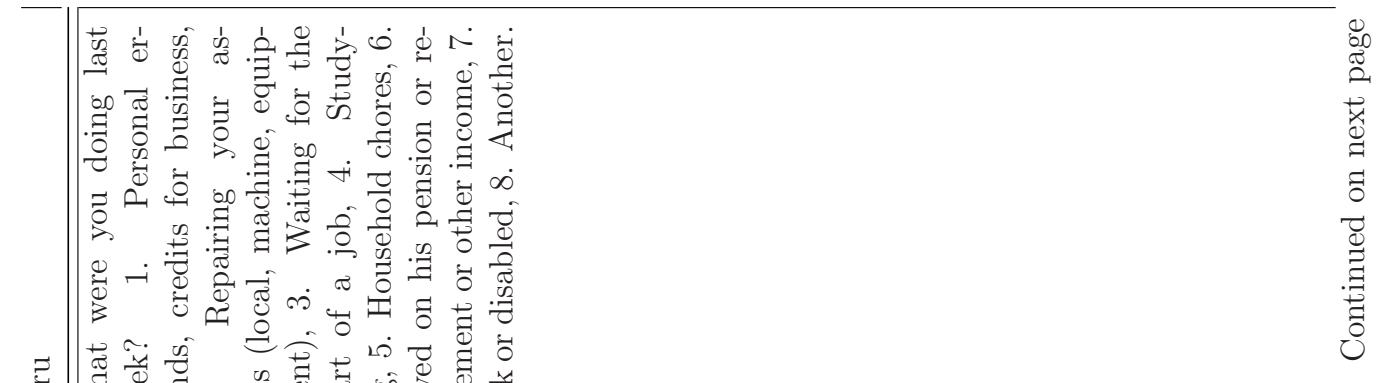




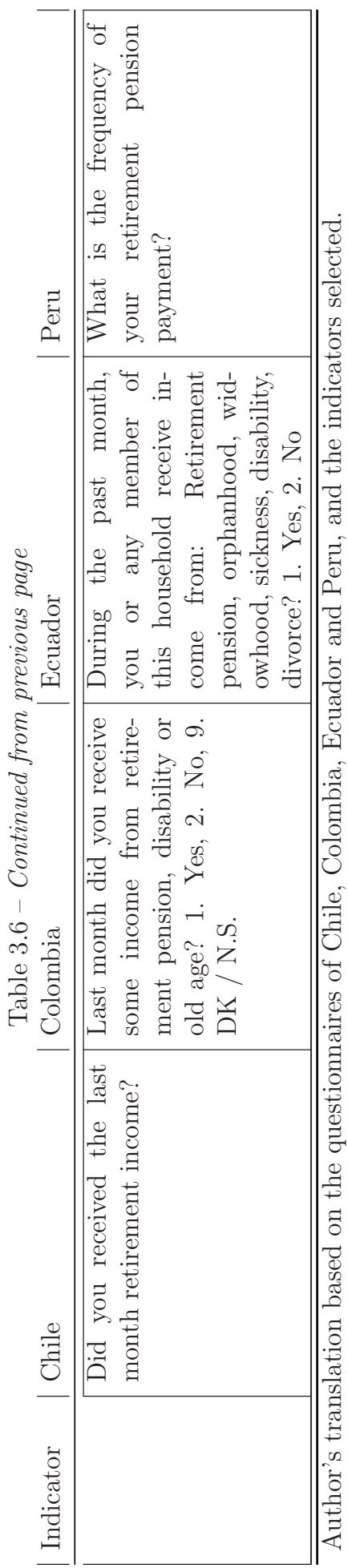




\subsubsection{Indicators Cut-off and particularities of each dataset}

\begin{tabular}{|c|c|c|}
\hline Indicator & Cut-off & Exemptions \\
\hline \multicolumn{3}{|c|}{ Household Level } \\
\hline Dwelling & $\begin{array}{l}\text { The individual does not live in a } \\
\text { house, apartment or room. It in- } \\
\text { cludes options not made for human } \\
\text { habitation }\end{array}$ & None \\
\hline Wall & $\begin{array}{l}\text { Material that is not permanent and } \\
\text { resistant }\end{array}$ & $\begin{array}{l}\text { None although materials differ in } \\
\text { name }\end{array}$ \\
\hline Floor & Earth or sand & None \\
\hline Electricity & Do not have access to electricity & $\begin{array}{l}\text { If access to other types for Peru and } \\
\text { Ecuador (gas, kerosene, among oth- } \\
\text { ers) }\end{array}$ \\
\hline Overcrowdec & $\begin{array}{l}\text { Relation number of persons and num- } \\
\text { ber of sleeping rooms is higher than } 3\end{array}$ & None \\
\hline Sanitation & $\begin{array}{l}\text { Not connected to a pipe or lack of ser- } \\
\text { vice }\end{array}$ & None \\
\hline Water & Main source is not a pipe & $\begin{array}{l}\text { It also includes not bottle water for } \\
\text { Colombia }\end{array}$ \\
\hline Tenure & $\begin{array}{l}\text { Not legal and/or not supported by a } \\
\text { title }\end{array}$ & $\begin{array}{l}\text { The cut-offs includes de facto occupa- } \\
\text { tion and other types of squatters }\end{array}$ \\
\hline
\end{tabular}

\begin{tabular}{ll}
\hline Literacy & $\begin{array}{l}\text { Does not read and write } \\
\text { Early Edu- } \\
\text { cation }\end{array}$ \\
& $\begin{array}{l}\text { The child is not assisting to a program } \\
\text { of early education and the reasons for } \\
\text { not attending are not related to per- } \\
\text { sonal beliefs from parents }\end{array}$ \\
& The reason for not being enrolled \\
& is related to either the service (e.g. \\
& there are not schools nearby) or to \\
& the socio-economic conditions of the \\
& individual (e.g. economic difficulties, \\
& disability)
\end{tabular}

Years of Less than 8 years of schooling Schooling

None

Ecuador and Peru datasets do not provide a reason

None

The deprivation is not stated by the individual but calculated of a combination of the highest education level achieved and the last year approved

Access Individual does not have access to None

to health health insurance

insurance

Effective If the individual that manifests a need access to did not access to professional health health ser- services (excluding cases in which the vices when manifested need was low impact) needed

A combination of three questions was used: need, where did you seek for healthcare? and reasons to not seek for professional healthcare 
Table 3.7 - Continued from previous page

Indicator Cut-off Exemptions

Long run Only applies to unemployed individu- Unemployment is considered a short unemploy- als with three conditions: i) available term effect specially in high informal ment to work, ii) still looking for a job, iii) economies. In order to find the indiduring 24 or more weeks viduals which were deprived the long run unemployment concept was used. The international threshold of one year was modified to 6 months or 24 weeks.

Income Elderly are not receiving any source None

security in of income (pension transfers or labor old age income)

Child Applies to individuals younger than labor $\quad 18$ years old, who are not studying and work a minimum of hours

Every country has a different cutoff which is related to the commitments signed for them with the International Labor Organization Convention's for Minimum Age and Worst Forms of Child labor

Author's elaboration 


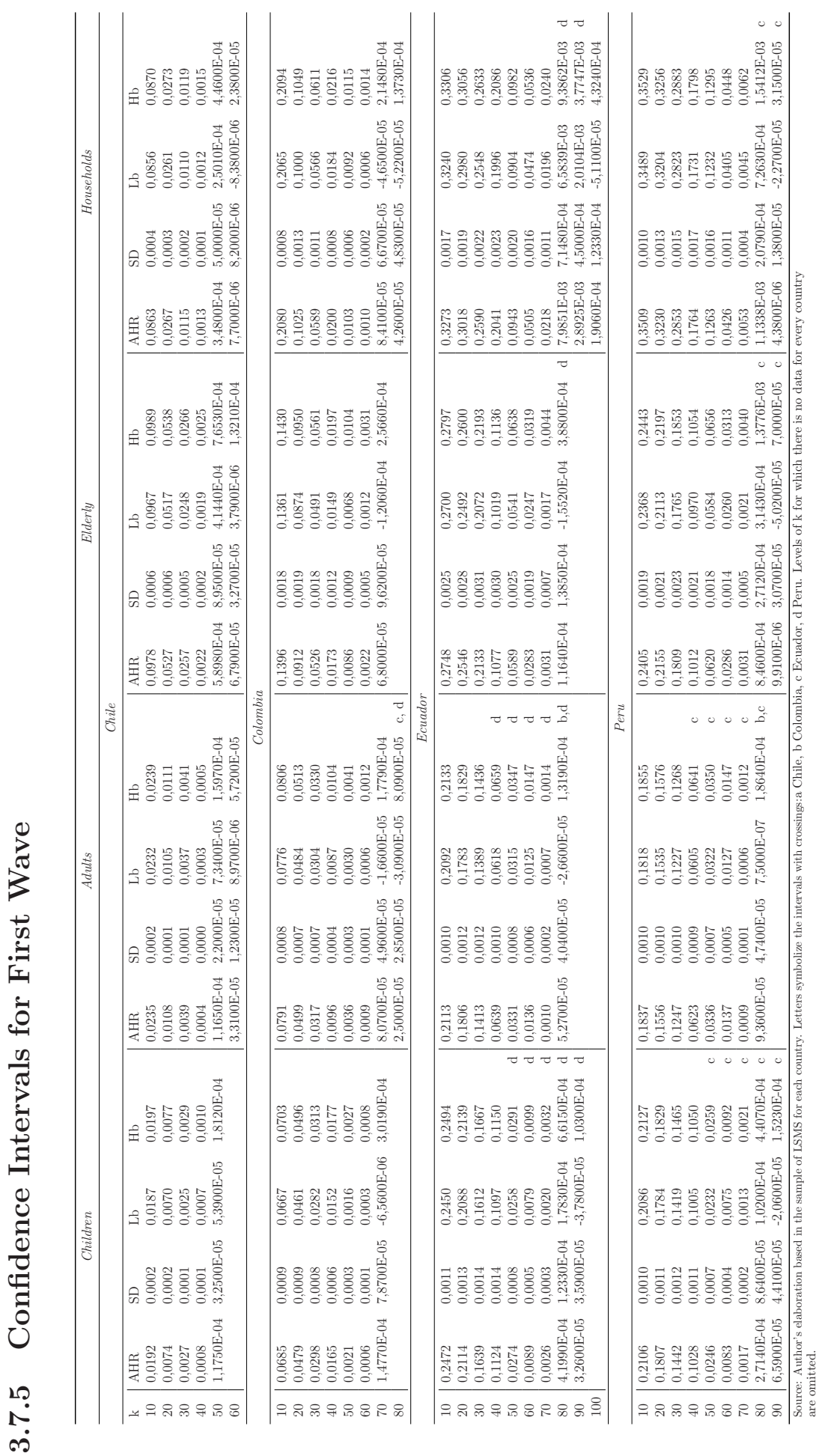




\subsubsection{Effects of the elimination of a controversial indicator: Years of Schooling in Elderly}

By excluding the indicator of years of schooling for elderly, Chile and Colombia are less poor in the final composite index result. Gap differences between both countries are lower, and therefore Colombia is closer to Chile. Ecuador and Peru, are also closer to each other, for levels below $k=50 \%$ Peru is better and for higher levels it is worse. The difference on the one hand, between Ecuador and Peru and on the other between Colombia and Chile is bigger when education for elderly is excluded. In general, it is obvious that excluding this indicator benefits Chile and Ecuador in the ranking, while it is accompanied by other deprivations in the case of Ecuador and Peru. The ranking prevails with or without the particular indicator.

Figure 3.9: Comparison of AHR with and without years of schooling in elderly
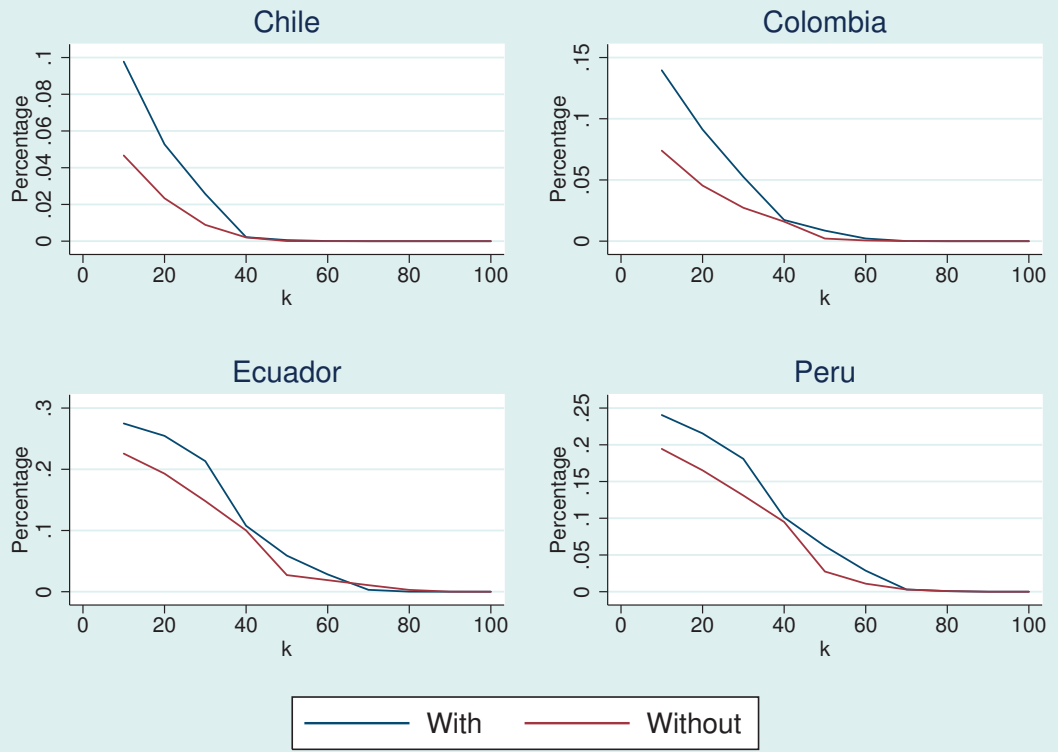

Source: Chilean, Colombian, Ecuadorian and Peruvian LSMS. Author's calculations.

A comparison of variance ratios shows a similar proportion of variance ratio in all the countries for levels of $k=40 \%$ of the indicators (between $87 \%$ and $84 \%$ ). Excluding the indicator increases the variance in the tails of the threshold value for Ecuador and Peru, while it is reduced in Chile and Colombia (excluding the highest level of deprivation possible). Variance ratios show how the variance changes by excluding one indicator, in this case years of schooling. In most of the cases the ratio is lower than one, meaning that the variance without years of schooling is lower. The closer to one the ratio means that the variance is practically unchanged. Only in few cases (Ecuador for levels of $k \leq$ $20 \%$ and Peru for the case of $k=80 \%$ ) the variance increases. 
Table 3.8: Variance Ratio: Excluded over Included

\begin{tabular}{llccc}
\multicolumn{1}{c}{ Chile } & Colombia & Ecuador & Peru \\
\hline $\mathrm{k}$ & \multicolumn{4}{c}{$V_{y \mid x-i} / V_{y}$} \\
\hline 10 & 0.6813 & 0.8611 & 1.006 & 0.9788 \\
20 & 0.5071 & 0.6475 & 1.022 & 0.9385 \\
30 & 0.3776 & 0.5897 & 0.8999 & 0.8622 \\
40 & 0.8526 & 0.8520 & 0.8652 & 0.8749 \\
50 & 0.1229 & 0.2719 & 0.5154 & 0.5019 \\
60 & 0.2868 & 0.2846 & 0.4106 & 0.4171 \\
70 & & 0.9491 & 0.9514 & 0.9592 \\
80 & & & 0.9699 & 1.0215 \\
90 & & & & 0.9861 \\
\hline
\end{tabular}

Source: Author's calculations based on country LSMS. There are no deprived individuals at $k=100 \%$ of the indicators.

In summary, as the ranking is not altered, and due to the intrinsic value of education for elderly, the indicator is included for further applications shown in the following chapters. It is also an indication of the added information obtained whenever the intermediate approach is selected, as union and intersection approaches do not differentiate between individuals. In other words the higher the deprivations, the less important different indicators are. 



\title{
CHAPTER
}

\author{
4
}

\section{FOLDING AND UN-FOLDING MULTIDIMENSIONAL POVERTY INDICATORS: AN ANALYSIS OF SUB-GROUP DECOMPOSITION}

Rankings of multidimensional poverty indicators are being increasingly used in the last years to compare different countries, but few examples decompose the results in regional indices. This chapter uses the subgroup decomposability property of counting methods, and measures regional decompositions in a ranking of individual poverty for Chile, Colombia, Peru and Ecuador, using one particular method, the AF Adjusted Headcount Ratio. By using the individual as unit of analysis and dividing the population in age categories, the chapter introduces the limitations of creating a national ranking for subpopulations with different indicators for comparative purposes. Stochastic dominance conditions of first and second order, as well as Hasse Diagrams are obtained to find out a partial ordering when, all the other parameters stable, a different poverty line is decided. It is particularly interesting to find out that when the poverty cut-off is restricted to a smaller boundary, strong dominance is more commonly found. 


\subsection{Introduction}

Rankings are becoming more and more widespread as a tool for monitoring advances or recessions in different fields. Since the seminal paper of Atkinson (1972), for income poverty measurement, comparisons of distributions have attracted a great deal of attention. According to him, one of the objectives of performing comparisons of distributions of poverty measurement is to obtain an ordering. The measurement of multidimensional poverty has joined those fields interested in creating a ranking of different distributions. There are different methodological applications of the measurement but the most widely used for comparative purposes are the counting methodologies (Atkinson, 2003; Silber and Yalonetzky, 2014).

Counting methods evaluate poverty through the number of people considered poor as explained in Section 2.1.2. Because the counting methods use mostly categorical or dummy variables and several parameters are set normatively, the comparisons of distributions are challenging. Nonetheless, counting methodologies have the advantage of fulfilling basic properties that make comparisons possible, as shown in Appendix 2.5.1. To find differences, to compare or to identify drivers of poverty, decompositions of the measures of poverty is highly useful. Traditionally, static decompositions have been used to find gaps between different groups in the same country. Decompositions are common and classical in the monetary poverty literature but until recently they were not so common in the multidimensional poverty measurement. Beyond pointing out internal differences and patterns within a country, comparative rankings of regions between countries are rarely analyzed. Dispersion and inequalities within countries are neglected whenever national averages are the main focus.

Like in income poverty measurement, judgements about which region or country has a better distribution of wealth can be false, or as pointed out by Foster and Shorrocks (1988, p. 197) "the resulting ranking may be upset by even minor changes in the chosen poverty line". Under a scenario of uncertainty and the need to take a particular decision, normatively or arbitrarily, the use of stochastic dominance techniques becomes an important evaluation tool. Nonetheless, techniques to test the robustness of rankings are not usually shown.

There is a vast literature on decomposing differences of living standards and poverty measurement. ${ }^{1}$ Following Muller (2008), the type of decomposition applied in this chapter is static. $^{2}$ It shows a ranking for 39 regions in the four countries (Chile, Colombia, Ecuador and Peru) built using a counting measure of multidimensional poverty: The Alkire-Foster family of indicators (Alkire and Foster, 2011b), in particular

\footnotetext{
${ }^{1}$ Most of the traditional techniques come from the regression based techniques as the Oaxaca-Blinder decomposition (Blinder (1973); Oaxaca (1973)). Several other authors have worked and expanded the application of these techniques to different types of models. For a concise summary of different techniques as variance decompositions, residual imputation, conditional quantiles see (Fortin et al., 2010). The 'regression based techniques' are directed to find out the contributions of explanatory variables.

${ }^{2}$ The time dimension, dynamic decomposition is analyzed in Chapter 5.
} 
the Adjusted Headcount Ratio or AHR. Regional disparities are supposed to show patterns of poverty that deviate, positively and negatively, from the national average. Because of the existence of a second cut-off or poverty line that can be arbitrarily set, a wide range of options can modify the final ranking (both when comparing regions in an international context or when a national ranking is constructed). Therefore, dominance conditions are presented in this chapter in order to find a range in which less ambiguous results can be obtained, as well as a partial ordering of resulting rankings.

The multidimensional index used in this empirical application is presented in Chapter 3 where population characteristics, country basic information and indicators were described for the national average. Two different techniques will be performed: a stringent and less stringent derivation of first and second order dominance conditions following Yalonetzky (2014) and Gallegos et al. (2015), and a graphic analysis of partial ordering of rankings using Hasse Diagrams Techniques (HDT) following Bruggemann and Carlsen (2006) and Bruggemann and Patil (2012, Ch. 2).

The chapter finds that national averages hide important information for policy making and comparisons between regions of the same country. It is clear that ambiguous rankings are found when all the range of possibilities for the poverty line are included ( $0 \%$ to $100 \%)$. However, a more stable ordering is found for a limited range $(20 \%$ to $40 \%$ for the particular case of the countries in the sample).

The chapter is organized as follows. The second section summarizes the subgroup decomposability and its importance in terms of poverty analysis. The third section shows the results of two decompositions: one decomposition based on the stochastic dominance conditions for counting methods with categorical, ordinal or dummy variables, and the empirical application of second order stochastic dominance conditions. The fourth section presents a graphical representation of ranking orderings using the Hasse Diagram Technique. Finally the concluding remarks are presented at the end.

\subsection{Subgroup decomposition in Multidimensional Poverty Indicators}

Whenever international comparisons of poverty are shown, aggregated figures are the preferred way of communication. For instance, the United Nations stated that: "The world reached the MDG target- of halving the proportion of people living in extreme poverty- five years ahead of the 2015 deadline ... Despite this overall achievement, progress on poverty reduction has been uneven." (UNDP, 2014, p. 9). In this particular case, a global goal was set, and although it was fulfilled, regional and national disparities are preventing the goal to be reached by each country. 
When a country level comparison is performed, without considering the subregional data, a piece of information is lost. Different trends are easy to identify when spatial decompositions are included. Some regions can be consistently behind (or consistently above) the national average. This information is key for public policy interventions within a particular country, as well as for international comparisons. One application for which information from decomposable indicators is desirable concerns the targeting of social policy beneficiaries, in order to efficiently reduce poverty levels, independently of the measurement applied. It is not strange to find that gaps inside a country are as wide or even worse than those found in country level comparisons.

In this sense, the measurement of poverty becomes more and more an issue of inequality. Disparities between regions that show a pattern through time are a proof of serious faults of interventions designed to overcome poverty. Or as Milanovic (2010, p. 115) puts it (he writes in terms of monetary poverty, but his observation is applicable to any type of poverty measurement): "We shall find that there are people who live in poorer countries and who are richer that some people who live in richer countries (which of course is excluded by looking at the averages only)". Social policies interventions relying on simple averages are trying to read through a very limited lens, when a powerful magnifying glass would be preferable and even necessary.

To find those differences at the regional level it is required to use a decomposable measure. Indicators or indices used to measure deprivation poverty must follow a set of standard properties, originally postulated for monetary poverty indicators: symmetry or anonimity, population invariance, scale invariance, normalization, and finally the one that makes differentiation possible, subgroup decomposability. ${ }^{3}$ This axiomatic approach aims to certify the type of information gathered and consistency achieved by a particular method.

Subgroup decomposability states that poverty is "a population share weighted average of subgroup poverty levels" (Alkire and Foster, 2011b, p. 3). In other words, the national average is built taking into account the size of the region, age or other type of subgroups. ${ }^{4}$ Following Foster et al. (1984), if a deprivation vector is broken down in subgroups $\left(y^{1}, \ldots, y^{m}\right)$, where $m$ is the total number of subgroups, $\frac{n_{j}}{n}$ is the population share of subgroup $j$, then it is possible to define a social poverty function $P(y, z)$ (as in Equation 2.6) that depends on different indicators $y$ and different thresholds for each indicator $z$, and:

\footnotetext{
${ }^{3}$ For a wider explanation of the functionalities of each property see: (Bourguignon and Chakravarty, 2003) and (Foster et al., 2013) or refer to Appendix 2.5.1.

${ }^{4}$ The subgroup decomposability that the AF index fulfils is additive. This property is related to the concept of subgroup consistency, defined as: "if poverty falls in one subgroup and is unchanged in another and both have fixed population sizes, then the overall poverty level must likewise fall" (Foster et al., 2013, p. 37).
} 


$$
P_{\alpha}(y ; z)=\sum_{j=1}^{m} \frac{n_{j}}{n} P_{\alpha}\left(y^{j} ; z\right)
$$

Then the counting poverty measure is additively decomposable, and the population share measures the impact of a positive (or negative) shock in the vector of a subgroup on the aggregated result, and therefore disparities are easily identified.

\section{Subgroup decomposability and the second cut-off in the AHR}

In order to find who are the poor and where they are located, spatial decomposition is required. The AHR packs into a single composite index information from several indicators and/or dimensions, and aggregates at a national level. Because the AHR is an additive decomposable measure, unpacking it will restore the lost information about different regional patterns of poverty caused by the process of aggregation. This particular feature of the counting methods has been highlighted as an advantage and also as a drawback of the method. It is an advantage to find out where the poor are located, and what is the contribution of particular regions to the overall poverty. But whenever a composite is used and if unpacking is needed to understand the patterns, what is the need to pack it in the first place? ${ }^{5}$

Moreover, counting methods and the AHR in particular are supported by several normative decisions (e.g. indicators, indicators' thresholds, weights, poverty cut-off and aggregation method) to perform the identification of the poor and the aggregation of the social poverty function. The poverty cut-off or $k$ is one of the arbitrary decisions that has to be taken and plays a central role on multidimensional poverty measurement. First, it is the last step in the identification process. The condition implies that a person is considered deprived if he or she has been identified as deprived in at least $k$ indicators. And second, this is the cut-off that implies multidimensionality and aggregation. Before imposing the condition each individual has a dashboard of indicators. Once the $k$ is imposed, the results are reduced to a simple composite index. Through fixing a particular value the decision maker can opt for an intermediate approach besides the union or intersection, as explained in Section 2.1.2.

The $k$ is defined as a "non-trivial dichotomized identification function that fulfils the poverty consistency property" (Lasso de la Vega, 2010, p. 5-6). In other words, it is dichotomous because it converts the vector of deprivations into an scalar taken from $[0,1]$, in which a person is assigned the value of 1 whenever the counting vector or $c_{i} \geq k$ and the

\footnotetext{
${ }^{5}$ To elaborate on the particular debate of the advantages and disadvantages of composites indices of multidimensional poverty the reader can refer to the special issue of the Journal of Economic Inequality on Multidimensional Poverty Measurement: Vol.9(2) of 2011. A summary of the main arguments is found in Section 2.1.2.
} 
value of 0 otherwise. The decision about the [0 or 1$]$ value assigned only depends on the results of each individual. It is a "poverty consistent" measure because every other person deprived in equal or higher number of dimensions/indicators is also classified as poor.

The decompositions of a multidimensional measure of poverty presented in this chapter, are restricted to analyze ceteris paribus the effect of selecting different poverty cut-offs or $k$ values, ${ }^{6}$ for a ranking constructed with 39 regions in Chile, Colombia, Ecuador and Peru. ${ }^{7}$

\subsection{Stochastic Dominance by region}

Stochastic dominance is used as a tool to order and compare pairs of distributions. If conditions that specify a particular result can vary, as in this case, normative conditions and particularly the $k$ value, then a process of decision making needs to follow. Taking decisions implies, as described in Whitmore and Findlay (1978), that: 1. There are different courses of action, 2. A decision maker has to choose only one course of action, 3. Often consequences are uncertain, and 4. Different outcomes can occur. Under these circumstances, the use of stochastic dominance techniques is helpful and should be mandatory to reduce the uncertainty about the possible and relevant outcomes or to deduct further information from this uncertainty. Stochastic dominance will be used in this chapter as a tool to compare the ranking of two different regions, in order to find if by changing the value of the second cut-off $(k)$ in the AF counting method, then the dominance of one region does persist or not. Dominance conditions can be of different orders: first, second and so on, but this chapter only shows results for the first and second order conditions.

\subsubsection{First Order Dominance Comparisons}

First Order Stochastic Dominance (FSD) conditions imply an 'unanimity result' (Wolfstetter, 1999). Once a FSD has been proven between two distributions on monotonic functions, dominance at all higher orders are fulfilled.

\footnotetext{
${ }^{6}$ This means that the decisions about which indicators to include, their thresholds and weights do not vary. The chapter tries to assess, all else being equal, what are the implications in terms of rankings if and only if the $k$ threshold variates. An analysis of this type over only one source of variation is called a local sensitivity analysis.

${ }^{7}$ The previous chapter proved that when the individual is used as the unit of analysis there is a ranking reversal ordering when different levels of $k$ are selected, especially for the case of elderly and levels higher than $k \geq 50 \%$. In this sense, this chapter elaborates a broader perspective and deeper analysis using decomposition techniques at regional level.
} 
In other words, FSD are stronger when compared to second or higher order stochastic dominance conditions, and therefore: "no alternative specifications can alter the direction of comparison" (Alkire et al., 2015a, p. 79)

Lasso de la Vega (2010), Chakravarty and Zoli (2012) and Yalonetzky (2014), based on first order dominance conditions, derived robustness conditions for a pair-wise comparison on counting methods, when different poverty lines are chosen: 8 "Poverty in $\mathrm{A}$ is never higher than in $\mathrm{B}$ for all multidimensional cut-offs related to the values that $P$ can take, for a given vector of weights and deprivation lines, and for poverty functions that are weakly monotonically increasing with respect to $c$ if and only if the cumulative distribution of deprivation scores in A is never below than in B" (Yalonetzky, 2014, p. 799-800). ${ }^{9} \quad P$ is the particular index of multidimensional poverty used, in the case of this chapter the AHR, $c_{i}$ is the weighted counting vector of dimensions in which a person is considered multidimensionally deprived, and its minimum value $(k)$ a poverty line, following the notation on 2.5.1.

Alkire and Foster (2011b) showed that if dominance conditions are found by performing pair-wise comparisons of headcount ratios $(\mathrm{H})$ among the complete span of $k$, then dominance was also true for AHR. The results presented in this chapter show strong and weak ${ }^{10}$ dominance conditions for the pair-wise comparisons of Headcount Ratios for each population group (see Appendix 4.6.2 and Appendix 4.6.4).

In order to assess the dominance conditions, a comparison of each pair of headcount ratios under each possible $\mathrm{k}$ value by region is performed at $10 \%$ level of significance. ${ }^{11}$ First, as an academic exercise, the complete range of $k$ is selected. Every single possible range of $k$ is included without regards to the suitability and relevance of the results. Row $(\mathrm{R})$ regions are compared with column regions $(\mathrm{C})$, and if the statistic switches sign, no dominance is declared. ${ }^{12}$

\footnotetext{
${ }^{8}$ It is also possible to derive different robustness conditions from other choices of counting methods: different weights, different dimensions, and different functional forms of $\mathrm{P}$. This means that the robustness conditions are not exclusively designed for the AF functional form but for greater and general cases of counting methods. However, this thesis only focuses on the particular application more widespreadly used.

${ }^{9}$ The application that is shown in this chapter is a weakly monotonic decreasing function in the particular case of $c_{i}$ because the higher the levels of deprivations, the lower the number of deprived individuals.

${ }^{10}$ According to Russell (2008): "for strong dominance it is required that the inequality should be strict for at least one value of the argument". In this case, and following the conditions derived by (Davidson and Duclos, 2012), strong dominance requires that it is strict for every argument, and weak dominance that it is strict for at least one argument.

${ }^{11}$ The critical value was selected taking into account that it is a conservative range to compare different z-values.

${ }^{12}$ The fact that a sign switches is an indication of crossing lines of the distributions of headcount ratios of two regions. Whenever the crossing happens, the relations between the two regions become ambiguous to changes on $k$. That is, there is a reversal in the ranking and the robustness condition is violated. Therefore dominance is not established.
} 
Strong dominance is defined as the case in which for every value of $k$, the statistical difference of headcount ratios is significant $(\mathrm{C}+$ or $\mathrm{R}+)$. Weak dominance is defined in the cases in which, under not reversed signs, at least one difference was found to be significant ( $\mathrm{C}$ or $\mathrm{R}$ ). Cases in which it was not possible to find at least weak dominance but the sign prevails, are also identified (C- or R-). The hypothesis tested for each pair-wise comparison is shown in Equation $4.2^{13}$.

$$
\begin{aligned}
& H_{0}: \mu_{A}=\mu_{B} \\
& H_{a}: \mu_{A}<\mu_{B}
\end{aligned}
$$

An analysis of these strict dominant comparisons for the case of the complete range of $k$, was performed for each age group. Regional comparisons for elderly show a smaller level of strong dominance ( $16.33 \%$ of the pair-wise comparisons) when compared to the other age groups (adults $37.65 \%$ and children $28.07 \%$ ), as well as weak dominance (at least one is significant above or below in $36.57 \%$ of the possible comparisons). In the case of children, Santiago shows a clear pattern of dominance over most of the regions within Chile, and most of the regions of the other countries. The exemption is Bogota for which there is not a dominance.

For all the age groups, all the regions of Chile dominate (either strongly or weakly) two regions in Colombia (Atlantica, and Pacifica), four in Ecuador (Guayaquil, Sierra, Costa and Amazonia), and all the regions in Peru. For children, Chile strongly dominates Guayaquil in Ecuador, and for adults Pacifica in Colombia and Machala and Sierra in Ecuador. For elderly there is not strong dominance. By regions, Magallanes in Chile shows the most consistent dominance over the other regions, in all the age groups, except when compared to Santiago and Bogota. The capital of Colombia, Bogotá, dominates, at least weakly, every region in Ecuador and Peru, as well as within the country.

As mentioned by Yalonetzky (2014) and Lasso de la Vega (2010) the stricter the conditions imposed in the comparisons the less robust a counting measure of poverty is. Asking for dominance over a wider range of $k$ is neglecting that: i) there are some values that are irrelevant or ii) that "poverty comparisons are ambiguous" in nature (Foster and Shorrocks, 1988, p. 197). In the same sense, "if only a single outcome state can possibly prevail, the consequence of the decision problem is completely determined by the course of action selected" (Whitmore and Findlay, 1978, p. 6) and therefore testing different normative choices becomes unnecessary.

Because of the arguments of relevance and the possibility of different outcomes, it makes sense to restrict the range of $k$ to a non-redundant boundary. This decision also needs to be based on the particular objective of the measure. In this chapter, the objective is to achieve regional comparability. It is also possible that the neglected range is important to analyze when for instance, the measurement is used for targeting social programs under limited budget (an argument to include the upper range of $k$ ). Therefore the size

\footnotetext{
${ }^{13}$ Where $\mu_{X}$ is in the case of First Order Stochastic Dominance Conditions is the Headcount ratio of the AHR
} 
of the range of $k$ is also a normative decision that should be made explicit. The higher the number of indicators in which a person is considered deprived the less frequency is found (weak monotonicity).

However, it is possible to reduce the range only in the lower level of $\mathrm{k}$, as reducing it on the higher range will affect the comparison of the test. In the upper boundary the comparisons can be defined to be statistically significant or not, but in stricter sense it is not a stochastic dominance condition, which is the case in this chapter. In the sample considered in this chapter, none of the regions reports population deprived in every indicator (for every age group) or $k=100 \%$. In this case event though comparisons are not longer interesting when a higher number of regions does not report any deprived population, if some regions still show deprivations numbers it is not possible to define stochastic dominance conditions for the upper boundary. On the other side, the closer the $k$ to the union approach $(k=10 \%)$ the more people are considered deprived, and the ability to discriminate is no longer possible. In other terms, when measuring multidimensional poverty as mentioned by Alkire and Santos (2010, p. 60), considering the union approach could mean that one indicator is being considered as a proxy for multidimensional poverty and therefore the multidimensionality is no longer necessary. Another argument, against the selection of the union approach comes from analyzing the data. Pair-wise comparisons showed that the switch in the sign is more prevalent when including $k=10 \% .^{14}$

Accordingly, the range of $k$ values is limited between $20 \%$ and $100 \%$, whenever there is data to compare. This chapter proves that strong dominant conditions are more evident (see Annex 4.6.4) after censoring the range. In the case of children, almost $30 \%$ of the 741 possible comparisons are strongly dominant, in adults, $38.73 \%$ and in elderly, $16.6 \%$. All the regions of Chile dominate (strongly or weakly) most of the regions in Ecuador and Peru. Magallanes and Santiago, in Chile dominate the sample of other regions, excluding Bogotá. Sierra Norte in Peru is the region that is most dominated in the sample. There is not any clear dominance pattern within the regions of Ecuador.

The decision about which value of the poverty cut-off to select when several dimensions are included in a measure of counting poverty is in any case a normative decision with implications on the results. Different values will lead to ambiguous results when compared to each other. In this case the utility of running dominance conditions over a narrower range of values of $k$ will provide further information to select a less ambiguous account of multidimensional poverty.

\footnotetext{
${ }^{14}$ In a similar way, the decision about including the minimum threshold of $k$ could be important to analyze for instance, when the framework of the measure is the rights-based approach. Deprivation in only one indicator can be translated as a violation of a basic right.
} 


\subsubsection{Second Order Dominance Conditions}

As mentioned by Russell (2008): "higher order dominance criteria put more and more weight on the welfare of the poorest members of the society". The Second Order Dominance Conditions (SODC) although less powerful than the first one, could complement the information gathered in the previous section, for the cases in which dominance could not be proven. It is therefore necessary to check the Second Order Stochastic Dominance Condition. Following a tradition on income poverty measurement (Atkinson, 1972, p. 247), if the comparison of Lorenz Curves of two different distributions are consistently above (or below) of each other, that is if the distributions do not cross, then an ordering between them can be established. Gallegos et al. (2015, p. 6) introduced the formal representation of SODC for the case of comparisons through time on counting methods, using reverse generalized Lorenz curves. The authors prove that the AHR is nothing more than the reversed generalized Lorenz Curve:

$$
L(s)=\frac{1}{N} \sum_{n=1}^{s N} c_{n} \quad \text { for a } \quad k=s
$$

Lower order of stochastic dominance implies higher order dominance conditions but not the opposite. Distributions that are found to fulfil second order dominance do not necessary fulfil first order dominance. Again two different ranges are used to calculate the dominance conditions. First, second order dominance is calculated for pair-wise comparisons of 39 regions over the complete range of $k \in[0 \%, 100 \%]$. Second, the range was restricted following the same logic used in the previous section to $k \in[10 \%, 100 \%]$.

Results show there are less strictly dominant comparisons, than when FODC are calculated, and there is a slight difference when reducing the range of $k$ Children $(28.07 \%$ to $22.4 \%$ ), Adults (37.65\% and $21.46 \%$ ) and Elderly (16.33\% and $14.48 \%$ ). However, there are more second order weak dominance comparisons than first order weak dominance comparisons, especially on the restricted case, for children and adults. The previous result is expected as the comparisons are made over the AHR instead of the Headcount Ratio, and therefore a higher variability is expected. Using the remark 1 on Gallegos et al. (2015, p. 8), as summarized below on Equation 4.4, one can imply that, if at least one Headcount $(\mathrm{H})$ in region $\mathrm{A}$ is significantly smaller than in region $\mathrm{B}$ over a range of $k$ then the condition over the comparisons of AHR is also accomplished:

$$
\begin{gathered}
\text { If } H^{A}(k) \leq H^{B}(k) \forall k \in[0,1] \wedge \exists k \mid H^{A}(k)<H^{B}(k) \\
\text { then } \quad M^{A}(k) \leq M^{B}(k) \forall k \in\left[0, v_{2}, \ldots, 1\right] \wedge \exists k \mid M^{A}(k)<M^{B}(k)
\end{gathered}
$$


Nonetheless, a testing over the sign of the $z$ statistic over the range of $k$ was conducted to check that without considering the size of the errors that affect the significance, the trend found was consistent.

\subsubsection{Contributions of regions and indicators}

Another important piece of information that can be extracted from an additively decomposable measure of multidimensional poverty is the contribution of each region to the overall score of a country and the contributions of each indicator to the results per region. In this section, a simple report of contributions is presented to complement the ranking analysis. As an illustration, contributions to the overall national indicator are calculated for only one value of $k(30 \%)$. A report of the contributions per region and for each age group is shown in Appendix 4.6.3. Magallanes (12) in Chile, San Andrés (23) in Colombia and Costa Sur (34) in Peru are the regions which contribute less to the national average of multidimensional poverty for every age group. For the case of Ecuador different patterns by age group are shown, Cuenca (27) is the region which contributes less in the case of children and adults, while Machala (28) does it for elderly. The regions which contribute most to the final national average are Atlántica (16) in Colombia and Costa (30) in Ecuador, for every age group. In the case of Peru, Selva (38) contributes more for children and adults, and Sierra Sur (37) for elderly. Valparaiso (5) in Chile is the highest contributor for children, La Araucanía (9) in the case of adults and Bio Bio (8) for elderly ${ }^{15}$.

With regards to the contributions of particular indicators to each region, sanitation is either the highest or the second contributor for every region in the case of children. In the case of adults, sanitation is still very important but not for every country. In the case of Colombia, the highest contributor is years of schooling, and in the case of Ecuador it is the lack of health insurance. For elderly, years of schooling is the highest contributor for every region.

\subsection{Hasse diagram and ranking orderings}

From the previous results, it is easy to deduct that under different values of $k$ the position of a particular region in a ranking will not prevail. Moreover, taking into consideration that the situation of the three age groups is clearly different for each region, it is still possible to map the ordering of a ranking, for which a partial order is expected. In this sense, and depending on the objective of the measure constructed, a more usual comparison can be performed only to analyze poverty within different regions of a country.

\footnotetext{
${ }^{15}$ Regions have been numbered from 1 to 39 , for an easier representation. Regions of Chile from 1 to 15, Colombia from 16 to 24, Ecuador from 25 to 31 and Peru from 32 to 39
} 
This section provides the results and methodology to perform ranking orderings for regional decompositions for different age groups, and compares them with the aggregation by country, using the Hasse Diagram Technique (HDT). The idea is to try to identify a pattern of multidimensional poverty ranking for the regions in each country when the whole range of $k$ and its restricted version are considered. The HDT is mainly a graphic tool to analyze the ordering of a ranking.

Hasse diagrams are widely used in natural sciences. Recently their application has expanded to test the ordering of rankings to find "a system of comparabilities and incomparabilities among their elements and to determine how different selection criteria will influence the behavior of a particular object in the ranking" (Bruggemann and Carlsen, 2006, p. 62). Applications to poverty measurement have been done by Reedy et al. (2006) using a limited definition of capabilities (ability to be adequately nourished) and Annoni et al. (2015) for fuzzy sets identification.

The hypothesis behind this is that even in situations in which there are ambiguous results, some order is preserved. What's more, the literature on partial orders states that by simplifying the range of possibilities, for instance by choosing a linear order much of the information is lost. In this sense, ambiguity is not perceived as a negative characteristic but as a source of additional information. In the following paragraphs the method and the jargon of this technique an its simile in counting methods is introduced.

The HDT requires the identifications of the main components. A first step is to identify the object space or $(X)$ in which the vector of $\mathrm{X}$ will measure the multidimensional poverty for each region. In the case presented in this chapter the space is defined by the number of regions $(n)$ in each country $(c)$ :

$$
X_{c}=1,2, \ldots, n
$$

There is also a measurement space $(\mathrm{Q})$, in which the multidimensional poverty for every element on $\mathrm{X}$ is calculated. For this an Information Base or (IB) is needed to identify the set of attributes used in the measurement space. The measurement space is the multidimensional poverty index and the information base is the range of different levels of $k \in[0,1]{ }^{16}$ If we have two different regions $\mathrm{x}$ and $\mathrm{y}$ in our order set $(\mathrm{X})$, and the results of their transformations are $\mathrm{q}(\mathrm{x})$ and $\mathrm{q}(\mathrm{y})$ respectively:

$$
x \leq y, \text { iif } q(x) \leq q(y), \quad q(x) \leq q(y), \quad \text { iif } q_{k}(x) \leq q_{k}(y), \quad \forall k \in I B
$$

\footnotetext{
${ }^{16} k$ is expressed as a percentage of indicators in which a person is considered multidimensionally deprived.
} 
In other words, and similar to the logic followed by Yalonetzky (2014) not using hypothesis testing but the final ranking position, a region is consistently richer if the resulting position on a ranking of multidimensional poverty is consistently lower than that in another region. Then if the condition is stable, comparable $(x \perp y)$ relations are determined, otherwise the relation is considered incomparable $(x \| y)$. If $x \perp y$ then a line is drawn between the pair of elements. If the relation is $x \leq y$ then $x$ is positioned in a higher position than $y .{ }^{17}$ Relations between sub-sets of elements $(x \perp y$, and $y \perp z)$ of an object $(\mathrm{X})$ are called chains, if the objects are considered incomparable $(x \| y)$ then it is called an anti-chain. Chains and anti-chains are helpful to identify the number of levels in the relations ${ }^{18}$ among elements in an object (X) and how chaotic or simple the pattern is. Not every relation is drawn due to the transitivity principle:

$$
x \leq y, y \leq z \text { then } x \leq z \text { is excluded }
$$

In this chapter, if there is an element that is not covered by any other element of $\mathrm{X}$, then it is called a 'maximal', and it corresponds to the least poor region. If an element is not covered by any other element of X, it is called 'minimal' and it corresponds to the poorest region. A graphic example to understand Hasse Diagrams is shown in Figure 4.1. In this case, seven (A-G) subgroups are ordered in a multidimensional ranking. The richest subgroup is found at the top of the graph $(\mathrm{G})$ and constitutes a maximal, and the poorest region is found at the bottom of the graph (A) and it is a minimal. Regions $\mathrm{B}$ and $\mathrm{C}$ are incomparable, therefore they occupy the second level (from bottom to top), an so do regions D, E and F. They are the two anti-chains because between them they are incomparable. There are three chains, and an ordering is found from bottom to top in the following cases: (A, B, D, G), (A, B, E, G) and (A, C, F, G).

Figure 4.1: Hasse Diagrams- Example

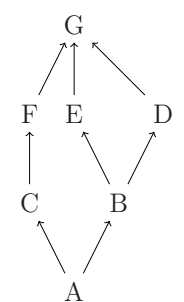

Source: Author's elaboration

Hasse diagrams for Chile (Annex 4.6.5), Colombia (Annex 4.6.5), Ecuador (Annex 4.6.5) and Peru (Annex 4.6.5) are presented by age group with a restricted and unrestricted range of $k$. By far, the Chilean case is the most chaotic one. Only in the case of adults (both restricted and unrestricted ( $k$ Annex 4.6.5 (c) and $(d)$ ), there is a greatest element (region 12 or Magallanes y de la Antártida Chilena). Between 5 and 8 levels of relations

\footnotetext{
${ }^{17}$ Usually the interpretation requires to be positioned in a lower level from bottom to top, but because the richer regions are dominant and ranked on top, the analysis is inverted.

${ }^{18}$ levels are read from bottom to top
} 
are found (with a restricted value of $k$ more levels are identified) and although clear covered relations are also found there are many more incomparable relations (with special attention to the length of the anti-chain for adults in level 3 for both restricted and unrestricted cases). It is also clear that the prevalent minimal for each age group is La Araucanía (9). The ambiguous pattern is reproduced when a composite index of the national level is used, although some nodes are easily identified: Tarapacá (1), Valparaíso (5) and Aysén del General Carlos Ibañez del Campo (11). The maximum and minimum regions are the same but the order is also alterable by the proportion of people in each group, as for instance the level of Valparaíso (5) in the diagram by group as compared with the national aggregation.

In the case of Colombia (Annex 4.6.5) a less chaotic picture is found. There is for each group and the national aggregation a clear greatest element (Bogotá, 20). The levels of poverty in Bogotá, as confirmed by the analysis performed in the previous section are clearly most of the time above the rest of the regions in every country. For the unrestricted children, elderly and the national aggregate the graphic pattern is kite shaped. For adults a less clear pattern is found, and therefore less levels are identified. Nonetheless, it is clear that some regions are always in the minimal position (Atlántica -16 and Pacífica-19).

A more symmetric pattern is depicted in the case of Ecuador (Annex 4.6.5). Not only for a more hierarchical behavior but also for a lower number of regions as compared with Chile. The pattern of children and adults is very similar, and therefore replicated in the final aggregation. It is clear that the minimal position is taken by the Amazonía (31). Anti-chains for all the cases are of a maximum length of 2 elements and between 4 and 5 levels are easily identified. A dual behavior of chains is evident for the cases of children, adults and the final aggregation. Quito (25), the capital of the country is consistently better off than the rest of the country (in fact it is the greatest element for elderly and the national aggregate), shared with Cuenca (27). When a restriction in the range of $k$ is shown, a more linear pattern is evident, and the aggregate case replicates the same order as the order for elderly population.

Finally, the results for Peru are presented in Annex 4.6.5. An intermediate case is portrayed in the figures unrestricted. For elderly, adults and the final national aggregation, Costa Centro (39) and Lima (39) are the maximal elements of the chains. In the case of children, the less poor regions are Lima (39) and Costa Sur (34). The minimal element is consistent among the three age groups, with Selva (38) as the lowest element for adults and a minimal shared with Sierra Norte (35) replicated as well on the national aggregated level. Between 4 and 5 levels are found and the maximum anti-chain is of length 3 (adults level 2). When the ordering is graphed with a restricted range of $k$ a linearisation of the partial order is clear. For instance, in the case of elderly there is a non-ambiguous order. 


\subsection{Conclusions}

Rankings in general are extremely sensitive to small changes in the parameters of the model they are based on. In order to find out where and who the poor are decompositions are needed. Information that is lost during the process of creating the index can be extracted. Regional differences are important to analyze in order to use the index as a public policy tool. For instance, a benchmark to adopt a particular normative decision can be found.

Through the use of HDT and first and second order dominance, this chapter compares 39 regions in four countries, following the same index presented in previous chapters (same countries, individual as a unit of analysis and 3 age groups). The chapter has shown that not only the figures of multidimensional poverty at the national level but also the patterns of ordering among the different age groups are consistently different. First order conditions are scarcely found in the literature to prove stability of rankings and to support normative decisions. Recently, second order dominance conditions have been found useful for the case of the AHR (Gallegos et al., 2015), and therefore they are still not widely used. Hasse Diagram Techniques are applied for other composite indicators but to the knowledge of the author they have not been applied to the AHR yet. They have been applied to the capabilities framework in the case of Reedy et al. (2006) and in multidimensional material deprivation using the fuzzy set approach as shown in Fattore et al. (2011) and Annoni et al. (2015). The combination of the three techniques gives a pattern by using different approaches to the same problem, confirming that a non-redundant boundary for the decision can be found, and finally giving some support for opting for a single choice.

Disparities within and between countries are easily identified and by reducing the range of the poverty line from the entire space to a range between $20 \%$ and $100 \%$ of the indicators a partial ordering is more evident. In some cases, the regions that come out as the poorest ones are not considered poorest when individual level indices are calculated. This proves the importance of constructing indicators using the individual as unit of analysis and trying thereby to obtain a broader picture about the state of poverty for each age group. In the case of first and second order dominance conditions, pair-wise comparisons are more often found for adults than for the other groups, for both restricted and unrestricted range of $k$. Elderly is the group for which less dominance is found, showing less inequality between the regions. It is not surprising that for this group the level of deprivations is higher. Most of the regions of Chile dominate most of the regions of the other countries (Colombia, Ecuador and Peru). Bogotá, the capital city of Colombia, and Santiago the capital city of Chile are the most dominant regions over the whole sample. In Ecuador and Peru, there is no clear region that dominates the rest of the country. It depends on the age group and the restriction. In Chile, Magallanes and Santiago are the most dominant regions, as expected. 
Finding a clear ordering within Chile is extremely challenging. Taking conclusions from the results on first and second order of dominance and the Hasse Diagrams, Chile presents an erratic pattern. There are three regions that are consistently dominant and one clearly being dominated by the rest (La Araucanía). Colombia, Ecuador and Peru show a more hierarchical behavior. Peru exhibits a perfect and stable partial order.

By performing robustness testing and by finding dominance conditions to a range of normative choices decision makers are provided with information and knowledge about the distribution of multidimensional poverty and transparency about the results found. Unfortunately there are few examples in which these tests are performed, and the results in this chapter are considered more of an exception to that rule. The results give an idea about the sensitivity of the measures to particular choices, and as a general contribution this chapter proves that it is a mistake to think that a full ordering is possible to achieve. However, as stochastic dominance has shown for decades, information about the uncertainty obtained is also valuable information, especially for policy making and comparisons of results in different contexts.

It would be advisable that whenever multidimensional poverty is constructed as an index, and when normative conditions are an important part of the results, sensitivity analysis, stochastic dominance techniques and robustness tests should be part of the information presented by policy-makers. They could benefit from the application of stochastic dominance techniques and the recent developments on counting methods for multidimensional poverty measurement. 


\subsection{Appendix}

\subsubsection{List of regions}

Table 4.1: $\quad$ Sample size by region and age group

\begin{tabular}{|c|c|c|c|c|c|c|c|}
\hline \multicolumn{8}{|c|}{ Basics } \\
\hline Country & Number & ID & Region & Children & Adults & Elderly & Total \\
\hline \multirow[t]{15}{*}{ Chile } & 1 & 1 & Tarapacá & 1.421 & 2.359 & 657 & 4.437 \\
\hline & 2 & 2 & Antofagasta & 2.344 & 4.067 & 904 & 7.315 \\
\hline & 3 & 3 & Atacama & 1.786 & 3.137 & 682 & 5.605 \\
\hline & 4 & 4 & Coquimbo & 2.842 & 6.026 & 1.970 & 10.838 \\
\hline & 5 & 5 & Valparaiso & 7.063 & 15.295 & 4.848 & 27.206 \\
\hline & 6 & 6 & Libertador Bernardo O'higgins & 5.763 & 12.802 & 3.961 & 22.526 \\
\hline & 7 & 7 & Maule & 5.701 & 12.556 & 3.813 & 22.070 \\
\hline & 8 & 8 & Bio Bio & 10.909 & 23.254 & 7.036 & 41.199 \\
\hline & 9 & 9 & La Araucania & 5.885 & 11.401 & 3.977 & 21.263 \\
\hline & 10 & 10 & Los Lagos & 5.139 & 10.169 & 3.064 & 18.372 \\
\hline & 11 & 11 & $\begin{array}{l}\text { Aysén del General Carlos Ibañez del } \\
\text { Campo }\end{array}$ & 970 & 1.897 & 529 & 3.396 \\
\hline & 12 & 12 & Magallanes y de la Antártica Chilena & 572 & 1.241 & 359 & 2.172 \\
\hline & 13 & 13 & Santiago Metropolitana & 13.129 & 28.794 & 7.783 & 49.706 \\
\hline & 14 & 14 & Los Ríos & 2.341 & 4.482 & 1.485 & 8.308 \\
\hline & 15 & 15 & Arica y Paranicota & 738 & 1.339 & 434 & 2.511 \\
\hline \multirow[t]{9}{*}{ Colombia } & 1 & 16 & Atlántica & 3.354 & 4.158 & 719 & 8.231 \\
\hline & 2 & 17 & Oriental & 2.458 & 3.625 & 846 & 6.929 \\
\hline & 3 & 18 & Central & 2.562 & 3.806 & 924 & 7.292 \\
\hline & 4 & 19 & Pacífica & 3.024 & 4.246 & 854 & 8.124 \\
\hline & 5 & 20 & Bogotá & 1.181 & 2.425 & 397 & 4.003 \\
\hline & 6 & 21 & Antioquia & 2.659 & 3.913 & 770 & 7.342 \\
\hline & 7 & 22 & Valle & 2.163 & 4.046 & 876 & 7.085 \\
\hline & 8 & 23 & San Andrés y Providencia & 648 & 1.303 & 161 & 2.112 \\
\hline & 9 & 24 & Orinoquía y Amazonía & 910 & 1.249 & 176 & 2.335 \\
\hline \multirow[t]{7}{*}{ Ecuador } & 1 & 25 & Quito & 1.097 & 1.815 & 270 & 3.182 \\
\hline & 2 & 26 & Guayaquil & 1.750 & 2.595 & 394 & 4.739 \\
\hline & 3 & 27 & Cuenca & 713 & 1.092 & 176 & 1.981 \\
\hline & 4 & 28 & Machala & 732 & 983 & 133 & 1.848 \\
\hline & 5 & 29 & Sierra & 10.202 & 11.326 & 2.653 & 24.181 \\
\hline & 6 & 30 & Costa & 6.494 & 7.481 & 1.253 & 15.228 \\
\hline & 7 & 31 & Amazonía & 2.209 & 2.026 & 272 & 4.507 \\
\hline \multirow[t]{8}{*}{ Peru } & 1 & 32 & Costa norte & 4.096 & 6.420 & 1.263 & 11.779 \\
\hline & 2 & 33 & Costa centro & 1.880 & 3.303 & 838 & 6.021 \\
\hline & 3 & 34 & Costa sur & 1.324 & 2.470 & 429 & 4.223 \\
\hline & 4 & 35 & Sierra norte & 2.447 & 2.833 & 698 & 5.978 \\
\hline & 5 & 36 & Sierra centro & 6.693 & 8.022 & 2.151 & 16.866 \\
\hline & 6 & 37 & Sierra sur & 4.214 & 5.977 & 1.658 & 11.849 \\
\hline & 7 & 38 & Selva & 8.325 & 10.112 & 1.560 & 19.997 \\
\hline & 8 & 39 & Lima metropolitana & 3.172 & 5.992 & 1.170 & 10.334 \\
\hline
\end{tabular}

Source:Statistical Offices Official Manuals: Chile; Ministerio de Desarrollo Social, Colombia:

DANE, Ecuador: INEC, Peru: INEI 


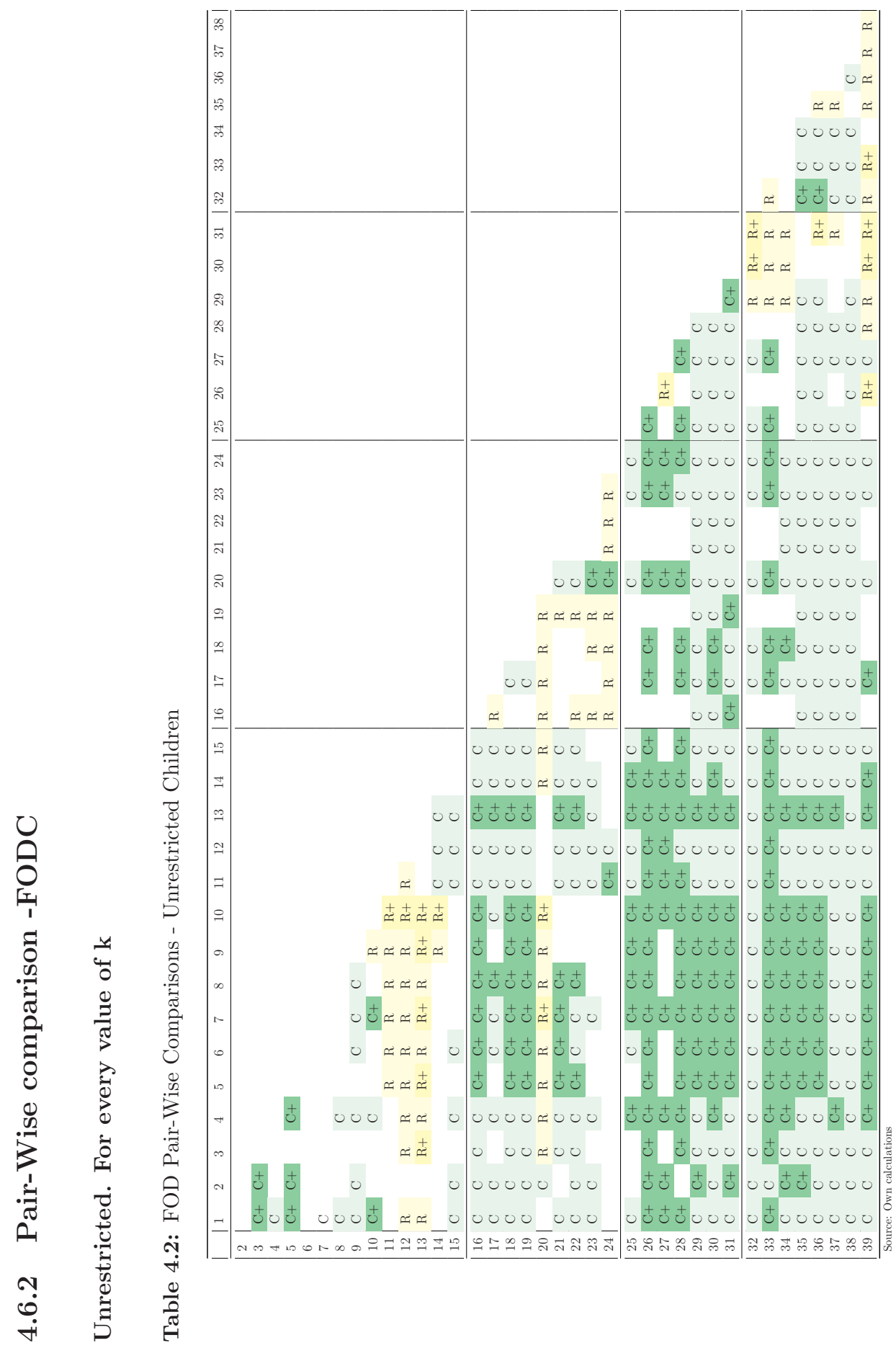




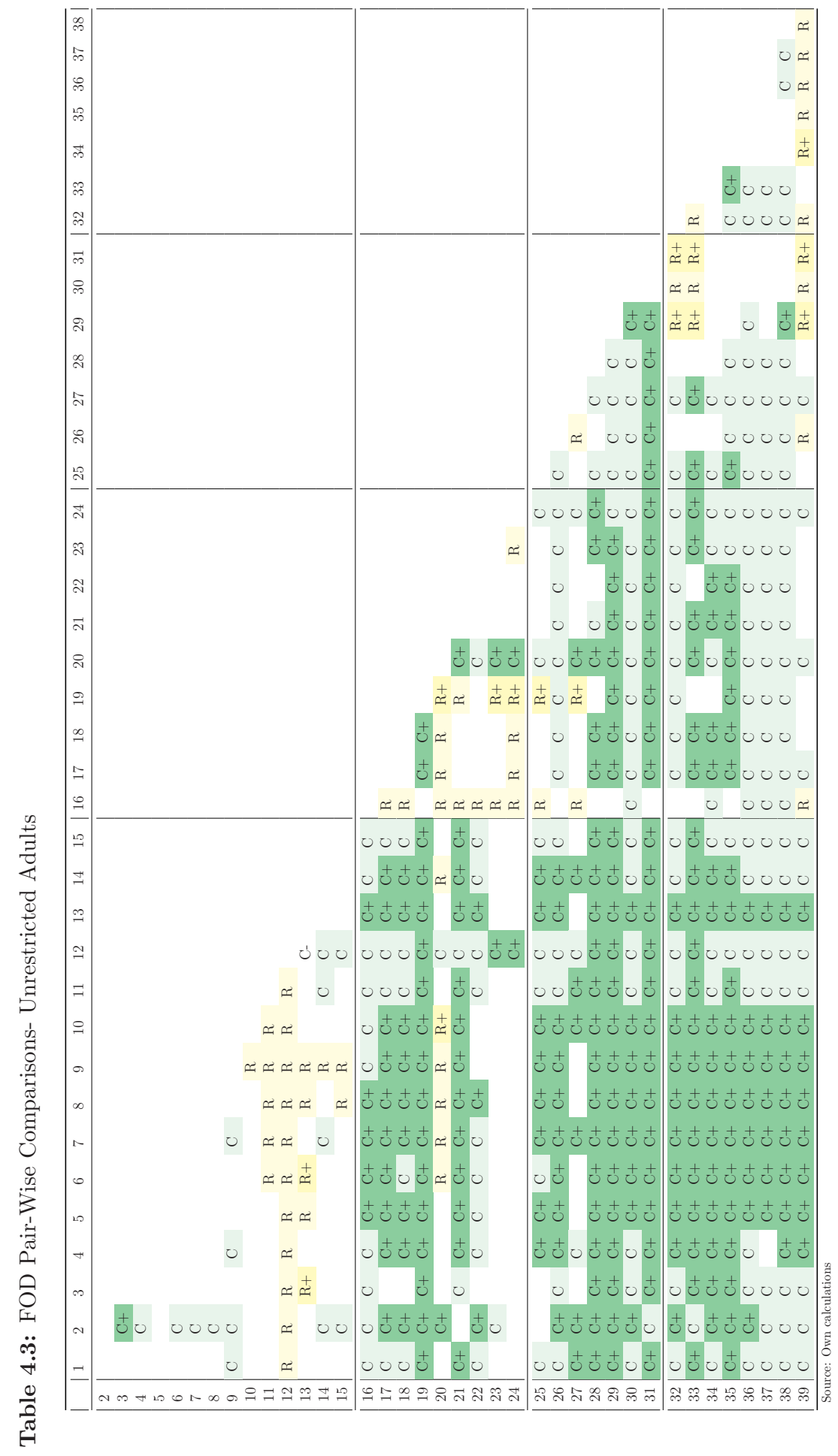




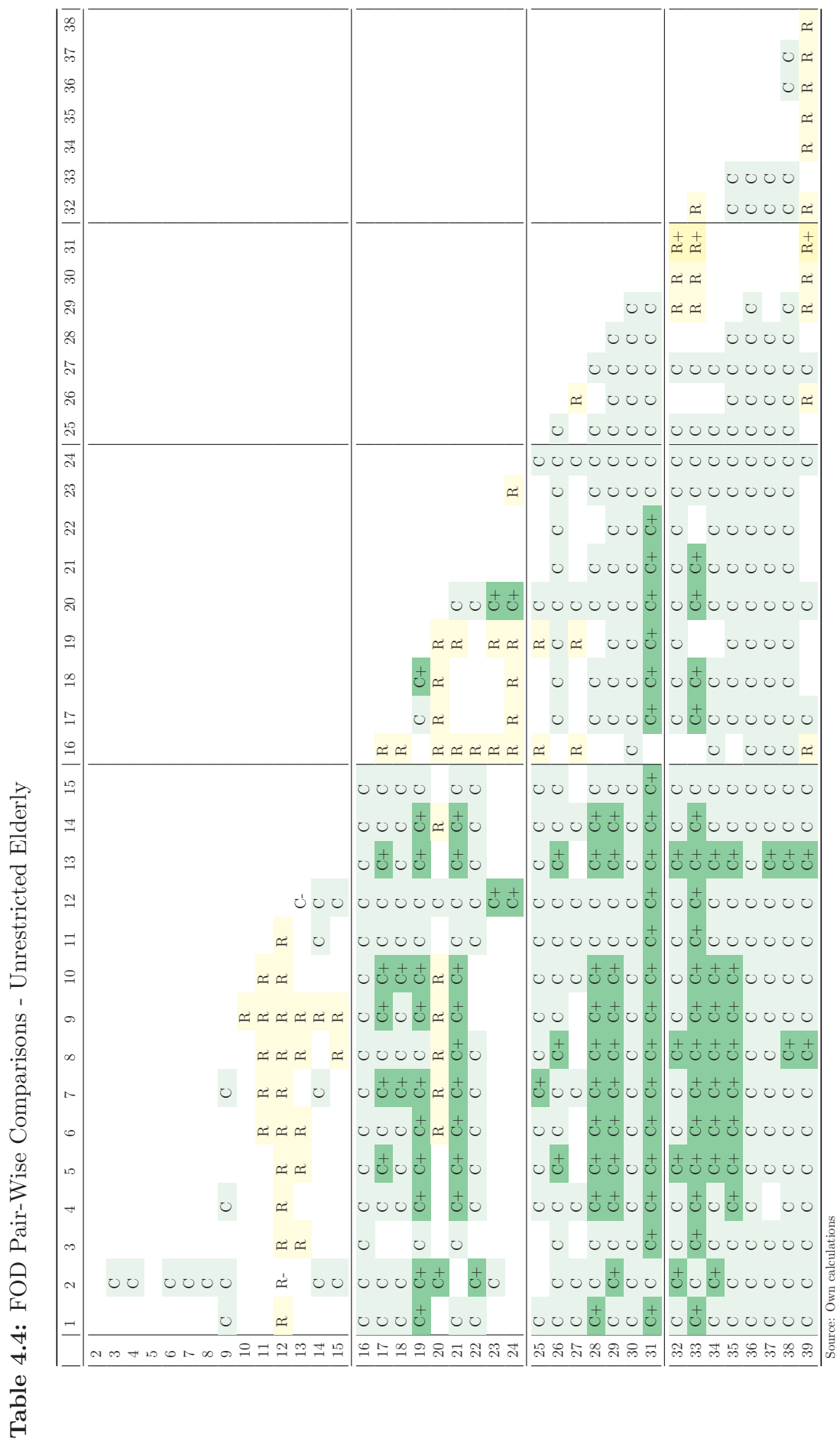




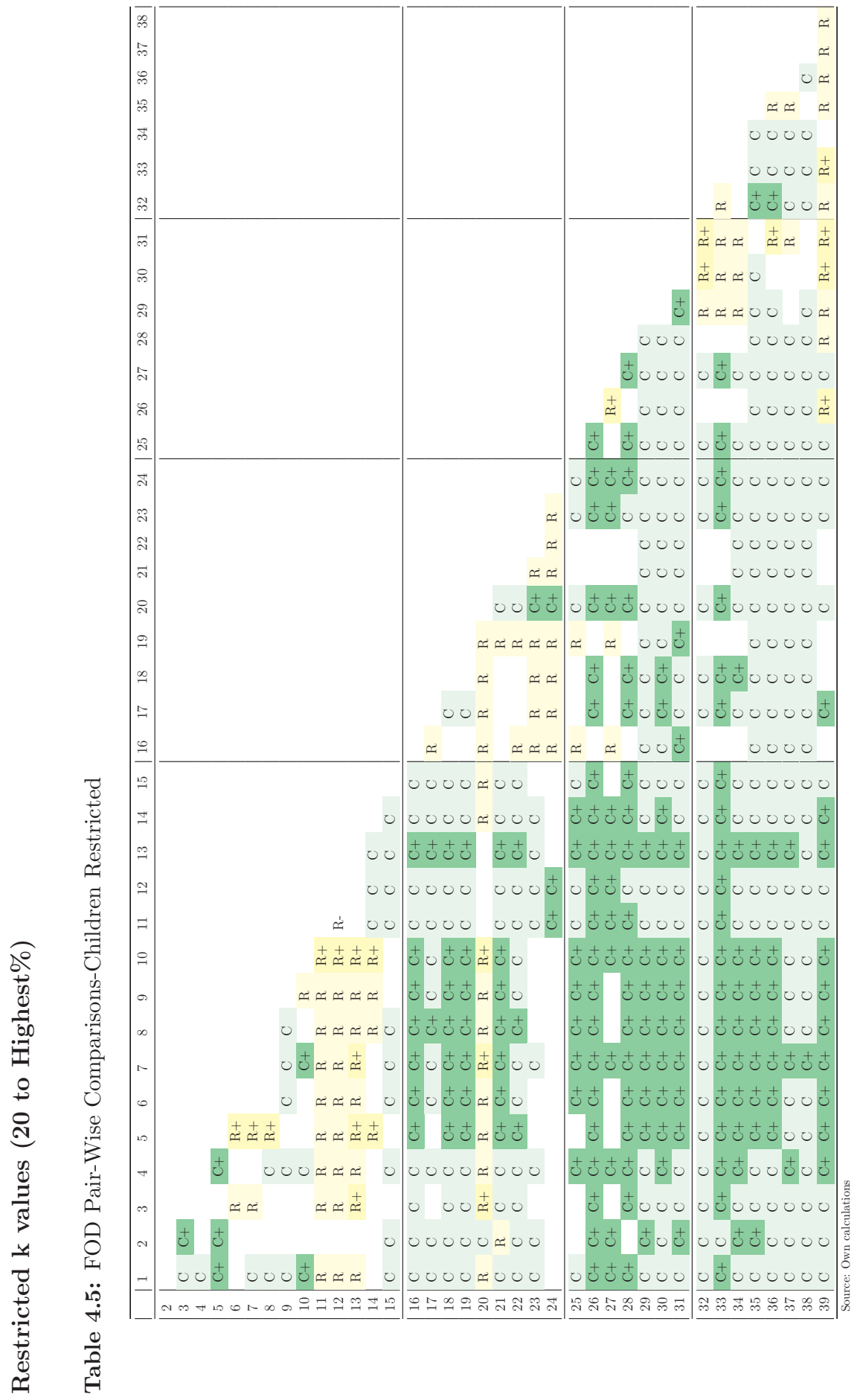




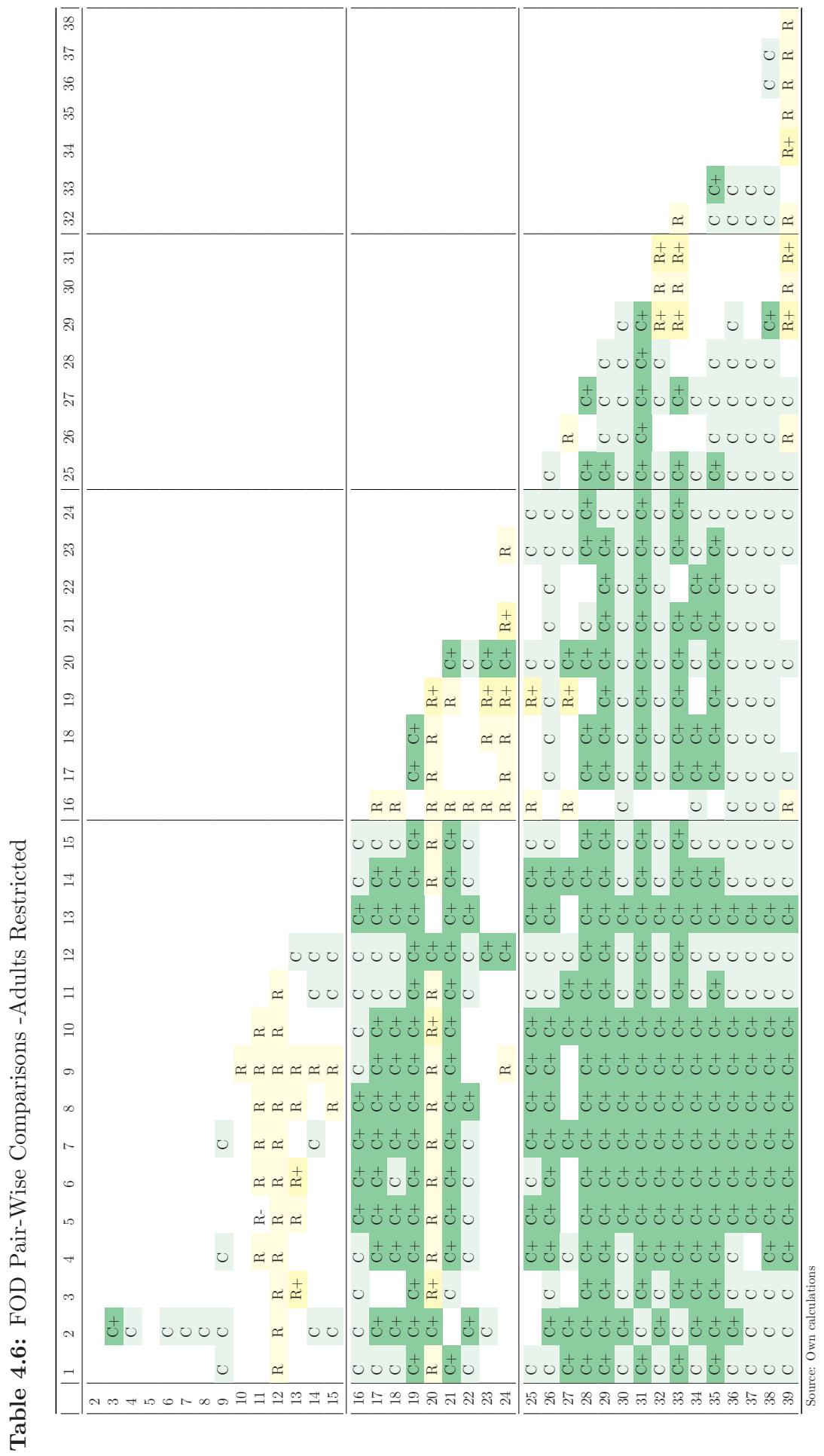




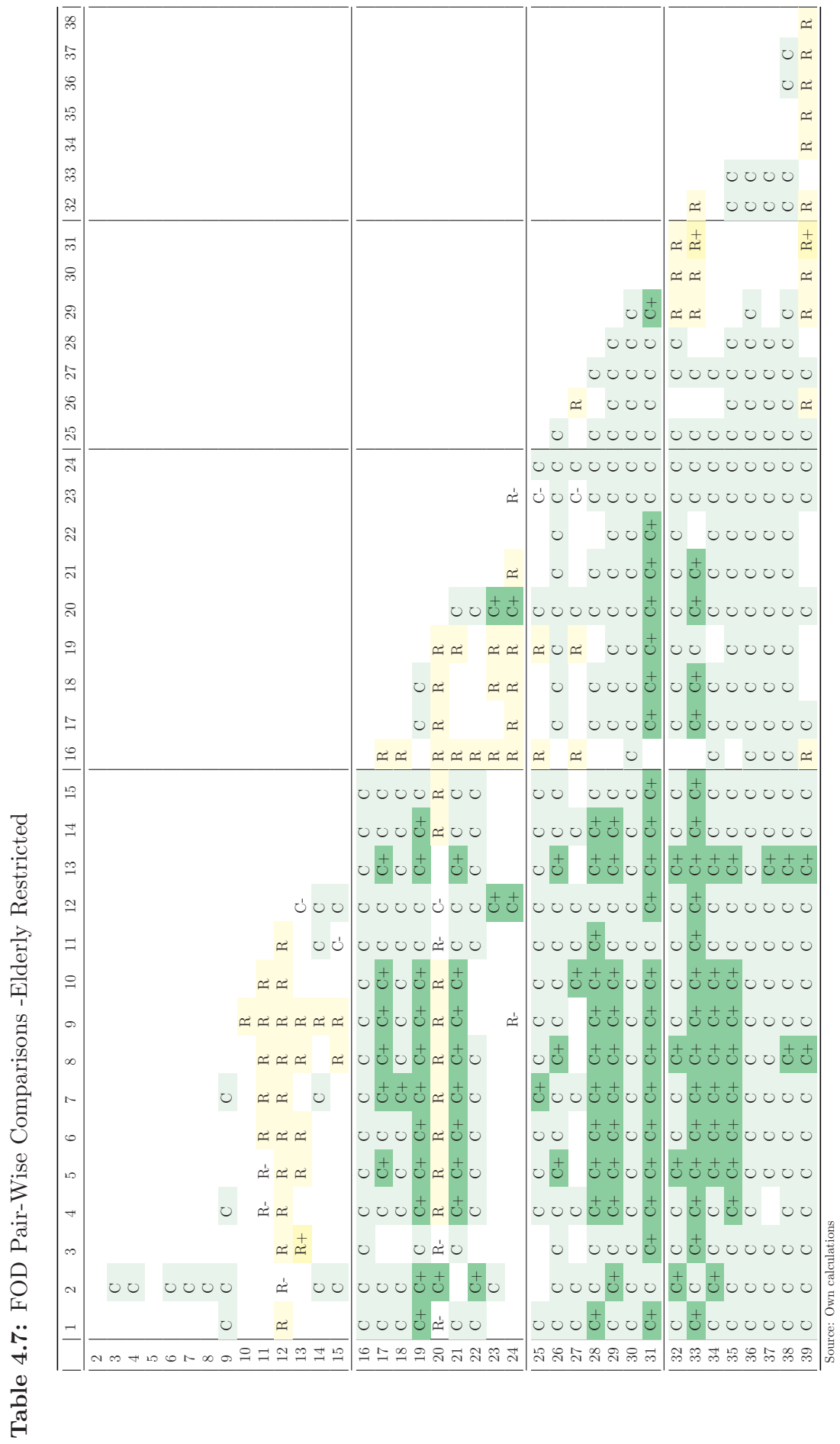




\subsubsection{Contributions per Region to the National Average}

Table 4.8: Contributions (\%) per Region to the National Average when k=30\%

\begin{tabular}{|c|c|c|c|c|}
\hline Country & Region & Children & Adults & Elderly \\
\hline \multirow{15}{*}{ Chile } & 1 & 1,5 & 1,8 & 1,4 \\
\hline & 2 & 0,8 & 0,9 & 0,6 \\
\hline & 3 & 5,5 & 2,2 & 1,0 \\
\hline & 4 & 4,5 & 5,0 & 5,2 \\
\hline & 5 & 23,4 & 11,2 & 5,2 \\
\hline & 6 & 3,2 & 5,6 & 8,9 \\
\hline & 7 & 4,7 & 8,9 & 11,8 \\
\hline & 8 & 14,2 & 19,1 & 19,6 \\
\hline & 9 & 16,6 & 19,2 & 19,5 \\
\hline & 10 & 7,2 & 9,6 & 12,4 \\
\hline & 11 & 0,3 & 0,5 & 0,7 \\
\hline & 12 & 0,3 & 0,2 & 0,4 \\
\hline & 13 & 12,5 & 10,3 & 6,2 \\
\hline & 14 & 1,9 & 3,9 & 6,5 \\
\hline & 15 & 3,4 & 1,7 & 0,5 \\
\hline \multirow{9}{*}{ Colombia } & 16 & 38,7 & 40,4 & 35,4 \\
\hline & 17 & 14,1 & 14,4 & 18,0 \\
\hline & 18 & 16,7 & 12,6 & 13,6 \\
\hline & 19 & 12,2 & 14,4 & 14,9 \\
\hline & 20 & 0,9 & 1,1 & \\
\hline & 21 & 9,8 & 10,2 & 11,9 \\
\hline & 22 & 8,1 & 6,4 & 3,9 \\
\hline & 23 & 0,0 & 0,1 & 0,0 \\
\hline & 24 & 0,3 & 0,6 & 1,1 \\
\hline \multirow{7}{*}{ Ecuador } & 25 & 1,4 & 2,2 & 2,7 \\
\hline & 26 & 10,1 & 12,2 & 10,0 \\
\hline & 27 & 0,3 & 0,4 & 1,2 \\
\hline & 28 & 1,1 & 1,1 & 0,8 \\
\hline & 29 & 31,0 & 28,5 & 39,5 \\
\hline & 30 & 47,2 & 49,5 & 41,5 \\
\hline & 31 & 8,9 & 6,0 & 4,4 \\
\hline \multirow{8}{*}{ Peru } & 32 & 10,1 & 11,5 & 11,7 \\
\hline & 33 & 2,7 & 3,7 & 4,2 \\
\hline & 34 & 0,8 & 1,3 & 1,1 \\
\hline & 35 & 14,1 & 13,2 & 13,4 \\
\hline & 36 & 19,2 & 17,9 & 21,9 \\
\hline & 37 & 16,4 & 16,9 & 22,5 \\
\hline & 38 & 28,6 & 24,7 & 13,9 \\
\hline & 39 & 8,2 & 10,9 & 11,2 \\
\hline
\end{tabular}

Source: Own calculations. Green identifies the region that contributes less to the country score, and gray identifies the region that most contributes to the country score. 


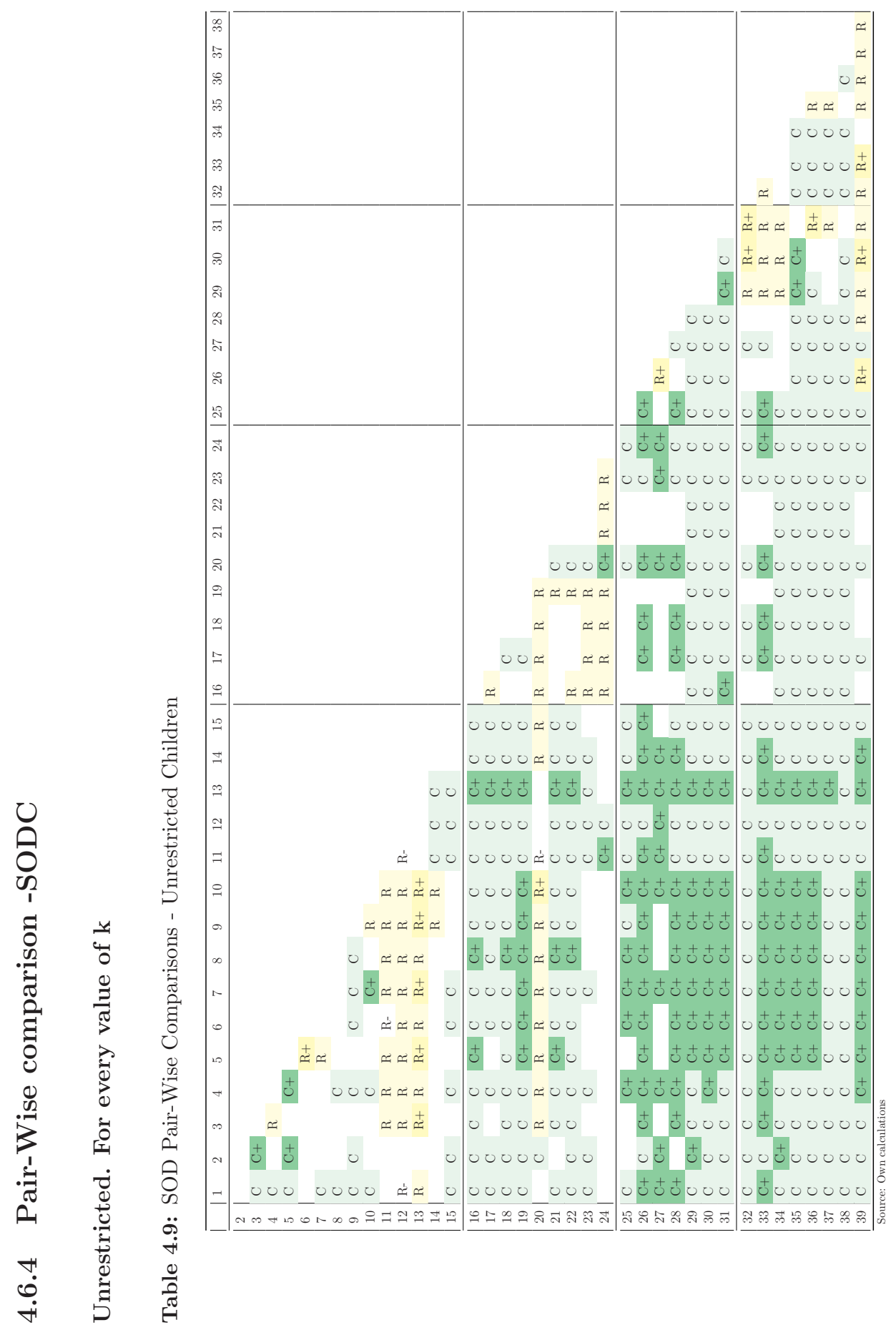




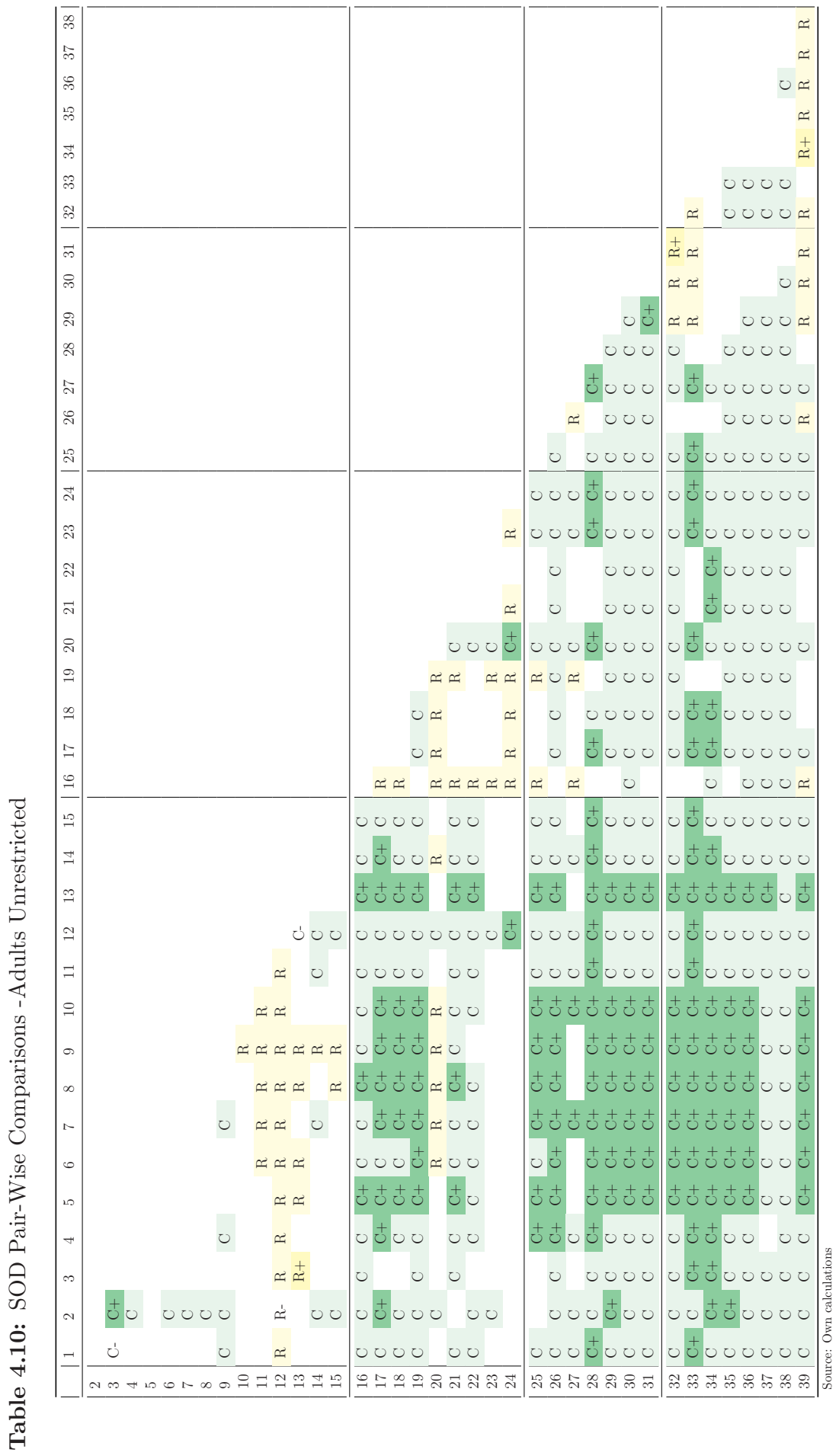




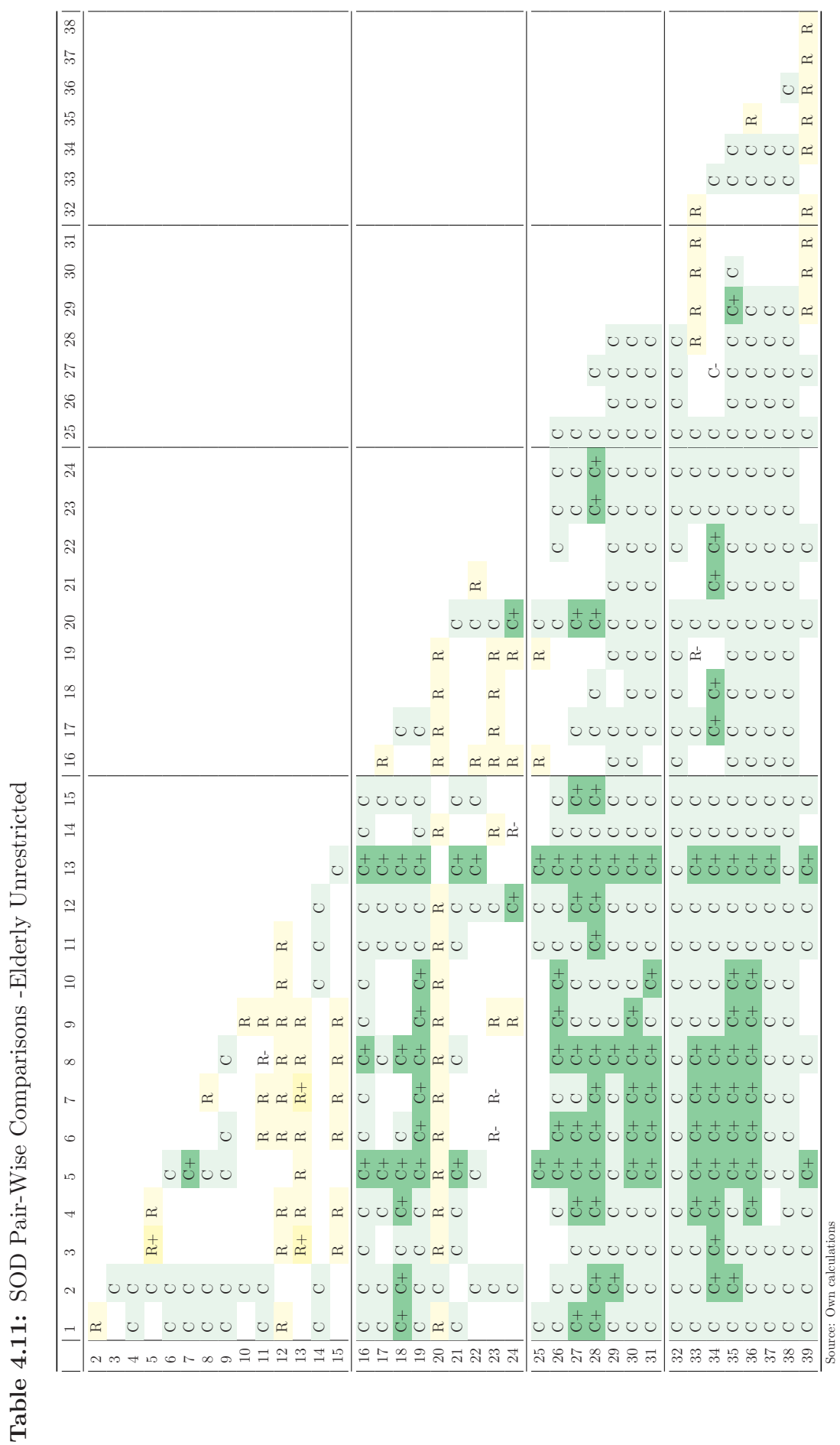




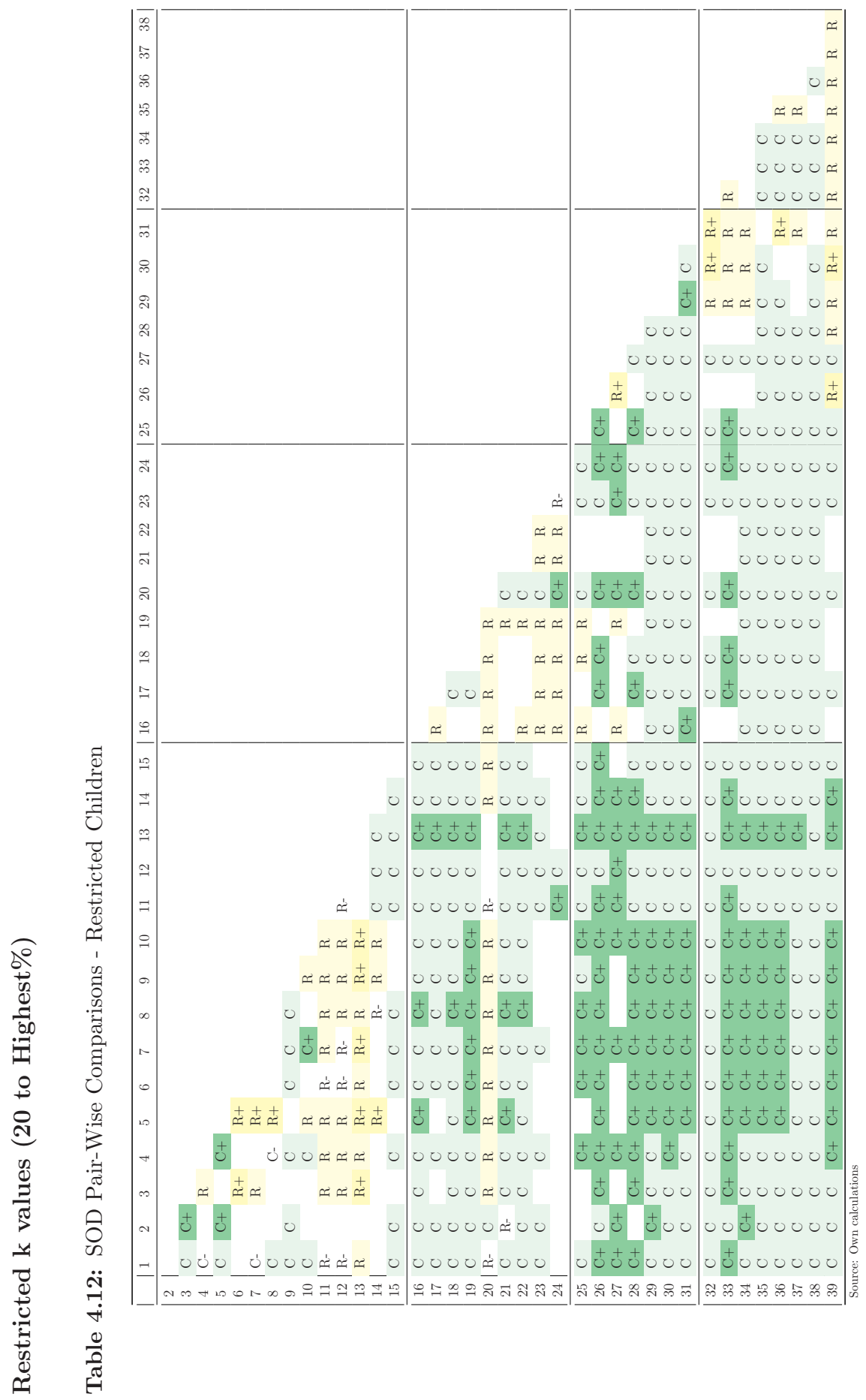




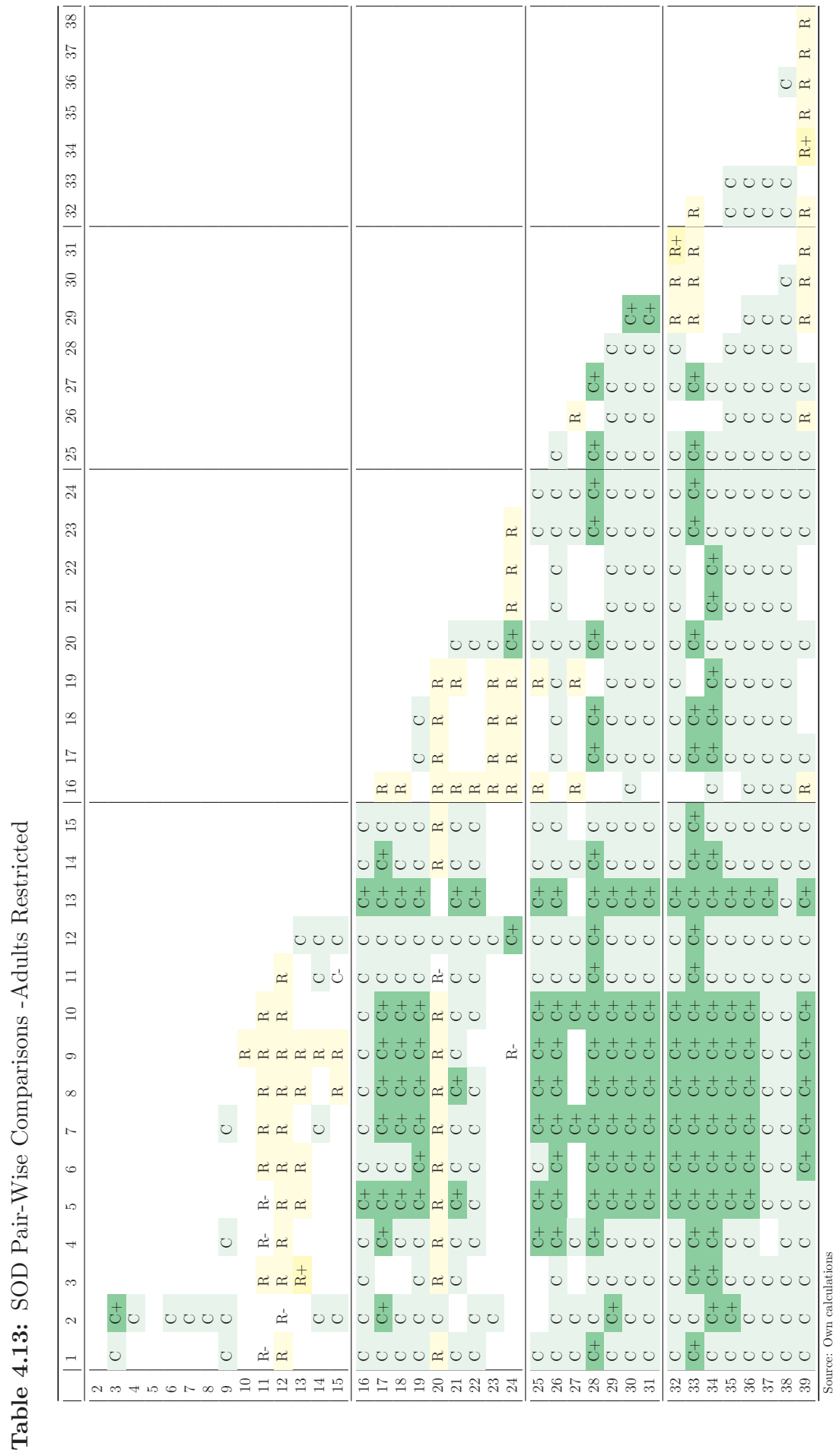




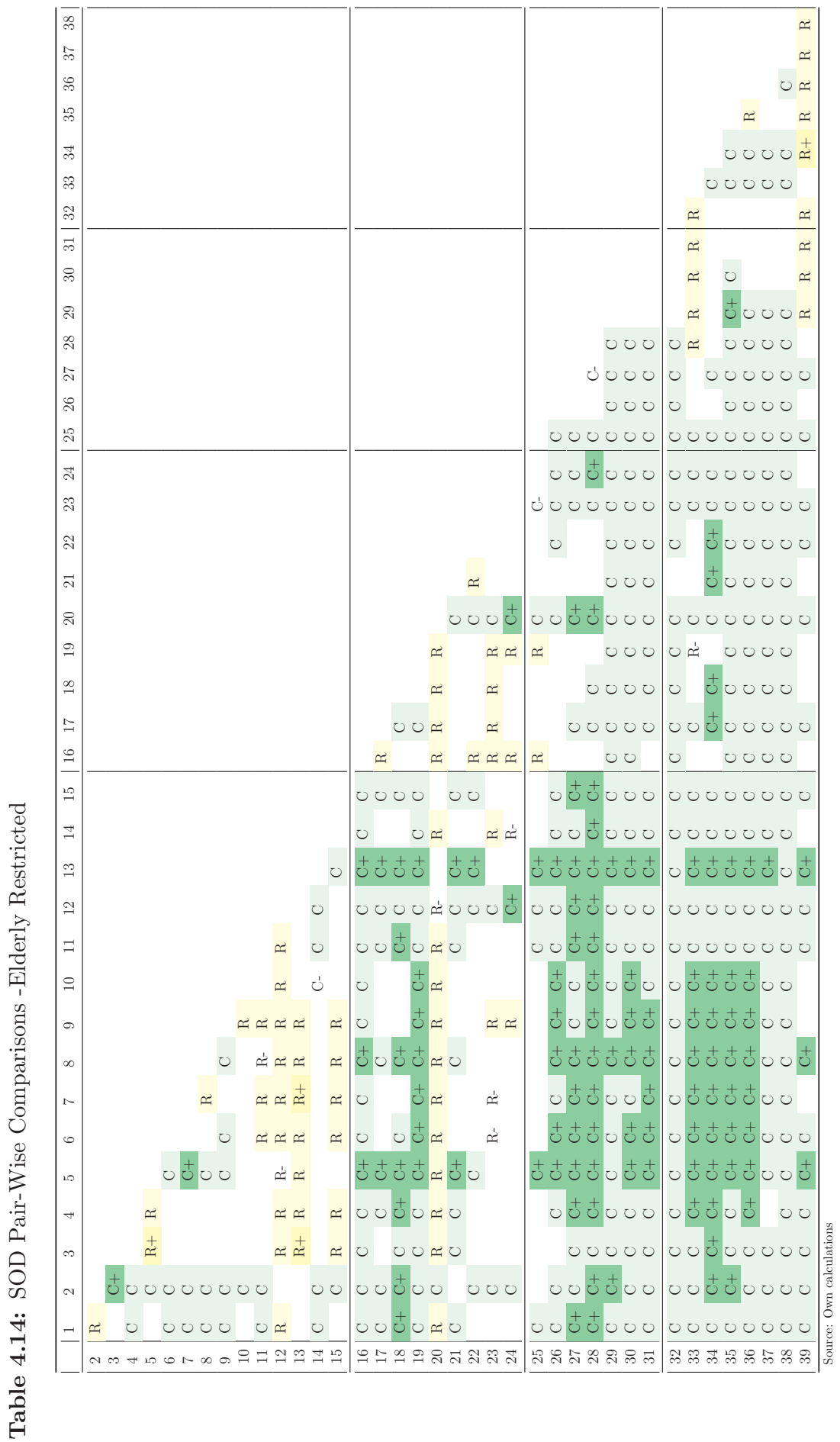




\subsubsection{Hasse Diagrams}

\section{Chile}

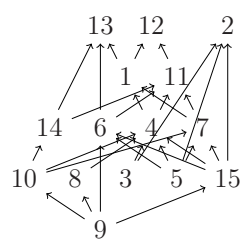

(a) Children Unrestricted

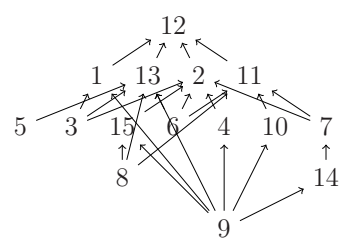

(c) Adults Unrestricted

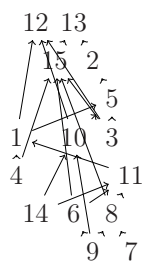

(e) Elderly Unrestricted

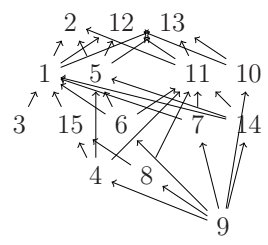

(g) Chile Unrestricted

Source: Author's elaboration

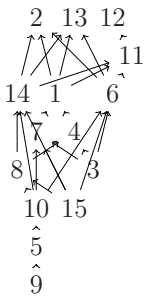

(b) Children Restricted

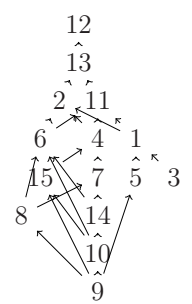

(d) Adults Restricted

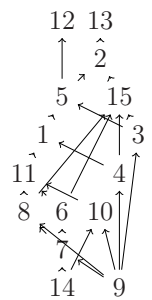

(f) Elderly Restricted

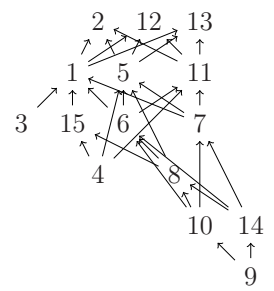

(h) Chile Restricted 


\section{Colombia}

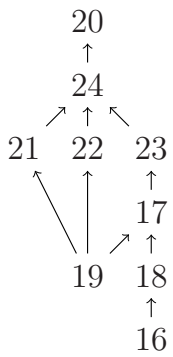

(a) Children Unrestricted

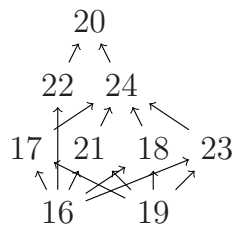

(c) Adults Unrestricted

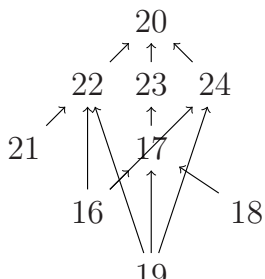

(e) Elderly Unrestricted

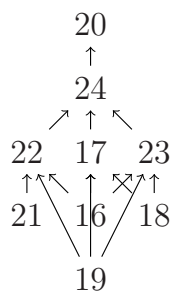

(g) Colombia Unrestricted

Source: Author's elaboration

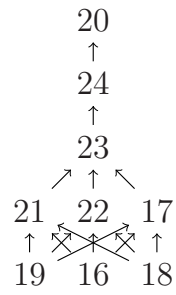

(b) Children Restricted

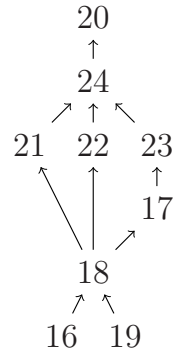

(d) Adults Restricted

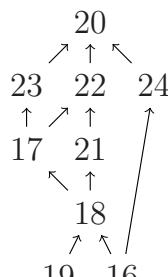

(f) Elderly Restricted

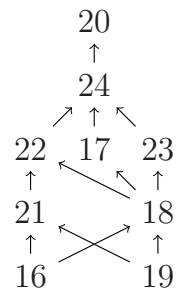

(h) Colombia Restricted 


\section{Ecuador}

$$
\begin{array}{cc}
25 \quad 27 \\
\uparrow & \times \uparrow \\
26 & 28 \\
\uparrow & \times \uparrow \\
30 & 29 \\
\uparrow & \uparrow \\
31
\end{array}
$$

(a) Children Unrestricted

$$
\begin{array}{cc}
25 & 27 \\
\uparrow & \times \uparrow \\
26 & 28 \\
\uparrow & \nearrow \\
29 \\
\nearrow & \uparrow \\
30 & 31
\end{array}
$$

(c) Adults Unrestricted

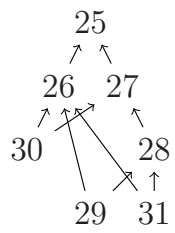

(e) Elderly Unrestricted

$$
\begin{array}{cc}
25 & 27 \\
\uparrow & \uparrow \\
26 & 28 \\
\uparrow & \times \uparrow \\
29 & 30 \\
\uparrow & \\
31 &
\end{array}
$$

(g) Ecuador Unrestricted

Source: Author's elaboration

$$
\begin{array}{cc}
25 \quad 27 \\
\uparrow \times \uparrow \\
26 \quad 28 \\
\uparrow \uparrow \\
29 \\
\uparrow \\
30 \\
\uparrow \\
31
\end{array}
$$

(b) Children Restricted

$$
\begin{array}{cc}
25 \quad 27 \\
\uparrow & \times \uparrow \\
26 \quad 28 \\
\uparrow \uparrow \\
29 \\
\uparrow \\
31 \\
\uparrow \\
30
\end{array}
$$

(d) Adults Restricted

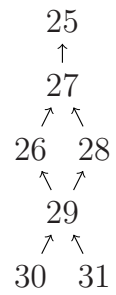

(f) Elderly Restricted

$$
\begin{aligned}
& 25 \\
& \begin{array}{c}
\uparrow \\
27
\end{array} \\
& 7+ \\
& 26 \quad 28 \\
& \uparrow \uparrow \\
& 29 \\
& \uparrow+
\end{aligned}
$$

(h) Ecuador Restricted 


\section{Peru}

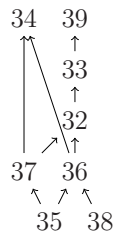

(a) Children Unrestricted

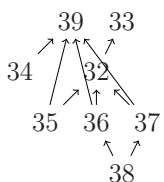

(c) Adults Unrestricted

(e) Elderly Unrestricted

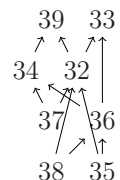

(g) Peru Restricted

Source: Author's elaboration

39
$\uparrow$
34
$\uparrow$
33
$\uparrow$
32
$\uparrow$
37
$\uparrow$
36
$\uparrow \uparrow$
$35 \quad 38$

(b) Children Restricted

39
$\uparrow \uparrow$
$34 \quad 33$
$\uparrow \uparrow$
32
$\uparrow$
37
$\uparrow$
36
$\uparrow$
38
$\uparrow$
35

(d) Adults Restricted

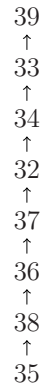

(f) Elderly Restricted

$$
\begin{array}{cc}
39 \\
\uparrow \\
34 & 33 \\
\uparrow & 7 \\
32 \\
\uparrow \\
37 \\
\uparrow \\
36 \\
7 & 4
\end{array}
$$$$
38 \quad 35
$$

(h) Peru Unrestricted 



\section{CHAPTER}

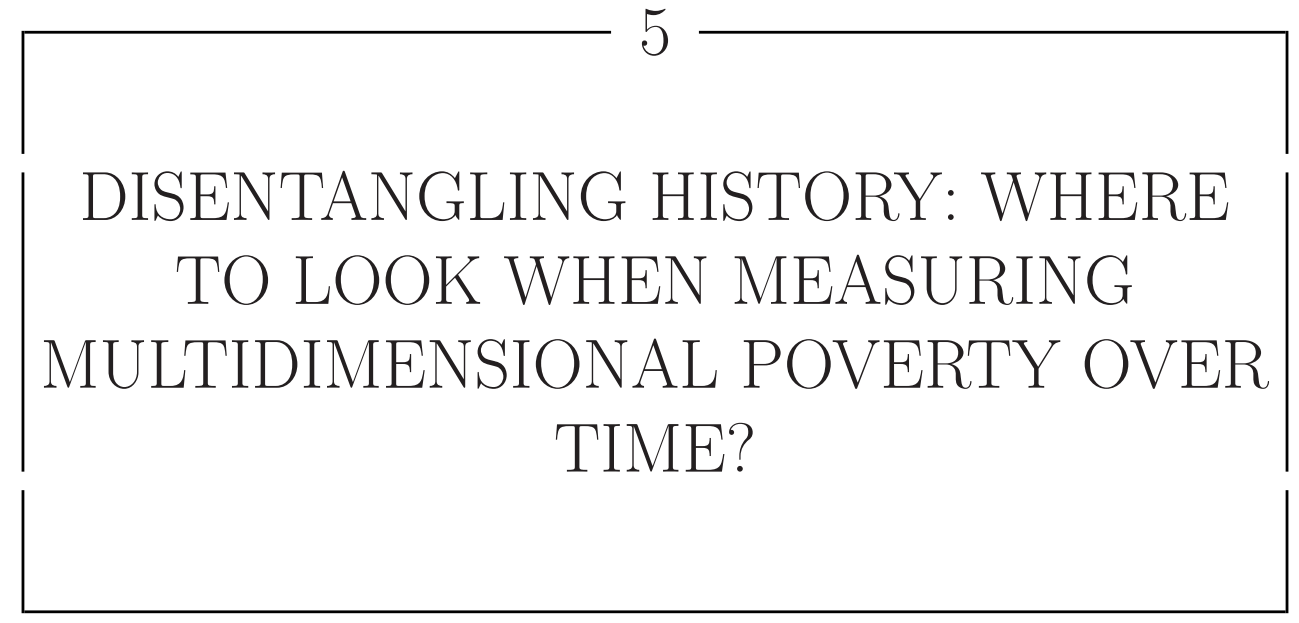

Different measurement tools are used to determine the poverty status of individuals and their transitions into and out of poverty. These tools can also be used to identify target populations for policy interventions to reduce poverty. However, poverty is multidimensional and dynamic and new measurement techniques are evolving to analyze the average change over time of poverty indicators, in the absence of longitudinal data.

This chapter compares the results of the application of three techniques, the Shapley decomposition, percentage changes, and reversed generalized Lorenz curves. The results of the AHR comparisons over time show the effects of population changes over time. Then, the results are tested for robustness using a range of values for the second cut-off. Finally, the policy relevance of the indicators resulting from the use of the measurement tools is discussed as part of an evidence-based approach to poverty reduction. Over time, effects of changes in norms, regulations and institutions can improve/deteriorate the conditions of the population. This chapter shows that poverty measurement cannot be isolated from the public policy reality. 


\subsection{Introduction}

Static measures of poverty are known to have a low explanatory power, as they provide a picture of a situation at a specific moment in time. By contrast, dynamic measures of poverty are focused on the evolution of poverty over time, and on determining the causes for its persistence (Hulme and Shepherd, 2003). There is a longer experience of dealing with poverty over time by using monetary approaches.

Using the monetary legacy in the measurement of poverty, non-monetary measures are increasingly adapting techniques to improve their explanation of poverty dynamics. Multidimensional poverty is not an exception, and lately more and more examples of adding time to the analysis are available. The analysis presented in this chapter is based on the evolution of poverty figures (e.g. poverty over time) as summarized in Addison et al. (2009).

Despite the differences between monetary and non-monetary approaches to the measurement of poverty, time is at the center of the debate in both. "The time dimension is a fundamental poverty dimension since it enables and restricts any individual activity" (Merz and Rathjen, 2014b, p. 452). The definition of time is also controversial. It is an intangible asset but undoubtedly it affects the decisions that individuals take: "Time is lived, experienced, known, theorized, created, embodied and objectified, abstracted and constructed, represented and commodified. In these multiple expressions time is an inescapable fact of social life and cultural existence" (Adams, 2004, p. 1).

Furthermore, time is perceived differently in different societies. The results of well-being, living standards and poverty indicators are also influenced by the particular context in which these measures are applied. Changes through time rely on cultural and geographical aspects as well as on demographic trends, political changes and particular developments in the social protection schemes. ${ }^{1}$ In the countries of the sample, population has changed not only due to the ageing of their societies but also because of emigration particularly in Colombia and Peru due to their internal conflicts and/or economical crisis, while countries as Ecuador and Chile have increasingly received migrants. Economic inequality and the composition of minority groups as Afro-descendants and natives also plays a role.

This chapter compares three different techniques, recently developed, to include poverty over time in a multidimensional poverty indicator using the Adjusted Headcount Ratio (AHR) of Alkire and Foster when panel data is not available. The techniques are: á la Shapley decomposition, analysis of percentage changes and reversed generalized Lorenz curves (RGL). Each technique shows a different aspect of poverty over time and therefore provides different information.

\footnotetext{
${ }^{1}$ Social Protection Systems are used as a tool to fight poverty and vulnerability.
} 
The contribution of the chapter is the empirical application of the techniques in the particular context of four Latin American countries: Chile, Colombia, Ecuador and Peru, at two different moments in time, depending on the availability of information. The main objective is to study the evolution of well-being in a particular demographic and political context and to explore the robustness of the results when the second cut-off in Alkire and Foster (2011a) is varied. As mentioned in Section 2.2, a static assessment of poverty neglects the analysis of processes that occur over time and that are fundamental to understand its persistence and key to its elimination. It is particularly relevant to study poverty over time from monetary and non-monetary perspectives. On the multidimensional poverty approach, understanding poverty or well-being requires to understand the trajectories that individuals or households follow: "The standard of living is not a static, timeless state, but a state that evolves over time. The standard of living follows a trajectory, a path with a history and a future" (Calvo and Dercon, 2009, p. 29). These paths could show that despite years of severe deprivation a household has managed to cope and recover, or on the contrary, that a household is trapped in a vicious circle of poverty or even becomes more and more destitute. This cannot be assessed with a static analysis of poverty.

The chapter is organized as follows: The second section describes the demographic and political changes shown in the countries of the sample, with particular care on the description of changes in the Social Protection Systems. The third section introduces the techniques. The fourth section shows the empirical application and the results. Finally, the last section summarizes the findings and discusses their policy relevance.

\subsection{Demographic and Political Changes in the Re- gion}

As noted in the Introduction, the context in which the dynamic multidimensional measures are applied is relevant. "The nature of chronic poverty, and the causal factors that underpinned it, differ from context to context and so explanations may also vary" (Hulme and Shepherd, 2003, p. 413). This context-specific analysis cannot neglect the importance of the demographic profile of each country, the political and electoral environment and the characteristics of the social protection system. This section introduces this three aspects.

\subsubsection{Demographic Profile}

"Demographic changes result in quantitative and qualitative changes in the way societies are organized and shaped. Ultimately, the demographic transition is prompting a reexamination of the state-market-family equation" (Huenchuan, 2003, p. 25). In average, the region is experiencing a fast ageing process, mainly driven by the acuteness of the process in the Caribbean Islands. Huenchuan (2003) shows that for instance in countries 
like Chile and Colombia ageing is taking between three and two decades while in countries as France and Spain it lasted between one and half a century, respectively. The demographic profile is of great interest for the analysis of poverty. Demographic changes have a direct impact on the figures of poverty (by the effect of the population shares) and an indirect effect related to the mortality, fertility and dependency ratios.

Figure 5.1: Population Pyramids

(a) Chile

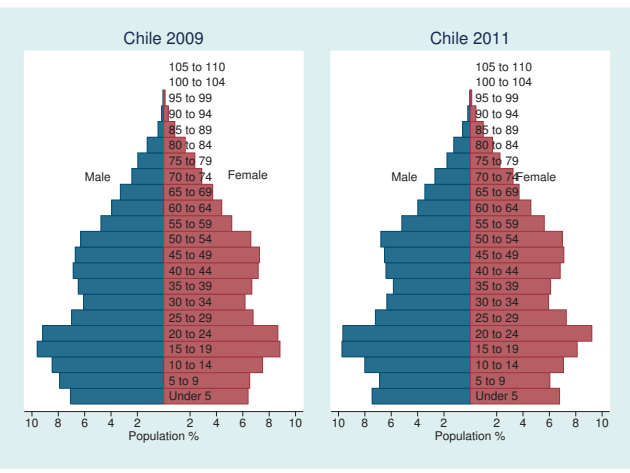

(c) Ecuador

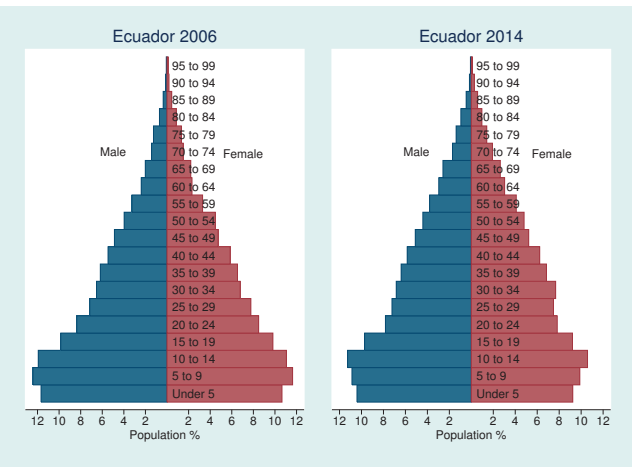

(b) Colombia

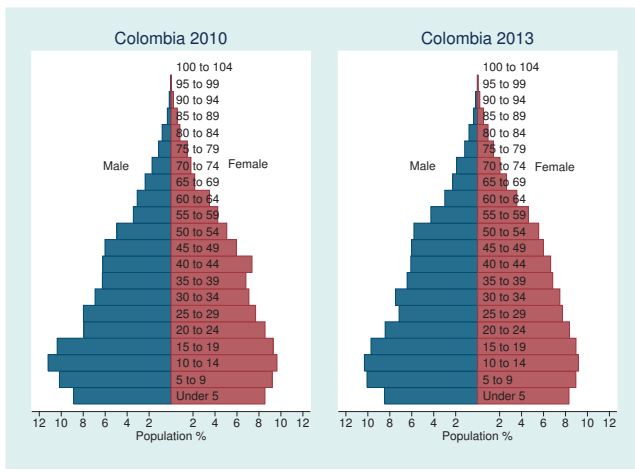

(d) Peru

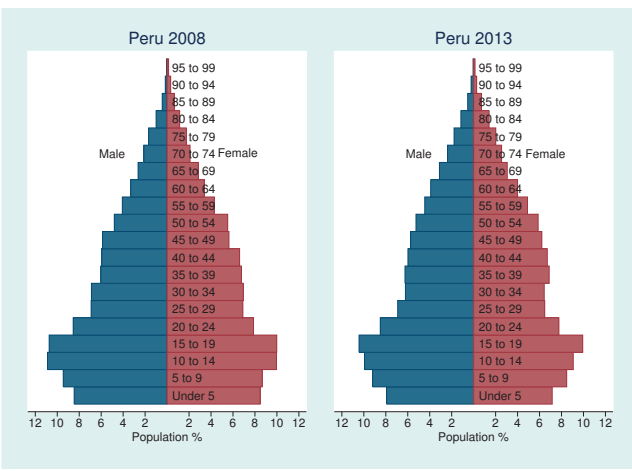

Source: Chilean, Colombian, Ecuadorian and Peruvian LSMS. Author's elaboration

Demographic changes can be measured by population pyramids that show changes over time in the population divided in age groups of 5 years of length (under 5 , from 6 to 10 , and so on). Acute cases of ageing processes show the shrinking of the base and the expansion of the top of the pyramid resulting in an inverted pyramid. This is not yet the case in the countries of the sample. The proximity between the available datasets does not show the predicted increase of the population share of 65 years and older but the bottom of the pyramid is shrinking rapidly as shown in Figure 5.1.

Demographic dependency ratio, the relation between dependants (population either under 15 years or older than 65 years) and the working-age population (between 15-64 years old), is also a measure of the demographic changes in a population and the pressure over the families, households and the economies of a process of ageing. Moreover, it is 
Table 5.1: Dependency Ratios and Population Shares through Time

\begin{tabular}{|c|c|c|c|c|c|c|c|c|}
\hline \multirow[t]{2}{*}{ Country } & \multicolumn{2}{|c|}{$\begin{array}{c}\text { Dependency } \\
\text { Ratio (\%) }\end{array}$} & \multicolumn{2}{|c|}{$\begin{array}{c}\text { Younger } \\
15 \text { years }(\%)\end{array}$} & \multicolumn{2}{|c|}{$\begin{array}{l}\text { Working } \\
\text { Age (\%) }\end{array}$} & \multicolumn{2}{|c|}{$\begin{array}{l}\text { Older than } \\
64 \text { years }(\%)\end{array}$} \\
\hline & $t_{1}$ & $t_{2}$ & $t_{1}$ & $t_{2}$ & $t_{1}$ & $t_{2}$ & $t_{1}$ & $t_{2}$ \\
\hline Chile & 48.50 & 47.69 & 21.88 & 21.04 & 67.34 & 67.71 & 10.79 & 11.25 \\
\hline Colombia & 55.33 & 53.73 & 28.80 & 27.63 & 64.38 & 65.05 & 6.82 & 7.32 \\
\hline Ecuador & 69.37 & 63.19 & 34.67 & 31.10 & 59.04 & 61.28 & 6.29 & 7.62 \\
\hline Peru & 57.41 & 59.52 & 27.94 & 27.86 & 63.53 & 62.69 & 8.53 & 9.45 \\
\hline
\end{tabular}

Source:LSMS, Author's elaboration. Chile: $t_{1}=2009$ and $t_{2}=2011$, Colombia: $t_{1}=2010$ and $t_{2}=2013$, Ecuador: $t_{1}=2006$ and $t_{2}=2014$, Peru: $t_{1}=2008$ and $t_{2}=2013$.

also used as an indication of the length of the demographic dividend. It occurs when two conditions are present: a rapid and steady decrease of the fertility rate and the stagnation of the elderly population. It is considered a window of opportunity for development as the society has the chance to save on expenses because of the reduction of the the absolute number of children and to reap the benefits of an increase of the labor force (Huenchuan, 2003) just before the share of the elderly starts growing faster.

Dependency ratios have been decreasing in all the countries of the sample but one, Peru, as shown in Table 5.1. The biggest reduction was experienced by Ecuador (9\%). ${ }^{2}$ In the four countries the share of the population under 15 years old has decreased, Chile being the country that in average experienced the biggest reduction ( $2 \%$ per year). ${ }^{3}$ At the same time, all the countries experienced an increase in the share of the elderly population. In average, Colombia (2.44\% per year) and Ecuador (2.66\% per year) are the countries showing a faster growth in this segment of the population. Peru is the only country that experienced a decline in the share of the working-age population.

The results are consistent with the demographic changes shown by other studies in the region. According to Ullmann et al. (2014), Chile is classified as being in an advanced stage of ageing. This means that fertility rates are below the replacement rate (1.85). All the countries are experiencing a reduction in the number of children dependants, so they are classified as experiencing a 'full demographic transition'4 and a steady growth of the elderly segment.

\footnotetext{
${ }^{2}$ Even considering the difference on the time span, Ecuador's dependency ratio decreased at an average rate of $1.11 \%$ per year, compared to a rate lower than $1 \%$ in Chile and Colombia and an increase in Peru.

${ }^{3}$ Ecuador shows a higher reduction but the distance between the two available datasets is of 8 years $(10.3 \%)$.

${ }^{4}$ Peru is the only case where the number of children dependants is still growing. They are doing so at an average rate of $0.21 \%$.
} 


\subsubsection{Political and electoral changes}

The political systems affect the policies and the living standards of the societies depending on them. However, as mentioned by Pierson (1996, p. 144), "social welfare is more resilient than other key components of national political economies". This resilience makes possible the expansion and continuation of social programs and the emphasis on the creation of a social protection system despite the political changes of the parties in power. It is politically easier to expand than to shrink social benefits, as the unpopularity of these measures has a higher cost to the incumbents and their parties. Resilience can be easily grasped by studying the behavior of social expenditure. Chile was the only country in the analysis that experienced a radical switch of the party in power and where the effect on the social protection system went unnoticed. ${ }^{5}$

Table 5.2: Social Expenditure as a \% of the GDP

\begin{tabular}{lcccc|cccc}
\hline Country & 2000 & 2005 & 2010 & 2012 & 2000 & 2005 & 2010 & 2012 \\
\hline \multicolumn{9}{c}{ Total } \\
\hline Chile & 15.02 & 12.09 & 14.75 & 14.66 & 3.88 & 3.41 & 4.19 & 4.25 \\
Colombia & 10.15 & 11.89 & 13.75 & 13.07 & 3.25 & 3.15 & 3.33 & 3.02 \\
Ecuador & 2.86 & 4.68 & 8.14 & 8.30 & 1.74 & 2.56 & 4.56 & 4.73 \\
Peru & 8.62 & 9.55 & 9.38 & 9.45 & 2.91 & 3.00 & 2.92 & 2.86 \\
\hline \multicolumn{1}{c}{ Health } \\
\hline Chile & 2.84 & 2.79 & 3.54 & 3.68 & 7.93 & 6.43 & 6.60 & 6.30 \\
Colombia & 1.91 & 1.88 & 1.96 & 1.95 & 4.03 & 6.32 & 7.81 & 7.41 \\
Ecuador & 0.63 & 1.14 & 1.58 & 1.84 & 0.35 & 0.74 & 1.66 & 1.43 \\
Peru & 1.47 & 1.51 & 2.11 & 2.41 & 3.61 & 4.33 & 3.16 & 2.92 \\
\hline \hline
\end{tabular}

Source: ECLAC- Stats. The remain percentage is the expenditure on the housing sector that for each case is lower than $1 \%$

Social policies have been traditionally used as mechanisms to manipulate voters. The collision between public servants and politicians during electoral campaigns creates inaccurate expectations on the continuation, expansion or the risk of retrenchment of particular social policies. ${ }^{6}$ Moreover, politicians take advantage of the access to anti-poverty programs in order to increase the electoral support of beneficiaries during elections. In Nupia (2011), an example of this practice is shown. The author found a relation between results in the presidential election and the expansion of Familias en

\footnotetext{
${ }^{5}$ One particular reason for this is that just days after taking power President Piñera (conservative) had to deal with the aftermath of a severe earthquake.

${ }^{6}$ Public officials take decisions about who the beneficiaries are, which regions are the focus of interventions and the length of the service provided. The weaker the institutions the higher the discretionary power of public officials and the higher the incentives to engage in obscure practices. In cases in which rules and laws are already established for the procedures (the amount of subsidies, the targeted population and so on) lack of information of beneficiaries is used to exercise those obscure practices (getting bribes in-cash or in-kind). (Rose-Ackerman, 2006, p. xviii)
} 
Accion (CCT) in Colombia in the period 2006-2010. Several claims from beneficiaries about the use of the program and their beneficiaries during elections played a definitive role in the formalization by law of the CCT (Law 1532 of 2012).

Uncertainties within the political system and lack of trust in the institutions also affect directly the extent of the effectiveness of a social protection system. A particular case worth highlighting is the electoral turmoil that affected Ecuador during the years 2005-2007, during which three presidents took office, as shown in Table 5.3. ${ }^{7}$

Table 5.3: Presidential Changes in the four countries

\begin{tabular}{|c|c|c|c|c|c|}
\hline Country & Name & Period & Party & $\begin{array}{l}\text { Political } \\
\text { Affiliation }\end{array}$ & $\begin{array}{l}\text { In/out } \\
\text { of Office }\end{array}$ \\
\hline \multirow[t]{3}{*}{ Chile } & Michel Bachelet & 2006-2010 & Socialist Party & $\mathrm{C}-\mathrm{L}$ & Election \\
\hline & Sebastian Piñera & 2010-2014 & National Renewal & $\mathrm{C}-\mathrm{R} / \mathrm{R}-\mathrm{W}$ & Election \\
\hline & Michel Bachelet & 2014- Now & Socialist Party & $\mathrm{C}-\mathrm{L}$ & Election \\
\hline \multirow[t]{2}{*}{ Colombia } & Alvaro Uribe & $2002-2010$ & Colombia First & $\mathrm{R}-\mathrm{W}$ & Election \\
\hline & Juan M. Santos & 2010-Now & National Unity & Coalition & Election \\
\hline \multirow[t]{3}{*}{ Ecuador } & Lucio Gutierrez & $2003-2005$ & $\begin{array}{l}\text { Patriotic Society } \\
\text { Party }\end{array}$ & C/C-L & Removed \\
\hline & Alfredo Palacio & $2005-2007$ & Independent & C-L & Acting \\
\hline & Rafael Correa & 2007-Now & PAIS Alliance & $\mathrm{L}-\mathrm{W}$ & Election \\
\hline \multirow[t]{2}{*}{ Peru } & Alan Garcia & $2006-2011$ & $\begin{array}{l}\text { American Popular } \\
\text { Revolution Alliance }\end{array}$ & $\mathrm{C}$ & Election \\
\hline & Ollanta Humala & 2011-Now & $\begin{array}{l}\text { Peruvian Nationalist } \\
\text { Party }\end{array}$ & $\mathrm{C}$ & Election \\
\hline
\end{tabular}

Source:CIA World Factbook. Now= Incumbent, C= Center, L=Left, R=Right, $\mathrm{W}=$ Wing, Election=Democratic Elections, Removed= Constitutional Dismissal, Acting $=$ Constitutional Nominated

\footnotetext{
${ }^{7}$ Since the last years of the 90s Ecuador has had eight Presidents. Four of them democratically elected (Bucharam, Mahuad, Gutierrez and Correa), three Interim (Alarcón, Noboa and Palacio), and one acting (Arteaga). The democratic elected Presidents were mostly overturned by political turmoil in the country caused by the unpopular policies adopted by their governments. Mostly lead by the indigenous movement, excluding a military coup. This uncertainty spread from the incompleteness of the adopted policies and the constant reversal of the decisions taken by the incumbents.
} 


\subsubsection{Social Protection Profiles}

The definition of social protection is a highly contested issue. This chapter considers that social protection schemes, ${ }^{8}$ in a broader sense, as in (Esping-Andersen, 2013) and (Barrientos, 2013, p. 24), are a central element for the reduction of poverty and to explain the changes in multidimensional poverty over time. "In particular, social protection should guarantee a sufficient level of welfare to sustain living standards that are considered basic for a person's development, while also facilitating access to social services and promoting decent work" (Cecchini et al., 2014, p. 9).

During the last 25 years, and following a global trend, the countries studied in this chapter made increasing efforts towards universalism; particularly in health and education but with a strong segmented approach. Universalism coexists with different targeting schemes as well as access to contributory, mandatory and non-contributory social programs. Targeting mechanisms were implemented and improved in Latin America with two main objectives: to increase the efficiency of the selection of beneficiaries entitled to social benefits, and to discourage the selection of those not entitled. ${ }^{9}$

The region is the origin of the Conditional Cash Transfers (CCT), a tool that became popular at the end of the 90s after its success in Brazil and Mexico. The contributory schemes are attached to the formal workers, and therefore there is still a big portion of the population (informal workers and unemployed) who does not have access to these mechanisms of protection (e. g. unemployment benefits, pension coverage and health insurance, among others), thereby segregating not only the access but also the quality of the acquired services. Although similar measures were followed by every country, the results show a lot of variation.

Latin America has also focused on the protection of children. Early childhood education and integral care have been common in all the countries under study, although implemented much more successfully in some cases than in others. Many programs have also expanded their coverage and adapted their initial objectives. An example of this is the Human Development Grant (Bono de Desarrollo Humano) of Ecuador. Initially conceived as a CCT, its conditionality has not been enforced. In the last years, it has expanded not only the coverage among families with school-age children but it has also included the disable and the elderly population as beneficiaries.

\footnotetext{
${ }^{8}$ Barrientos (2013) adopts the definition of Social Protection as constituted by three main aspects: Social insurance, social assistance and labor market interventions, both passive and active.

${ }^{9}$ Schüring and Gassmann (2013) using attitudinal surveys in Zambia and drawing on the political economy of targeting, found that the focus on cost-effectiveness neglects not only the costs associated to the design and implementation of the targeting mechanisms in itself, but also the political considerations of it.
} 
The region moved from a sectorial policy approach to a more comprehensive pool of programs and policies aimed at the protection and promotion of the well-being, as summarized by Cook (2013, p. 19). At the same time, political commitment allowed the continuation of policies implemented by previous governments either by adaptation, replication or by making them Laws (e.g. Ingreso Ético Familiar in Chile or Familias en Acción in Colombia). As mentioned by Cecchini et al. (2014, p. 38), Latin America "is clearly in a stage of progressive construction of social citizenship, both in terms of protection and in the promotion of human development".

Despite the fact that many of these changes started in the early 1990s, the consolidation and expansion of social policies and programs only became evident in the last 10 to 5 years. This is the reason why decomposition of multidimensional poverty measurement over time constitutes an important policy tool. The following section explains the logic behind each technique proposed for analysis.

\subsection{Decomposition Techniques in Multidimensional Poverty Indicators}

\subsubsection{Shapley decomposition}

According to Shorrocks (2013, p. 100) the objective of decomposing is to determine what are the contributions of different factors to the overall result. Based on the paper from Shapley (1953) on games with finite players, Shorrocks derives what is called the 'Shapley Decomposition' or the technique to calculate the marginal effect on an aggregate statistical indicator of contributory variables excluded in a predefined order. Á la Shapley decompositions are considered part of the dynamic construct of poverty and are part of the optimal decomposition techniques (Kolenikov and Shorrocks, 2005).

The literature that dominated before the implementation of the Shapley decomposition relied on interaction effects to explain the residual. An example of decompositions over time can be seen in Ravallion and Huppi (1991). The authors calculate the change in aggregate poverty between two different moments in time and decompose it in intrasectoral effects (e. g. urban vs. rural), population shifts and the interaction between intrasectoral effects and population shifts. Another approach relies on regression-based decompositions as in Bouillon et al. (2003), or the construction of counterfactual distributions as in Azevedo et al. (2013). 
By contrast, the Shapley Decomposition is an exact additive decomposition. In other words, the sum of the marginal effects is equal to 1 and factors are treated symmetrically. The latter feature is considered as its main limitation, as mentioned by Garcia-Diaz and Prudencio (2015). Treating the factors as similar fails to acknowledge the effect of the order in which the factors are being excluded. This effect could be zero in the cases where the factors considered for the decomposition are independent. However, this is not the case with the AHR. It is known that the intensity sub-indicator or (A) depends on the incidence sub-indicator (or H). Shapley decompositions show the average effect for each variable and therefore cancel out the path dependence on the selection of the order of the factors [p. 10](Azevedo et al., 2013).

An application of the Shapley Decomposition over time in a Multidimensional Poverty Indicator has been done for the case of Children's Multidimensional Poverty in Bangladesh (Roche, 2013, p.387). Roche decomposes the within-group and demographic or sectoral effects, using the functional form presented in Equation 5.1.

$$
\Delta M_{0}=\underbrace{\sum_{l=1}^{m}\left(\frac{v_{l}^{t}+v_{l}^{t^{\prime}}}{2}\right)\left(M_{0 l}^{t}-M_{0 l}^{t^{\prime}}\right)}_{\text {within-group effect }}+\overbrace{\sum_{l=1}^{m}\left(\frac{M_{0 l}^{t}+M_{0 l}^{t^{\prime}}}{2}\right)\left(v_{l}^{t}-v_{l}^{t^{\prime}}\right)}^{\text {Demographic or Sectoral Effect }}
$$

In this particular case, the author calculates the marginal effects of: a. changes on the multidimensional poverty $\left(M_{0 l}^{t}-M_{0 l}^{t^{\prime}}\right)$ ceteris paribus (within-group effect) and b. changes in time due to a change in the share of the population $\left(v_{l}^{t}-v_{l}^{t^{\prime}}\right)$ (demographic effect), in two different moments in time $\left(t\right.$ and $\left.t^{\prime}\right)$ and for different sub-groups $(l)$.

In a second stage, Roche (2013) also decomposes the changes over time in terms of the variation in the incidence and intensity of poverty. It is known that the AHR of Alkire and Foster (2011a) is composed of two sub-indicators: The incidence (Censored Headcount or $\mathrm{H}$ ) and the intensity (Intensity of Deprivations or A), hence Shapley's decomposition is also possible. Then the changes can be expressed as shown in Equation 5.2 .

$$
\Delta M_{0 l}=\underbrace{\left(\frac{A^{t}+A^{t^{\prime}}}{2}\right)\left(H^{t}-H^{t^{\prime}}\right)}_{\text {Incidence of poverty effect }}+\overbrace{\left(\frac{H^{t}+H^{t^{\prime}}}{2}\right)\left(A^{t}-A^{t^{\prime}}\right)}^{\text {Intensity of poverty effect }}
$$


Shapley decompositions do not explain causal factors, but provide information to focus on the most important quantitative elements into action, and therefore constitute an important source of information for policy-makers.

\subsubsection{Percentage changes}

Apablaza and Yalonetzky (2013) measure the dynamics of multidimensional poverty in children from Andhra Pradesh, Ethiopia, Peru and Vietnam. The authors study whether the observed differences in the measure of poverty ${ }^{10}$ are due to differences in the headcount ratio $(\mathrm{H})$, the average deprivation of the poor $(\mathrm{A})$ or a combination of both. For this method, the authors relied on a decomposition of "percentage change in the number of multidimensionally poor people, the percentage change in the average number of deprivations of the multidimensionally poor, and a multiplicative effect" (Apablaza and Yalonetzky, 2013, p. 4), as shown in Equation 5.3

$$
\Delta \% M_{(t)}=\Delta \% H_{(t)}+\Delta \% A_{(t)}+\Delta \% H_{(t)} * \Delta \% A_{(t)}
$$

As opposed to the decomposition shown in Section 5.3.1, the multiplicative effect of $\Delta \% H_{(t)} * \Delta \% A_{(t)}$ is included to sum up to $100 \%$ and to avoid double counting. However, the result of this effect is difficult to interpret. Another drawback of this approach is the dependency between $\mathrm{H}$ and $\mathrm{A}$, and therefore the dependency between their respective changes. As noted by the authors; there are cases in which a change in $\mathrm{H}$ could not affect A, and vice-versa (particular cases). This method is useful whenever there is only access to anonymous data. Aggregated average changes are found over time. The results will show if there was a reduction/increase in poverty between two time frames.

\subsubsection{Reversed Generalized Lorenz Curves}

The concept of 'pro-poor growth' has been traditionally attached to monetary poverty. Nonetheless, recently the concept of 'pro-poor' has also been extended to non-monetary measures of well-being as in the case of Gallegos et al. (2015). By using a counting social poverty index (Equation 5.4) that is sensitive to the distribution of the poorest as the AHR of Alkire and Foster, Gallegos, Yalonetzky and Azpitarte derivate a pro-poor condition.

\footnotetext{
${ }^{10}$ The authors account for transitions between poor and non-poor states for the cases in which panel data is available.
} 
The pro-poorness is related to the distribution of well-being. In other words, one is interested in finding out which poverty reduction strategy provides a 'better' reduction of poverty as compared with another. The classification of 'better reduction' refers undoubtedly to an 'inequality-reducing poverty' result. Gallegos et al. (2015, p. 6), following Lasso de la Vega (2010) and Chakravarty and Zoli (2012), formalized the conditions in which a reduction in poverty can be considered pro-poor for counting methods whenever other different normative decisions vary (e.g. second cut-off, weights) and compared the values of the AHR at $t=0$ and $t=1$ as necessary and sufficient conditions for an inequality-reducing evaluation. In other words, if: " $P^{1}<P^{0} \forall P$ in Equation 5.4 $\leftrightarrow L^{0}(s) \leq L^{1}(s) \forall s \in[0,1] \wedge \exists s \mid L^{1}(s)<L^{0}(s)$ ". They used the reversed generalized Lorenz curve (RGLC) as a tool to determine if a reduction of poverty over time also decreased the inequality among the poor. In Equation 5.5 the RGLC or $L(s)^{11}$ is the same AHR of Alkire and Foster.

$$
\begin{aligned}
& P=\frac{1}{N} \sum_{n=1}^{N} \mathbb{I}\left(c_{n} \geq k\right) g\left(c_{n}\right) \\
& L(s)=\frac{1}{N} \sum_{n=1}^{N} C_{n}
\end{aligned}
$$

By analyzing the distributions of the population, the use of anonymous data is sufficient to provide a clear picture of the behavior of poverty reduction on average. As mentioned in Chapter 1, under the lack of available panel data, the anonymous case is a tool that can be exploited for the policy analysis benefit.

\subsection{Results}

Using LSMS data comparable through time for Chile, Colombia, Ecuador and Peru, ${ }^{12}$ the AHR of Alkire and Foster (2011a) is calculated for the individual case, for three population subgroups (children, adults and elderly), and results are shown for the complete span of options for the second cut-off (poverty cut-off or $k$ ). In general, the measure of intensity (A) does not change over time, except for a slight improvement in the case of Ecuador, for the lowest $k$ value. Except for Peru, the rest of the countries experience a better behavior in terms of multidimensional poverty, mainly driven by the changes in

\footnotetext{
${ }^{11}$ The $L(s)$ is a function: $L:[0,1] \rightarrow[0,1]$, showing the cumulative share of the population, ranked in inverse order (from the highest to the lowest) and calculated for every value of the second cut-off.

${ }^{12}$ Chile 2009-2011, Colombia 2010-2013, Ecuador 2006-2014, and Peru 2008-2013, for details about the sample composition refer to Table 3.2 .
} 
the headcount ratio $(\mathrm{H})$. In other words the amount of people considered poor decreased over time. AHR curves cross or overlap in almost any case. The exception is Ecuador, the only country for which conditions clearly improved in every single age group, and where the curve of 2014 dominates that of $2006 .{ }^{13}$

Figure 5.2: AHR over time: Children
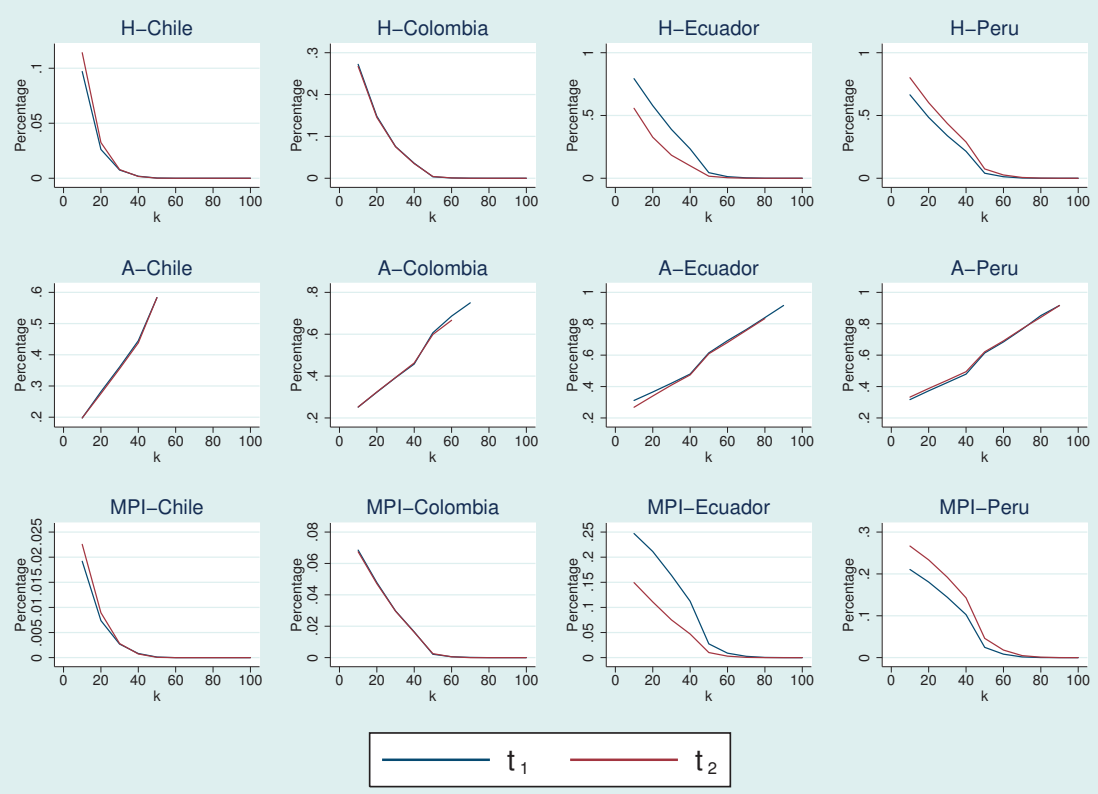

Source: Chilean, Colombian, Ecuadorian and Peruvian LSMS. Author's calculations. $t_{1}$ is the first wave of each survey available, and $t_{2}$ the second wave.

In Figure 5.2 the improvement in Ecuador is clearly noticeable. Chile shows a slightly better result, especially in the lower $k$ range, while in the case of Colombia, it is difficult to tell if it improved or not due to overlapping, as confirmed by the confidence intervals analysis in Appendix 5.6.1. Peru shows a deterioration in the conditions of children, mainly driven by the amount of children considered multidimensionally poor. Chile, Colombia and Ecuador also show that despite the clear overlapping of the Intensity curves (A), there is a reduction in the intensity for the highest level of $k$.

In Figure 5.3 a similar pattern is found. Chile, Colombia and Ecuador performed better over time, although the results for Chile (higher than $k=40 \%$ ), Colombia and Peru are overlapping. The average intensity (A) shows a decrease in the upper limit (higher values of $k$ ) for Colombia and Ecuador, while in Peru it increased. In Chile it did not decline, nor did it increase, but there is a slight improvement for the case of $k=50 \%$.

\footnotetext{
${ }^{13}$ In Appendix 5.6.1 a table with the confidence intervals for every sample is presented.
} 
Figure 5.3: AHR over time: Adults
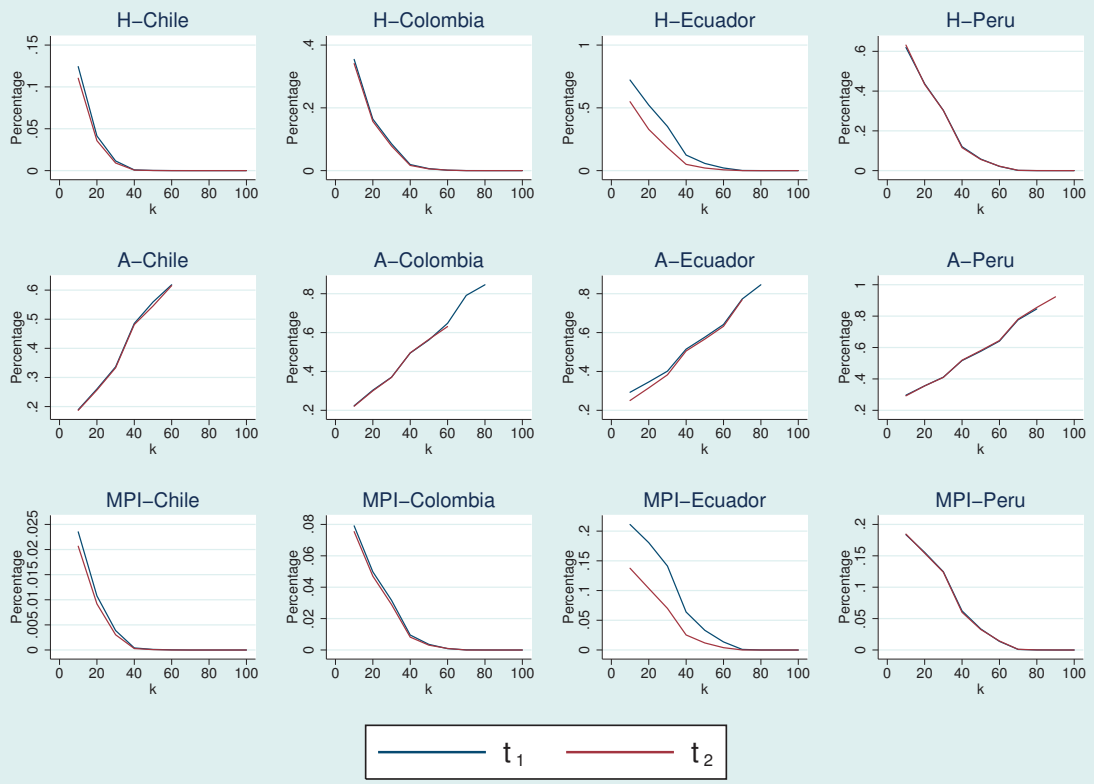

Source: Chilean, Colombian, Ecuadorian and Peruvian LSMS. Author's calculations. $t_{1}$ is the first wave of each survey available, and $t_{2}$ the second wave.

In Figure 5.4 the AHR for elderly is shown. Chile, Colombia and Peru show crossing of curves. In Ecuador, there is a clear improvement in the multidimensional poverty of this age group (overlapping only for levels of $k$ higher than $80 \%$ ). The difference is bigger for lower levels of $k$, due to an improvement of the intensity measure. In the case of Peru, the situation is unclear. The curves cross in multiple points, and therefore it is impossible to robustly conclude if the elderly were better or worse off. That means that the results for Peru critically depend on the choice of $k$.

The results shown in this section only compare the behavior of the AHR over time and hence the information obtained is limited. On the following sections the different decompositions techniques are applied and complementary information is obtained to interpret the patterns found.

\subsubsection{Shapley Decomposition Results}

As explained in Section 5.3.1, calculations for two different decompositions are shown: the decomposition by components and the decomposition by incidence and intensity of poverty. 
Figure 5.4: AHR over time: Elderly
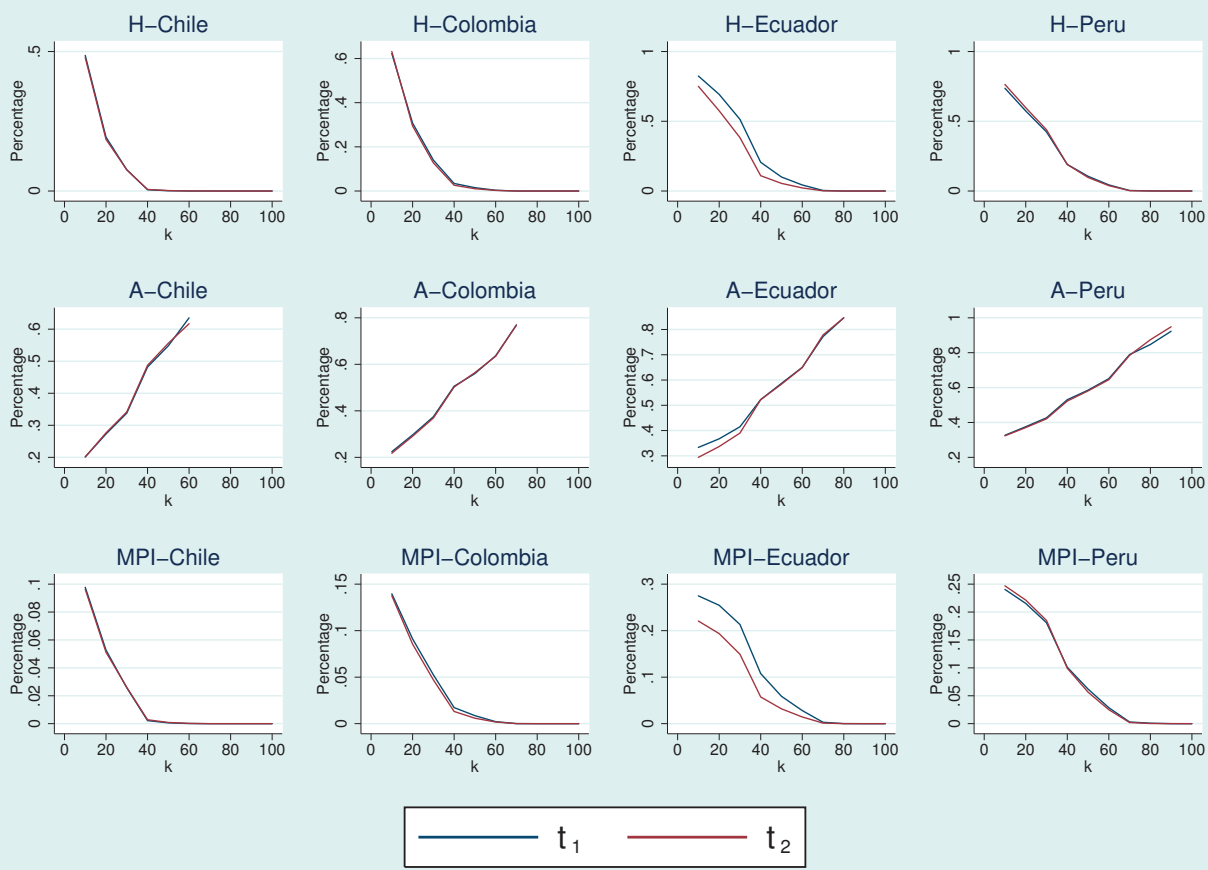

Source: Chilean, Colombian, Ecuadorian and Peruvian LSMS. Author's calculations. $t_{1}$ is the first wave of each survey available, and $t_{2}$ the second wave.

\section{Within and Demographic Effects}

In this section, the isolation between demographic effects and the reduction/increase in poverty are shown. In the particular context of a rapid ageing process, as explained in Section 5.2.1, it is clearly important to differentiate between a change due to population or to an improvement/retrenchment in poverty. As the Shapley Decomposition does not have any residual, the effects of both components will behave as mirrored images, and hence only the within effect will be presented for illustrative purposes. The overall effect, in percentage points, always sums up to 100, despite the signs and values. The values are calculated for the complete span of the poverty cut-off or $k$ and the effects are calculated as percentage points of change. Whenever the curves abruptly peak the opposite effect is found in the demographic component, or in other words there is a switching in the marginal effect that depends on the cut-off. If both effects were drawn the curves will cross and therefore no dominance of one effect over the other will be found. Also slightly changes are easily perceived when only one effect is presented (changes for children in Peru is a good example) therefore it is also important to note the levels of the changes. The aggregation of the results of each subgroup is shown in the last graph of the set (national or aggregated AHR). A comparative pattern can be analyzed for adults in Chile, children, adults and national in Ecuador, according to Figure 5.5 where a tendency to reduction of the effect is found to higher levels of $k$. 
Figure 5.5: Shapley Decomposition Within Effect
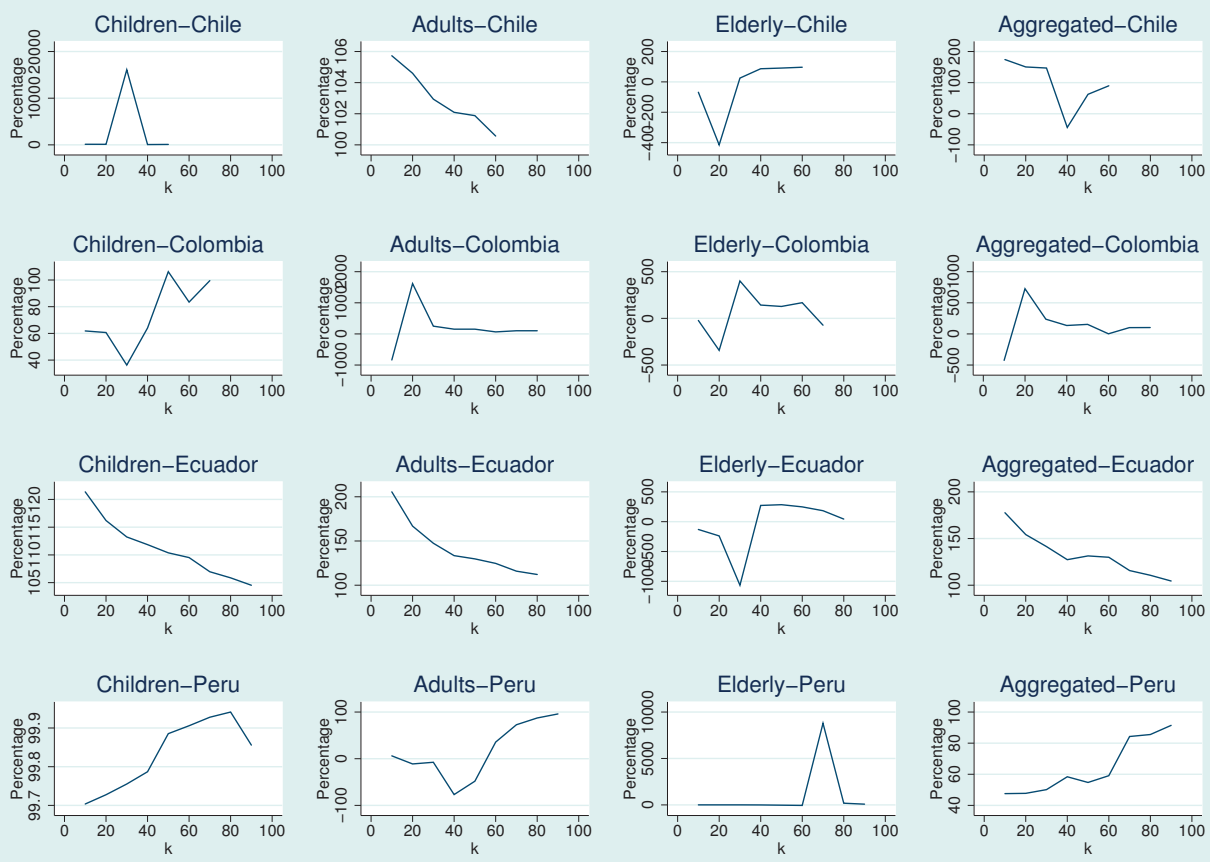

Source: Chilean, Colombian, Ecuadorian and Peruvian LSMS. Author's calculations

Shapley decompositions show the interplay of two different forces in opposite directions. From Equation 5.1, the case of within and demographic decompositions, when poverty increased $M_{0 l}^{t}<M_{0 l}^{t^{\prime}}$ from year $t=0$ to year $t^{\prime}=1$, then $\left(M_{0 l}^{t}-M_{0 l}^{t^{\prime}}\right) \leq 0$ and therefore the 'within' effect is negative. At the same time when the population increased $v_{l}^{t} \leq v_{l}^{t^{\prime}}$ then $\left(v_{l}^{t}-v_{l}^{t^{\prime}}\right) \leq 0$ and the demographic effect is negative.

Four combinations are possible to track consistently through the span of $k$ by looking at the size of the variation over time: a. Positive within and demographic effects (there are no examples of this effect), b. Negative within and demographic effects (both poverty and population increased, e.g. children and aggregated in Peru ), c. Positive within and negative demographic (poverty decreased and population increased, e.g. adults in Chile, elderly in Colombia, children, adults and aggregated in Ecuador), and d. Negative within and positive demographic effect (poverty increased and population decreased, e.g. None). Lastly, switching signs can also be found. This means that the results are not consistent and heavily rely on the choice of $k$, exclusively motivated by the within effect, as the demographic effect does not depend on $k$ (e.g. children, elderly and aggregated in Chile, children, Adults and aggregated in Colombia, elderly in Ecuador, adults and elderly in Peru). 
The behavior of the effects are classified in 9 (out of 24 possible combinations) depending on the following parameters: 1 . The variations are below/above 105\%, 2. The graph shows no peaks/at least one, 3. The effects do not/do cross and 4 . The shape is not/is erratic, as described in Appendix 5.6.2. Summarizing, three main groups can be found: a. low dependence on the level of $k$ (patterns (1) e.g. children in Peru, (2) e.g. children in Ecuador and (3) e.g. Peru), b. mild dependence on the level of $k$ (patterns (6) e.g. elderly in Peru, (11) e.g. children in Chile, (12) e.g. adults in Chile and (13) e.g. adults in Peru), and c. high dependence on $k$ (pattern (4) e.g. elderly in Chile and (5) e.g. children in Colombia). Whenever the curves cross and peak, the researcher can determine that there are no robust results as the assessment of the effect will always depend on the decision about the poverty cut-off.

\section{Incidence and Intensity}

In a similar way, as explained at the end of Section 5.3.1, it is also possible to construct a decomposition of multidimensional poverty on the incidence (depending on $\mathrm{H}$ ) and intensity (depending on A). From Equation 5.2, when the amount of poor people increases $H^{t} \leq H^{t^{\prime}}$ from year $t=0$ to year $t^{\prime}=1$, then $\left(H^{t}-H^{t^{\prime}}\right) \leq 0$, and therefore the Incidence effect is negative. At the same time when the average number of deprivations increases $A^{t} \leq A^{t^{\prime}}$ then $\left(A^{t}-A^{t^{\prime}}\right) \leq 0$ and the Incidence effect is negative. Opposed to the previous result, both $\mathrm{H}$ and $\mathrm{A}$ depend on the poverty cut-off or $k$.

Of the four combinations described in Section 5.4.1, in this case only two cases were found. The case in which both the number of poor people and the average dimensions decreased (case A) and the opposite case in which both effects were negative (case B). Mirroring the analysis of graphs, in this case new combinations are found, as shown in Appendix 5.6.2. Summarizing, also three patterns are found: a. low dependency on the level of $k$ (patterns (1) e.g. Ecuador, (2) e.g. adults in Colombia and (3) e.g. elderly in Colombia; b. mild dependency on the level of $k$, mainly driven by small crossings and the lack of an erratic path (patterns (6) children in Chile, (7) e.g. adults in Chile and (9) e.g. adults in Peru); and c. high dependency on the level of $k$ (patterns (4) e.g. elderly in Chile, (5) e.g. Colombia and (10) e.g. children in Colombia).

\subsubsection{Percentage Changes}

In this section, the results of the method by Apablaza and Yalonetzky (2013) are shown. Despite its simplicity, whenever different choices of poverty cut-off are found, different patterns result. In general, the percentage changes on the multidimensional poverty indicator (AHR) move along the same trend as the number of multidimensional poor $(\mathrm{H})$. Also, the average number of deprivations (A) moves along with the multiplicative effect $\left(\mathrm{H}^{*} \mathrm{~A}\right)$, for all the countries in the sample. Small deviations of the trend are evident with 
Figure 5.6: Shapley Decomposition Incidence Effect
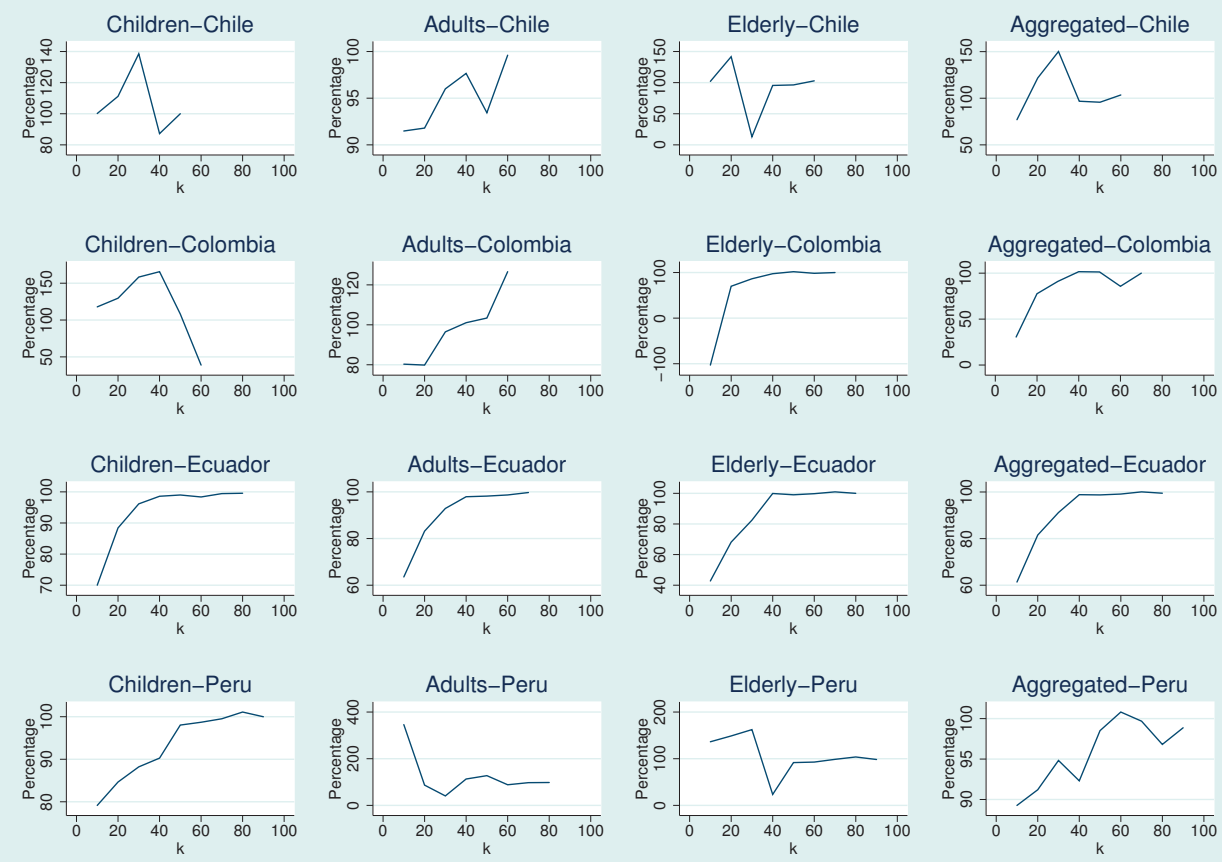

Source: Chilean, Colombian, Ecuadorian and Peruvian LSMS. Author's calculations

low levels of $k$. To facilitate the interpretation of the figures, it is important to keep in mind Equation 5.3. The higher the $k$, the less people are considered multidimensionally poor. It is very common to find peaks/trough in the figures. The direction of the behavior determines if the situation is better(trough) or worse (peak) in the nearest date $\left(t_{2}\right)$ when it is compared with the initial date $\left(t_{1}\right)$.

In the case of children and adults in Chile, it is evident that the percentage changes over time decreases the higher the level of $k$. However, increases in poverty are shown in the case of elderly the higher the $k$. For all the age groups the intensity of poverty remains closer to 0 , so the changes in these components are negligible.

The behavior of percentage changes in Colombia was close to zero for all the age groups, but especially for children and adults for lower levels of $k$. Both populations also show a peak at $k=50 \%$. The case of elderly is particularly interesting because although the reduction was negative, it has the shape of a $U$ with the global minimum in $k=50 \%$. This means that the more deprived elderly are (after $50 \%$ of dimensions as poverty cut-off), the less gains on the reduction of multidimensional poverty. 
Figure 5.7: Percentual Changes Chile
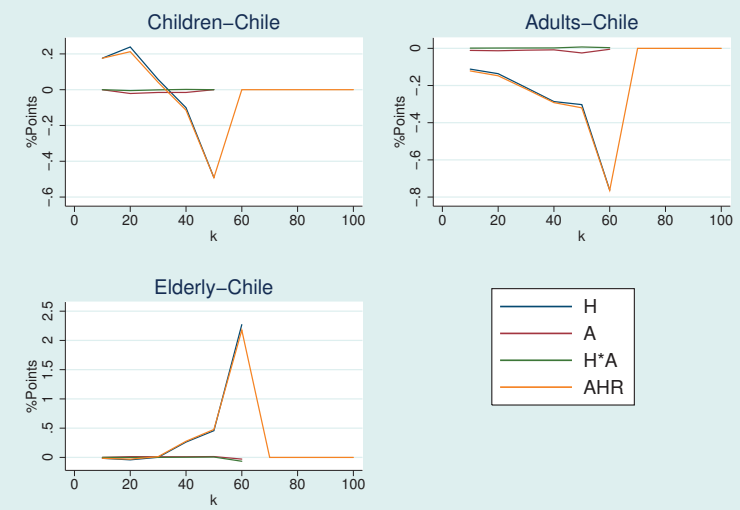

Source: Chilean LSMS. Author's calculations

Figure 5.8: Percentual Changes Colombia
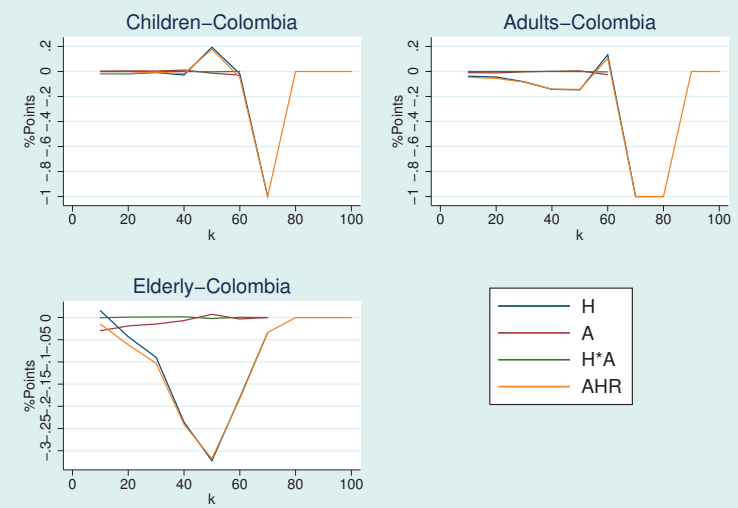

Source: Colombian LSMS. Author's calculations

The case of Ecuador is particular as it is the country in which the effect of A is higher, particularly for lower levels of $k$. A higher change due to A means that poverty decreased because there was a smaller amount of poor people but also because the depth of poverty was also lower. There is a downward trend, which means that poverty was reduced in the three population groups despite the choice of $k$. 
Figure 5.9: Percentual Changes Ecuador
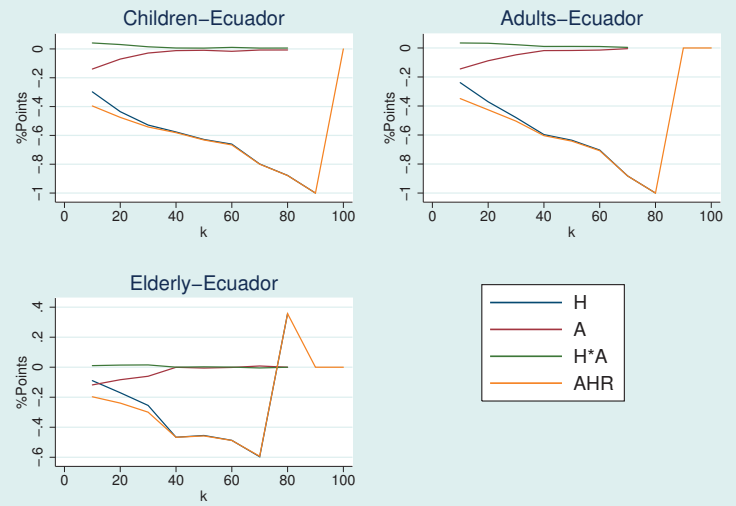

Source: Ecuadorian LSMS. Author's calculations

Figure 5.10: Percentual Changes Peru
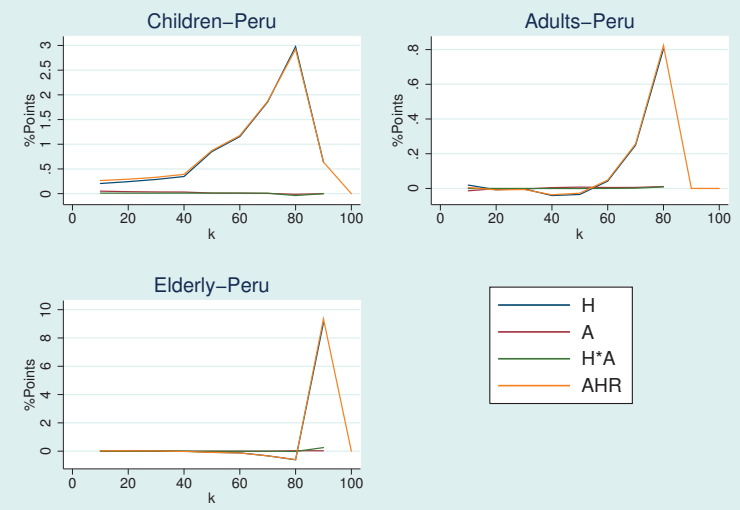

Source: Peruvian LSMS. Author's calculations

Finally, in the case of Peru, it is evident that multidimensional poverty increased as opposed to the rest of the countries of the sample, in all the age groups. In the cases of adults and elderly, the changes of each sample are around zero for lower levels of $k$. Poverty increases when a higher condition on the average number of deprivations is imposed, clearly showing a worsening in the situation of all the age groups. 


\subsubsection{Reversed Generalized Lorenz Curves}

A good way to analyze the results from the reversed generalized Lorenz curves, as explained in Section 5.3.3 is to compare if the curve of the second wave is always below that of the first wave. In this sense, what the researcher wants to find out is whether for a particular choice of indicators, thresholds and weights, there was a reduction in multidimensional poverty or not; no matter which the second cut-off (poverty cut-off) is.

In Figure 5.11 a graph depicting the Headcount (x-axis) against the AHR (y-axis) for each country and age group is shown. If a curve strongly dominates another, then one can safely conclude that the results are robust to different poverty cut-off as the level of $\mathrm{H}$ depends on the number of indicators in which a person is considered multidimensionally deprived. According to Gallegos et al. (2015), reductions in poverty were pro-poor whenever the area under the curve is clearly smaller in $t=2$.

Figure 5.11: Reversed Generalized Lorenz Curves
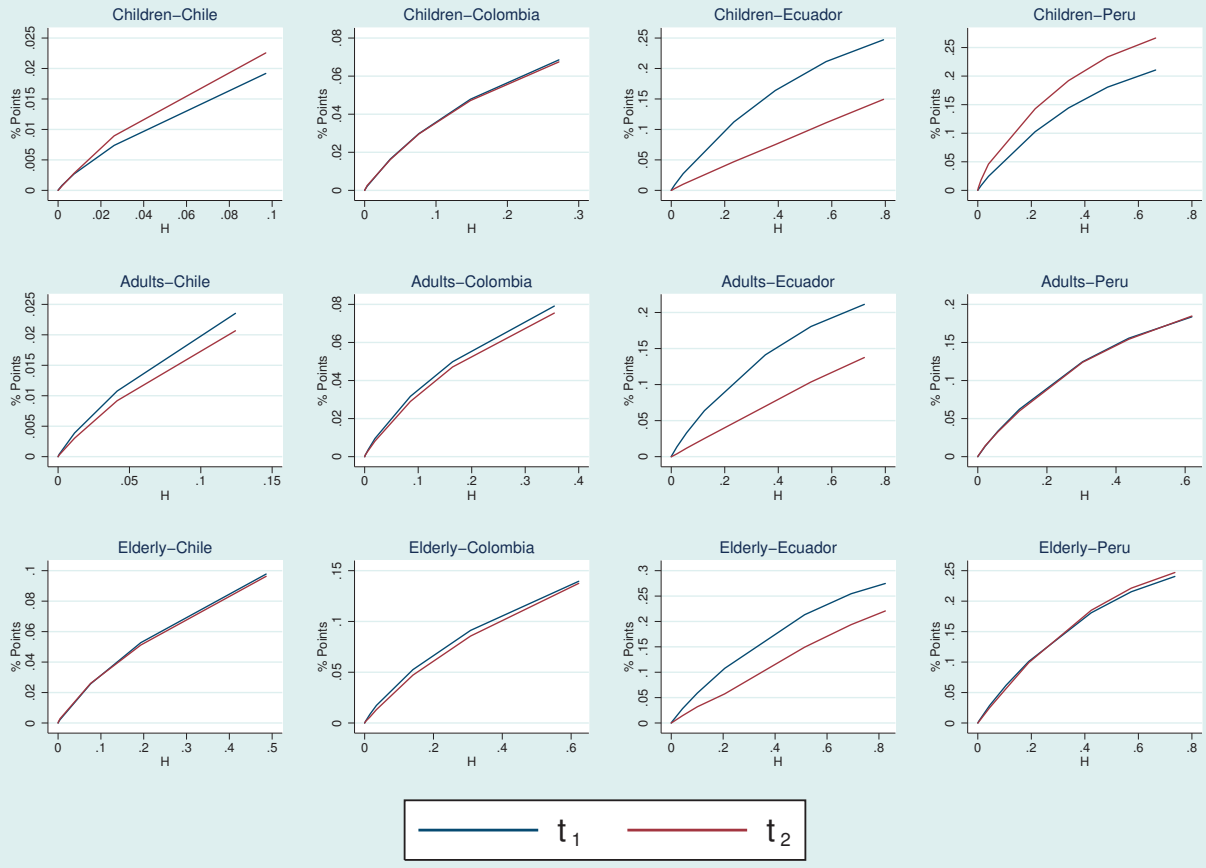

Source: Chilean, Colombian, Ecuadorian and Peruvian LSMS. Author's calculations

In the case of Ecuador there is a clear improvement in the multidimensional poverty for the three population groups (See Appendix 5.6.1). Crossing in the origin is expected, as the headcount is sorted in reversed order, so fewer people are found to be deprived in all the dimensions at the same time. Chile shows that although reduction in multi- 
dimensional poverty was found in adults and elderly, overlaps are common for higher levels of $k$. For adults there is a clear improvement when smaller levels of $k(10-30 \%)$ are considered while for children there was a worsening of the situation (overlaps occur when levels of $k>=30 \%$ are chosen). In elderly the reduction is minimal and confidence intervals show a constant crossing of lines. Colombia shows the smaller gap between the two curves, although whenever it is compared with Chile, the initial conditions were higher. However, despite the fact that graphically the curves of 2013 dominate the curves of 2010, there is overlapping in all the groups when the sample is considered.

Ecuador is the clearest case of a strong multidimensional poverty reduction. The curves of 2014 strongly dominate the curves of 2006, not only because of the difference in years between the two measured points but also because the starting point of multidimensional poverty was higher compared to the other countries. It is the only case in which all the groups are dominant (Overlapping of confidence intervals only occurs for elderly and levels of $k$ higher than $70 \%$ ).

The case of Peru is a particular one. Children are clearly worse off in 2013 than they were in 2008. In this case multidimensional poverty increased, and 2008 dominates 2013. For adults and elderly there is no dominance, the curves constantly cross and therefore there is no robust result of improvement/deterioration of their situation. The results for Peru clearly prove that the reduction/increase on multidimensional poverty depends on measurement choices, in this particular case to the level of $k$.

\subsection{Conclusion}

Multidimensional poverty dynamics is a recent field for research and exploration. Inherited from the monetary approaches, the field has benefited from their lessons. Despite the lack of consensus and the incipient advance on available techniques for the analysis, public policy making could benefit greatly from these lessons. Poverty and well-being are a sensitive topic in countries with high levels of inequality. Access to social assistance and social security has been the focus of both left and right wing governments in middle income countries. Social protection systems, especially in Latin America, have advanced in coverage and in creating mechanisms to transfer the benefits of growth to the poorest. Nonetheless, they are still in early stage of development. Efforts seem ineffective both in monetary and non-monetary indicators. Services are segmented by the enrolment in the formal or informal labor market. The debate on quality and on the effect on the reduction of poverty and inequality has not happened. Finally, all of the above is happening at the same time as the region is experiencing a rapid shift in demographic distribution, resulting in an increase of the population older than 65 years old. 
Increasingly, countries in Latin America have started using multidimensional measures of poverty to assess the impact of the policies to reduce it. From the countries analyzed in this chapter, Colombia, Chile and recently Ecuador have already created and started using their own composite indicator.

New techniques to evaluate the performance over time along different dimensions are increasingly available but scarcely used and understood. This chapter condensed the known techniques to assess the reasons behind average changes over time in multidimensional poverty through counting methods in four countries in Latin America. Their empirical application shows interesting results and recommends their application continuously. Decisions about where to fix the second cut-off should be taken with considerations not only on what is the ideal situation for a society but also how do it performs in different scenarios.

This chapter found that despite the methodological differences between the different techniques, there are no contradictory findings. In that sense, whenever the comparisons over time are robust for all the measures, prevalence of results is found through the entire span of the second cut-off. If curves do not cross, the methods provide complementary information. That is the case for the reduction of poverty over time in children and adults in Chile and all the age groups in Ecuador. In other words, for these cases the decision about the value $k$ does not impact on the average but only on the score of the index. Any normative decision about this parameter will maintain a general trend. Considerations of these cases should be based on the objective of the measure.

The most complicated findings to interpret are the Shapley decompositions. However it is clear that whenever robustness is found, the higher effect can be found in the reduction in multidimensional poverty instead that in the demographic effect. Those reductions are mainly driven by the decrease in the number of the multidimensionally poor (as the incidence-intensity and percentage changes show). Also, in the case of the percentage changes technique, the multiplicative effect is difficult to interpret, although negligible in size on the particular application shown in this chapter. The clearest comparison is therefore the one shown by the reversed generalized Lorenz technique.

Not surprisingly, when the curves cross, there is no robustness in the results. Consistently, the different methods show the lack of consensus on the results. For example, the lack of robustness on the Shapley decompositions by components in the different groups in Colombia is reinforced with a high dependency on the $k$ value when both incidence-intensity and percentual changes are calculated. 
In terms of pro-poor reductions, the higher similarity is found between percentual changes and reversed generalized Lorenz curves. It is clear that Ecuador was better off in 2014 than in 2006. The RGL curves give a better spectrum of analysis than the sole comparison of MPI curves. The inverse ordering and the condition that in the origin it is expected to find overlapping due to the higher requirements for poverty along a very small percentage of the population is the key element.

The context specificity of the result is even shown in the small sample of analyzed countries. An example is the comparison between the performance of Peru with that of Ecuador, the extreme cases. Peru experienced a step back in terms of well-being, mainly for children, while Ecuador moved forward in all the age groups.

In terms of application for social policy making the results show that a higher dependency of the second cut-off impacts the final result. In cases like Colombia, between 2010 and 2013, it is difficult to tell if there is a reduction or not in poverty; and if in general the behavior depends more on the poverty or on the demographic effect. There are no clear signs of differences between the number of multidimensionally poor or the intensity of poverty. The decision has to be taken with consideration on the applicability of the measure; with a focus on the tails of the distribution (targeting or evaluation). In these cases considering a range of poverty cut-off is advisable and more needed than in cases where robustness is found.

Finally, the case of Chile is a particular one. Changes over time are very small and difficult to analyze. Its starting point is already too low. It is clear at least, that the focus of the policy making has to be the neglected population above 65 years old and the worsening of the situation for children. Not only because of the lack of robustness in the findings but also because the stage of the demographic profile of the country. This is another example of why the integration between policy-making and measurement is highly useful. 


\subsection{Appendix}

\subsubsection{Confidence Intervals}

Table 5.4: Confidence Intervals for comparisons over time

\begin{tabular}{|c|c|c|c|c|c|c|c|c|c|c|c|c|c|c|c|}
\hline \multicolumn{6}{|c|}{ Children } & \multicolumn{5}{|c|}{ Adults } & \multicolumn{5}{|c|}{ Elderly } \\
\hline \multicolumn{16}{|c|}{ Chile } \\
\hline $\mathrm{k}$ & $\mathrm{Lb} t_{1}$ & $\mathrm{Hb} t_{1}$ & $\mathrm{Lb} t_{2}$ & $\mathrm{Hb} t_{2}$ & & $\mathrm{Lb} t_{1}$ & $\mathrm{Hb} t_{1}$ & $\mathrm{Lb} t_{2}$ & $\mathrm{Hb} t_{2}$ & & $\mathrm{Lb} t_{1}$ & $\mathrm{Hb} t_{1}$ & $\mathrm{Lb} t_{2}$ & $\mathrm{Hb}_{2}$ & \\
\hline 20 & 0,0070 & 0,0077 & 0,0085 & 0,0094 & & 0,0105 & 0,0111 & 0,0089 & 0,0095 & & 0,0517 & 0,0538 & 0,0499 & 0,0524 & * \\
\hline 30 & 0,0025 & 0,0029 & 0,0025 & 0,0031 & $*$ & 0,0037 & 0,0041 & 0,0028 & 0,0032 & & 0,0248 & 0,0266 & 0,0250 & 0,0271 & * \\
\hline 40 & 0,0007 & 0,0010 & 0,0006 & 0,0009 & $*$ & 0,0003 & 0,0005 & 0,0002 & 0,0004 & * & 0,0019 & 0,0025 & 0,0024 & 0,0032 & * \\
\hline \multicolumn{16}{|c|}{ Colombia } \\
\hline 10 & 0,0667 & 0,0703 & 0,0658 & 0,0691 & $*$ & 0,0776 & 0,0806 & 0,0742 & 0,0767 & & 0,1361 & 0,1430 & 0,1349 & 0,1402 & * \\
\hline 20 & 0,0461 & 0,0496 & 0,0456 & 0,0487 & $*$ & 0,0484 & 0,0513 & 0,0459 & 0,0483 & * & 0,0874 & 0,0950 & 0,0827 & 0,0886 & * \\
\hline 30 & 0,0282 & 0,0313 & 0,0282 & 0,0310 & $*$ & 0,0304 & 0,0330 & 0,0279 & 0,0301 & & 0,0491 & 0,0561 & 0,0445 & 0,0498 & $*$ \\
\hline 80 & 0 & 0 & 0 & 0 & & $-3,1 \mathrm{E}-05$ & 0,0001 & 0 & 0 & * & 0 & 0 & 0 & 0 & \\
\hline \multicolumn{16}{|c|}{ Ecuador } \\
\hline 10 & 0,2450 & 0,2494 & 0,1479 & 0,1509 & & 0,2092 & 0,2133 & 0,1363 & 0,1388 & & 0,2700 & 0,2797 & 0,2177 & 0,2238 & \\
\hline 20 & 0,2088 & 0,2139 & 0,1094 & 0,1126 & & 0,1783 & 0,1829 & 0,1023 & 0,1050 & & 0,2492 & 0,2600 & 0,1903 & 0,1971 & \\
\hline 30 & 0,1612 & 0,1667 & 0,0736 & 0,0767 & & 0,1389 & 0,1436 & 0,0687 & 0,0713 & & 0,2072 & 0,2193 & 0,1457 & 0,1530 & \\
\hline 40 & 0,1097 & 0,1150 & 0,0457 & 0,0484 & & 0,0618 & 0,0659 & 0,0243 & 0,0262 & & 0,1019 & 0,1136 & 0,0544 & 0,0605 & \\
\hline 50 & 0,0258 & 0,0291 & 0,0094 & 0,0108 & & 0,0315 & 0,0347 & 0,0112 & 0,0126 & & 0,0541 & 0,0638 & 0,0295 & 0,0344 & \\
\hline 60 & 0,0079 & 0,0099 & 0,0025 & 0,0034 & & 0,0125 & 0,0147 & 0,0035 & 0,0044 & & 0,0247 & 0,0319 & 0,0127 & 0,0162 & \\
\hline 70 & 0,0020 & 0,0032 & 0,0003 & 0,0007 & & 0,0007 & 0,0014 & 0,0000 & 0,0002 & & 0,0017 & 0,0044 & 0,0007 & 0,0018 & * \\
\hline 80 & 0,0002 & 0,0007 & 0,0000 & 0,0001 & & $-2,7 \mathrm{E}-05$ & 0,00013 & 0 & 0 & & $-0,0002$ & 0,0004 & $-0,0001$ & 0,0004 & * \\
\hline 90 & $-3,8 \mathrm{E}-05$ & 0,0001 & 0 & 0 & & 0 & 0 & 0 & 0 & & 0 & 0 & 0 & 0 & \\
\hline \multicolumn{16}{|c|}{ Peru } \\
\hline 60 & 0,0075 & 0,0092 & 0,0171 & 0,0193 & & 0,0127 & 0,0147 & 0,0135 & 0,0152 & * & 0,0260 & 0,0313 & 0,0231 & 0,0269 & * \\
\hline 70 & 0,0013 & 0,0021 & 0,0042 & 0,0054 & & 0,0006 & 0,0012 & 0,0009 & 0,0014 & * & 0,0021 & 0,0040 & 0,0014 & 0,0027 & * \\
\hline 80 & 0,0001 & 0,0004 & 0,0008 & 0,0014 & & $7,5 \mathrm{E}-07$ & 0,0002 & 0,0001 & 0,0003 & $*$ & 0,0003 & 0,0014 & 0,0001 & 0,0006 & * \\
\hline 90 & $-2,1 \mathrm{E}-05$ & 0,0002 & $9 \mathrm{E}-06$ & 0,0002 & * & 0 & 0 & $-1,8 \mathrm{E}-05$ & 0,0001 & * & $-5 \mathrm{E}-05$ & 0,00007 & $-5,1 \mathrm{E}-05$ & 0,00026 & * \\
\hline
\end{tabular}




\subsubsection{Grouping Shapley Decompositions}

Table 5.5: Shapley Classification

\begin{tabular}{|c|c|c|c|c|c|c|c|c|c|c|c|c|}
\hline \multirow[b]{2}{*}{ Group } & \multicolumn{6}{|c|}{ Within-Demographic } & \multicolumn{6}{|c|}{ Incidence and Intensity } \\
\hline & (1) & (2) & (3) & (4) & Pattern & Class & (1) & (2) & (3) & (4) & Pattern & Class \\
\hline \multicolumn{13}{|c|}{ Chile } \\
\hline Children & 0 & 0 & 1 & 1 & (11) & & 0 & 0 & 1 & 0 & (6) & \\
\hline Adults & 1 & 1 & 1 & 0 & (12) & $\mathrm{C}$ & 1 & 0 & 1 & 0 & (7) & A \\
\hline Elderly & 0 & 0 & 0 & 0 & (4) & & 0 & 0 & 0 & 0 & (4) & \\
\hline Aggregated & 0 & 0 & 0 & 0 & (4) & & 0 & 0 & 1 & 0 & (6) & \\
\hline \multicolumn{13}{|c|}{ Colombia } \\
\hline Children & 1 & 0 & 0 & 0 & $(5)$ & & 0 & 0 & 0 & 1 & $(10)$ & \\
\hline Adults & 0 & 0 & 0 & 0 & $(4)$ & & 0 & 1 & 1 & 1 & $(2)$ & \\
\hline Elderly & 0 & 0 & 0 & 0 & (4) & $\mathrm{C}$ & 1 & 1 & 0 & 1 & (3) & \\
\hline Aggregated & 0 & 0 & 0 & 0 & (4) & & 1 & 0 & 0 & 0 & $(5)$ & \\
\hline \multicolumn{13}{|c|}{ Ecuador } \\
\hline Children & 0 & 1 & 1 & 1 & $(2)$ & $\mathrm{C}$ & 1 & 1 & 1 & 1 & (1) & $\mathrm{A}$ \\
\hline Adults & 0 & 1 & 1 & 1 & $(2)$ & $\mathrm{C}$ & 1 & 1 & 1 & 1 & (1) & $\mathrm{A}$ \\
\hline Elderly & 0 & 0 & 0 & 0 & (4) & & 1 & 1 & 0 & 1 & (3) & \\
\hline Aggregated & 0 & 1 & 1 & 1 & (2) & $\mathrm{C}$ & 1 & 1 & 1 & 1 & (1) & $\mathrm{A}$ \\
\hline \multicolumn{13}{|c|}{ Peru } \\
\hline Children & 1 & 1 & 1 & 1 & (1) & B & 1 & 1 & 1 & 1 & (1) & \\
\hline Adults & 1 & 0 & 0 & 1 & (13) & & 0 & 1 & 0 & 1 & (9) & \\
\hline Elderly & 0 & 0 & 1 & 0 & (6) & & 0 & 0 & 0 & 0 & (4) & \\
\hline Aggregated & 1 & 1 & 0 & 1 & (3) & B & 1 & 0 & 1 & 0 & (7) & B \\
\hline
\end{tabular}

Source: Statistical Offices of the Countries. By Class the following classification is understood: $\mathrm{A}=$ Both effects are positive, $\mathrm{B}=$ Both effects are negative, $\mathrm{C}=$ Positive first (within or incidence), and negative second (demographic or intensity, and $\mathrm{D}=$ Negative first and positive second. By pattern, 24 possible combinations are found, and basically it describes the different combinations of the following conditions, identified by the columns in parenthesis:(1) Variation is under 105\%. (2) The graph has no peaks. (3) The mirroring effects do not cross. (4) The graph does not show any erratic behavior. 


\section{CHAPTER}

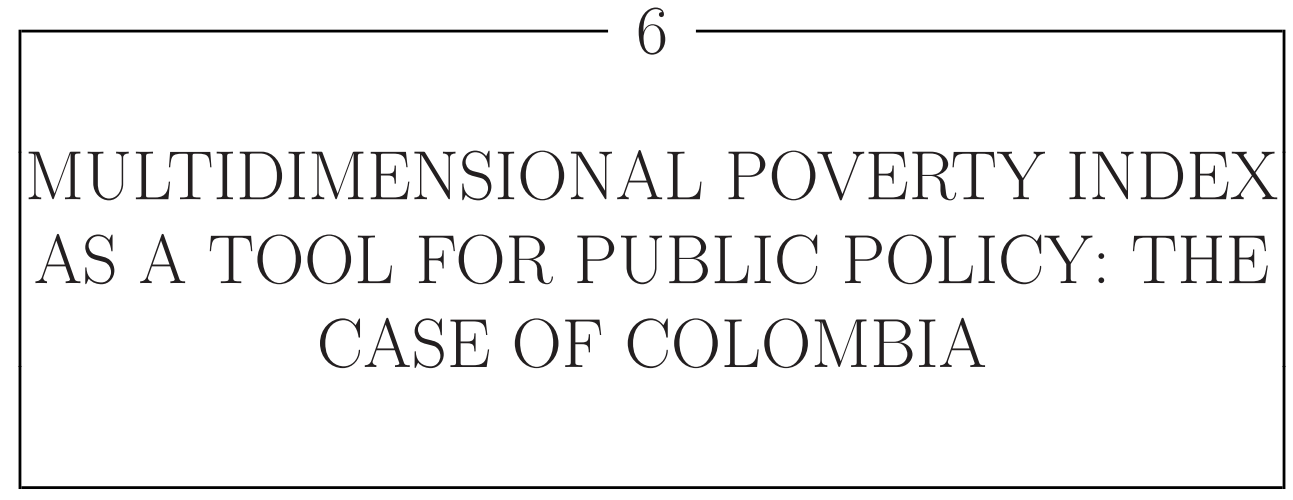

The objective of this chapter is to describe and analyse the process of adopting a multidimensional poverty measure as a tool to monitor public policies, particularly in the case of Colombia. A qualitative analysis of the design, implementation and monitoring of multidimensional poverty goals is performed for the cases of a medium term national goal (4 years) and an application in a social program (Red UNIDOS). The chapter compares the results of in-depth interviews with policy-makers, the analysis of official documents and how newspaper articles reflect the change in the language from exclusively a monetary measure of poverty, to a combination with a multidimensional poverty measure. The analysis is motivated in the widespread use of the Adjusted Headcount Ratio (AHR) of the Alkire-Foster (2011a) family of indicators. This chapter finds that the successful implementation of a Multidimensional Poverty Index (MPI) in Colombia as a national goal is due to a convergence of different events. The main drivers of this process were the timing, commitment of public servants and communication strategies. On the other hand, the driver of using an MPI as a condition in a social program is completely different. It is a consequence of the adoption of a national goal. How sustainable in time is the use of an MPI as a public policy tool is not possible to be assessed. Nonetheless, the evidence provided by this chapter suggests that an adaptation of indicators, a change in the language and better awareness of the effects of normative decision making are needed to guarantee its continuity and utility. 


\subsection{Introduction}

The measurement of poverty goes beyond the counting of individuals who are considered deprived in comparison with the rest of the society they live in. "What we measure shapes what we collectively strive to pursue -and what we pursue determines what we measure" (Stiglitz et al., 2009, p. 9). Policy decisions are taken based on a particular situation that has been diagnosed through an indicator or a measure. How good the measure is in itself and how well that measurement is understood by the decision makers are key elements to those decisions. Compare the case of a policy-maker with a pilot. Imagine the pilot reading the plane's instruments. The more accurate the measures are, the easier it is for the pilot to fly. Policy-makers are also pilots. In the case of social policy, the instruments are the indicators and the plane is the social protection system or a particular policy program that will allow people to be better off in terms of well-being.

The measurement of multidimensional poverty has been largely debated. The Oxford Poverty and Human Initiative (OPHI) at University of Oxford took the lead on the operationalization of a measure of multidimensional poverty, based on the counting approach: The Alkire-Foster Adjusted Headcount Ratio (AHR). A multidimensional poverty measure is included since 2010 in the Human Development Report: The Real Wealth of Nations. Pathway to Human Development (HDR). Simultaneously, OPHI organized a series of seminars and workshops on the AHR, in which public officials were trained. A network of policy-makers was also created in 2013, the Multidimensional Poverty Peer Network. Co-founded by OPHI, and the governments of Mexico and Colombia, it has the aim to promote the use of multidimensional measures. The increased demand for cooperation from governments all over the world was the seed of this network (OPHI, 2013).

Colombia is one of the exemplary cases of the use of a multidimensional poverty as a public policy tool. It was the third country to apply the AHR as a tool for public policy, after Mexico and Bhutan. The added value of the Colombian measure is that it was not only used as a benchmark for national policies, but it was accompanied by an institutional change on the measurement of poverty and widespread applications in social programs. This chapter proves that the success in this particular case was linked not only to an internal need, but also to the willingness and commitment of policy-makers, and the support of an informal network of academics. The timing of the decision was also crucial as well as the phenomenon of horizontal revolving doors of public servants. Currently in Colombia, poverty is officially measured and reported in monetary and multidimensional terms. This chapter also argues that there was a switch in the language used by the media. This last aspect is strengthening the use of a multidimensional measurement of poverty. Colombia recently approved a new National Development Plan (2014-2018), and a multidimensional measure of poverty as a policy tool was also included as a goal.

The remainder of this chapter is organized as follows. The next section discusses the context of poverty measurement in Colombia. Section three introduces the qualitative approach used. Section four presents the main findings. Section five analyzes a particular application and section six concludes. 


\subsection{Measurement of poverty and public policy ap- plications in Colombia}

In Colombia the measurement of poverty has traditionally included both monetary and non-monetary indices, a common practice in Latin America. Since the late 80s the Unsatisfied Basic Needs Index (NBI) ${ }^{1}$ has been used to diagnose the lack of access of the population to goods and services considered a priority (DNP, 2012). Additionally an official targeting index (SISBEN) ${ }^{2}$ is also a measure of living standard variables, and ideally, it should be used to find the beneficiaries of every social program. The SISBEN is the mandatory targeting mechanism for social programs in Colombia. The tool is updated to avoid an increase of the percentage of inclusion error through time. A description of the main milestones of the tool is shown in Figure 6.1. The multidimensional concept lies behind the use of the SISBEN since the second version. The main changes in the different versions of the index are: i) the methodology used to calculate the result (e.g. principal components, fuzzy sets), ii) the definition of the cut-off points, and iii) the variables considered (exclusion of those that are easily manipulable by the beneficiaries).

Figure 6.1: Targeting Mechanisms Milestones in Colombia -SISBEN

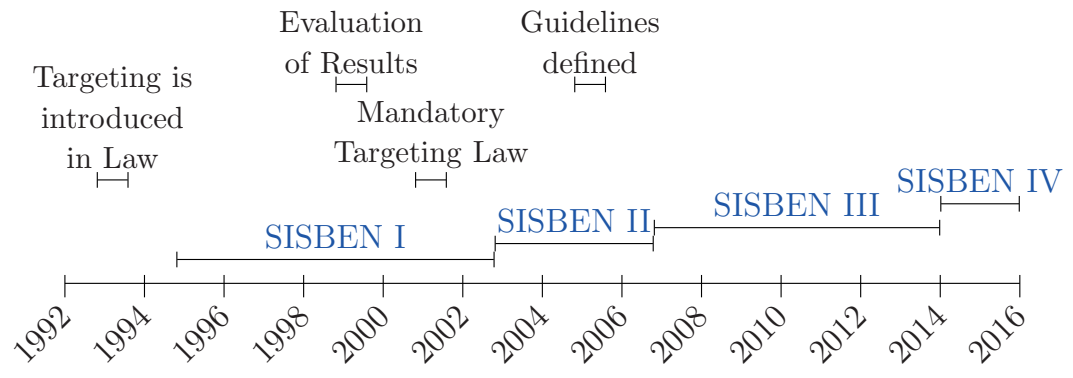

Source: Author based on (Flórez et al., 2008).

In 2011, Colombia joined Mexico and Bhutan at the pioneering group of countries in the world to apply a Multidimensional Poverty Index (MPI), using Alkire and Foster (2011a), as a public policy goal. In the case of Colombia, the multidimensional measure of poverty became part of the monitoring and evaluation system to reduce poverty,

\footnotetext{
${ }^{1}$ The NBI was introduced in Latin America by the Economic Commission for Latin America and the Caribbean (ECLAC) in the early 80s. The framework on which it is based is the Basic Needs Approach led by the World Bank (Streeten, 1979) and inspired by the 'basic goods' of Rawls (1971) as explained in Chapter 2. The variables included as needs are basically the characteristics of the shelter and household demographics. The main source of information is Census Data. Feres and Mancero (see 2001, p. 7-8)

${ }^{2}$ The SISBEN was implemented in 1995 and officially adopted as a targeting mechanism in 1997. Due to its objective it has to be updated regularly. Currently the index is in its third version, and the DNP is working in a fourth version. It includes the following dimensions: Health, Education, Living Standards and Vulnerability (Collective and Individual). (Flórez et al., 2008)
} 
together with the measurement of monetary poverty. The objective of this chapter is to describe the process of adopting an MPI, to explain the reasons why it is included as an official measure and to analyze the mechanisms that led to this event.

Selecting the MPI as a policy goal was possible due to a convergence of different forces. First, a general distrust in the Statistical Office, especially in the measurement of monetary poverty performed by it. In 2006, the Statistical Office (DANE) changed the survey source to calculate monetary poverty. In doing so, the splicing protocol was not included and comparability was lost. A mission of experts (MESEP ${ }^{3}$ in Spanish) was assembled in 2009 to solve the comparability issues of data on employment, poverty and inequality. Second, a new President took office in August 2010. A new National Development Plan needed to be designed and goals had to be set ${ }^{4}$. And third, OPHI responsible for the Multidimensional Poverty Indicator (MPI) of the HDR in 2010, made a series of workshops to spread the knowledge about their method.

On one hand, the MESEP improved the trust in the results provided by DANE. A result of this mission was to guaranteed a splicing protocol, to update the poverty lines and to implement the multidimensional measurement of poverty. Among the recommendations to avoid inconveniences in the future, a new institutional arrangement was designed. Since 2012, DANE has been in charge of coordinating the experts teams that, under the guidelines of the recommendations of MESEP, provide transparency, accuracy and continuity to the measurement of poverty. The National Department of Planning (DNP) and the Department of Social Prosperity (DPS) are part of both committees. Any changes in the methodology and surveys need to be approved by the committee. ${ }^{5}$

The design of a multidimensional poverty measure was an initiative of DNP, based on the AHR of Alkire and Foster (2011a). DNP is also in charge of the monitoring and evaluation of policies and programs. An impact evaluation of the National Strategy to Overcome Extreme Poverty (UNIDOS) was delivered in 2012. The report includes a chapter with the design of an exit mechanism of UNIDOS. The report established the need to define: i) optimal and ii) minimum conditions to end the participation of beneficiaries in the strategy. The initial proposal considered the mix of both monetary and non-monetary indicators (e.g. NBI, Quality of Life and Monetary Poverty Lines)

\footnotetext{
${ }^{3}$ The Misión para el Empalme de las Series de Empleo, Pobreza y Desigualdad [Mission for Splicing of Employment, Poverty and Inequality Data] or MESEP, was formed by a team of technical experts from both DANE and DNP, as well as academics, independent researchers and representatives of the World Bank and ECLAC.

${ }^{4}$ In Colombia, a Constitutional mandate requires that the "Plan" has to be presented to the Congress by the elected President. The 2014-2018 National Development Plan was finally approved by the Parliament on 9th of June 2015 and formalized in Law 1753 of 2015 . The analysis performed in this chapter refers exclusively to the monitoring of the 2010-2014 National Development Plan.

${ }^{5}$ An explanation of the current institutional arrangement for relevant institutions in Colombia is presented in Annex 6.8.3.
} 
and the accomplishment of the priority goals proposed by the strategy. ${ }^{6}$ UNIDOS uses a multidimensional measure of poverty as part of the conditions a household needs to fulfil in order to no longer be considered extremely deprived.

Although other programs adopted the use of a multidimensional measure (e.g. targeting of CCT -Más Familias en Acción.), only two applications of multidimensional poverty indices were selected to be analyzed in this chapter. The National Development Plan (PND) of 2010-2014 and the exit conditions of UNIDOS.

\subsection{Methodology}

This chapter performs 'process tracing' analysis through the use of qualitative tools, which allow researchers to analyze in-depth processes that highly depend on the context. The main objective of process tracing is "to obtain information about well-defined and specific events" (Tansey, 2007, p. 765). Several elements are included in order to follow up a particular process (e.g. interviews, archives, histories). This approach is called triangulation, which is basically the cross-referencing with different sources of information. A combination of sources is seen as a way to confirm what was found in a source (e.g. archives) with findings from another (e.g. interviews). However, triangulation needs to be read with caution. Findings are not only a representation of the same phenomena from a different point of view but also they could show different phenomena (see Davies, 2001, p. 75).

The particular process that will be analyzed in this chapter is the use of the MPI as a policy tool in Colombia. Although official documentation can be a main source of information, for this particular case, the unfolding of events and policy decisions that end up being definitive for the process were missing, making it necessary to complement it with other sources. This chapter triangulates three different sources: elite interviewing, analysis of official documentation and news coding. In the following subsections a description of the methodology used and the particular design of this study are presented.

\subsubsection{In-depth interviews}

Elite interviewing was selected as the best approach. By choosing the public servants who are, or were, part of a particular process, the author was able to reconstruct the actions that lay behind it. The group of possible interviewees was reduced to those who had a direct participation in the process, or elite. They constitute an elite in the sense that a limited amount of individuals were involved in the decision making and in the process itself. The recalling of events and actions during their participation in the

\footnotetext{
${ }^{6}$ For a detailed description of UNIDOS please see Section 6.6
} 
process is an important source of information. The reasons why some of the decisions were taken are easily found by sampling the adequate individuals and reducing the randomness of the information gathered from them (see Tansey, 2007, p. 766 -769).

Members of the elite were selected based on the level of participation in the process. Possible interviewees needed to fulfill the following two conditions: " 1 . That the information obtained should be from first-hand witness, and not based on hearsay; 2 . That the level of access of the interviewee to the events in question should be known, with senior-level elites to be viewed as more reliable" (Davies, 2001).

The initial sample consisted of nine interviewees. To be included in the sample the interviewee had to be a public official during the design, implementation or monitoring of an application of a multidimensional poverty measure, or an academic with proven knowledge of the application and calculation of a multidimensional poverty index. ${ }^{7}$ The author acknowledges that due to the moment in which the interviews were performed (March 2014), the recalling of events by individuals can be biased not only by their current professional status but also by the fact that time has passed (the design of an MPI Colombia started in 2009). The author found that the start date and the duration of design, implementation and monitoring of the MPI Colombia were very difficult to be recalled by participants.

Individuals were approached by the author either by person or mail. Before the interview meeting, they were introduced to a brief explanation of the objective of the research and a consent form in English ${ }^{8}$ (See Annex 6.8.1). During this stage, only one person declined to participate in the interview, therefore the size of the sample was reduced to eight ${ }^{9}$. None of the participants refused to sign the consent form, and none of them manifested interest in dropping out during or after the interview was performed. Every participant agreed to be quoted.

The design used was semi-structured interviews. The same set of topics were asked to every participant although the order depended on the flow of the conversation more than on a rigorous structure. The author adapted the questions according to the behavior of the interviewee and the topics on which the person was more interested in focusing. The first question was always the same: In what part of the process did you participate? Design, implementation and/or monitoring?. Identification of the personal involvement

\footnotetext{
${ }^{7}$ Also former public servants were included.

${ }^{8} \mathrm{~A}$ translation to Spanish was provided to each participant. Interviews were performed and transcribed in Spanish. In section 6.4 translations of quotes are shown. Quotes selected and presented in this chapter are own translations from the author.

${ }^{9}$ Drop-out participant did not offered any explanation for it. So there are no reasons to think that it was a sensitive subject to other interviewees.
} 
in the process was a key aspect to follow up the conversation. Questions were designed based on each one of the three stages. Most of the interviewees participated in more than one stage.

Anonymity was promised to interviewees. Once they signed the consent form, the author identified participants with a code. In Section 6.4 every interviewee will be identified with the same nickname in order to preserve the identity of the participants while maintaining the detailed information provided. After performing the interview the participants were not contacted by the author about this topic again.

Transcriptions of the recorded interviews and the process of coding were performed and analyzed on RQDA (Huang, 2014). The coding phase has the objective of summarize the content of disperse data by grouping it according to a similar pattern. There is no an unique coding method. It depends on the classification reasoning adopted by the author (Saldana, 2013). Different categories depending on the hypotheses were set, and others were added during the process itself. An explanatory table with categories and definitions is presented in Annex 6.8.4.

\subsubsection{Analysis of Official Documents}

Official documents constitute an important source of information. ${ }^{10}$ They are the official repository of the memory of the process and the actors who intervened in it. Advice of caution is raised when using solely official documents for the analysis of a particular process. Documents have a tendency not to include complete information about the process, and neglect the description of details and actors that lead to the final outcome. Hence the importance of combining different data sources. A list of documents included in the analysis is presented in Annex 6.8.2 in chronological order.

Documents were selected on the basis of the case studies and references from the interviewees. They refer to either applications of a particular measure of multidimensional poverty in Colombia or monitoring reports. Two processes were performed with them in the following order: 1. An exploratory text mining analysis and 2. In-depth reading and content use. Text mining was performed for three different clusters: documents related to the National Development Plan, those related to the measurement of poverty in Colombia and finally, the documents related to the description of social programs in which a multidimensional indicator is being used (includes applications).

\footnotetext{
${ }^{10}$ Official documents and news articles were originally found in Spanish. Quotes shown in this chapter are own translations from the author.
} 
The text mining approach was used prior to the reading and content analysis of the documents as a neutral way to find out the patterns that are underlining each cluster of documents. The exploratory analysis was performed in $\mathrm{R}$ using the package tm (Feinerer et al., 2008). Frequencies, correlations and associations were drawn to find out if there is a common pattern of chosen words.

The second step was the content analysis of the documents. The collected files were read and analyzed to find out complementary information about the application of an MPI as a public policy tool. The information collected from the documents was used to describe Section 6.2 and Section 6.6.

\subsubsection{News}

News are an important source of information for common citizens. Studies have proved that what is shown in the media (television, radio, newspapers and bloggers) shapes not only the perception of individuals but also the mechanisms of governance in place (Dick and Zingales, 2002). By including this source, the author is acknowledging the added value of a broader area of knowledge in explaining the process that took place.

This chapter presents content analysis of newspaper articles, that are often neglected as a source of information. The sample is formed by newspaper articles related to the measurement of poverty in Colombia. The hypothesis behind is that part of the successful application of a multidimensional poverty measure in Colombia is related to a change in the language as shown by media. Another assumption is that multidimensional poverty indices are easier to communicate to the general public: "The advantage of using a multidimensional index, complementary to monetary measures of poverty (income/expenditure), is to offer a complete analysis, similarly easy to communicate and understand by a non-specialized public" (Angulo et al., 2011, p. 11).

In Colombia there is only one newspaper that publishes daily and is distributed nationally: El Tiempo. There are other newspapers and magazines that publish either weekly or monthly, and daily newspapers with local distribution. The sampling of news was performed using the archives search engine of El Tiempo. News were filtered between the 1st of January of 2008 and until the 31st of December of 2014. The search engine included the words: poverty data, Colombia (in Spanish: cifras de pobreza, Colombia). The results were ordered according to the relevance of the topic and $5 \%$ of the page results by year were sampled. ${ }^{11}$

\footnotetext{
${ }^{11}$ Unfortunately, the search engine algorithm mixed the search words. Many news related to other topics were also selected by the engine. $5 \%$ was selected as an arbitrary threshold after checking that the most important news were already selected in the $1 \%$ of the entries.
} 
The news were coded according to different categories than the ones used for interviews. A total of 118 articles were coded according to different categories using RQDA package in $\mathrm{R}$. The date, and section in which the news were published are also considered in the analysis. The categories included are: i) the source of the article: independent or official, ii) the article refers to the institutional design of the measurement of poverty, and iii) the article is about a particular type of poverty measurement. The central focus of coding performed in this section is to identify the source of the news excerpts, and to categorize according to the type of poverty measurement. The codes were set prior to the collection of data, but in a second stage new codes were established. A list of the final codes used is presented in Annex 6.8.5.

\subsection{Hypothesis tested}

Different hypotheses were set prior to the data gathering. After coding, triangulation of sources and analysis, they were categorized in four main topics: elements of the process, building consensus between different stakeholders, methodological awareness and poverty measurement as shown in news excerpts (see Section 6.3.3). This chapter considers that the key factors determining the process are commitment of public servants, intensive use of technical cooperation and knowledge transfer, and as a result the strengthening of the institutional capacity.

Commitment of public servants is difficult to define and measure. Committed public officials work by the intrinsic motivation they obtained from the activity performed. Motivated public servants obtain satisfaction from increased social capital, extensive social networks and reputation (see Csíkszentmihályi (1975), Frey et al. (2013), and Georgelis and Tabvuma (2010)). In this environment, technical cooperation and knowledge transfer act as intangible outcomes of the extent of social networks. The changes performed by them strengthen the institutional capacity.

The second element, consensus building, is understood as collaborative planning in which different stakeholders are brought together to deal with differences in the ways to approach a problem. By including different actors, the process is enhanced not solely to create an agreement but also through learning and bringing innovation. The topic of this collaboration has to be of common interest to everyone involved. Through communication and collaboration participants establish new relationships and trust. "A process which ignored a vulnerable interest failed to take into account important constraints, would not only lack credibility, it would probably not produce a particularly good solution" (Innes and Booher, 1999, p. 416). 
The third element is the methodological awareness. The application of a new measure of poverty as a policy tool requires from public servants awareness of the drawbacks and strengths of their approach. The great deal of effort and knowledge put in the initiative makes them experts on the method. The learning process that occurs and the diffusion of knowledge to others has to consider that any measure has the potential to change, adaptation and improvement. In the particular case study in this chapter several normative conditions need to be adopted. The normative conditions had an impact on the outcome. Different decisions will imply different results. The adoption of a multidimensional poverty measure as a policy tool can be divided in three parts: design, implementation and monitoring. In each stage, public officials made one particular decision as opposed to an alternative one. The inclusion of methodological awareness tries to consolidate the information about decisions that were taken, the reasons why they were taken and possible changes. In the following sections, the main results by each category of hypothesis are presented.

\subsection{Main Results}

The key elements of the process itself: commitment, technical cooperation, institutional capacity building and knowledge transfer.

A reason to explain why the measurement of multidimensional poverty was successfully implemented as a policy tool is the high level of commitment and willingness of key actors to include it as an official measure. This hypothesis is related to the process of institutional capacity building and the presence of a constant flux of technical cooperation. The process, as recalled by interviewees took three years. From the early stages the technical team of the DNP was closely linked to the OPHI team. This relationship was kept until the final stage of the design. ${ }^{12}$ Through the interviews and the documents of the Multidimensional Poverty Peer-Network at OPHI this chapter found that the link between the measurement team and the OPHI phased out during the monitoring phase. The relationship was transferred to the DPS as head of the Social Sector. The support of higher ranking officials in two different administrative periods was also mentioned to be key in the process.

"We started collaborating with them [OPHI]. At the same time, inside DNP, we were discussing the variables, dimensions and weights to be included. Afterwards we selected the source dataset, with the largest number of available variables, and then we estimated the first version. It was not before we got preliminary results that the decision to include it in the National Development Plan was taken".

Interviewee 01 -design, implementation and monitoring

\footnotetext{
${ }^{12}$ The two developers of the method Sabina Alkire and James Foster presented their method in an event in Bogotá in July 2010. Their presence at the event was perceived as a backing up of the official measure presented by the team at DNP, and therefore a key element to achieve a higher degree of acceptance from the community.
} 
The milestone to guarantee continuity was the publication of a policy document (Conpes Social 105, DNP (2012)) compiling the recommendations of MESEP about the official measurement of poverty. The recommendations can be summarized in the following: i) The estimation and publication of the official measurement of poverty in Colombia should be coordinated by DANE, ii) A committee of experts for each methodology (monetary and multidimensional) has to be created, iii) The necessary information to calculate the data has to be guaranteed by DANE (continuity, comparability and sample size).

The recommendations were perceived by the interviewees as fulfilled. DANE took the leading role by creating committees of experts with public servants of both institutes (DNP and DANE) and external experts (academics and international organizations). The role of the committee on multidimensional poverty was openly discussed by most of the interviewees. It is recognized as an opportunity to provide transparency, a high level of technical discussion and to evaluate changes in the forthcoming future. The creation and operation of the committee has been a major topic of enquiries from other governments when technical cooperation south-south has been required from the government of Colombia. In the end, a process that was born of a particular need to provide trust was established as a permanent consultation space.

"The mission's objective, in the first stage, was to find out what happened with the splicing when the survey questionnaire was changed. In a second stage, the objective was to adjust and update the methodology for the measurement of monetary poverty. At the same time, and as a result of the previous institutional 'issues', the Mission also evaluated the institutional alternatives. A diverse and independent setting [The Committee] that backs not only the calculation of data, but also its publication, and validates it was identified as a plus."

Interviewee 06-design, implementation and monitoring

"The agreement between DNP and DANE to jointly estimate the official data on poverty, keeping confidentiality before the official publication, and to guarantee that methodological changes will not be pursued unless the committee agrees on that, has strengthened the institutional arrangement".

Interviewee 03-monitoring

However, interviewees perceived that the change of initial team members in both institutes, DANE and DNP, reduced the emphasis put on this measure. Fortunately, the monitoring team regained the lead and it is now perceived as back on track. Discussions about the wide use of the measure and the implications of a proliferation of indices took place. Different initiatives were presented formally to the committee members. In order to avoid thematic dispersion and confusion in the public, the official measure is the one attached to the National Development Plan. 
"We were invited, for example to the committee of experts at DANE to show the results. Our application was well received. Some recommendations that we put forward were related to the need to preserve the structure of the questionnaires. Unfortunately, our recommendations came already too late".

Independent interviewee 07

Finally, interviewees were asked about their perception of their participation. The author asked about their personal involvement and about the process of learning and knowledge transfer. Every single interviewee who had been part of this process at any moment thinks that despite room for improvement the measure is a good measure. This positive statement reflects the satisfaction that each one of the interviewees draws from their participation in the process. Moreover, although the years pass by the participation of those involved in the process is still perceived as a personal achievement.

"I am very grateful. I feel this has been one of the most beautiful things I've ever done. To train other people, to discover how each time the measure is better understood, that it is now an official measure. I am convinced that this is a good measure. So I am grateful for having been part of it".

Interviewee 01-design, implementation and monitoring

Interviewees kept referring to other people in their teams, without having previous knowledge of who was part of this study and who was not. They are a closed, and small community (an elite) who have taken advantage of the knowledge transfer and praised each other's work. In general terms, they keep their social network ties. Transfer was described as smooth, although learning by doing was also mentioned. Only researchers outside the government did not receive any official knowledge transfer.

\section{The quest for a consensus}

An initial hypothesis adopted in this chapter was that a policy consensus played a determinant role to certify that the multidimensional measure was part of the National Development Goal. Though this research cannot prove that reaching consensus was perceived as necessary, from the beginning strategies to provide an open line of communication and validation were considered. The technical lead was from DNP, so initially the consensus about which dimensions, which indicators and what weights were going to be used in the measure was defined internally. Sector and thematic teams were included in the discussion. Once there was an agreement inside the DNP the communication strategy was put in place. Seminars to explain the method and the normative decisions used were held. These were done in academic and non-academic spaces, and in some regional locations. Interviewees perceived that the discussion of preliminary results and communicating the method and the normative decisions taken were not difficult. Voices for and against the measure were heard. Opposition was not perceived to have negative impact on normative decisions or the measure itself. 
"Exclusive discussion talks were performed, with teams of experts on the topic in Medellín, Bogotá, and also in Manizales. Those were technical discussions. Also inside the DNP. At this particular moment DANE did not participate. It was a technical work initiated and performed by DNP. It was also discussed inside the inter-sectoral commission of the UNIDOS strategy. In that space we discuss about the dimensions, variables and weights selected".

Interviewee 06-design, implementation and monitoring

In the case of the official measurement of multidimensional poverty in Colombia, the voices of the poor (e.g. participatory assessments) were not considered. Only the independent interviewee that designed a non-official measure mentioned participatory engagement during the course of the interview. ${ }^{13}$

"We used focus groups with two different categories of individuals. First, to identify from scratch which are the dimensions that are more important to them. We avoid any reference to poverty. In the second focus group, we validated pre-established dimensions (using other studies and other methodologies) and found out those that were missing."

Independent interviewee 07

\section{Methodological awareness: limitations, adaptation and normative decisions.}

This chapter hypothesized that the people involved in the process are fully aware of the constraints of the method used. It assumes that the level of specialized knowledge of the method for most of the interviewees is either high or very high compared to any one else. Their perception of how the measure is understood by a general public is also biased by their level of knowledge and understanding. The author also asked about the perception of a widespread use of the index, and what interviewees perceive will happen in the near future with this particular application.

All the interviewees mentioned that one of the advantages of the method used was that it is simple to calculate, and easy to communicate. Most of them mentioned that the indicators included in the proposed index are closely related to public policy, and therefore to the composite index as well. Moreover, DNP motivates the initiative stating that: "Limitations made explicit the need to have a measure of multidimensional poverty that fulfils axiomatic properties, is built with variables susceptible to be modified through public policy and that reflects the current conditions of quality of life in Colombia" (DNP, 2012, p. 5).

\footnotetext{
${ }^{13}$ Non government multidimensional indicators in Colombia use qualitative techniques to support normative decisions as weights and indicators.
} 
The method was perceived as highly flexible and easy to adapt to other circumstances or particular cases. One interviewee mentioned that the fact that there are no econometrics involved makes it easier to understand. For the interviewees the mechanism to get the result of the index was quite clear. However, the interviewees said that their knowledge of its drawbacks and weaknesses was vague. Some mentioned that they knew that there are some limitations but acknowledged not to know them in detail.

"What I am most attracted to the method is its simplicity. We experienced it with other indicators [names excluded], or other much more complex methods, and at the end we do not know how they work. This one is fairly simple. It fulfils a series of conditions and properties. It is quite clear and useful for social policy applications. It supersedes other methods like principal components or fuzzy sets".

Interviewee 02

Interviewees were aware of the need to improve the index in order to keep using it as a policy tool. The need to update and adapt the different indicators is evident, but at the same time interviewees mentioned the need to guarantee that any change would not prevent the comparability over time. According to interviewees, the index is focused on coverage of basic services and it is lacking information about their quality. New topics need to be included and those which do not discriminate among the poorest population need to be excluded. Again there was a constant mention to the committee of experts as the proper space in which these technical decisions have to be taken. This argument is aligned with the objectives for the creation of the Committee (DNP, 2012).

In every interview, the author asked about the reasons to make particular normative decisions as opposed to others. In terms of weights, several interviewees mentioned that there was no a technical or empirical proof that could help them go through the selection of weights. Moreover, interviewees believe that equal weights (either in indicators or dimensions) is comparable to equal importance. In the official MPI Colombia document it is explicitly mentioned that equal weights at the level of dimensions was selected because it reflects equal importance and that the majority of experts consulted agree that it was the best choice (Angulo et al., 2011, p. 21). Nonetheless there is empirical evidence that suggests that "nominal weights are not a measure of variable importance, although weights are assigned so as to reflect some stated target importance, and they are communicated as such" (Paruolo et al., 2013, p. 610).

In terms of the definition of the number of dimensions in which a person is considered deprived, most of the interviewees did not make any comment. Only the independent researcher mentioned that as there is no a clear method to define the threshold, and so they opted for replicating the methodology used in the MPI Colombia. The description states that after selecting a robust subset of values, they evaluated average deprivation of different groups according to subjective assessment of poverty and compared their selection with other applications (Angulo et al., 2011, p. 22). 
On the topic of unit of analysis, the interviewees were asked about what they think about the unit of analysis used. For the MPI Colombia, the unit of analysis selected is the household. Similar arguments were used by different interviewees in concordance with the official methodology. The official document cites three reasons for this selection: i) individuals are not considered as an isolated entity, the responsibility lies with the government, the society and the family, as it is shown in the Constitution of Colombia, ii) there is empirical evidence in Colombia of the family importance as a resource social network in case of need, and iii) policies and programs consider the household as a unit for intervention of social policy (Angulo et al., 2011, p. 12-13). The first two arguments are supported in the Political Constitution of the country and in studies as for instance DNP (2001). The last argument does not fall into the same category. Selection of beneficiaries is decided according to the objectives of the programs and policies, and needs, status, age and gender of individual members in the household. In some particular cases, such as conditional cash transfers, the household is the unit of intervention but not in every social policy intervention. Lastly, interviewees mentioned that the household is conceived as the unit of analysis because it is odd to find two individuals in the same household classified in different groups (poor and non-poor). Contrastingly, the independent application advocates for the use of the individual as unit of analysis, exactly for the same reasons. Two members of the same household can have access to different opportunities and therefore have a different path and quality of life, even though they share common goods.

"I am going to give you an example. A household in which the material of the floor is sand, it has access to drinkable water and there are two children. One of the children is not malnourished and he is enrolled in school. The other is not enrolled in school and suffers from malnutrition. The second one is multidimensionally poor, the first one is not. We want to show this type of situations". 


\section{Exploratory analysis of official documents}

The hypothesis underlying this section is that in policymaking documents, multidimensional poverty has acquired a place as important as monetary poverty. Three clusters of documents were created: i) documents related to the National Development Plan, ii) documents related to the measurement of poverty and iii) documents related to a particular application (social programs or children MPI). The analysis showed that the last two clusters have a common behavior (See Figures 6.2a and 6.2b). Analysis was performed for the 15 most common words. ${ }^{14}$

\footnotetext{
${ }^{14}$ Similar analyses were performed for a bigger number of words. The trend is the same. For a clearer diagram the words were restricted to only 15. As documents are in spanish graphs are in spanish, a translation is provided: Graph a: salud=health, programa=programme, pobreza=poverty, poblacion $=$ population, ingreso $=$ income, resultado $=$ results, nacional $=$ national, familias $=$ family, educacion=education, hogar $=$ household, social=social, mayor=higher, acceso=acces, parte=part, gobierno=government, desarrollo=development, pais=country, estrategia $=$ strategy, rechazo $=$ rejection . Graph b: incidencia=impact, urbana=urban, salud=health, rural=rural, nacional=national, vida=life, $\quad$ poblacion=population, $\quad$ hogar $=$ household, multidimensional $=$ multidimensional, condiciones $=$ carachteristics, privacion $=$ deprivation, $z$ ona $=$ zone, indice $=$ index, dimensiones $=$ dimensions, variables $=$ variables, pobreza $=$ poverty, personas=individuals; Graph c: millones $=$ millions, sector $=$ sector, resultado $=$ result, meta $=$ goal, pais $=$ country, cuatrienio $=$ four years, gobierno=government, programa $=$ programme, desarrollo=development, nacional=national, social=social, parte $=$ part, educacion $=$ education, poblacion $=$ population, pobreza $=$ poverty, estrategia $=$ strategy, sistema $=$ system.
} 
Figure 6.2: Cluster of words in official documents

(a) Applications of MPI-JUNTOS

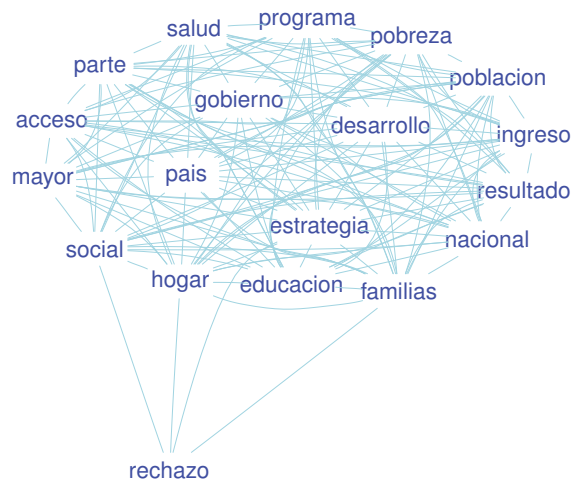

(b) Measurement of Poverty -MPI

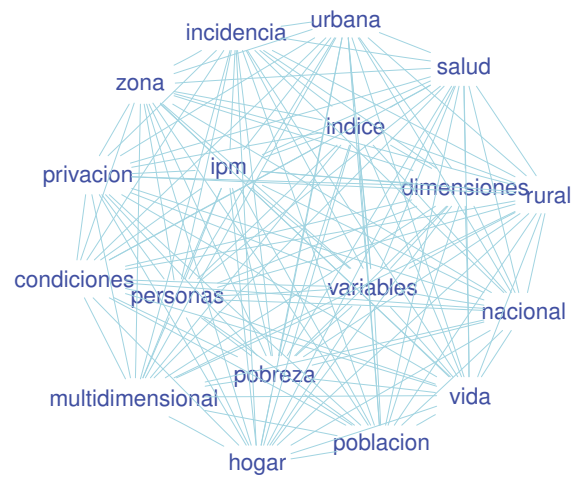

(c) Measurement of Poverty-PLAN
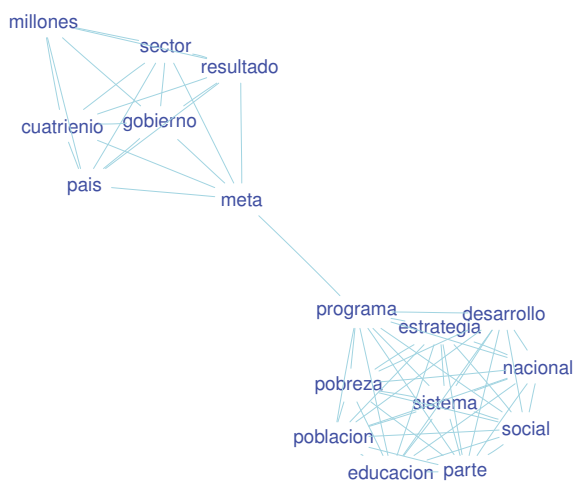

Source: Colombian Official Documents. Author calculations. 
In the case of the documents of the National Development Plan (see 6.2c), the behavior is quite different. There are two clusters, one related to goals for the presidential period and the second to the objective of the documents.

Of the most common words, using different thresholds according to the sizes of each cluster of documents, the author found that besides within the cluster of the MPI, the word 'multidimensional' is not common. In the case of the cluster of applications and social programs, neither 'income' or related words (e.g. 'consumption', 'lines' -poverty line, 'monetary') nor 'multidimensional' are found in the highest frequency groups. When lowering the thresholds, monetary poverty related terms are more frequent than multidimensional poverty. Finally, the cluster of the National Development Plan has no common words related to poverty. Instead, the common words are: 'development', 'government' and those related to particular sectors as 'education', 'health', 'social' or 'policy', for example.

When analyzing the correlations between words, or in other words "how often transactions that involved A tend to involve also B" (when A and B are words) (Hearst, 1999), this chapter found that still whenever 'poverty' is mentioned, there is a higher correlation (closer to 1) to terms categorized as 'monetary'. Only in the case of the cluster of measurement of poverty documents, the correlation of 'poverty' with 'monetary' and 'multidimensional' categories is the same.

In general, the analysis performed in this section shows that: i) To position an MPI as a public policy tool did not transfer in an immediate higher focus on multidimensional poverty, ii) There is still a higher dominance of terms related to monetary poverty as opposed to multidimensional poverty in the official documents.

\section{The measurement of poverty as shown in the media}

There are two leading hypotheses about the analysis of newspaper articles presented in this chapter. First, the application of a multidimensional poverty measure substantially changed the language and understanding of poverty. The evidence suggests that, for the time frame sampled, monetary poverty is still the most common measure. It is not only shown in the higher frequency of mentions whenever official data is reported but also it is commonly mentioned in editorials. Inequality, in income terms, although less frequently mentioned is also relevant in two moments in time. First in 2011, due to the poor performance of the country compared to others and then, in 2013, when inequality receded. 
The use of 'multidimensional' in the language used by the media to categorize poverty started in 2010 and was increasingly used in 2011. At the same moment DNP was developing the measure and presenting the first results. This moment coincides with the timing of the launching of the HDR by UNDP, and its Multidimensional Poverty Index in 2010. Afterwards, the Colombian newspaper El Tiempo is still reporting the multidimensional poverty results but mentioning it less often than before.

"The DNP, in collaboration with the World Bank and Oxford University, is working in a multidimensional measure of poverty and well-being that includes different aspects from those related to income".

El Tiempo [10th of May 2010, Section: Others]

"We even present a new index, complementary to income measures. We call it multidimensional, as it includes measures of education, health, shelter, early childhood and labor"

Hernando José Gómez, Director DNP, El Tiempo [18th of September 2011, Section: Others]

Mention of other multidimensional concepts and indices (e.g. NBI) was substituted by the MPI. Since 2012, news related to the NBI, for example, disappeared in the sample of articles related to the measurement of poverty. ${ }^{15}$

The second hypothesis was that multidimensional poverty was easier to communicate and be understood by the public. The analysis performed in this chapter did not find evidence about it. What was evident from the sampled articles was that the same phrasing was constantly used. In this sense, it is unclear if the results are easily understood or are just a standard way of reporting the data, as analysis and Op-Ed columns do not mention the MPI.

"With the support of the University of Oxford, a multidimensional poverty index was created. It evaluates poverty from different perspectives. It includes the access to education, health, employment, adequate shelter and public services, among others".

El Tiempo [5th of May of 2013, Section: Editorial-Opinion]

Another important topic that attracted the attention of the media was the distrust in the measurement of poverty in Colombia, particularly between 2008 and 2011. As mentioned in Section 6.2, splicing of monetary measures got lost in 2006 because of an unfortunate technical decision. This event forced the creation of a Mission of Experts. The limbo in the data that motivated the setting up of the Mission was a recurrent topic in the newspaper. MESEP started in 2008 and finished in 2012. During 2009 and 2011, MESEP backed up the publication of official results of poverty in Colombia. Members of MESEP are quoted several times in the news excerpts. Attention was also drawn

\footnotetext{
${ }^{15}$ The mention of NBI is limited to regional coverage (whenever news refer to a particular city or region) but it is absent from the national level and from official or critical op-ed columns.
} 
to recommendations made by the experts. Special mentions were made to the decision about which institute should be in charge of the measurement and the need to make the anonymous micro-data of household surveys available to the public.

MESEP also worked on updating the monetary poverty lines. The new methodology was presented before the new institutional arrangement. A political controversy, led by the Colombian Vice-president, started inside the government and became public. No attention was given to the final arrangement, published in a Policy Document (DNP, 2012).

"Reducing poverty is not a matter of technicians but of politicians. We need to improve wealth distribution and the purchasing power of the population." Angelino Garzón, Colombian Vice-president. El Tiempo [Section: Politics, 16th of September 2011. Own translation]

Another way of reading the focus of poverty measurement news excerpts is through the section in which they were published. Op-Eds and others were the sections in which a higher density of news was found. Particularly for the period between 2008 to 2010. The Politics and Economy sections were relevant for the period between 2011 and 2014. Mentions of poverty are more relevant on the Editorial and Op-Eds columns during the period of presidential elections.

\subsection{The exit conditions of the Strategy to Overcome Extreme Poverty}

\subsubsection{UNIDOS in a nutshell}

In 2004, as part of a prospective planning exercise, the DNP established the Mission against poverty and inequality $\left(\mathrm{MERPD}^{16}\right)$. The objective was to describe the situation in terms of poverty and inequality in Colombia and to design strategies to reduce extreme poverty by 2019. The study identified that poverty is persistent and dynamic. Chronic poor and vulnerable populations are trapped in a vicious circle of poverty. By 2005, almost half of the population in Colombia was considered income poor. The goal was to reduce it to $17 \%$ by 2019 . Additionally, the MERPD found that scattered programs and poor targeting mechanisms in an incipient social protection system were problematic for achieving reduction of poverty with a limited social expenditure budget.

\footnotetext{
16 "Misión para el diseño de una estrategia para la reducción de la pobreza y la desigualdad" in Spanish (DNP, 2006a)
} 
The main strategy proposed by the MERPD was the creation of a special program to reduce extreme poverty integrated into a broader Social Protection System. The ambitious objectives of the strategy can be summarized as follows (DNP, 2006a):

- To strengthen the targeting of social expenditure.

- To grant preferential access to social services based on need of beneficiaries.

- To adapt the existent supply of social programs to the needs of the extreme poor.

- To encourage the improvement of human capital.

- To focus on the family as the unit of analysis.

- To provide face to face assistance and monitoring to beneficiaries.

- To include local governments as active stakeholders in the reduction of poverty.

- To empower families in the improvement of their own quality of life.

The strategy was built under a multidimensional platform that identified nine dimensions and 45 goals: identification, income and labor, education, health, shelter, nutrition, family dynamics, financial literacy, and access to justice (DNP, 2006b).

A new institutional framework was proposed, consisting of four levels: 1) The General Coordination in charge of the Social Policy Council in which the DNP took the role of the Technical Secretary, 2) The General Council for the Strategy, composed of the Ministry of Social Protection ${ }^{17}$ and the Agency for Social Action and International Cooperation (Accion Social in charge of the implementation of the strategy), 3) the government of states, and 4) local municipalities governments. ${ }^{18}$

By 2010, the Strategy had adopted the name of Red JUNTOS ${ }^{19}$ and had over a million of beneficiary households and 1.028 municipalities (see Fedesarrollo, 2010, p. 9). The coordination among a network of programs and institutions with separate budgets, objectives and interest was proving extremely complicated. An inter-sectoral committee was formally established in 2010 to provide the Red with a formal mechanism of monitoring. Base line data of beneficiaries was already in place and adaptation of social programs to the demand coming from the beneficiaries was a big challenge. There was a recurrent call from academics and policy-makers to define the exit conditions: "The success of the Red JUNTOS should be measured by the number of families

\footnotetext{
${ }^{17}$ The Social Sector was re-organized again in 2011 and the new arrangement will be presented in Figure 6.3.

${ }^{18}$ According to the administrative local government organization of Colombia.

${ }^{19}$ Nowadays it is called Red UNIDOS
} 
that exited and not by the number of families enrolled" (See Steiner, R., Fedesarrollo, 2010, p. 12). An impact evaluation of the Red JUNTOS was in the last stages and one of the outcomes of the study was precisely the design of a proposal for exit conditions.

In 2011, the social sector went through another institutional reform. The former Accion Social became the Department of Social Prosperity (DPS), the Red JUNTOS became the Red UNIDOS under the direction of the also created Agency to Overcome Extreme Poverty (ANSPE). (see Annex 6.8.3 and Figure 6.3). Institutes that depended on the former Ministry of Social Protection (today Ministry of Health and Social Protection) became part of the DPS, as well as those involved in the attention to victims of the conflict in Colombia.

Figure 6.3: Current Institutional Framework

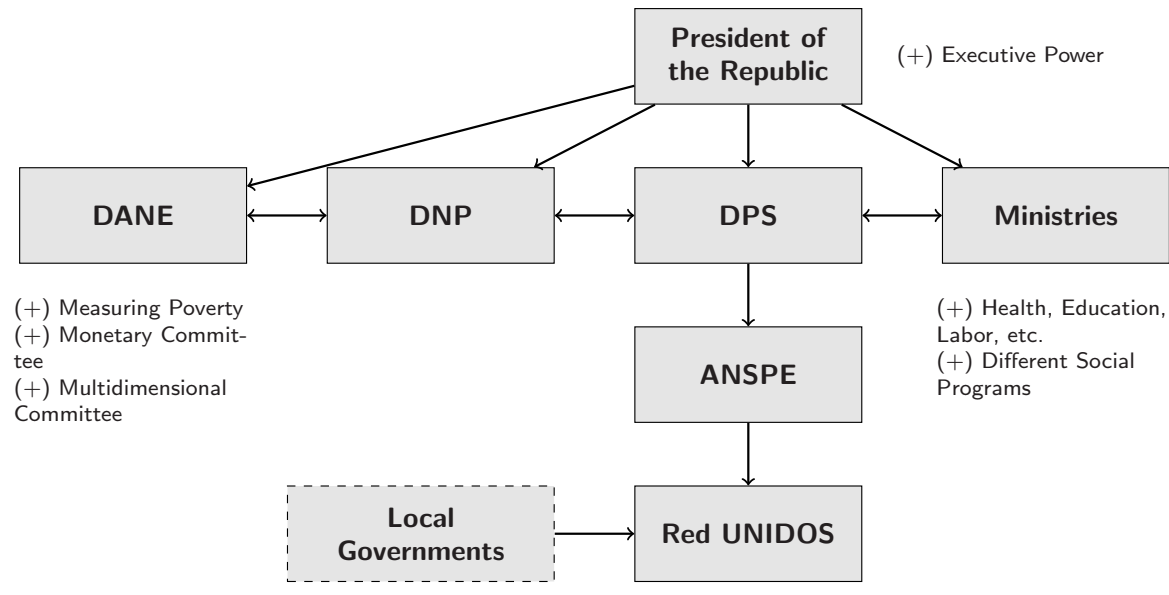

Source: Author based on institutional and legal framework described in Annex 6.8.3.

In 2012, the exit conditions were defined by DNP, using as input the results of the impact evaluation proposal. Two conditions were defined: a) A necessary condition, attached to the goals of the Red UNIDOS: The achievement by families of the priority goals defined by themselves in their personalized "Family Plan" and b) A sufficient condition: The households should not be classified as extremely poor (by monetary and multidimensional measures). Only households that fulfil both conditions will exit extreme poverty. 


\subsubsection{Multidimensional Poverty Index used as exit condition}

Two hypotheses constitute the starting point of this section: 1) The MPI Colombia, was already adopted, accepted, discussed and measured, its use and positive acceptance were crucial to implement it as the exit condition of a social program, and 2) Cooperation and coordination where needed to certify the process of knowledge transfer from the team at DNP to the team at ANSPE.

The DNP took the lead on the design of the exit conditions of Red UNIDOS. The proposal at different stages was discussed within a technical committee created for that purpose. When the sector reform was finalized, members of the original team at DNP switched to positions inside the DPS and ANSPE. This sort of 'horizontal revolving doors' phenomena was determinant for the adoption and implementation of an MPI as exit condition of Red UNIDOS.

"A necessary condition was defined and discussed with the High Level Council of Social Prosperity, back then [...] Committee meetings included members of the Council, the DNP and Acción Social. I do not recall if the Ministry of Social Protection was also included. Several elements of the final proposal of the necessary condition were proposed by the team from Acción Social. The DNP influenced more in the definition of the sufficient condition".

Interviewee 08

"The MPI was already validated by DNP. Consensus around the exit conditions was inherited by the ANSPE. In the end it was the same team, same program, only a different institutional framework".

Interviewee 08

The concept of 'revolving doors' is used in organizational studies to "describe the interchange of personnel between the government and the private sector" (Johnson, 1984 , p. 95). It is usually used in a negative sense, when public servants in regulatory agencies, the revolvers, become employees of the firms that they previously regulated. In this particular chapter, the concept of 'revolving doors' is used in a different way. The chapter considers the case of revolvers inside the government, in a case in where hierarchical organization between the entities is almost or non-existent, hence the 'horizontal' aspect. Considerations about collusion behavior, conflict of interest and incentives mechanisms are not contemplated in the analysis (Che, 1995). The practice is very common among young and highly technical public servants and particularly increases when institutional reforms are in place, which was the exact case in Colombia. The new sector of Social Prosperity was in need of specialized knowledge. 
So in this case as found in the analysis and coding of interviews, although there was some transfer of knowledge, the main mechanism was the horizontal revolving doors phenomena. In two particular cases former public servants involved in the original MPI were involved: the re-restructuring of the conditional cash transfer program Familias en Acción (Now Más Familias en Acción) and the exit conditions of Red UNIDOS.

The final exit mechanism, as explained by the interviewees requires necessary conditions: i) timing (In order to exit the strategy a family has to be enrolled at least for one year, had undergone the analysis of its status and had planned its own goals), ii) priority goals are achieved, and iii) categorized as low risk in a sub-set of social policy goals: domestic violence, sexual abuse and child labour. The sufficient condition is obtained based on two indicators: income poverty and MPI.

"What we did was to use the same official method to calculate both income and multidimensional poverty. We built a questionnaire exactly with the same questions as they appear in the LSMS and Household Surveys used by the official method [...]. We applied the questionnaire when social promoters in the region considered it [...] Families are classified in nine different groups, with every possible combination between income and multidimensional poverty [...] If families are considered not income poor and not multidimensionally poor the sufficient condition is fulfilled, exit is straightforward. If families are considered income poor but not multidimensionally poor then we keep granting access to income generation programs".

Interviewee 08

Through the measurement of multidimensional poverty families are granted the exit of the Red UNIDOS. Monetary poverty takes a secondary role. The decision was based, according to the interviews, on what the Red UNIDOS can achieve in terms of supply of social programs and empowerment. In terms of income the Red UNIDOS is an indirect channel and cannot certify sustained access to the labor market and income generation for families.

\subsection{Conclusions}

The adoption of an MPI in Colombia was the result of a combination of different aspects. Timing, both in terms of the need to set policy goals but also at the same time as a particular method was being communicated (AHR) internationally. In this particular case, not only senior and high ranking public servants were key to support and defend the decision but also a group of enthusiastic public servants. The lack of trust in the national statistics office in terms of monetary poverty measurement was also a key determinant to position a multidimensional measure of poverty, as the MPI, as an official measure from the central government. 
The process in itself was mainly driven by the commitment of a team in an institute, the National Department of Planning (DNP). Technical cooperation and support with foreign experts made the process of learning easier. Consensus was not a main driving factor but the communication strategy and convincing stakeholders outside DNP were very important. Interesting exercises of methodological variations have not been published yet, and therefore part of the exercise of decision making during the design phase is unknown to outsiders.

A great deal of effort was put on the measurement of poverty both in monetary and multidimensional terms, and a new institutional framework to protect the transparency of the measurement was achieved and is still in place. However, the extensive use of the multidimensional concept is still incipient. This chapter proved, through the process of triangulation of different sources and using different methodologies, that monetary poverty is still highly dominant in the official discourse of both the official documents of the government as well as in the media.

What is being measured in Colombia is shaping not only the national goals in terms of poverty reduction but also entry and exit conditions on several programs. The perception of simplicity from public servants is not transformed in a better understanding from the public. Judging from what was found in the in-depth interviews and in the coding of news excerpts, there is no clear understanding yet of the drawbacks and/or effects of the normative decisions in the final results. This understanding will be key for a future adaptation and updating of the indicator in a forthcoming National Development Plan.

The parallel process of creating an institutional framework for the measurement of poverty in general has been one of the most successful results of this process. Though it was not driven by the inclusion of a multidimensional poverty measure, the benefits in terms of trust and political discussion are evident. Unfortunately, this particular event has not been followed up by the media, though the initial issues and the political debate were openly and widely discussed. 


\subsection{Appendix}

\subsubsection{Consent Form -English}

I agree to participate in Policy

Implications of using a Multidimensional Poverty Measure in Colombia research study. The purpose and nature of the study has been explained to me in writing.

I had read and understood this Consent Form either in English or its translation attached to this document in Spanish

I am participating voluntarily. I am giving permission for my interview with Andrea Franco-Correa to be tape-recorded.

I understand that I can withdraw from the study, without repercussions, at any time, whether before it starts or while I am participating.

I understand that I can withdraw permission to use the data within two (2) weeks of the interview, in which case the material will be deleted.

I understand that anonymity will be ensured in the write-up by disguising my identity.

I understand that disguised excerpts from my interview may be quoted in the thesis and any subsequent publications if I give permission below:

(Please tick one option):

1. I agree to quotation and or publication of excerpts from my interview

2. I do not agree to quotation/publication of excerpts from my interview

Code of interviewee:

Signature of interviewee:

Signature of interviewer:

Date: 


\subsubsection{List of Official Documents Included in the Analysis}

\begin{tabular}{ll} 
Document Name & Institution \\
\hline Retos y desafíos de la Red & Fedesarrollo \\
JUNTOS & -Konrad Ade- \\
& nauer Stiftung
\end{tabular}

Bases del Plan Nacional de DNP Desarrollo 2010-2014

Índice de Pobreza Multidimensional para Colombia $1997-2010$

Informe al Congreso: Juan Manuel Santos

Documento Conpes Social 150: Metodologías oficiales y arreglos institucionales para la medición de pobreza en Colombia

Evaluación de Impacto UNIDOS -Chapter 2

UT-ANSPEDNP

DNP-DANEDPS

Presidencia de la República -DNP

\section{DNP}

Presidencia de la
República -DNP

Main objective

Compiles a series of present-

Year

ations on the analysis of the implementation of the Red Juntos (UNIDOS since 2011)

The document presents the main objectives of the upcoming presidential period, goals, priorities and investment plan

Presents the official methodology to measure multidimensional poverty in Colombia and the results Progress Report of the National Development Plan according to Law 152nd of 1994 and Law 1450th of 2011

Introduces the official methodology to measure monetary and multidimensional poverty in Colombia, clarifies the sources of information to perform the measurement and sets the institutional arrangement to perform measurement and publish the results

Final report on the impact evaluation of Red UNIDOS. Chapter 2 is focused on the definition of the exit conditions of beneficiaries

Informe al Congreso: Juan Manuel Santos

Presidencia de la República -DNP

Progress Report of the National Development Plan according to Law 152nd of 1994 and Law 1450th of 2011

Informe al Congreso: Juan Manuel Santos
Progress Report of the Na-

2013

tional Development Plan according to Law 152nd of 1994 and Law 1450th of 2011

Continued on next page 
Table 6.1 - Continued from previous page

\begin{tabular}{llrlrl} 
Document Name & Institution & Main objective & Year \\
\hline Análisis de la pobreza & Escuela de & Introduces a proposal for 2014 \\
multidimensional en niños, & Gobierno, Uni- & measurement of multidi- & \\
niñas y adolescentes en & versidad de los & mensional poverty in chil- & \\
Colombia: metodología y & Andes & & $\begin{array}{l}\text { dren and adolescents in } \\
\text { principales resultados }\end{array}$ & & Colombia.
\end{tabular}

\subsubsection{Institutional Arrangement in Colombia: Main actors in the measurement of poverty}

$\begin{array}{ll}\text { Fame } & \text { Founding Main objective Law } \\ \text { Year } & \end{array}$

Office of the Presid- 1819 Head of State, Government and Article 188.
ent of the Republic of

Colombia

Department of Plan- 1958 ning (DNP)

Department of Social 2011 Prosperity (DPS)

Department of Statistics -Statistical Office (DANE)

Agency to Overcome Extreme Poverty (ANSPE)

Más Familias en Acción
Supreme Administrative Authority from the Executive Branch. The President is elected for a term of 4 years. Reelection is allowed only one consecutive time.

Planning, Design, Monitoring and Evaluation of the National Development Plan and the Public Investment Plan. Overseen by the Office of the President.

Design, implementation and coordination of policies and programs to overcome extreme poverty, social inclusion, reparation and rehabilitation of victims of conflict. Overseen by the Office of the President.

1951 Planning, collecting, processing, analyzing and publishing official statistics in Colombia. Overseen by the Office of the President.

2011 Coordination and implementation of the National Strategy to Overcome Extreme Poverty in Colombia (Red UNIDOS). Overseen by the DPS.

Conditional transfers program redesign in 2011. Beneficiaries are conditioned on goals of education, health and care. Overseen by the DPS. off) (spin-
Political Constitution 1991.

Decree 3519 of 2009.

Decree 4155 of 2011.

Decree 262 of 2004.

Decree 4160 of 2011

Law 1532 of 2011 


\subsubsection{Coding Categories-Interviews}

Code Category

ID of participation

Designing

Implementation

Monitoring

Consensus

Individual willingness and commitment Institutional capacity building

Learning by doing

Institutional arrangement on the measurement of poverty Methodological knowledge and awareness Normative decisions

Personal position

Monitoring poverty results and public policy

Revolving doors

Technical cooperation

National Development Goal

Transfer of knowledge

\author{
Definition
}

Identifies the role of the interviewee in the process. Interviewee mentions topics related to the design phase of the process.

Interviewee mentions topics related to the implementation phase of the process.

Interviewee mentions topics related to the monitoring phase of the process.

Interviewee manifests that different actors were involved in the process or mentions the actors involved in the process.

Interviewee remembers his/her personal effort and involvement during the process.

Interviewee reflects about the changes in the institutions during the process took place.

Interviewee describes his/her individual learning path during the process.

Interviewee describes or refers to the institutional arrangement in place since 2012 .

Interviewee talks about methodological drawbacks and states his/her position about them.

Interviewee talks about the normative decisions taken during the process and their implications.

Interviewee states his/her position about the overall process, how does he/she perceives it.

Interviewee mentions the process of monitoring public policies through the use of the MPI created during the process.

Interviewee manifests that he/she moved from an institute to another or has direct knowledge about anyone of the team doing it, to follow up the process from a different place.

Interviewee manifests that during the designing, implementation or monitoring he/she had direct knowledge of activities focused on cooperation with other entities or the lack of it.

Interviewee describes how the MPI became a National Development Goal.

Interviewee describes how she/he was either involved in transferring the knowledge acquired during the process or received a transfer of knowledge from someone else involved on it.

Continued on next page 
Table 6.3 - Continued from previous page

Code Category Definition

Unit of analysis Interviewee reflects about his/her position about the particular unit of analysis used in the particular application of the MPI.

Widely (or not) used Interviewee reflects about his/her position regarding about the usability of the MPI, and different applications according to his/her knowledge. 


\subsubsection{Coding Categories-News}

Code Category Definition

\section{Source}

Independent The excerpt's source is independent. It usually refers to an independent critic or another calculation of poverty that is not official.

Official The news excerpt is citing an official source of poverty measurement or the excerpt is written by a public servant.

Type of Poverty Measure

Monetary

The excerpt mentions the measurement of monetary poverty (income/expenses/consumption).

Multidimensional The excerpt mentions the measurement of multidimen-

(MPI)

Inequality sional poverty, exclusively the MPI.

NBI or others The excerpt mentions data on income inequality. Other indices, multidimensional or not are mentioned in the excerpt.

Process related topics

Institutional The news excerpt mentions the framework for the measdesign urement of poverty. Particularly refers either to the Statistical Office or the Experts Committee.

Politics The news excerpt refers to a political debate about the measurement of poverty, or public distrust is manifested in the excerpt about poverty data, delays on the publications of official data, nonconformity with the methods used, changes performed and/or results presented of the measurement of poverty.

Regional Focus The news excerpt presents or discusses the measurement or the results of poverty for particular regions. 


\section{CHAPTER}

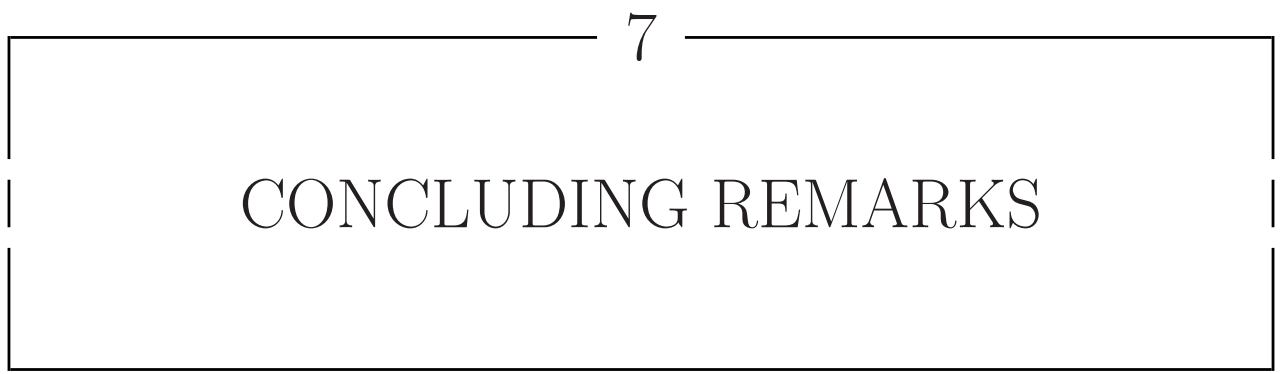

This thesis has focused on finding the variations in the results of a particular multidimensional poverty index when different normative conditions are selected. The main research question of this thesis is: Under what conditions does a measure of multidimensional poverty, using counting methods, remain stable when different normative choices are made (for the particular contexts of Chile, Colombia, Ecuador and Peru)? The argument is that changes in normative decisions affect the final measure of multidimensional poverty. This has implications for the utility of this measure as a governance tool, as the changes in normative make the final measure extremely sensitive to initial conditions. The approach used throughout the thesis is that poverty is multidimensional, and to sustain this assertion, the capability approach is used. Counting methods, and specially the Alkire-Foster Adjusted Headcount Ratio are used in each chapter to operationalize the multidimensional poverty index.

Different sub-questions have been developed and they constitute the core of earlier chapters:

1 How does the index reflect the modification of the unit of analysis?

2 Does the index reflect the regional variation under different identification choices?

3 How does changes over time reflect in the measurement of multidimensional poverty?

4 Under what conditions does a multidimensional poverty index establish itself as a governance tool? 
In this chapter, the findings that respond to the sub-questions are presented, using the results obtained in the earlier chapters. The result is an agenda for future work in the field.

\section{Summary of the thesis contributions and main find- ings}

Chapter 3 focuses on the effects of taking a different unit of analysis, the individual rather than the household. The findings reported in the chapter show that when individuals are classified into different age groups, information about deprivations differ. Elderly, as opposed to children, is the most multidimensional deprived population subgroup. The driving factors for this result are the minimum years of education and the access to sources of income after retiring age (either pension or remaining in the labor force). For countries with weaker social protection systems (Ecuador and Peru) access to health insurance and to effective healthcare in case of need were also factors. For children and adults, living conditions are the main source of deprivations.

Lack of piped water and adequate facilities for sanitation are known for increasing probabilities of contagious diseases. Although numbers have fallen in the region they are still a major cause of preventable deaths. Conflicts over the ownership of the land are of particular interest in the Colombian case. Crowdedness is a reason for conflict in the case of Peru. Comparisons between subgroups, and for a national aggregated index, showed that multidimensional poverty in Chile is comparatively lower than in the other countries.

Based in the context of application, the usefulness of the empirical findings and their relations with policies and systems in place can be seen. When comparing the results of an individual with a household index, a common pattern was found. Chile was still the least multidimensionally poor country followed by Colombia, Ecuador and Peru. The ranking of the two last countries was reversed compared with the one obtained in the individual case. The reason was the weight assigned to age groups in the sample. However, taking into consideration comparable thresholds, for households, multidimensional poverty is consistently higher. One of the main findings is that by considering the individual as a unit of analysis and using different indicators for each age group, the measurement of poverty includes the different experiences throughout the lifetime of the individual.

In Chapter 4, a combination of stochastic dominance techniques (first and second order conditions) and the use of Hasse Diagrams, applied to counting methods for the first time to the knowledge of the author, when this research was first carried out. Techniques were used to perform pair-wise comparison over 39 regions. A less redundant boundary 
(that is a sub-set of normative decisions over which a partial ordering can be found) for the decision about the identification of multidimensional poor people $(k)$ can be found, giving some technical support to opt for a single choice in a smaller range.

The two techniques used showed that Chile is by far the case where less partial ordering can be found, both among the complete span of the 39 regions as well as for the case within Chile. This erratic pattern confirms that the results are extremely sensitive to normative choices. However, the extreme cases (richer and poorer regions) are clearly identified. In contrast, Peru showed cases in which a complete order can be found by reducing the boundary of choices. Similarly, when comparisons are performed using the 39 regions, most of the regions in Ecuador and Peru are always poorer than the regions of Chile and Colombia. The pattern found at the national level is replicated. Second order dominance conditions are more often found for adults than for the other groups, for both restricted and unrestricted range of $k$.

The elderly group exhibited less dominance, showing less inequality between the regions and higher levels of deprivation. Dominance conditions and diagrammatic partial ordering over a range of normative choices provides the decision makers with information and knowledge about the distribution of multidimensional poverty and transparency about the results found. It also gives an idea about the sensitivity of the measures to particular choices. Stochastic dominance has shown for decades that information about the uncertainty obtained is also valuable information, especially for policy-making and comparisons of results in different contexts.

Chapter 5 focuses on the dynamic multidimensional measurement of poverty. The index used in previous chapters is replicated for a second cycle of survey data depicting improvement/deterioration of living conditions over time. In addition, the chapter focuses on the application of different methodological techniques to gather complementary information: Shapley decomposition, percentage changes and reversed generalized Lorenz curves. Despite the methodological differences, findings are complementary to each other.

In the case of Ecuador a robust improvement in the reduction of poverty was clearly found. It meant that, without regard to which identification choice $(k)$ is made, the decline in poverty over time was evident. However, this was not the case for Colombia, where the reduction in poverty was not robust to changes in normative choices. In the case of children in Peru and Chile there was a deterioration of their situation, that depended on the choice of $k$. 
Chapter 6 presents the case study of the application of a multidimensional poverty index, using counting methods, as a public policy tool in Colombia. It focuses on two particular cases, the definition of a national development goal, complementary to the monetary poverty goal, and the "exit" condition of a multidimensional strategy to overcome extreme poverty.

Through the use of qualitative techniques, several findings led to the argument developed in Chapter 6. Timing, both in terms of the need to set political goals but also the positioning and advocacy campaign for the use of the AHR of AF, mixed with institutional distrust on the national statistics office, were key determinants that position the multidimensional poverty index it as an official measure of the central government. The process was led by the National Department of Planning (DNP) with the technical cooperation and support of foreign and independent experts. However, achieving consensus was not considered to be very important during the process. Parallel to the development of the multidimensional poverty index a new institutional framework was developed to protect the transparency of the measurement of poverty. Despite all the efforts, monetary poverty is still the most dominant measure used in the official discourse of both the government and the media in Colombia.

In summary, although simplicity of composite indices is highly attractive, when the objective is to reduce poverty and use indices as a tool for monitoring improvements/retrenchments of policies and programs implemented a big question arises. What is being measured shapes not only national goals in terms of poverty reduction but it also conditions individual's access to policies and programs. If a perception of simplicity of a particular measure is not transformed in a better understanding of the effects of normative conditions then a big part of the uncertainty about what is being understood as poverty is not solved yet. By using well known techniques inherited from the monetary measurement of poverty and complementing them with new available techniques, at the same time that different robustness and sensitivity analysis tests are performed the information lost can be retrieved.

\section{Implications of this thesis on the measurement of mul- tidimensional poverty}

Despite the coherent story shown by the empirical findings of this thesis, it is important to mention that the methods used in this thesis are replicable but the results of the analysis are context specific. It also depends on the normative choices that are made, and it needs to be performed exhaustively in every case. In social sciences the need to find scientific objectivity has been disregarded as there is no way to generalize the findings without taking into consideration the particular context in which they are applied. "The problem in the study of human activity is that every attempt at a context-free definition of an action, that is, a definition based on abstract rule or laws, will not necessarily accord with the pragmatic way an action is defined by the actors in a concrete social 
situation" Flyvbjerg (2001). However, the pattern found in this thesis is that despite the significant volatility of composite indicators of multidimensional poverty whenever normative decisions are questioned, there are new techniques and established methods available to make the measurement and provide further information, transparency and credibility in support of the decisions taken that, in the end, affect those who are being identified as poor.

The claim, based on the analysis presented in this thesis, is that there is a benchmark to be replicated whenever multidimensional poverty is performed as a public policy tool. The argument is that replicating methods and normative decisions taken for a different context could be misleading. The thesis provides academics and public officials with results, in a particular context, and application of established and new techniques available to discern, at the very least, the direction of the effects of normative decisions. It suggests that there should be no fear in questioning the unquestionable. An example of such a question is why a particular measure use the household as the unit of analysis and not the individual. The thesis proposes new ways of approaching the results from a theoretical, context and methodological perspective.

Especially when the measurement of poverty is used as a public policy tool, key information can be lost when results are aggregated and can only be retrieved if the researcher uses a mix of different techniques in order to find patterns, trends or commonalities. Techniques transferred from the measurement of income poverty, like measurement of poverty over time, as well as techniques drawn from different fields, such as stochastic dominance, or new techniques, such as the Hasse Diagrams, demonstrated that the field of this dissertation is rapidly evolving.

However, this thesis is only the tip of the iceberg. Further research should focus on several under-researched areas and three suggestions as follow:

First, the normative decision about the choice of weights. The literature on composite indexes has shown that there is a wide range of choices at the moment for selecting the type of weights to assess different dimensions. In the case of monetary poverty, as explained in Chapter 1, this problem is solved with prices. However, multidimensionally poverty experts assert that there are dimensions for which prices can not be found or imposed. Examples are the accessibility of education or health. At present, efforts to select normative weights range between completely data-driven to being arbitrarily imposed.

Second, restrictions imposed on the measurement of multidimensional poverty due to the lack of available data. Dimensions, as disability, labor informality and healthcare had to be considered missing despite the evident context-specific importance because the variables needed to measure them were not included in the datasets, or are only applicable to some sub-population sets. Another issue is the lack of panel data in 
developing countries that could support causal analysis of policy interventions in preference to using repeated cross-sectional data to analyse trends and to observe correlations. Multidimensional Poverty Dynamics could benefit from this availability if and only if, variables were regularly measured. Finally, the change in the content of the questionnaires between measuring cycles also affects comparability over time of the resulting data. An example is the multidimensional poverty index for children in Colombia, shown in Chapter 6, for which follow-ups could not be performed.

Third, new methods could be adapted to facilitate the assessment of robustness to normative decisions, such as the global sensitivity analysis. However, these methods require the understanding of the constraints that counting methods, and particularly, dichotomous or categorical variables, impose over continuous settings. In the same vein, stochastic dominance conditions have been tested using methods applied to income poverty but they are not strictly designed for multidimensional poverty purposes, or when initial conditions as weights are considered stable.

The field of measurement of multidimensional poverty is rapidly evolving, and hopefully many of the current gaps will be addressed in the near future. This thesis has contributed to the understanding of the measurement of multidimensional poverty as a public policy tool, especially regarding the questions resulting from normative decisions. To do this, it has used new and existing techniques, as well as has adapted techniques from different fields. All of these techniques have been empirically tested in the analysis presented in the thesis. As a result, this thesis provides a direction for future work in addition to its new findings and contribution to the knowledge of the subject of multidimensional poverty indexes. 


\section{KEY TERMS}

- Achievement: In the CA framework and achievement is known as the materialization of the choice among different capability sets. And achievement is the visible realization of the freedom to choose among different sets of "things a person can or want or values to do". It is also a functioning(Sen, 1999, p. 75).

- Aging:In an individual is defined as the process of growing old, linked to the life course, and not only to the old age. It is the base for the process of demographic change as a reduction of the birth rate and the increase of the life expectancy, inverts the demographic pyramids (Binstock et al., 2011; Huenchuan, 2003)

- Capability: According to Sen (1999, p. 75) it is the combinations of feasible functionings. It assumes that the individual have the freedom to choose among different sets.

- Censoring: It is a process of limiting the multidimensional poverty counting only to those above the poverty cut-off (minimal number of dimensions, see below). (Alkire and Foster, 2011b)

- Cross-Sectional Data: Data collected, mostly in surveys, that measures the performance of random selected units from a population. (Wooldridge, 2002)

- Cut-off: Also known as thresholds are defined as the point in which two different categories are limited. Poverty cut-off (or second cut-off or $k$ ) refers especially in the case of the AHR to the minimum number of dimensions a person has to be deprived to be considered as multidimensionally poor. (Alkire and Foster, 2011b) 
- Inequality: It refers to the distribution of income, health, access to services, and so on. It considers not only those considered well-off but also how far are they from those in the bottom. There is still discussion about if inequality harms or benefits a society (Deaton, 2013, p. 10).

- Life Satisfaction: Linked to the happiness framework, life satisfaction is the subjective measure performed by individuals of their current feelings, as defined by the OECD (2015).

- Lorenz Curve: It is a graphical representation of distributions of wealth, that "plots the percentage of total income earned by various portions of the population" (Gaswirth, 1971). The reversed generalized Lorenz Curve is also a graphical representation but inverting the order of the variables or "scaling up to the ordinary Lorenz Curve by the mean of the distribution" (Shorrocks, 1983).

- Needs: Refers to primary goods and services that are basic for the individuals to live a decent life in a determined society. It is the basis of the Basic Needs Framework, although there is not a unique definition of those needs (Streeten, 1979).

- Panel Data: Also called longitudinal data is defined as "repeated observations on the same cross section [...], over time" (Wooldridge, 2002, p. 5).

- Poverty: There are multiple definitions of what is poverty. It is linked to the measurement. As for instance, lack of resources (monetary) or in the terms of Sen (1999, p. 20) "a deprivation of basic capabilities".

- Poverty Identification: It is the process of selecting among a group of people, according to a particular definition who are below or above a poverty line. It could be used as a direct (absolute poverty) or indirect (relative poverty). (Sen, 1981, Ch. 3)

- Quality of Life: The definition adopted in this thesis follows Sen (1999, p. 24): "concentrates on the way human life goes (perhaps even the choice one has) and not just on resources or income that a person commands"

- Resources: On one hand it represents attached to means, such as income, and in the other hand, those commodities or goods which are a necessity in a society. Following the train of thought adopted by Sen (1999, p. 73) with the example of Adam Smith, the linen shirt and the ability to appear in public without shame.

- Social Cohesion: is a well debated term, it includes "adherence to norms of behavior and institutional rules, [...] more participation in civil society, [...] increased support for action to produce collective goods" (Stanley, 2003). 
- Social Exclusion: Social Exclusion is "a complex and multidimensional process. It involves the lack or denial of resources, rights, goods, and services, and the inability to participate in the normal relationships and activities, available to the majority of people in a society" (Levitas et al., 2007, p. 25)

- Stochastic Dominance: It is a way to determine the partial ordering on the comparison of two cumulative distribution functions by using different moments of it (first, second and so on). Generically the first order is known as stochastic dominance, the following orders will be named as follows; second, third, etc (Hadar and Russell, 1969)

- Vulnerability: It is a broader concept than poverty: "Has a close relationship to notions of suffering, on the one hand and classical philosophical notions of virtue on the other $[\ldots]$ and on the attendant risks to which such vulnerability leave us prey" (Turner, 2010, Ch. 1)

- Well-being: In the neoclassical tradition understood as a synonym of utility. Amartya Sen redefines it and expresses it in terms of functionings as "the valuation of his being" (Basu, 1987, p. 71). 


\section{BIBLIOGRAPHY}

Adams, B. (2004). Time. Polity Key Concepts Series. Cambridge: Polity Press.

Addison, T., Hulme, D., and Kanbur, R. (2009). Poverty Dynamics: Measurement and Understanding from an interdisciplinary perspective. In Addison, T., D., H., and Kanbur, R., editors, Poverty Dynamics: Interdisciplinary Perspectives. Oxford University Press.

Alcalde, J., Lazo, O., and Nigenga, G. (2011). Sistema de Salud en Peru. Salud Pública México, 53(Suplemento 2):s243-s254.

Alkire, S. (2002). Valuing freedoms. Sen's capability approach and poverty reduction. Oxford University Press.

Alkire, S. (2008). Using the Capability Approach: Prospective and Evaluative Analyses. In Commim, F., Qizilbash, M., and Alkire, S., editors, The Capability Approach, pages 26-49. Cambridge University Press.

Alkire, S. (2011). Multidimensional Poverty and its Discontents. Working Paper 46, OPHI.

Alkire, S., Apablaza, M., Chakravarty, S., and Yalonetzky, G. (2014). Measuring Chronic Multidimensional Poverty: A Counting Approach. Working Paper 75, OPHI.

Alkire, S. and Foster, J. (2011a). Counting and Multidimensional Poverty Measurement. Journal of Public Economics, 95:476-487.

Alkire, S. and Foster, J. (2011b). Understandings and Misunderstandings of Multidimensional Poverty Measurement. The Journal of Economic Inequality, 9(2):289-314. 
Alkire, S., Foster, J., Seth, S., Roche, J., Santos, M., and Ballon, P. (2015a). Multidimensional Poverty Measurement and Analysis. Oxford University Press.

Alkire, S., Roche, J., Seth, S., and Sumner, A. (2015b). Identifying the Poorest People and Groups: Strategies Using the Global Multidimensional Poverty Index. Journal of International Development, 27(3):362-387.

Alkire, S. and Santos, M. (2010). Acute Multidimensional Poverty: A New Index for Developing Countries. Working Paper 38, OPHI.

Alkire, S. and Santos, M. (2014). Measuring Acute Poverty in the Developing World: Robustness and Scope of the Multidimensional Poverty Index. World Development, $59: 251-274$.

Alkire, S. and Seth, S. (2013). Selecting a Targeting Method to Identify BPL Households in India. Social Indicators Research, 112(2):417-446.

Anand, P., Krishnakumar, J., and Tran, N. (2011). Measuring welfare: Latent variable models for happiness and capabilities in the presence of unobservable heterogeneity. Journal of ublic Economics, 95:205-215.

Angulo, R., Díaz, Y., and Pardo, R. (2011). Índice de pobreza multidimensional para Colombia (IPM-Colombia) 1997-2010. Working Paper 382, DNP.

Annoni, P., Bruggemann, R., and Carlsen, L. (2015). A multidimensional view on poverty in the European Union by partial order theory. Journal of Applied Statistics, 42(3):535-554.

Apablaza, M. and Yalonetzky, G. (2013). Decomposing multidimensional poverty dynamics. Working Paper 101, Young Lives.

Asselin, L. and Anh, V. (2008). Multidimensional poverty and multiple correspondence analysis. In Kakwani, N. and Silber, J., editors, Quantitative Approaches to Multidimensional Poverty Measurement, pages 80-103. Palgrave Macmillan.

Atkinson, A. (1972). On the measurement of inequality. Journal of Economic Theory, $2(3): 244-263$.

Atkinson, A. (1999). The contributions of Amartya Sen to welfare economics. Scandinavian Journal of Economics, 101(2):173-190.

Atkinson, A. (2003). Multidimensional deprivation: contrasting social welfare and counting approaches. Journal of Economic Inequality, 1:25-49.

Atkinson, A. and Marlier, E. (2011). Human development and indicators of poverty and social exclusion as part of the policy process. Indian Journal of Human Development, 5(2):293-320. 
Atkinson, T., Cantillon, B., Marlier, E., and Nolan, B. (2002). Social Indicators: The EU and Social Inclusion. Oxford University Press.

Ayala, L., Jurado, A., and Perez-Mayo, J. (2011). Income poverty and multidimensional deprivation: Lessons from cross-regional analysis. Review of Income and Wealth, 57(1):40-60.

Ayuya, O., Gido, E., Bett, H., Lagat, J., Kahi, A., and Bauer, S. (2015). Effect of certified organic production systems on poverty among smallholder farmers: Empirical evidence from Kenya. World Development, 67:27-37.

Azevedo, J., Inchaust, G., and Sanfelice, V. (2013). Decomposing the recent inequality decline in Latin America. Policy Research Working Paper 6715, World Bank.

Azevedo, V. and Robles, M. (2013). Multidimensional targeting: Identifying beneficiaries of conditional cash transfer programs. Social Indicators Research, 112(2):447-475.

Azpitarte, F. (2012). Measuring poverty using both income and wealth: A cross-country comparison between the US and Spain. Review of Income and Wealth, 58(1):24-50.

Bank, W. (2016). Monitoring Global Poverty. Report of the Commission on Global Poverty. World Bank Group.

Barcena-Martin, E. and Lacomba, B. (2014). Country differences in material deprivation in Europe. Review of Income and Wealth, 60(4):802-820.

Barnes, D., S., K., and Smad, H. (2011). Energy poverty in rural Bangladesh. Energy Policy, 39(2):894-904.

Barrientos, A. (2013). Social protection for poverty reduction: Approaches, effectiveness and challenges. In Bender, K., Kaltenborn, M., and Pfleiderer, C., editors, Social Protection in Developing Countries: Reforming Systems. Routledge.

Basarir, H. (2011). Poor, multidimensionally speaking: Evidence from South Africa. Journal of African Economies, 20(3):463-504.

Basu, K. (1987). Achievements, capabilities and the concept of well-being. Social Choice and Welfare, 4:69-76.

Batana, Y. (2013). Multidimensional measurement of poverty among women in SubSaharan Africa. Social Indicators Research, 112(2):337-362.

Battiston, D., Cruces, G., Lopez, L., Lugo, M., and Santos, M. (2013). Income and beyond: Multidimensional poverty in six Latin American countries. Social Indicators Research, 112(2):291-314.

Baulch, B. (2006). Aid distribution and the MDGs. World Development, 34(6):933-950. 
Baulch, B. and Masset, E. (2003). Do monetary and non-monetary indicators tell the same story about chronic poverty? a study of Vietnam in the 1990s. World Development, 31(3):441-453.

Bavier, R. (2008). Reconciliation of Income and Consumption Data in Poverty Measurement. Journal of Policy Analysis and Management, 27(1):40-62.

Becerril, V., Reyes, J., and Manuel, A. (2011). Sistema de salud en chile. Salud Pública México, 53(Suplemento 2):s.132-s.143.

Becker, G., Philipson, T., and Soares, R. (2005). The quantity and quality of life and the evolution of world inequality. The American Economic Review, 95(1):277-291.

Bennett, C. and Mitra, S. (2013). Multidimensional poverty: Measurement, estimation and inference. Econometric Reviews, 32(1):57-83.

Betti, G., Cheli, B., Lemmi, A., and Verma, V. (2008). The fuzzy set approach to multidimensional poverty: the case of Italy in the 1990s. In Kakwani, N. and Silber, J., editors, Quantitative Approaches to Multidimensional Poverty Measurement, pages 30-48. Palgrave Macmillan.

Binstock, R., George, L., Cutler, S., Hendricks, J., and Schulz, J. (2011). Handbook of Aging and the Social Sciences. Elsevier.

Blackburn, M. (1998). The sensitivity of international poverty comparisons. Review of Income and Wealth, 44(4):449-472.

Blazquez, M. and Budria, S. (2014). Deprivation and subjective well-being evidence from panel data. Review of Income and Wealth, 60(4):655-682.

Blinder, A. (1973). Wage discrimination: Reduced form and structural estimates. The Journal of Human Resources, 8(4):436-455.

Bolt, V. and Bird, K. (2003). The intrahousehold disadvantages framework: A framework for the analysis of intra-household difference and inequality. Working Paper 32, Chronic Poverty Research Centre.

Bossert, W., Chakravarty, S., and D'Ambrosio, C. (2012). Poverty and time. Journal of Economic Inequality, 10(2):145-162.

Bossert, W., Chakravarty, S., and D'Ambrosio, C. (2013). Multidimensional poverty and material deprivation with discrete data. Review of Income and Wealth, 59(1):29-43.

Bouillon, C., Legovini, A., and Lustig, N. (2003). Rising inequality in Mexico: Household characteristics and regional effects. The Journal of Development Studies, 39(4):112133. 
Bourguignon, F. (2006). From income to endowments: The difficult task of expanding the income poverty paradigm. In Grusky, D. and Kanbur, R., editors, Poverty and Inequality. Stanford University Press.

Bourguignon, F. and Chakravarty, S. (2003). The measurement of multidimensional poverty. Journal of Economic Inequality, 1:25-49.

Bouzarovski, S., Petrova, S., and Salamanov, R. (2012). Energy poverty policies in the EU: A critical perspective. Energy Policy, 49:76-82.

Brandolini, A., Magri, S., and Smeeding, T. (2010). Asset-based measurement of poverty. Journal of Policy Analyis and Management, 29(2):267-289.

Bruggemann, R. and Carlsen, L. (2006). Introduction to partial order theory exemplified by the evaluation of sampling sites. In Bruggeman, R. and Carlsen, L., editors, Partial Order in Environmental Sciences and Chemistry, pages 61-110. Springer.

Bruggemann, R. and Patil, G. (2012). Ranking and Prioritization for Multi-indicator Systems. Introduction to Partial Order Applications. Springer.

Callender, E., Schofield, D., and Shrestra, R. (2012). Multiple disadvantages among older citizens: What a multidimensional measure of poverty can show. Journal of Aging and Social Policy, 24(4):368-383.

Calvo, C. (2008). Vulnerability to multidimensional poverty: Peru, 1998-2002. World Development, 36(6):1011-1020.

Calvo, C. and Dercon, S. (2009). Chronic poverty and all that: The measurement of poverty over time. In Addison, T., D., H., and Kanbur, R., editors, Poverty Dynamics: Interdisciplinary Perspectives. Oxford University Press.

Cecchini, S., Filgueira, F., and Robles, C. (2014). Social Protection Systems in Latin America and the Caribbean: A comparative view. Social Policy Series, ECLAC. United Nations Publications.

Cerioli, A. and Zani, S. (1990). A fuzzy approach to the measurement of poverty. In Dagum, C. and Zenga, M., editors, Income and Wealth Distribution, Inequality and Poverty, Studies in Contemporary Economics, pages 272-284. Springer.

Chakravarty, S. and D'Ambrosio, C. (2006). The measurement of social exclusion. Review of Income and Wealth, 52(3):377-398.

Chakravarty, S. and Silber, J. (2008). Measuring multidimensional poverty: The axiomatic approach. In Kakwani, N. and Silber, J., editors, Quantitative Approaches to Multidimensional Poverty Measurement, pages 192-209. Palgrave Macmillan.

Chakravarty, S. and Zoli, C. (2012). Stochastic dominance relations for integer variables. Journal of Economic Theory, 147(4):1331-1341. 
Chambers, R. (1995). Poverty and livelihoods- whose reality counts? Environment and Urbanization, 7(1):173-204.

Chambers, R. (2007). Participatory, pluralism and perceptions of poverty. In Kakwani, N. and Silber, J., editors, The Many Dimensions of Poverty, pages 140-164. Palgrave Macmillan.

Che, Y. (1995). Revolving doors and the optimal tolerance for agency collusion. The RAND Journal of Economics, 26(3):378-397.

Chiappero, E. (2006). Capability approach and fuzzy set theory: Description, aggregation and inference issues. In Lemmi, A. and Betti, G., editors, Fuzzy Set Approach to Multidimensional Poverty Measurement., Economic Studies in Inequality, Social Exclusion and Well-Being, pages 93-111. Springer.

Chiappero, E. (2008). Complexity and vagueness in the capability approach: strenghts and weakness? In Comim, F., Qizilbash, M., and Alkire, S., editors, The Capability Approach, pages 268-309. Cambridge University Press.

Chiappori, P.-A., Haddad, L., Haddinoff, J., and Kanbur, R. (1993). Unitary versus collective models of household: Time to shift the burden of proof. Policy Research Working Paper 1217, Working Bank.

Chow, N. (1983). The extent and nature of poverty in Hong Kong. Resource Paper Series 7, University of Hong Kong.

Cook, S. (2013). Rescuing social protection from the poverty trap. In Bender, K., Kaltenborn, M., and Pfleiderer, C., editors, Social Protection in Developing Countries: Reforming Systems. Routledge.

Coromaldi, M. and Zoli, M. (2012). Deriving multidimensional poverty indicators: Methodological issues and an empirical analysis for Italy. Social Indicators Research, 107(1):37-54.

Cowling, K., Dandona, R., and Dandona, L. (2014). Social determinants of health in India: Progress and inequities across states. International Journal for Equity in Health, 13:1-12.

Csíkszentmihályi, M. (1975). Beyond boredom and anxiety. Jossey-Bass Publishers.

Damioli, G. (2010). How and why the dynamics of poverty differ across European countries. Conference proceedings, IARIW.

Davidson, R. and Duclos, J. (2012). Testing for restricted stochastic dominance. Econometric Reviews, 32(1):84-125.

Davies, P. (2001). Spies as informants: Triangulation and representation of elite interview data in the study of the intelligence and security services. Politics, 21(1):73-80. 
Davis, K., Fisher, A., Kingsbury, B., and Sally, M. (2012). Governance by indicators. Oxford University Press.

De Neubourg, C. nd Chai, J., De Milliano, M., Plavgo, I., and Wei, Z. (2012). Step-bystep guidelines to the multiple overlapping deprivation analysis (moda). Working Paper 10, Innocenti Research Centre-UNICEF.

Deaton, A. (2013). The Great Escape: Health, Welath and the Origins of Inequality. Princeton University Press.

Decanq, K. and Lugo, M. (2010). Weights in multidimensional indices of well-being: An overview. Discussion paper, Katholieke Universiteit Leuven.

Del Popolo, F. (2001). Características sociodemográficas y socioeconómicas de las personas de edad en América Latina. Población y Desarrollo 19, ECLAC.

Delamonica, E. and Minujin, A. (2007). Incidence, depth and severity for children in poverty. Social Indicators Research, 82(2):361-374.

Deneulin, S. (2006). The capability approach and the praxis of development. Palgrave Macmillan.

Deutsch, J. and Silber, J. (2005). Measuring multidimensional poverty: An empirical comparison of various approaches. Review of Income and Wealth, 51(1):145-174.

Devicienti, F., Gualtieri, V., and Rossi, M. (2014). The persistence of income poverty and lifestyle deprivation: Evidence from italy. Bulletin of Economic Research, 66(3):246278.

Devicienti, F. and Poggi, A. (2011). Poverty and social exclusions: Two sides of the same coin or dynamically interrelated processes? Applied Economics, 43(25):3549-3571.

Dick, A. and Zingales, L. (2002). The corporate governance role of the media. Working Paper 9309, NBER.

DNP (2001). Familias colombianas: estrategias frente al riesgo. DNP-PNUD-ICBF.

DNP (2006a). Pobreza y desigualdad en Colombia: diagnóstico y estrategias. DNP.

DNP (2006b). Red de protección social contra la pobreza extrema. Documento Conpes Social 102, DNP.

DNP (2012). Metodologías oficiales y arreglos institucionales para la medición de la pobreza en Colombia. Documento Conpes Social 150, DNP.

Duclos, J., Sahn, D., and Younger, S. (2006). Robust multidimensional poverty comparisons. The Economic Journal, 116:943-968. 
ECLAC (2006). Compendium of Best Practices in Poverty Measurement: Expert Group on Poverty Statistics, Rio Group. United Nations Economic Commission for Latin America and the Caribbean.

ECLAC (2012). Social Panorama of Latin America. United Nations Economic Commission for Latin America and the Caribbean.

Esping-Andersen, G. (2013). The Three Worlds of Welfare Capitalism. Wiley.

EUROSTAT (2015). Statistics explained: Arope. http://ec.europa.eu/eurostat/statistics-explained/. Accessed: 2015-05-31.

Evans, P. and Rauch, J. (1999). Bureaucracy and growth: A cross-national analysis of the effects of "weberian" state structures on economic growth. American Sociological Review, 64(5):748-765.

Fattore, M., Bruggeman, R., and Owsinski, J. (2011). Using poset theory to compare fuzzy multidimensional material deprivation across regions. In Ingrassia, S., Rocci, R., and Vichi, M., editors, New Perspectives in Statistical Modeling and Data Analysis, Studies in Classification, Data Analysis and Knowledge Organization. Springer Berlin Heidelberg.

Fedesarrollo (2010). Debates de coyuntura económica y social: Los retos y desafíos de la red juntos. Working Paper 83, Fedesarrollo.

Feinerer, I., Hornik, K., and Meyer, D. (2008). Text mining infraestructure in r. Journal of Statistical Software, 25(5):1-54.

Feres, J. and Mancero, X. (2001). El método de las necesidades básicas insatisfechas (NBI) y sus aplicaciones para América Latina [The Unsatisfied Basic Needs method and its application in Latin America]. Series: Estudios Estadísticos y Prospectivos. 7 , ECLAC.

Ferreira, F. and Lugo, M. (2013). Multidimensional policy analysis: Looking for a middle ground. The World Bank Research Observer, 28(2):220-235.

Filmer, D. and Scott, K. (2008). Assessing asset indices. Policy Research Working Paper 4605, World Bank.

Fleurbaey, M. (2015). Beyond income and wealth. Review of Income and Wealth, 61(2):199-219.

Flyvbjerg, B. (2001). Making Social Science Matter: Why social inquiry fails and how it can succeed again. Cambridge University Press.

Flórez, C., Espinosa, F., Sánchez, L., and Angulo, R. (2008). Diseño del Índice SISBEN en su Tercera Versión. Final report, DNP. 
Fortin, N., Lemieux, T., and Fipo, S. (2010). Decomposition methods in economics. Working Paper 16045, NBER.

Foster, J. (2009). A class of chronic poverty measures. In Addison, T., D., H., and Kanbur, R., editors, Poverty Dynamics: Interdisciplinary Perspectives. Oxford University Press.

Foster, J., Greer, J., and Thorbecke, E. (1984). A class of decomposable poverty measures. Econometrica, 52(3):761-766.

Foster, J., Seth, S., Lokshin, M., and Sajaia, Z. (2013). A Unified Approach to Measuring Poverty and Inequality: Theory and Practice. World Bank.

Foster, J. and Shorrocks, A. (1988). Poverty orderings and welfare dominance. Social Choice and Welfare, 5(2-3):179-198.

Frey, B., Homberg, F., and Osterloh, M. (2013). Organizational control systems and pay-for-performance in the public service. Organization Studies, 34(7):949-972.

Fukuda-Parr, S. (2003). The human development paradigm: Operationalizing Sen's ideas on capabilities. Feminist Economics, 9(2-3):301-317.

Fukuda-Parr, S. (2010). Reducing inequality- the missing mdg: A content review of prsps and bilateral donor policy statements. IDS Bulletin, 41(1):26-35.

Fusco, A. and Dickes, P. (2008). The rasch model and multidimensional poverty measurement. In Kakwani, N. and Silber, J., editors, Quantitative Approaches to Multidimensional Poverty Measurement, pages 49-62. Palgrave Macmillan.

Gallegos, J., Yalonetzky, G., and Azpitarte, F. (2015). Robust pro-poorest poverty reduction with counting measures: The anonymous case. Melbourne Institute Working Papers.

Gammage, S. (2010). Time pressed and time poor: Unpaid household work in Guatemala. Feminist Economics, 16(3):79-112.

Garcia-Diaz, R. and Prudencio, D. (2015). On the dynamics of multidimensional chronic poverty. Working Paper 16, UNU-WIDER.

Gaswirth, J. (1971). Notes and comments: A general definition of the lorenz curve. Econometrica, 39(6):1037-1039.

Georgelis, Y. and Tabvuma, V. (2010). Does public service motivation adapt? Kyklos, 63:176-191.

Gerovska-Mitev, M. (2015). Poverty and social exclusion in Macedonia, Serbia and Croatia: status and policy responses. Revija Za Socijal Nu Politiku, 22(1):81-94. 
Greenstein, J., Gentilini, U., and Sumner, A. (2014). National or international poverty lines or both? setting goals for income poverty after 2015. Journal of Human Development and Capabilities, 15:132-146.

Grosh, M. and Muñoz, J. (1996). A manual for planning and implementing the living standard measurement study survey. Working Paper 126, World Bank.

Guardiola, J. and Garcia-Quero, F. (2014). Buen vivir (living well) in Ecuador: Community and environmental satisfaction without household material prosperity. Ecological Economics, 107:177-184.

Guerrero, R., Gallego, A., Becerril, V., and Vásquez, J. (2011). Sistema de salud en colombia. Salud Pública México, 53(Suplemento 2):s.144-s.155.

Günther, I. and Klasen, S. (2009). Measuring chronic non-income poverty. In Addison, T., D., H., and Kanbur, R., editors, Poverty Dynamics: Interdisciplinary Perspectives. Oxford University Press.

Hadar, J. and Russell, W. (1969). Rules for ordering uncertain prospects. American Economic Review, 59(1):25-34.

Hagenaars, A. and de Vos, K. (1988). The definition and measurement of poverty. The Journal of Human Resources, 23(2):211-221.

Harttgen, K., Klasen, S., and Vollmer, S. (2013). An African growth miracle? or: What do asset indices tell us about trends in economic performance? Review of Income and Wealth, 59(Supplement):S37-S61.

Headey, B., Marks, G., and Wooden, M. (2005). The dynamics of income poverty in Australia: evidence from the first three waves of the HILDA survey. Australian Journal of Social Issues, 40(4):541-552.

Hearst, M. (1999). Untangling text data mining. In Proceedings of the 37th Annual Meeting of the Association for Computational Linguistics on Computational Linguistics, ACL '99, pages 3-10. Association for Computational Linguistics.

Hicks, N. and Streeten, P. (1979). Indicators of development: The search for a basic needs yardstick. World Development, 7:567-580.

Holmqvist, E. and Turner, L. (2014). Swedish welfare state and housing markets: Under economic and political pressure. Journal of Housing and the Built Environment, 29(2):2237-254.

Holzmann, R. and Jorgensen, S. (2001). Social risk management: A new conceptual framework for social protection, and beyond. International Tax and Public Finance, 8:529-556. 
Huang, R. (2012-2014). RQDA: R-based qualitative data analysis. R package version 0.2-6. http://rqda.r-forge.r-project.org/.

Huenchuan, S. (2003). Ageing, Solidarity and Social Protection in Latin America and the Caribbean: Time for Progress Towards Equality. Libros de la CEPAL. United Nations Publications.

Hulme, D. and Shepherd, A. (2003). Conceptualizing chronic poverty. World Development, 31(3):403-423.

Innes, J. and Booher, D. (1999). Consensus building and complex adaptative systems. Journal of American Planning Associaton, 65(4):412-423.

Islam, T. (2014). An exercise to evaluate an anti-poverty program with multiple outcomes using program evaluation. Economic Letters, 122(2):365-369.

Jenkins, S. and Mickelwright, J. (2007). New directions in the analysis of inequality and poverty. Working paper 11, ISER.

Jenkins, S. and Rigg, A. (2001). The dynamics of poverty in Britain. Research Report 157, Department of Work and Pensions.

Jenkins, S. and Van Kerm, P. (2011). Patterns of persistent poverty: evidence from EU-SILC. Working paper 30, ISER.

Jenkins, S. and Van Kerm, P. (2014). The relationship between eu indicators of persistent and current poverty. Social Indicators Research, 116(2):611-638.

Jimenez, W. and Gonzalez, J. (2014). Calidad de vida urbana: Una propuesta para su evaluacion. Revista de Estudios Sociales, pages 159-175.

Johnson, E. (1984). Agency "capture": The "revolving door" between regulated industries and their regulating agencies. University of Richmond Law Review, 18:95-120.

Khan, A., Saboor, A., Hussain, A., Sadiq, S., and Mohsin, A. (2014). Investigating multidimensional poverty across the regions in the Sindh province of Pakistan. Social Indicators Research, 119(2):515-532.

Khandker, S., Barnes, D., and Samad, H. (2012). Are the energy poor also income poor? evidence from India. Energy Policy, 47:1-12.

Kim, S. (2015). Fuzzy multidimensional poverty measurement: An analysis of statistical behaviors. Social Indicators Research, 120(3):635-667.

Kingdon, G. and Knight, J. (2006). Subjective well-being poverty vs. income poverty and capabilities poverty? Journal of Development Studies, 42(7):1199-1224. 
Klasen, S. (1997). Poverty, inequality and deprivation in South Africa. Social Indicators Research, 41(1):51-94.

Kolenikov, S. and Shorrocks, A. (2005). A decomposition analysis of regional poverty in Russia. Review of Development Economics, 9(1):25-46.

Krishnakumar, J. (2008). Multidimensional measures of poverty and well-being based on latent variable models. In Kakwani, N. and Silber, J., editors, Quantitative Approaches to Multidimensional Poverty Measurement, pages 118-134. Palgrave Macmillan.

Krishnakumar, J. and Ballon, P. (2008). Estimating basic capabilities:a structural equation model applied to Bolivia. World Development, 36(6):992-1010.

Krishnakumar, J. and Nagar, A. (2008). On exact statistical properties of multidimensional indices based on principal components, factor analysis, mimic and structural equation models. Social Indicators Research, 86:481-496.

Kuklys, W. (2005). Amartya's Sen Capability Approach. Theoretical Insights and Empirical Applications. Studies in Choice And Welfare. Springer.

Kyzyma, I. (2014). Changes in the patterns of poverty duration in Germany, 1992-2009. Review of Income and Wealth, 60(Supplement Issue):S305-S331.

Lang, V. and Lingdau, H. (2015). Defining and measuring poverty and inequality post2015. Journal of International Development, 27(3):399-414.

Lasso de la Vega, M. (2010). Counting poverty orderings deprivation curves. In Bishop, J., editor, Research on Economic Inequality, pages 153-172. Emerald Group Publishing Limited.

Lemmi, A. and Betti, G. (2006). Fuzzy Set Approach to Multidimensional Poverty Measurement. Economic Studies in Inequality, Social Exclusion and Well-Being. Springer.

Levitas, R., Pantazis, C., Fahmy, E., Gordon, D., Lloyd, E., and Patsios, D. (2007). The multi-dimensional analysis of social exclusion. Report, Department of Sociology and School for Social Policy Townsend Centre for the International Study of Poverty and Bristol Institute for Public Affairs at University of Bristol.

Li, G. and Weng, Q. (2007). Measuring the quality of life in city of Indianapolis by integration of remote sensing and census data. International Journal of Remote Sensing, 28(2):249-267.

Lokshin, M. and Ravallion, M. (2000). Welfare impacts of the 1998 financial crisis in Russia and the response of the public safety net. Economics of Transition, 8(2):269295. 
Lucas, K. (2011). Making the connections between transport disadvantage and the social exclusion of low income populations in the Tshwane region of South Africa. Journal of Transport Geography, 19:1320-1334.

Lucchini, M. and Assi, J. (2013). Mapping patterns of multiple deprivation and wellbeing using self-organizing maps: An application to swiss household panel data. Social Indicators Research, 112(1):129-149.

Lucio, R., Villacres, N., and Henriquez, R. (2011). Sistema de salud en ecuador. Salud Pública México, 53(Suplemento 2):s.177-s.187.

Luzzi, G., Fluckiger, Y., and Weber, S. (2008). A cluster analysis of multidimensional poverty in Switzerland. In Kakwani, N. and Silber, J., editors, Quantitative Approaches to Multidimensional Poverty Measurement, pages 63-79. Palgrave Macmillan.

Machado, A., Golgher, A., and Antigo, M. (2014). Deprivation viewed from a multidimensional perspective: The case of Brazil. ECLAC Review, 112:125-146.

Madden, D. (2011). Health and income poverty in Ireland, 2003-2006. Journal of Economic Inequality, 9(1):23-33.

Maestri, V. (2015). A measure of income poverty including housing: Benefits and limitations for policy making. Social Indicators Research, 121(3):675-696.

Main, G. and Bradshaw, J. (2012). Child material deprivation index. Child Indicators Research, 5(3):503-521.

McKay, A. (2013). Growth and poverty reduction in Africa in the last two decades: Evidence from an AERC growth-poverty project and beyond. Journal of African Economies, 22(Supplement):i49-i76.

Melamed, C. (2015). Income poverty, MDG1 and the post-2015 agenda: Goals and targets that work. Journal of International Development, 27(3):388-398.

Merz, J. and Rathjen, T. (2014a). Multidimensional time and income poverty: Well-being gap and minimum 2dgap poverty intensity -German evidence. Journal of Economic Inequality, 12(4):555-580.

Merz, J. and Rathjen, T. (2014b). Time and income poverty: An interdependent multidimensional poverty approach with German time use diary data. Review of Income and Wealth, 60(3):450-479.

Meyer, B. and Sullivan, J. (2012). Winning the war: Poverty from the great society to the great recession. Brookings Papers on Economic Activity, Fall:133-200.

Milanovic, B. (2010). The Haves and the Have-Nots: A brief and idiosyncratic history of global inequality. ReadHowYouWant.com. 
Mitra, S. (2006). The capability approacch and disability. Journal of Disability Policy Studies, 16(4):236-247.

Mitra, S., Jones, K., Vick, B., McGinn, E., and Alexander, M. (2013). Implementing a multidimensional poverty measure using mixed methods and a participatory framework. Social Indicators Research, 110(3):1061-1081.

Moser, C. and Felton, A. (2009). The construction of an asset index: Measuring asset accumulation in Ecuador. In Addison, T., D., H., and Kanbur, R., editors, Poverty Dynamics: Interdisciplinary Perspectives. Oxford University Press.

Muller, A. (2008). Clarifying poverty decomposition. Working paper, Socio-Economic Institute, University of Zürich.

Narayan, D. and Patel, R. (2000). Voices of the Poor: Can Anyone Hear Us? Voices of the Poor. Oxford University Press for the World Bank.

National Research Council (1995). Measuring Poverty: A New Approach. National Academies Press.

Nicholas, A., Ray, R., and Sinha, K. (2013). A dynamic multidimensional measure of poverty. Working Paper 25, Monash University.

Nolan, B., Whelan, C., and Callan, T. (1993). Resources deprivation and the measurement of poverty. Journal of Social Policy, 22(2):141-172.

Nupia, O. (2011). Anti-poverty programs and presidential election outcomes: Familias en Acción in Colombia. Working Paper 14, CEDE.

Nussbaum, M. (2003). Capabilities as fundamental entitlements: Sen and social justice. Feminist Economics, 9(2-3):33-59.

Oaxaca, R. (1973). Male-female wage differentials in urban labor markets. International Economic Review, 14(3):693-709.

OECD (2007). Glossary of Statistical Terms. OECD.

OECD (2008). Handbook on Constructing Composite Indicators. Methodology and User Guide. OECD-European Commission.

OECD (2015). How's life? 2015 Measuring Well-being. OECD.

OPHI (2013). Measuring multidimensional poverty: Insights from around the world.the global multidimensional poverty peer network. Brochure N.A., OPHI, Oxford Department of International Development.

Osberg, L. (2012). Measuring economic insecurity in rich and poor nations. Research Paper 03, Centre for the Study of Living Standards. 
Osberg, L. and Sharpe, A. (2014). Measuring economic insecurity in rich and poor nations. Review of Income and Wealth, 60:S53-S76.

Oshio, T. and Khan, M. (2014). Multidimensional poverty and health: Evidence from a nation-wide survey in Japan. International JOurnal for Equity in Health, 13:1-11.

Oxley, H., Dang, T., and Antolin, P. (2000). Poverty dynamics in six OECD countries. Economic Studies 30, OECD.

Paruolo, P., Saisana, M., and Saltelli, A. (2013). Ratings and rankings: vodoo or science? Journal of the Royal Statistical Society, 176(3):609-634.

Permanyer, I. and Riffe, T. (2015). Multidimensional poverty measurement: Making the identification of the poor count. Conference Proceedings 107, ECINEQ.

Pfoertner, T., Andress, H., and Janssen, C. (2011). Income or living standard and health in Germany: Different ways of measurement of relative poverty with regard to selfrated health. International Journal of Public Health, 56(4):373-384.

Pierson, P. (1996). The new politics of the welfare state. World Politics, 48(2):143-179.

Polin, V. and Raitano, M. (2014). Poverty transitions and trigger events across eu groups of countries: Evidence from the EU-SILC. Journal of Social Policy, 43(4):745-772.

Ravallion, M. (2011). On multidimensional indices of poverty. Journal of Economic Inequality, 9(2):235-248.

Ravallion, M. (2016). The Economics of Poverty: History, Measurement and Policy. Oxford University Press.

Ravallion, M. and Huppi, M. (1991). Measuring changes in poverty: A methodological case study of Indonesia during and adjustment period. The World Bank Economic Review, 5(1):57-82.

Rawls, J. (1971). A Theory of Justice. Original Edition. Harvard paperback. Harvard University Press.

Ray, R. and Sinha, K. (2015). Multidimensional deprivation in China, India and Vietnam: A comparative study on micro data. Journal of Human Development and Capabilities, 16(1):69-93.

Reedy, S., Visaria, S., and Asali, M. (2006). Inter-Country Comparisons of Poverty Based on a Capability Approach: An Empirical Exercise. Working Paper 27, International Poverty Centre UNDP.

Riegg, S., McKernan, S., and Ratcliffe, C. (2008). The dynamics of poverty in the United States: a review of data, methods, and findings. Journal of Policy Analysis and Management, 27(3):577-605. 
Rippin, N. (2010). Poverty severity in a multidimensional framework: The issue of inequality between dimensions. Discussion Paper 47, Courant Research Center, University of Gottingen.

Robeyns, I. and Van der Veer, R. (2007). Sustainable quality of life. conceptual analysis for a policy relevant empirical specification. Report 550031006, Netherlands Environmental Assessment Agency and University of Amsterdam.

Roche, J. (2013). Monitoring progress in child poverty reduction: Methodological insights and illustration to the case study of Bangladesh. Social Indicators Research, 112(2):363-390.

Roelen, K. (2014). Multidimensional child poverty in vietnam from a longitudinal perspetive-improved lives or impoverished conditions? Child Indicators Research, $7(3): 487-516$.

Roelen, K., Gassmann, F., and De Neubourg, C. (2009). The importance of choice and definition for the measurement of child poverty-the case of Vietnam. Child Indicators Research, 2(3):245-263.

Roelen, K., Gassmann, F., and De Neubourg, C. (2010). Child poverty in Vietnam: Providing insights using a country-specific and multidimensional model. Social Indicators Research, 98(1):129-145.

Rojas, E. and Medellin, N. (2011). Housing policy matters for the poor. Working Paper 289, Interamerican Development Bank.

Rojas, M. (2008). Experienced poverty and income poverty in Mexico: A subjective well-being approach. World Development, 36(6):1078-1093.

Roodman, D. (2011). Composite indices. Journal of Economic Inequality, 9:483-484.

Rose-Ackerman, S. (2006). International Handbook on the Economics of Corruption. Edward Elgard.

Rowntree, B. (1908). Poverty: A Study of Town Life. MacMillan and Co.

Ruggeri, C., Saith, R., and Stewart, F. (2003). Does it matter that we do not agree on the definition of poverty? a comparison of four approaches. Oxford Development Studies, 31(3):243-274.

Russell, D. (2008). Stochastic dominance. In Durlauf, S. and Blume, L., editors, The New Palgrave Dictionary of Economics. Palgrave Macmillan.

Saldana, J. (2013). The coding manual for qualitative researchers. SAGE.

Saltelli, A., Ratto, M., Tarantola, S., and Campolongo, F. (2005). Sensitivity analysis for chemical models. Chemical Reviews, 105(7):165-177. 
Santos, M. (2013). Tracking poverty reduction in Bhutan: Income deprivation alongside deprivation in other sources of happiness. Social Indicators Research, 112(2):259-290.

Saunders, P., H., W., and W., W. (2014). Deprivation and poverty in Hong Kong. Social Policy Administration, 48(5):556-575.

Saunders, P. and Naidoo, Y. (2009). Poverty, deprivation and consistent poverty. Economic Record, 85(271):417-432.

Schüring, E. and Gassmann, F. (2013). Whom to target -an obvious choice? In Bender, K., Kaltenborn, M., and Pfleiderer, C., editors, Social Protection in Developing Countries: Reforming Systems. Routledge.

Sen, A. (1976). Poverty: An ordinal approach to measurement. Econometrica, 44(2):219231.

Sen, A. (1981). Poverty and Famines: An Essay in the Entitlement and Deprivation. Oxford University Press.

Sen, A. (1988). The concept of development. In Chenery, H. and Srinivasan, T., editors, Handbook of Development Economics: Volume I, pages 9-26. Elsevier Science Publishing Company.

Sen, A. (1992). Inequality Reexamined. Oxford University Press.

Sen, A. (1999). Development as Freedom. Random House.

Sen, A. (2006). Conceptualizing and measurign poverty. In Grusky, D. and Kanbur, R., editors, Poverty and Inequality. Stanford University Press.

Shams, K. (2014). Determinants of subjective well-being and poverty in rural Pakistan: A micro-level study. Social Indicators Research, 119:1755-1773.

Shapley, A. (1953). A value for n-person games. In Kuhn, H. and Tucker, A., editors, Contributions to the Theory of Games. Volume II, pages 307-317. Princeton University Press.

Shorrocks, A. (1983). Ranking income distributions. Economica. New Series, 50(197):317.

Shorrocks, A. (2013). Decomposition procedures for distributional analysis: a unified framework based on the shapley value. Journal of Economic Inequality, 11(1):99126.

Silber, J. and Yalonetzky, G. (2014). Measuring multidimensional deprivation with dichotomized and ordinal variables. In Betti, G. and Lemmi, A., editors, Poverty and Social Exclusion: New Methods of Analysis, pages 9-37. Routledge. 
Spinney, J. and Millward, H. (2010). Time and money: A new look at poverty and the barriers to physical activity in Canada. Social Indicators Research, 99(2):341-356.

Stanley, D. (2003). What do we know about social cohesion: The research perspective of the federal government's social cohesion research network. The Canadian Journal of Sociology, 28(1):5-17.

Stephens, M. and VanSteen, G. (2011). Housing poverty and income poverty in England and The Netherlands. Housing Studies, 26(7-8):1035-1057.

Stewart, F. (2012). The impact of global economic crises on the poor: Comparing the 1980's and 2000's. Journal of Human Development and Capabilities, 13(1):83-105.

Stiglitz, J., Sen, A., and Fitoussi, J. (2009). Report by the commission on the measurement of economic performance and social progress. Report, Commission on the Measurement of Economic Performance and Social Progress.

Streeten, P. (1979). Basic needs:premises and promises. Journal of Policy Modelling, 1(1):136-146.

Streeten, P. (1998). Beyond the six veils: Conceptualizing and measuring poverty. Journal of International Affairs, 52(1).

Tansey, O. (2007). Process tracing and elite interviewing: A case for non-probability sampling. Political Science and Politics, 40(4):765-772.

Tomlinson, M., Walker, R., and Williams, G. (2008). Measuring poverty in Britain as a multi-dimensional concept, 1991-2003. Journal of Social Policy, 37(4):597-620.

Townsend, P. (1979). Poverty in the United Kingdom. Penguin.

Trani, J., Biggeri, M., and Mauro, V. (2013). The multidimensionality of child poverty: Evidence from Afghanistan. Social Indicators Research, 112(2):391-416.

Trani, J. and Cannings, T. (2013). Child poverty in an emergency and conflict context: A multidimensional profile and an identification of the poorest children in Western Darfur. World Development, 48:48-70.

Turner, B. (2010). Vulnerability and Human Rights. Penn State Press.

Ullmann, H., Maldonado, C., and Rico, M. (2014). La evolución de las estructuras familiares en América Latina. 1990-2010. Serie Social Policy 193, ECLAC-UNICEF.

UNDP (2010). Human development report: the real wealth of nations: Pathways to human development. Report, UNDP.

UNDP (2013). Human development report: the rise of the south. human progress in a diverse world. Report, UNDP. 
UNDP (2014). The millenium development goals report. Annual report, United Nations.

UNDP (2015). Transforming our world: the 2030 agenda for sustainable development. Declaration, United Nations.

Valetta, R. (2006). The in and outs of poverty in advanced economies: poverty dynamics in Canada, Germany, Great Britain, and the United States. Review of Income and Wealth, 52(2):261-284.

Van Praag, B. and Ferrer-i Carbonell, A. (2008). A multidimensional approach to subjective poverty. In Kakwani, N. and Silber, J., editors, Quantitative Approaches to Multidimensional Poverty Measurement, pages 135-154. Palgrave Macmillan.

Victor, B., Blevins, M., Green, A., Ndatimana, E., Gonzalez-Calvo, L., Fischer, E., Vergara, A., Vermund, S., Olupona, O., and Moon, T. (2014). Multidimensional Poverty in Rural Mozambique. Plos One, 9(9).

Vijaya, R., Lahoti, R., and Swaminathan, H. (2014). Moving from the Household to the Individual: Multidimensional Poverty Analysis. World Development, 59:70-81.

Villalba, J., Liu, Y., Alvarez, M., Calderon, L., Canache, M., Cardenas, G., Del Nogal, B., Takiff, H., and De Waard, J. (2013). Low Child Survival Index in a Multidimensionally Poor Amerindian Population in Venezuela. Plos One, 8(12).

Wagle, U. (2009). Capability Deprivation and Income Poverty in the United States, 19942004: Measurement Outcomes and Demographic Profiles. Social Indicators Research, 94(3):509-533.

Wagle, U. (2014). The Counting-Based Measurement of Multidimensional Poverty: The Focus on Economic Resources, Inner Capabilities and Relational Resources in the United States. Social Indicators Research, 115(1):223-240.

Whelan, C. and Maitre, B. (2005). Vulnerability and multiple deprivation perpectives on economic exclusion in Europe: A latent class analysis. European Societies, 7(3):423450.

Whelan, C. and Maitre, B. (2007a). Income, deprivation and economic stress in the enlarged European Union. Social Indicators Research, 83(2):309-329.

Whelan, C. and Maitre, B. (2007b). Measuring material deprivation with EU-SILC: Lessons from the Irish survey. European Societies, 9(2):147-173.

Whelan, C. and Maitre, B. (2008). Social class variation in risk: A comparative analysis of the dynamics of economic vulnerability. British Journal of Sociology, 59(4):637-659.

Whelan, C. and Maitre, B. (2014). The great recession and the changing distribution of economic vulnerability by social class: The Irish case. Journal of European Social Policy, 24(5):470-485. 
Whelan, C., Nolan, B., and Maitre, B. (2013). Analysing intergenerational influences on income poverty and economic vulnerability with EU-SILC. European Societies, 15(1):82-105.

Whitmore, G. and Findlay, M. (1978). Stochastic Dominance. Lexington Books.

Wolfstetter, E. (1999). Topics in Microeconomics. Cambridge University Press.

Wooldridge, J. (2002). Econometric Analysis of Cross Section and Panel Data. MIT Press.

World Bank, . (2012). The labor market story behind latin america's transformation. Research paper, World Bank LAC.

Yalonetzky, G. (2014). Conditions for the most robust multidimensional poverty comparisons using counting measures and ordinal variables. Social Choice Welfare, 43(4):773-807.

Yu, J. (2013). Multidimensional poverty in China: Findings based on the CHNS. Social Indicators Research, 112(2):315-336. 


\section{VALORIZATION}

In accordance with article 23.5 of the "Regulation governing the attainment of doctoral degrees at Maastricht University" decreed by resolution of the Board of Deans, dated 3 July 2013, an addendum must be added about valorization.

The first of the Millennium Development Goals in the United Nations declaration of 2000 dealt with poverty reduction. The specific goal was "to eradicate extreme poverty and hunger by 2015". This opened a discussion about how the goal was to be achieved and the type of poverty to be eradicated. An important part of this debate, relevant to social scientists and policy-makers for the last sixteen years, was the best way to measure poverty. The question of measurement was part of the deliberation leading to the Sustainable Development Goals (SDGs) for 2030, the first of which was "End poverty in all its forms everywhere". Seven targets were related to this goal, one of which was: "By 2030, reduce at least by half the proportion of men, women and children of all ages living in poverty in all its dimensions according to national definitions".

The topics presented in each chapter of this doctoral thesis are centered on the measurement of multidimensional poverty. Focused in four countries in Latin America: Chile, Colombia, Ecuador and Peru, the thesis shows that despite the simplicity of the adjusted headcount ratio of the Alkire-Foster family of indices, the most widely known composite index to measure poverty in all its dimensions, the implications behind the method are not easily accessible to policy-makers. This issue was in the center of the deliberations about a particular way to understand poverty in all its dimensions at the SDG summit but there was no consensus on a method. Instead it was left to each nation to select the best measure of multidimensional poverty. As a result, policy-makers need to be aware of the effects of normative choices on the overall result of a poverty index, and that the 
choices that they will take have effects on the welfare of extremely disadvantaged people, depending on the use of the particular index. This thesis addresses these issues of social relevance.

In the following, a list of the main results and the arguments that support them are presented for each one of the chapters. The list shows the place of policy-makers, in addition to the academic community, the concrete results that can be used to further the debate about measuring multidimensional poverty and the innovative content based on making new or significantly improved tools available to potential users in governments, universities and civil society. Finally, there are observations on the broader applicability of this work.

1. Why is it socially relevant to compare the results of a household based multidimensional poverty indicator as opposed to an individual one?

Based on the theoretical framework supported in Chapter 1 and Chapter 2, the household should not be used as the unit of analysis of a multidimensional poverty index, as the Capabilities Approach states that functionings are permeated by individual choices. In other words, two individuals can share the same resources inside the same household, and nonetheless exhibit a different set of capabilities. Using the household as the unit of analysis, taking into account the same thresholds as fixed for an individual case, deprivations of one member imply deprivations of all the members which will inflate the multidimensional poverty of the society. Doing the opposite will mean that deprivations of some individuals are not important for their personal development.

2. What does the choice of a minimum number of dimensions needed to be considered multidimensionally poor matter for policy purposes?

The main reason to create a composite indicator is not the resulting number per se but how it permits comparisons with other regions, cities, countries, and so on. It means that sometimes the result of the index is not easily interpreted by policy-makers unless it is converted to a ranking. Rankings depend on the normative choices behind them, creating a loop of uncertainty about the results. It is why tools, such as stochastic dominance, which performs pair-wise comparisons of all the choices, or graphical techniques as the Hasse-Diagrams, allow the researcher to reduce that level of uncertainty and to make the results clearer to policy-makers. 
3. Can the performance of multidimensional poverty over time be measured?

One of the main features of multidimensional poverty measurement, using the AlkireFoster Adjusted Headcount Ratio, is that it requires the same information for the same subject. When measuring it over time the best approach is to follow the subject over time, meaning having access to panel datasets. However, most of the less developed countries do not have a culture of longitudinal data.

Recent developments in the field of multidimensional poverty measurement have given rise to techniques that calculate trends over time using anonymous data. In other words, despite the fact that different subjects have been questioned, the national, regional or municipality data is an average so it is possible to measure it over time.

Using this techniques, chapter 5 shows that, from all the countries in the sample, Ecuador was the one that experienced an evident improvement of its results in the last 10 years.

4. Is multidimensional poverty measurement replacing monetary poverty as a tool for policy-making?

Using the case of Colombia, the last chapter shows that despite the increasing efforts made by public officials to use a multidimensional poverty index, whenever public servants and policy-makers talk about poverty in the country, they refer to monetary poverty.

Multidimensional poverty as a concept is too difficult to transfer to the citizens and to other policy makers. Still, the measurement of multidimensional poverty requires an extensive knowledge of the technique which is limited to a small elite of public officials that work for the government.

\section{Broader application of this work}

The results shown in this research could be applied to other countries outside of the sample used for empirical application. The demands from the SDGs are that each nation should decide upon the best method to measure poverty in all its forms. The applications of different choices can be adopted by public officials that are on the verge of deciding the best way to report for the goal number one. 
First, I would like to bring this work to the attention to the persons that can benefit from the findings, policy-makers all over the world, but particularly in Latin America and the Caribbean, especially those in charge of measuring changes in national poverty goals (e.g. statistical offices, ministries of planning, ministries of social development), and the social policy-makers. The general comment they can take away from this research is that poverty measurement is not only about replicating the methods used in other countries. Poverty is context-specific and taking decisions about where to put a threshold, what are the dimensions to include and which is the best method to use, can only be achieved after a thorough inspection of the implications of each decision. Social policy-makers and those in charge of monitoring the path of indicators and indices cannot be isolated from the latest findings performed by social researchers, but at the same time should be creative and doubt of each one of their choices until they are absolutely sure of their implications. In other words, do not take for granted what you have not proved by yourself.

Second, PhD students, master students and researchers. The findings of this thesis are just the tip of the iceberg. This research opens a new way to improve the measurement of poverty, to use innovative techniques and mix all the findings to increase the knowledge of trends over time, effects of particular indicators selected, units of analysis, and especially, the role of stochastic dominance conditions to restrict the ranges of normative choices about the number of dimensions to be consider multidimensionally poor.

Lastly, after finishing my first draft and becoming a policy-maker myself, I found out that there is a gap in the implementation of monitoring systems, knowledge of indicators, and use of available resources that could benefit the public policy cycle. I had the advantage of coming from a quantitative perspective and the course of studies made me intrigued by the use of qualitative sources. The mix of methods can give a broader perspective to successful and not so successful policy interventions. In this particular sense, this research can benefit those not in the government or in academia. Community leaders, as well as workers in the field of social policy in small towns and with small projects have the most to gain by the knowledge and mix of methods used in this thesis.

However, further research is recommended. I suggest particularly that innovative work can be developed in the upper range censoring of stochastic dominance conditions as shown in Chapter 3. I also consider that the development of Hasse-Diagram rankings can be analyzed for a broader range of choices. The dynamic multidimensional poverty line of research is in its infancy. New developments would be shortly appearing despite the lack of panel datasets in less developing countries. Lastly, the results shown are replicable as all the datasets used in this thesis are freely available to be downloaded. All of them have different levels of quality, but individually each one has richness of variables and indicators that could be potentially included. I must remind the reader that in order to keep all the datasets comparable, and therefore the measurement of multidimensional poverty, I had to resist including other interesting variables. 


\section{ABOUT THE AUTHOR}

Andrea is an economist and M. Sc. in Economics at Universidad Nacional de Colombia. She had worked as a public official in different institutions in Colombia as the National Department of Planning and the Shelter and Housing Secretary of the Government of Bogota. She has also worked as researcher for the Universidad Nacional de Colombia. Most of her working experience has been related to Social Development issues but she has also work on transportation sustainability, monitoring and evaluation systems and corruption and governance. Currently she is the deputy director of national coordination of the family welfare system in Colombia. Andrea joined the PhD Program at Maastricht University in 2010. During her years at UNU MERIT/MGSoG she lectured in the MPP Program mainly in the social protection track and also collaborated in other teaching areas in the GPAC program. 


\section{UNU-MERIT/MGSoG Dissertation Series}

2017

Andrea Franco-Correa

On the Measurement of Multidimensional Poverty as a Policy Tool; Empirical Applications to Chile, Colombia, Ecuador and Peru

UNU-MERIT/MGSoG Dissertation Series, № 185

2016

Yesuf Awel

Insurance for Growth; Empirical Essays on Insurance Demand and Impacts in Africa UNU-MERIT Dissertation Series, № 108

Tigist Mekonnen Melesse

Grow More Food using Fewer Resources;

Agricultural Technology Adoption and Innovation Practices for Inclusive and Sustainable Development

UNU-MERIT Dissertation Series, № 107

Eleni Yitbarek

Getting Ahead or left Behind?; Essays on Poverty Dynamics and Social Mobility in Africa UNU-MERIT Dissertation Series, № 106

Thuy Dieu Nguyen

Firm-Level Theory and Evidence of Corruption

UNU-MERIT Dissertation Series, № 105

Raquel Tsukada Lehman

Essays on Household Production with Labor-Saving Technology

UNU-MERIT Dissertation Series, № 104

Eva Barteková

Multi-Problem Challenges for a Renewable Future; Empirical Studies on Competitive

Disadvantages from Electricity Price Differentials and Mineral Supply Risk in an Open

Economy

UNU-MERIT Dissertation Series, № 103

Jocelyn Olivari

Entrepreneurial Traits and Innovation; Evidence from Chile

UNU-MERIT Dissertation Series, № 102 
Muhammad Shafique

Essays on the role of knowledge, RED, and Technology-based Firms in the Evolution of Sociotechno-economic System

UNU-MERIT Dissertation Series, № 101

Serdar Türkeli

Governance of Innovation Policy; Empirical Studies on Applied Political Economy by MultiMethods Analysis

UNU-MERIT Dissertation Series, № 100

Ayokunu Adedokun

Pathways to Sustainable Peacebuilding in Divided Societies; Lessons and Experiences from Mozambique

MGSoG Dissertation Series, № 75

Luiz Rothier Bautzer

Organizing Concurrent Engineering through ICT Platforms:

Blueprinting Product Lifecycle Management Platforms across Disciplinary Agencies MGSoG Dissertation Series, № 74

Natalia Popova

Migration in the Periphery of the European Union;

Determinants of Successful and Sustainable Labour Market Integration of Return Migrants in Albania, Egypt, Moldova and Tunisia

MGSoG Dissertations Series, № 73

Richard A. Martina

Uncertainty and Resource Constraint in the Small Island Developing States;

Essays in Entrepreneurial Cognition

MGSoG Dissertations Series, № 72

Cécile Cherrier

The Expansion of Basic Social Protection in Low-income Countries;

An Analysis of Foreign Aid Actors' Role in the Emergence of Social Transfers in Sub-Saharan Africa

MGSoG Dissertations series, № 71

Paul Caldron

The Tacit Bargain in Short-Term Medical Missions; Why U.S. physicians go and what it costs

MGSoG Dissertation Series, № 70 
Mahmut Kobal

Customs \& Excellence: A Comparative Approach on Administrative and Regulatory

Compliance Perspectives of the EU-Turkey Customs Union

MGSoG Dissertation Series, № 69

Craig Loschmann

Essays on Conflict-related Migration and Development in the Case of Afghanistan

MGSoG Dissertations Series, № 68

Andrea Milan

Rural Livelihoods, Location and Vulnerable Environments; Approaches to Migration in

Mountain areas of Latin America

MGSoG Dissertation Series, № 67

Farida Lada

On Guarding the Welfare of Clinical Trial Subjects While Promoting Novel Drug Innovation A Game Theoretical Approach

MGSoG Dissertation Series, № 66

2015

Hibret Belete Maemir

Dissecting Aggregate Productivity; International Integration and Growth with

Heterogeneous Firms

UNU-MERIT Dissertation Series, № 96

Giorgio Triulzi

Looking for the Right Path; Technology Dynamics, Inventive Strategies and Catching-up in the Semiconductor Industry

UNU-MERIT Dissertation Series, № 95

Abdul Baseer Qazi

Knowledge flows and networks in the ICT sector; The case of Pakistan

UNU-MERIT Dissertation Series, № 94

Ajay Thutupalli

Technology Paradigm Shifts in Agriculture; Drivers of Sustainability and Catch up

UNU-MERIT Dissertation Series, № 93

Eduardo Urias

Improving access to HIVIAIDS treatment in Brazil; When are Compulsory Licenses effective in Price Negotiations?

UNU-MERIT Dissertation Series, № 92 
Francesca Guadagno

Why have so few Countries Industrialised?

UNU-MERIT Dissertation Series, № 91

Daniel Opolot

The Evolution of Beliefs and Strategic Behaviour

UNU-MERIT Dissertation Series, № 90

Alejandro Lavopa

Structural Transformation and Economic Development; Can Development Traps be Avoided UNU-MERIT Dissertation Series, № 89

Jinjin Zhao

Urban water management reform; The Case of China

UNU-MERIT Dissertation Series, № 88

Simona Vezzoli

Borders, Independence and Post-colonial Ties; the Role of the State in Caribbean Migration

MGSoG Dissertation Series, № 65

Silvia Consuelo Gómez Soler

Civil Conflict and Education; How Does Exposure to Civil Conflict Affect Human Capital Accumulation? Evidence from Standardized Exit Exams in Colombia

MGSoG Dissertation Series, № 64

Paula Nagler

Occupational Choice in the Developing World

MGSoG Dissertation Series, № 63

Jasmin Kientzel

Determinants of Professional Commitment to Environmental Sustainability

MGSoG Dissertation Series, № 62

Mehmet Güney Celbiş

Regional Policies; Convergence, Trade, and the Allocation of Public Capital

MGSoG Dissertation Series, № 61

Florian Henning

Living Up to Standard; Interoperability Governance and Standards Adoption in Government Information Networks

MGSoG Dissertation Series, № 60 
Niels P. Groen

The Never-Ending Project

Understanding E-Government Project Escalation

MGSoG Dissertation Series, № 59

Derek Copp

Teacher-Based Reactivity to Provincial Large-scale Assessment in Canada

MGSoG Dissertation Series, № 58

Michaella Vanore

Family-Member Migration and the Psychosocial Health Outcomes of Children in Moldova and Georgia

MGSoG Dissertation Series, № 57

\section{Sonja Fransen}

The Economic and Social Effects of Remittances and Return Migration in Conflict-Affected Areas; The Case of Burundi

MGSoG Dissertation Series, № 56

Ibrahim Khalil Conteh

The Impact of Floods on Primary School Education in Zambia

MGSoG Dissertation Series, № 55

Richard Bluhm

Growth Dynamics and Development

Essays in Applied Econometrics and Political Economy

MGSoG Dissertation Series, № 54

Nevena P. Zhelyazkova

Work-Family Reconciliation and Use of Parental Leave in Luxembourg; Empirical Analysis of Administrative Records

MGSoG Dissertation Series, № 53

\section{4}

\section{Dirk Crass}

The Impact of Brands on Innovation and Firm Performance; Empirical Evidence from Germany

UNU-MERIT Dissertation Series, № 87

Samyukta Bhupatiraju

The Geographic Dimensions of Growth and Development

UNU-MERIT Dissertation Series, № 86 
François Lafond

The Evolution of Knowledge Systems

UNU-MERIT Dissertation Series, № 85

Annalisa Primi

Promoting Innovation in Latin America; What Countries Have Learned (and What They

Have Not) in Designing and Implementing Innovation and Intellectual Property Policies

UNU-MERIT Dissertation Series, № 84

Fatoumata Lamarana Diallo

Evaluation of Meal and Deworming Programs for Primary Schools in Rural Senegal

UNU-MERIT Dissertation Series, № 83

Sachin Kumar Badkas

Metachoice and Metadata; Innovating with Environmental Policy Analysis in Europe

MGSoG Dissertation Series, № 52

Irina S. Burlacu

An Evaluation of Tax-Benefit Systems Impact on the Welfare of Frontier Worker;

The Case of Luxembourg and Belgium

MGSoG Dissertation Series, № 51

Özge Bilgili

Simultaneity in Transnational Migration Research; Links Between Migrants' Host and Home

Country Orientation

MGSoG Dissertation Series, № 50

Yulia Privalova Krieger

Reshaping the Big Agenda; Transnational Politics and Domestic Resistance

Financial crisis and social protection reform in Bosnia and Herzegovina

MGSoG Dissertation Series, № 49

Marieke van Houte

Moving Back or Moving Forward? Return migration after Conflict

MGSoG Dissertation Series, № 48

Oxana Slobozhan

Global Governance in the Management of Natural Resources; The Case of the Extractive Industries Transparency Initiative (EITI)

MGSoG Dissertation Series, № 47 
Luis Bernardo Mejia Guinand

The Changing Role of the Central Planning Offices in Latin America; A Comparative Historical Analysis Perspective (1950-2013)

MGSoG Dissertation Series, № 46

Cheng Boon Ong

Ethnic Segregation in Housing, Schools and Neighbourhoods in the Netherlands

MGSoG Dissertation Series, № 45

Luciana V. Cingolani

Bureaucracies for Development; Oxymoron or Reality? Studies on State Capacity in

Challenging Governance Contexts

MGSoG Dissertation Series, № 44

Carlos Cadena Gaitán

Green Politics in Latin American Cities - Sustainable Transport Agendas

MGSoG Dissertation Series, № 43

Katie Kuschminder

Female Return Migration and Reintegration Strategies in Ethiopia

MGSoG Dissertation Series, № 42

Metka Hercog

Highly-Skilled Migration and New Destination Countries

MGSoG Dissertation Series, № 41

Margaret Agaba Rugadya

Can Remittances Influence the Tenure and Quality of Housing in Uganda?

MGSoG Dissertation Series, № 40

Ilire Agimi

New Governance Under Limited Statehood; The Case of Local Government Reform in Kosovo

MGSoG Dissertation Series, № 39

2013

Anant Kamath

Information Sharing through Informal Interaction in Low-Tech Clusters

UNU-MERIT Dissertation Series, № 82 
Flavia Pereira de Carvalho

What we talk about when we talk about Brazilian Multinationals; An Investigation on

Brazilian FDI, Economic Structure, Innovation and the Relationship between them

UNU-MERIT Dissertation Series, № 81

\section{Jun Hou}

Complementarity in Innovation and Development; A Cross-country Comparison

UNU-MERIT Dissertation Series, № 80

Rufin Baghana

Impacts of Government Incentives to RED, Innovation and Productivity;

A Micro econometric Analysis of the Québec Case

UNU-MERIT Dissertation Series, № 79

Lilia I. Stubrin

High-Tech Activities in Emerging Countries; A Network perspective on the Argentinean Biotech Activity

UNU-MERIT/MGSoG Dissertation Series, № 78

Kristine Farla

Empirical Studies on Institutions, Policies and Economic Development

MGSoG Dissertation Series, № 38

Marina Petrovic

Social Assistance and Activation in the Pursuit of Happiness; Shedding New Light on Old Policy Solutions to Social Exclusion

MGSoG Dissertation Series, № 37

\section{Laura Torvinen}

Assessing Governance Assessments; The Case of Mozambique; Governance Assessments in the Context of Aid Effectiveness Discourse

MGSoG Dissertation Series, № 36

Biniam Egu Bedasso

Institutional Change in the Long Shadow of Elite; Essays on Institutions, Human Capital and Ethnicity in Developing Countries

MGSoG Dissertation Series, № 35

Sepideh Yousefzadeh Faal Deghati

Childhoods Embargoed; Constructing and Reconstructing Multidimensional Child Poverty in Iran 1984-2009

MGSoG Dissertation Series, № 34 
Robert Bauchmüller

Investing in Early Childhood Care and Education; The Impact of Quality on Inequality MGSoG Dissertation Series, № 33

Martin Rehm

Unified Yet Separated; Empirical Study on the Impact of Hierarchical Positions within Communities of Learning

MGSoG Dissertation Series, № 32

2012

Abdul Waheed

Innovation Determinants and Innovation as a Determinant; Evidence from Developing Countries

UNU-MERIT Dissertation Series, № 77

Bilal Mirza

Energy Poverty and Rural Energy Markets in Pakistan

UNU-MERIT Dissertation Series, № 76

Benjamin Engelstätter

Enterprise Software and Video Games; An Empirical Analysis

UNU-MERIT Dissertation Series, № 75

Fulvia Farinelli

Natural Resources, Innovation and Export Growth; The Wine Industry in Chili and Argentina

UNU-MERIT Dissertation Series

Rodolfo Lauterbach

Innovation in Manufacturing; From Product Variety and Labor Productivity Growth to Economic Development in Chile

UNU-MERIT Dissertation Series

Kirsten Wiebe

Quantitative Assessment of Sustainable Development and Growth in Sub-Saharan Africa UNU-MERIT/MGSoG Dissertation Series, № 74

Julio Miguel Rosa

Organizational Strategies, Firms' Performance and Spatial Spillovers; The Canadian Case in Research and Development.

UNU-MERIT Dissertation Series, № 73 
Johannes Wilhelmus Marie Boels

Joseph Schumpeter, Honderd Jaar Economische Ontwikkeling; Een Historisch-theoretische Beschouwing.

UNU-MERIT Dissertation Series

Dorcas Mbuvi

Utility Reforms and Performance of the Urban Water Sector in Africa

MGSoG Dissertation Series, № 31

Lina Salanauskaite

Distributional Impacts of Public Policies; Essays in Ex-Ante and Ex-Post Evaluation

MGSoG Dissertation Series, № 30

Esther Schüring

To Condition or not - is that the Question?

An Analysis of the Effectiveness of Ex-Ante and Ex-Post Conditionality in Social Cash

Transfer Programs

MGSoG Dissertation Series, № 29

Joe Abah

Strong Organisations in Weak States; Atypical Public Sector Performance in Dysfunctional Environments

MGSoG Dissertation Series, № 28

Zina Samih Nimeh

Social Citizenship Rights; Inequality and Exclusion

MGSoG Dissertation Series, № 27

2011

Daniel Vertesy

Interrupted Innovation; Emerging Economies in the Structure of the Global Aerospace

Industry

UNU-MERIT Dissertation Series, № 72

Tina Saebi

Successfully Managing Alliance Portfolios; An Alliance Capability View

UNU-MERIT Dissertation Series, № 71

Nora Engel

Tuberculosis in India; A Case of Innovation and Control

UNU-MERIT/MGSoG Dissertation Series, № 70 
Evans Mupela

Connectivity and growth in Sub-Saharan Africa; The Role of Communication Satellites UNU-MERIT Dissertation Series, № 69

Nantawan Kwanjai

Cross Cultural Intelligence amid Intricate Cultural Webs; A Tale of the UnDutchables in the Land of 1002 Smiles

UNU-MERIT Dissertation Series, № 68

Lina Sonne

Innovation in Finance to Finance Innovation; Supporting Pro-poor Entrepreneur-based Innovation

UNU-MERIT Dissertation Series, № 67

Lenka Eisenhamerová

Legitimacy of 'Humanitarian Military Intervention'

MGSoG Dissertation Series, № 26

Sonila Tomini

Informal Payments for Health Care Services in Albania

MGSoG Dissertation Series, № 25

Jinjing Li

Dynamic Microsimulation in Public Policy Evaluation

MGSoG Dissertation Series, № 24

Aziz Atamanov

Rural Nonfarm Employment and International Migration as Alternatives to Agricultural Employment; The Case of Kyrgyzstan

MGSoG Dissertation Series, № 23

Frieda Vandeninden

Poverty Alleviation; Aid and Social Pensions

MGSoG Dissertation Series, № 22

Juliana Nyasha Tirivayi

The Welfare Effects of Integrating AIDS Treatment with Food Transfers; Evidence from Zambia

MGSoG Dissertation Series, № 21 
Agnieska Ewa Sowa

Who's Left Behind? Social Dimensions of Health Transition and Utilization of Medical Care in Poland

MGSoG Dissertation Series, № 20

Emmanaouil Sfakianakis

The Role of Private Actors in the Provision of Public Goods with Applications to Infrastructure and Financial Stability

MGSoG Dissertation Series, № 19

Siu Hing Lo

White Collars Green Sleeves; An Inter-organizational Comparison of Determinants of Energy-Related Behaviors among Office Workers

MGSoG Dissertation Series, № 18

Treena $\mathrm{Wu}$

Constraints to Human Capital Investment in Developing Countries;

Using the Asian Financial Crisis in Indonesia as a Natural Experiment

MGSoG Dissertation Series, № 17

He No y Espinoza Peña

Impact Evaluation of a Job-Training Programme for Disadvantaged Youths;

The Case of Projoven

MGSoG Dissertation Series, № 16

2010

Fernando Santiago

Human Resources Management Practices and Learning for Innovation in Developing Countries; Pharmaceutical Firms in Mexico

UNU-MERIT Dissertation Series, № 66

Zakaria Babutsidze

Essays on Economies with Heterogeneous Interacting Consumers

UNU-MERIT Dissertation Series, № 65

Bertha Vallejo

Learning and Innovation Under Changing Market Conditions; The Auto Parts Industry in Mexico

UNU-MERIT Dissertation Series, № 64 
Donatus Ayitey

Technical Change, Competitiveness and Poverty Reduction; A Study of the Ghanaian Apparel Industry

UNU-MERIT Dissertation Series, № 63

Sergey Fillipov

Multinational Subsidiary Evolution; Corporate Change in New EU Member States

UNU-MERIT Dissertation Series, № 62

Asel Doranova

Technology Transfer and Learning under the Kyoto Regime; Exploring the Technological Impact of CDM Projects in Developing Countries

UNU-MERIT Dissertation Series, № 61

Florian Tomini

Between Family and Friend; Understanding the Interdependency of Private Transfers

MGSoG Dissertation Series, № 15

Michał Polalowski

The Institutional Transformation of Social Policy in East Central Europe; Poland and Hungary in Comparative and Historical Perspective

MGSoG Dissertation Series, № 14

Maha Ahmed

Defining, Measuring and Addressing Vulnerability; The Case of Post Conflict Environments MGSoG Dissertation Series, № 13

Pascal Beckers

Local Space and Economic Success; The Role of Spatial Segregation of Migrants in the Netherlands

MGSoG Dissertation Series, № 12

Victor Cebotari

Conflicting Demands in Ethnically Diverse Societies; Ethno political Contention and Identity Values in Europe

MGSoG Dissertation Series, № 11

Dennis Gyllensporre

Competing and Complementary Perspectives on the EU as a Crisis Management Actor;

An Examination of the Common Security and Defence Policy through the Lenses of Idealism and Realism

MGSoG Dissertation Series, № 10 
Judit Vall Castello

Business Cycle and Policy Effects on Labour Market Transitions of Older and Disabled Workers in Spain

MGSoG Dissertation Series, № 9

Keetie Roelen

False Positives or Hidden Dimensions; The Definition and Measurement of Child Poverty

MGSoG Dissertation Series, № 8

Denisa Maria Sologon

Earning Dynamics in Europe

MGSoG Dissertation Series, № 7

Melissa Siegel

Money and Mobility; Migration and Remittances

MGSoG Dissertation Series, № 6

Jessica S. Hagen-Zanker

Modest Expectations; Causes and Effects of Migration on Migrant Households in

Source Countries

MGSoG Dissertation Series, № 5

2009

Alexis Habiyaremye

From Primary Commodity Dependence to Diversification and Growth; Absorptive Capacity and Technological Catch Up in Botswana and Mauritius.

UNU-MERIT Dissertation Series, № 60

Yoseph Getachew

The Role of Public Capital in Economic Development

UNU-MERIT Dissertation Series, № 59

Sandra Leitner

Embodied Technological Change and Patterns of Investment in Austrian Manufacturing UNU-MERIT Dissertation Series, № 58

Semih Akçomak

The Impact of Social Capital on Economic and Social Outcomes

UNU-MERIT Dissertation Series, № 57 
Abraham Garcia

The Role of Demand in Technical Change

UNU-MERIT Dissertation Series, № 56

Saurabh Arora

Coherence in Socio-technical Systems; A Network Perspective on the Innovation Process

UNU-MERIT Dissertation Series, № 55

Mirtha R. Muniz Castillo

Human Development and Autonomy in Project Aid; Experiences from four bilateral projects in Nicaragua and El Salvador

MGSoG Dissertation Series, № 4

Christiane Arndt

Governance Indicators

MGSoG Dissertation Series, № 3

Britta Augsburg

Microfinance; Greater Good or Lesser Evil?

MGSoG Dissertation Series, № 2

2008

Rutger Daems

Medicines for the Developing World

UNU-MERIT Dissertation Series, № 54

Johannes Hanel

Assessing Induced Technology; Sombart's Understanding of Technical Change in the History of Economics

UNU-MERIT Dissertation Series, № 53

Rifka Weehuizen

Mental Capital; the Economic Significance of Mental Health

UNU-MERIT Dissertation Series, № 52

Danielle Cloodt

The Relationship between RED Partnership Formation, Social Embeddedness and Innovative Performance

UNU-MERIT Dissertation Series, № 51 
Sabine Fuss

Sustainable Energy Development under Uncertainty

UNU-MERIT Dissertation Series, № 50

Geranda Notten

Measuring and Managing Poverty Risks

MGSoG Dissertation Series, № 1

2007

Tobias Kronenberg

Reconciling Environmental Conservation with Economic Prosperity; The Feasibility of

Double Dividends in the Short and Long Run

UNU-MERIT Dissertation Series, № 49

Viktoria Kravtsova

Assessing the Impact of Foreign Direct Investment in Transition Economies

UNU-MERIT Dissertation Series, № 48

Suhail Sultan

The Competitive Advantage of Small and Medium Sized Enterprises; The Case of Jordan's

Natural Stone Industry

UNU-MERIT Dissertation Series, № 47

2006

Bulat Sanditov

Essays on Social Learning and Imitation

UNU-MERIT Dissertation Series, № 46

Mamata Parhi

Dynamics of New Technology Diffusion; A Study of the Indian Automotive Industry

UNU-MERIT Dissertation Series, № 45

Andreas Reinstaller

Social Structures and the Innovation Process; Their Role in the Demand of Firms and

Consumers

UNU-MERIT Dissertation Series, № 44

Rose Kiggundu

Innovation systems and Development; The Journey of a Beleaguered Nile Perch Fishery in Uganda

UNU-MERIT Dissertation Series, № 43 
Thomas Pogue

The Evolution of Research Collaboration in South African Gold Mining; 1886-1933

UNU-MERIT Dissertation Series, № 42

Geoffrey Gachino

Foreign Direct Investment, Spillovers and Innovation; The Case of Kenyan Manufacturing Industry

UNU-MERIT Dissertation Series, № 41

Önder Nomaler

Technological Change, International Trade and Growth; An Evolutionary, Multi-Agents-

Based Modeling Approach

UNU-MERIT Dissertation Series, № 40

2005

Samia Satti Osman Mohamed-Nour

Change and Skill Development in the Arab Gulf Countries

UNU-MERIT Dissertation Series, № 39

Elad Harison

Intellectual Property Rights; Economics and Policy Analysis

UNU-MERIT Dissertation Series, № 38

Daniel Dalohoun

The Relationship between RED Partnership Formation, Social Embeddedness and Innovative Performance; a Multi-level Approach of Social Embeddedness

UNU-MERIT Dissertation Series, № 37

Müge Ozman

Networks, Organizations and Knowledge

UNU-MERIT Dissertation Series, № 36

Bas Straathof

Product Variety and Economic Growth; The Counteracting Effects of Scale and Idiosyncrasy UNU-MERIT Dissertation Series, № 35

Wilfred Schoenmakers

Knowledge Flows between Multinational Companies; A Patent Data Analysis

UNU-MERIT Dissertation Series, № 34 
Myriam Cloodt

Mergers and Acquisitions ( $M$ and As) in High-Tech Industries; Measuring the Post-M and $A$ Innovative Performance of Companies

UNU-MERIT Dissertation Series, № 33

2004

Paola Criscuolo

RED Internationalisation and Knowledge Transfer; Impact on MNEs and their Home Countries

UNU-MERIT Dissertation Series, № 32

Maarten Verkerk

Trust and Power on the Shop Floor

UNU-MERIT Dissertation Series, № 31

Gottfried Leibbrandt

Adoption, Harmonization and Succession of Network Technologies across Countries

UNU-MERIT Dissertation Series, № 30

Mark Sanders

Skill Biased Technical change; Its Origins, the Interaction with the Labour Market and Policy Implications

UNU-MERIT Dissertation Series, № 29

2003

Nadine Roijakkers

Inter-firm Cooperation in High-tech Industries; a Study of RED Partnerships in

Pharmaceutical Biotechnology

UNU-MERIT Dissertation Series, № 28

Viki Sonntag

Speed, Scale and Sustainability

UNU-MERIT Dissertation Series, № 27

Masaru Yarime

From End-of-Pipe Technology to Clean Technology

UNU-MERIT Dissertation Series, № 26 
Stéphane Malo

The Combinatorial Chemistry Revolution; Sustaining a Superior Performance Position through Technological Learning

UNU-MERIT Dissertation Series, № 25

2002

Annelies Hogenbirk

Determinants of Inward Foreign Direct Investment; the Case of the Netherlands

UNU-MERIT Dissertation Series, № 24

Bastiaan Johan ter Weel

The Computerization of the Labour Market

UNU-MERIT Dissertation Series

2001

John Adeoti

Technology Investment in Pollution Control in Sub-Saharan Africa; The Case of the Nigerian Manufacturing Industry

UNU-MERIT Dissertation Series, № 23

Edward Huizenga

Innovation Management; How Frontrunners Stay Ahead; An Empirical Study on Key

Success Factors in the ICT sector

UNU-MERIT Dissertation Series, № 22

2000

Machiel van Dijk

Technological Change and the Dynamics of Industries; Theoretical Issues and Empirical evidence from Dutch Manufacturing

UNU-MERIT Dissertation Series, № 21

1999

Jan Cobbenhagen

Managing Innovation at the Company Level; A Study on Non-Sector-Specific Success Factors UNU-MERIT Dissertation Series, № 20

Marjolein Caniëls

Regional Growth Differentials; The Impact of Locally Bounded Knowledge Spillovers

UNU-MERIT Dissertation Series, № 19 
Aldo Geuna

Resource Allocation and Knowledge production; Studies in the Economics of University

Research

UNU-MERIT Dissertation Series, № 18

1996

Reinoud Joosten

Dynamics, Equilibria, and Values

UNU-MERIT Dissertation Series, № 17

Hugo Kruiniger

Investment, RED, and the Financing Decisions of the Firm

UNU-MERIT Dissertation Series, № 16

1995

Hans van Meijl

Endogenous Technological Change; The Case of Information Technology, Theoretical

Considerations and Empirical Results

UNU-MERIT Dissertation Series, № 15

René Kemp

Environmental Policy and Technical Change; A Comparison of the Technological Impact of Policy Instruments

UNU-MERIT Dissertation Series, № 14

Rohini Acharya

The Impact of New Technologies on Economic Growth and Trade; A Case Study of Biotechnology

UNU-MERIT Dissertation Series, № 13

Geert Duysters

The Evolution of Complex Industrial Systems; The Dynamics of Major IT Sectors

UNU-MERIT Dissertation Series, № 12

Marjan Groen

Technology, Work and Organisation; A Study of the Nursing Process in Intensive Care Units UNU-MERIT Dissertation Series, № 11 
Huub Meijers

On the Diffusion of Technologies in a Vintage Framework; Theoretical Considerations and Empirical Results

UNU-MERIT Dissertation Series, № 10

Theon van Dijk

The Limits of Patent Protection; Essays on the Economics of Intellectual Property Rights UNU-MERIT Dissertation Series, № 9

Hans Voordijk

Naar Integrale Logistiek in Bedrijfsketens; Ontwikkelingen in de Bouw

UNU-MERIT Dissertation Series, № 8

1993

Paul Diederen

Technological Progress in Enterprises and Diffusion of Innovation;. Theoretical Reflections and Empirical Evidence

UNU-MERIT Dissertation Series, № 7

Ben Dankbaar

Economic Crisis and Institutional Change; The Crisis of Fordism from the Perspective of the Automobile Industry

UNU-MERIT Dissertation Series, № 6

Hanno Roberts

Accountability and Responsibility; The Influence of Organisation Design on Management Accounting

UNU-MERIT Dissertation Series, № 5

1992

Bart Verspagen

Uneven Growth Between Interdependent Economies; An Evolutionary View on Technology Gaps, Trade and Growth

UNU-MERIT Dissertation Series, № 4

Sjoerd Romme

A Self-organization Perspective on Strategy Formation

UNU-MERIT Dissertation Series, № 3 
John Spangenberg

Economies of Scale, and Atmosphere in Research Organisations

UNU-MERIT Dissertation Series, № 2

1988

John Hagedoorn

Evolutionary and Heterodox Innovation Analysis; A Study of Industrial and Technological Development in Process Control and Information Technology UNU-MERIT Dissertation Series, № 1 

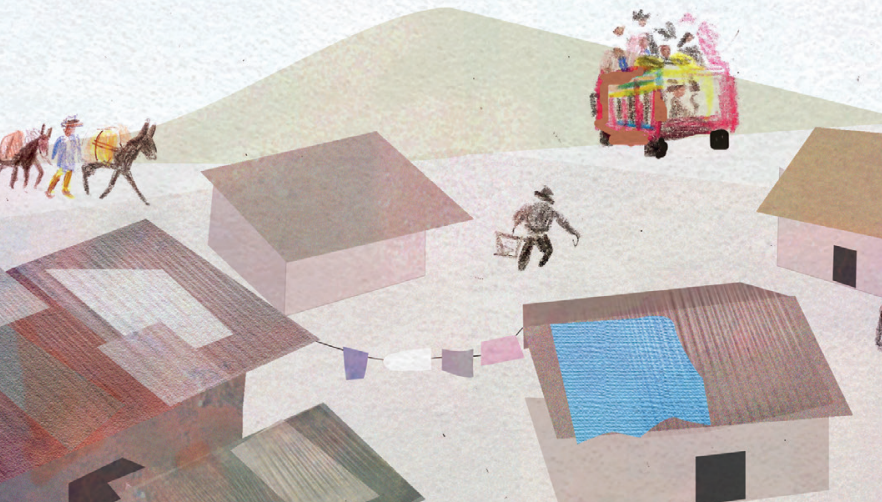